\title{
The paleoceanography of the Bering Sea during the last glacial cycle
}

\author{
by \\ Mea S. Cook \\ A.B., Princeton University, 1999 \\ Submitted in partial fulfillment of the requirements for the degree of \\ Doctor of Philosophy \\ at the \\ MASSACHUSETTS INSTITUTE OF TECHNOLOGY \\ and the \\ WOODS HOLE OCEANOGRAPHIC INSTITUTION
}

February, 2006

(C)MMVI Mea S. Cook

All rights reserved.

The author hereby grants to MIT and WHOI permission to reproduce paper and electronic copies of this thesis in whole or in part and to distribute them publicly.

Signature of Author

Joint Program in Oceanography Massachusetts Institute of Technology and Woods Hole Oceanographic Institution

February 10, 2006

Certified by . .

Lloyd D. Keigwin

Thesis Supervisor Senior Scientist Edna McConnell Clark Chair Woods Hole Oceanographic Institution

Accepted by

J. Gregory Hirth Chair, Joint Committee for Marine Geology and Geophysics Associate Scientist Woods Hole Oceanographic Institution 


\title{
The paleoceanography of the Bering Sea during the last glacial cycle
}

\author{
by \\ Mea S. Cook \\ Submitted to the Department of Marine Geology and Geophysics \\ Joint Program in Oceanography \\ Massachusetts Institute of Technology and Woods Hole Oceanographic Institution \\ on February 10, 2006, in partial fulfillment of the \\ requirements for the degree of \\ Doctor of Philosophy
}

\begin{abstract}
In this thesis, I present high-resolution stable-isotope and planktonic-fauna records from Bering Sea sediment cores, spanning the time period from 50,000 years ago to the present. During Marine Isotope Stage 3 (MIS3) at 30-20 ky BP (kiloyears before present) in a core from $1467 \mathrm{~m}$ water depth near Umnak Plateau, there were episodic occurrences of diagenetic carbonate minerals with very low $\delta^{13} \mathrm{C}(-22.4 \%)$, high $\delta^{18} \mathrm{O}(6.5 \%)$, and high $[\mathrm{Mg}] /[\mathrm{Ca}]$, which seem associated with sulfate reduction of organic matter and possibly anaerobic oxidation of methane. The episodes lasted less than 1000 years and were spaced about 1000 years apart. During MIS3 at 55-20 ky BP in a core from $2209 \mathrm{~m}$ water depth on Bowers Ridge, N. pachyderma (s.) and Uvigerina $\delta^{18} \mathrm{O}$ and $\delta^{13} \mathrm{C}$ show no coherent variability on millennial time scales.

Bering Sea sediments are dysoxic or laminated during the deglaciation. A high sedimentation rate core $(200 \mathrm{~cm} / \mathrm{ky})$ from $1132 \mathrm{~m}$ on the Bering Slope is laminated during the Bølling warm phase, Ållerød warm phase, and early Holocene, where the ages of lithological transitions agree with the ages of those climate events in Greenland (GISP2) to well within the uncertainty of the age models. The subsurface distribution of radiocarbon was estimated from a compilation of published and unpublished North Pacific benthic-planktonic ${ }^{14} \mathrm{C}$ measurements $\left(475-2700 \mathrm{~m}\right.$ water depth). There was no consistent change in ${ }^{14} \mathrm{C}$ profiles between the present and the Last Glacial Maximum, Bølling-Ållerød, or the Younger Dryas cold phase. N. pachyderma (s.) $\delta^{18} \mathrm{O}$ in the Bering Slope core decreases rapidly (in less than $220 y$ ) by $0.7-0.8 \%$ at the onset of the Bølling and the end of the Younger Dryas. These isotopic shifts are accompanied by transient decreases in the relative abundance of $N$. pachyderma (s.), suggesting that the isotopic events are transient warmings and sustained freshenings.
\end{abstract}




\section{Thesis Advisor:}

Dr. Lloyd Keigwin

\section{Thesis Committee:}

Dr. William Curry

Dr. Olivier Marchal

Dr. Daniel McCorkle

Dr. Jerry McManus (chair)

Prof. Carl Wunsch 


\section{Biographical Note}

The author was born on 25 January, 1977, in Englewood, Colorado. She grew up in the Washington, D. C., area and graduated from the Thomas Jefferson High School for Science and Technology in Alexandria, Virginia, in 1995. She then attended Princeton University, and in 1999, received an A. B. in Geosciences, magna cum laude, and the Edward Sampson, Class of 1914, Prize in Economic Geology. Her senior thesis, Late Maastrichtian Populations of Planktonic Foraminifera of the South Atlantic, was advised by Prof. Gerta Keller. She also received a Certificate in Violoncello and Viola da Gamba Performance from the Department of Music, where she studied with Vivian Barton Dozor. In Fall, 1999, she enrolled in the MIT/WHOI Joint Program in Oceanography, where she was a recipient of the WHOI Stanley Watson Fellowship. She won the IMAGES Student Poster Prize at the VIIth and VIIIth International Conferences on Paleoceanography in 2001 and 2004. At MIT, she was awarded a Cherry L. Emerson Music Fellowship, and studied violoncello with Dr. Carol Ou at the New England Conservatory of Music. 


\section{Acknowledgments}

The work in this thesis was supported by the National Science Foundation award OPP9912122 to Lloyd Keigwin, the Oak Foundation of Boston, Massachusetts, the Stanley Watson Fellowship, the Paul Fye Fellowship, and the Academic Programs Office at WHOI.

My thesis advisor, Lloyd Keigwin, gave me a wonderful opportunity in working on these Healy 02-02 cores. I'd like to thank Lloyd and the rest of my thesis committee, Bill Curry, Olivier Marchal, Dan McCorkle, Jerry McManus, and Carl Wunsch for their guidance, especially during the writing of this thesis.

This project would not have been possible without the support of many people who helped me with the analytical work. Sue Trimarchi and Luping Zou taught me how to process and pick foraminifer samples. Ellen Roosen, Mary Carman, Marti Jeglinski, and Kathy Elder helped with sample preparation and picking. Al Gagnon, Rindy Ostermann, and Marti Jeglinski taught me to how to run the mass spectrometers. Kristy Dahl and Rose Came helped me with preparing and running ICP-MS samples. Joan Bernhard provided

the microscope I used to photograph foraminifer specimens. All the ${ }^{14} \mathrm{C}$ analysis were conducted at the NOSAMS facility.

It was a privilege to be a student in the MIT/WHOI Joint Program. The staff of the Academic Programs Office and JCMG\&G were very helpful and supportive. I was fortunate to enter MIT and the Joint Program with a cohort of paleoceanographers, Rose Came, Kristy Dahl, Peter Huybers, Dave Lund, and Matt Makou, from whom I learned much and who all became good friends. I'd like to thank my classmates and friends in Woods Hole who made this a wonderful place to live and work, especially Hugh, Margaret, Linda, Heidi, Jonathan, John, Phoebe, Adam, Jeff F., Tetjana, Joe, Marsha, Julia, Jayne, Mark, Liz, Cara, Jeff S., Rhea, Boa, Patty, Luc, Jessica, Carlos, and Nathalie. I'm grateful to Luping Zou and Xin Huang for their friendship and for being a second family to me here in Woods Hole.

Finally, I'd like to thank my parents, Joung and Jungnim Cook, and my sister, Jean. 


\section{Contents}

1 Introduction $\quad 13$

2 The deglacial history of surface and intermediate water of the Bering Sea 19

3 The deglaciation in the Bering Sea $\quad 31$

3.1 Introduction . . . . . . . . . . . . . . . . . . . . . . 31

3.2 Methods . . . . . . . . . . . . . . . . . . 35

3.3 Results.............................. 43

3.4 Discussion . . . . . . . . . . . . . . . . . . . 51

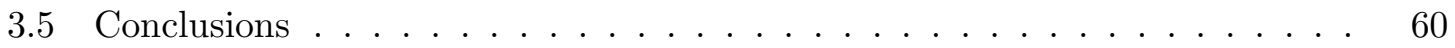

4 Marine Isotope Stage 3 in the Bering Sea $\quad 61$

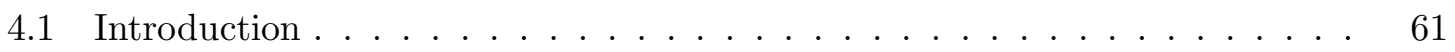

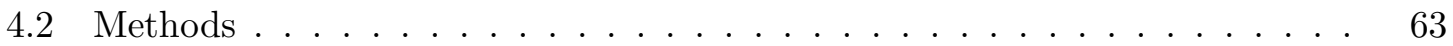

4.3 Results . . . . . . . . . . . . . . . . . . . . . 64

4.4 Discussion . . . . . . . . . . . . . . . . . . . 64

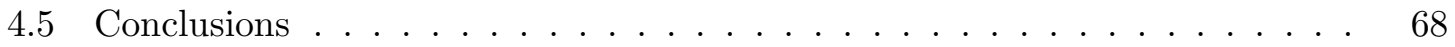

5 Evidence of Methane in Bering Sea Sediments during Marine Isotope $\begin{array}{ll}\text { Stage } 3 & 69\end{array}$

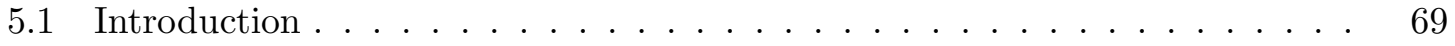

5.2 Methods . . . . . . . . . . . . . . . . . . . . 75

5.3 Results. . . . . . . . . . . . . . . . . . 76

5.4 Discussion . . . . . . . . . . . . . . . . . . . . . 81

5.5 Conclusions and Future Work . . . . . . . . . . . . . . . 88 
A Apparent ventilation age of the North Pacific during the last deglacial transition

A.1 Benthic-planktonic ${ }^{14} \mathrm{C}$ age difference . . . . . . . . . . . . . . . . . 97

A.2 $\Delta^{14} \mathrm{C}$ of subsurface water $\ldots \ldots \ldots \ldots \ldots$

A.3 Apparent ventilation age . . . . . . . . . . . . . . . . 104

A.4 Discussion . . . . . . . . . . . . . . . . . . . . 107 


\section{Chapter 1}

\section{Introduction}

The ocean circulation is an integral part of Earth's climate system. Seawater holds large amounts of heat and dissolved carbon dioxide, a strong greenhouse gas. As the ocean circulates, these quantities are moved around the globe and exchanged with the atmosphere. In the modern ocean, the physical properties of seawater, such as salinity and temperature, and the distribution of dissolved components, such as nutrients, oxygen, and carbon dioxide, are a product of the complex interaction of circulation, mixing, and biogeochemical processes in the ocean

Since the 1960s, paleoceanographers have been developing geochemical proxies of the properties of seawater in the past. Now we have a wide array of tools with which to study what was the state of the ocean as far back in time as the age of the oldest sediments on the seafloor. When these marine records are combined with continental records of changes in flora and ice sheet and glacier extent, and with ice core records of the composition of the ancient atmosphere and precipitation, we can get a sense of how the Earth's climate system has changed in the past, and even formulate tentative theories of why it changed.

The Pleistocene (the last 2 million years) is the most recent episode of Earth's history in which global climate was cold enough for there to be ice year-round at the poles, and where the Earth cycles into and out of ice ages. The focus of this thesis is the time from 50,000 years ago (the middle of the last glacial period) to the present. During this time period, superimposed upon the large-scale shift from a glacial state to an interglacial state (which took place 18,000-10,000 years ago) are millennial-scale climate fluctuations (events of duration and spacing on the order of $1000 \mathrm{y}$ ) which are about half the amplitude of the 
glacial-interglacial change, and appear to have had the greatest impact in the North Atlantic region. In this thesis, I study the manifestation of these shorter climate events in the North Pacific in order to learn what role the physical and biological processes in this region play in the global climate system.

Study of how the ocean, atmosphere, and cryosphere change under a variety of forcings and boundary conditions in the past helps us to understand Earth's climate system better than studying just the state of the modern ocean. This is vitally important today, as we humans are rapidly altering the concentration of atmospheric greenhouse gases, we can apply our understanding of the past in predicting what effects human activity will have on climate, and how this will impact human civilization.

One difficulty in studying the ancient ocean is that there are relatively few places where marine sediments suitable for paleoceanographic study can be recovered. So the geological record has rather poor spatial coverage, limited to the ocean margins and bathymetric highs, such as seamounts, hotspots chains, and mid-ocean ridges. Another difficulty is that each of the geochemical proxies we use to reconstruct ocean water properties is imperfect, so that the interpretation of any one proxy record is fraught with enough caveats to not make a very compelling story on its own. Yet another difficulty is that the ocean is heterogeneous, and local processes can influence a geological record as much as the basin-wide processes of interest. So reconstructing what the ocean was like in the past is a thorny problem!

The great strength of our arsenal of paleoceanographic tools is that there is often more than one proxy we can use to reconstruct a particular property of the ancient ocean. So our strategy is to build a database of sediment records from various locations, using more than one tool. This way, if several records of independent proxies tell a consistent story, we can believe the story much more than if we just had one record in one place. The process of collecting and analyzing sediment cores is time-consuming, labor-intensive, and expensive, so it can take years of work by multiple specialists to find out what story one sediment core has to tell.

Foraminifera, single-celled organisms that live near the sea surface and on the seafloor, are the workhorse of paleoceanography. They make their shells out of calcium carbonate, which records the chemistry of the environment in which they lived. Calcium carbonate is well preserved in the Atlantic, but poorly preserved in the Pacific, where bottom waters are more corrosive with respect to calcium carbonate. As a consequence, there are relatively few 


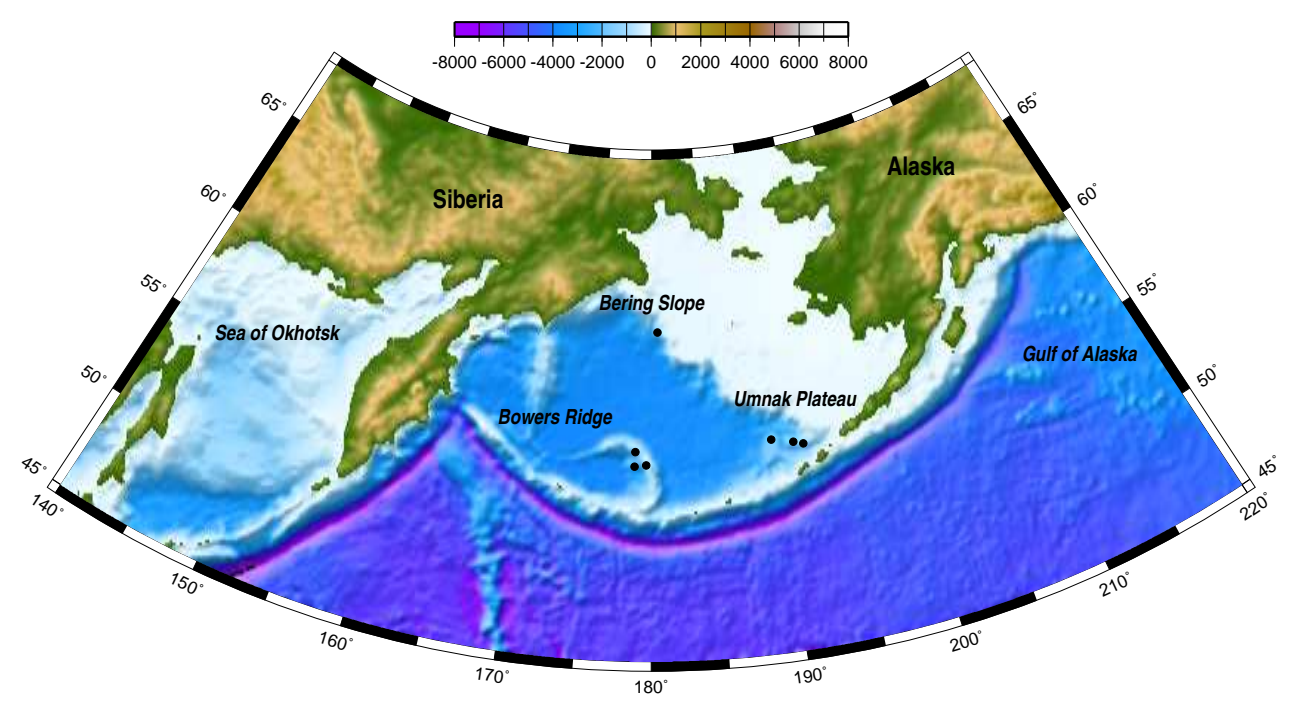

Figure 1-1: The Bering Sea. The scale for color bathymetry and topography is in meters. Coring sites from HLY02-02 are labeled with black dots.

high-resolution paleoceanographic records from the Pacific, and it is not well known what happened in this largest of ocean basins during the Pleistocene. Arguably the best of these records come from the Santa Barbara Basin. However, as a coastal site, the Santa Barbara Basin is influenced by coastal upwelling, and it is ambiguous how much the geological records from this site reflect local processes, and how much they reflect what is occurring in the open North Pacific. In fact, there are too few high-quality North Pacific records for there to be much of any consensus as to what are the most important physical and biological processes in this basin with respect to climate, and how they changed in the past.

For this thesis, I studied sediment cores that were collected from the Bering Sea by the science party lead by my thesis advisor, Lloyd Keigwin, Neal Driscoll of the Scripps Institute of Oceanography, and Julie Brigham-Grette of University of Massachusettes, Amherst, aboard the USCGC Healy in summer, 2002. The Bering Sea is the northern-most marginal basin of the Pacific. The sediment cores were collected from the Alaskan continental slope in the northeast Bering Sea, the Umnak Plateau in the southeast Bering Sea, and from Bowers Ridge, an aseismic ridge in the south-central Bering Sea (Figure 1-1). From foraminifer shells preserved in these cores, I have constructed records of $\delta^{18} \mathrm{O}$, a temperature and salinity proxy, $\delta^{13} \mathrm{C}$, a nutrient proxy, and ${ }^{14} \mathrm{C}$, which can be used to translate depth in the sediment core to calendar age. When ${ }^{14} \mathrm{C}$ is measured in benthic foraminifera, which live on the seafloor, it can be used to deduce how long the water mass bathing the seafloor 
has been out of contact with the atmosphere, providing insight on ocean circulation. I also produced records of the relative abundance of a planktonic (living near the surface ocean) foraminifer, $N$. pachyderma (s.), which is a qualitative proxy for sea surface temperature. The temporal resolution of the records presented in this thesis is as good as or better than most published North Pacific records, good enough to resolve millennial-scale events if they occured in this basin.

The preliminary stratigraphic data of the Healy cores are included in a paper in Deep Sea Research II (Cook et al., 2005), where I report the discovery of cores with high sediment accumulation rate and good carbonate preservation. In this paper (Chapter 2 of the thesis), I reviewed the hydrography of the Bering Sea, why the region is of paleoceanographic interest, and previous studies that were conducted in the area.

In Chapter 3, I present the lithology of Bering Sea sediments, and high-resolution data sets of $N$. pachyderma (s.) relative abundance and $\delta^{18} \mathrm{O}$ from Bering Slope and Bowers Ridge that span the Last Glacial Maximum (LGM, 21,000 years ago) to the present. I also compile published and unpublished measurements of ${ }^{14} \mathrm{C}$ in coeval planktonic and benthic foraminifera from the North Pacific and estimate the ${ }^{14} \mathrm{C}$ of subsurface water in the North Pacific during the LGM and deglaciation $\left({ }^{14} \mathrm{C}\right.$ calculations are detailed in Appendix A). The goals of this chapter are (1) to understand the history of temperature and salinity of Bering Sea surface water, (2) to look for evidence of whether the circulation in the North Pacific changed between the LGM and the present, and during the Bølling-Ållerød and Younger Dryas, two climate events during the deglaciation. A change in circulation of the North Pacific could affect both the oxygen content (oxygen affects lithology), and the ${ }^{14} \mathrm{C}$ content of subsurface water.

In Chapter 4, using planktonic and benthic $\delta^{18} \mathrm{O}$ and $\delta^{13} \mathrm{C}$ as well as relative abundance of N. pachyderma (s.) in a core from Bowers Ridge, I test the hypothesis of previous investigators that the sea surface temperature and the $\delta^{13} \mathrm{C}$ of intermediate-depth water changed on millennial time scales during the last glacial period (55,000-28,000 years ago). In Chapter 5 , I present planktonic and benthic $\delta^{18} \mathrm{O}$ and $\delta^{13} \mathrm{C}$ from a core from the Umnak Plateau region from the same time period. In this core, there are large excursions in benthic and planktonic $\delta^{13} \mathrm{C}$ which I hypothesize are caused by the precipitation of carbonate minerals on the foraminifer shells after they were buried in the sediment column. I formulate a simple mathematical model to calculate the isotopic composition of the carbonate overgrowths, 
in order to understand why these minerals formed. In Chapter 6, I summarize the main findings of this thesis and discuss future research directions. 


\section{Chapter 2}

\section{The deglacial history of surface and intermediate water of the Bering Sea}

This chapter was published as Cook, M. S., Keigwin, L. D., Sancetta, C. S., 2005. The deglacial history of surface and intermediate water of the Bering Sea. Deep-Sea Research II 52, 2163-2173. 


\title{
The deglacial history of surface and intermediate water of the Bering Sea
}

\author{
Mea S. Cook ${ }^{\mathrm{a}, *}$, Lloyd D. Keigwin ${ }^{\mathrm{b}}$, Constance A. Sancetta ${ }^{\mathrm{c}}$ \\ ${ }^{a}$ MIT-WHOI Joint Program in Marine Geology \& Geophysics, Woods Hole Oceanographic Institution, Woods Hole, MA 02543, USA \\ ${ }^{\mathrm{b}}$ Department of Marine Geology \& Geophysics, Woods Hole Oceanographic Institution, Woods Hole, Massachusetts 02543, USA \\ c1637 Irvin Street, Vienna, Virginia 22182, USA
}

Received 18 October 2003; accepted 31 July 2005

Available online 25 October 2005

\begin{abstract}
The lithology of deglacial sediments from the Bering Sea includes intervals of laminated or dysaerobic sediments. These intervals are contemporaneous with the occurrence of laminated sediments from the California margin and Gulf of California, which suggests widespread low-oxygen conditions at intermediate depths in the North Pacific Ocean. The cause could be reduced intermediate water ventilation, increased organic carbon flux, or a combination of the two. We infer abrupt decreases of planktonic foraminifer $\delta^{18} \mathrm{O}$ at 14,400 and $11,650 \mathrm{yr} \mathrm{BP}$, which may be a combination of both freshening and warming. On the Shirshov Ridge, the abundance of sea-ice diatoms of the genus Nitzschia reach local maxima twice during the deglaciation, the latter of which may be an expression of the Younger Dryas. These findings expand the extent of the expression of deglacial millennial-scale climate events to include the northernmost Pacific. (C) 2005 Elsevier Ltd. All rights reserved.
\end{abstract}

Keywords: Anoxic sediments; Deglaciation; Diatoms; Foraminifera; Oxygen isotope stratigraphy; Bering Sea

\section{Introduction}

Water-mass tracer proxies measured from the most intense cold events of the last deglaciation, Heinrich Event 1 and the Younger Dryas (YD), are consistent with a reduction in the strength of the Atlantic meridional overturning circulation (MOC) (Boyle and Keigwin, 1987; Zahn et al., 1997; Vidal et al., 1997; McManus et al., 2004). Because of the large transport of heat associated with the MOC, $60 \%$ of the Northern Hemisphere midlatitude poleward ocean heat transport takes place in the

\footnotetext{
*Corresponding author.

E-mail address: meacook@whoi.edu (M.S. Cook).
}

Atlantic (Talley, 2003), which is half the size of the Pacific. There is no analogous circulation like the MOC in the Pacific today, where heat transport is dominated by that associated with the shallow wind-driven gyre circulation. The lack of deep or intermediate convection is attributed to the low salinity of North Pacific surface waters, which even at their freezing point, are not dense enough to sink (Warren, 1983; Emile-Geay et al., 2003).

In the modern North Pacific, freshening and an increase in apparent oxygen utilization of NPIW in the last $60 \mathrm{yr}$ are linked to hydrographic changes in the Western Subarctic Gyre (WSAG) and the Okhotsk Sea (Andreev and Watanabe, 2002; Joyce and Dunworth-Baker, 2003; Hill et al., 2003), 
demonstrating a link between surface and intermediate water physical properties. From the presence of CFCs in the deepest Bering Sea Basin (Warner and Roden, 1995), there is a very small amount of deep-water formation occurring there today. Deep water in the rest of the North Pacific originates from the Southern Ocean (Roden, 1995).

From geochemical proxies of nutrients, dissolved oxygen, temperature, and salinity within intermediate (Keigwin and Jones, 1990; Behl and Kennett, 1996; Zheng et al., 2000; Keigwin, 1998; Ahagon et al., 2003) and deep water (Herguera et al., 1992; Lund and Mix, 1998; Matsumoto et al., 2002), it is hypothesized that the ventilation of the intermediate and the deep Pacific water masses was higher in the past. This implies that the balance of freshwater and salt in the ocean basins would have been significantly different than today, possibly with greater oceanic heat transport in the Pacific. Unfortunately, detailed interpretation of the paleo-geochemical evidence at most open-ocean sites is not possible because of low sediment accumulation rates.

The high-resolution records in laminated sediments from anoxic basins from the California coast and the Gulf of California have been extensively studied (Behl and Kennett, 1996; Zheng et al., 2000; van Geen et al., 2003; Ortiz et al., 2004). But because productivity in California margin anoxic basins is a function of coastal upwelling, it is difficult to distinguish between reduced ventilation and local increase in export production as the cause of laminations.

The Bering Sea's proximity to the Okhotsk Sea, which is the source of the precursor to modern NPIW, and its position as the gateway between the North Pacific and the Arctic make it a desirable place to study Pacific paleoclimatology. In addition, coring of the thickly sedimented continental margin (Carlson and Karl, 1988) and aseismic ridges allows for high-resolution studies.

On the USCGC Healy in summer, 2002, we collected new sediment cores from three regions: Bowers Ridge, an aseismic ridge in south-central Bering Sea; Umnak Plateau, on the southeast end of the continental slope; and between the Pervenets and Navarin Canyons, on the northwest end of the slope (Fig. 1, Table 1). Our preliminary data indicate many of these cores have very high sediment accumulation rates and good calcium carbonate $\left(\mathrm{CaCO}_{3}\right)$ preservation and will provide an excellent record of rapid climate variability over the last complete glacial cycle. Most coring locations are far enough away from continental land masses to be less influenced by coastal upwelling.

Due to the low $\mathrm{CaCO}_{3}$ accumulation rates endemic to the Pacific, most of the previous marine

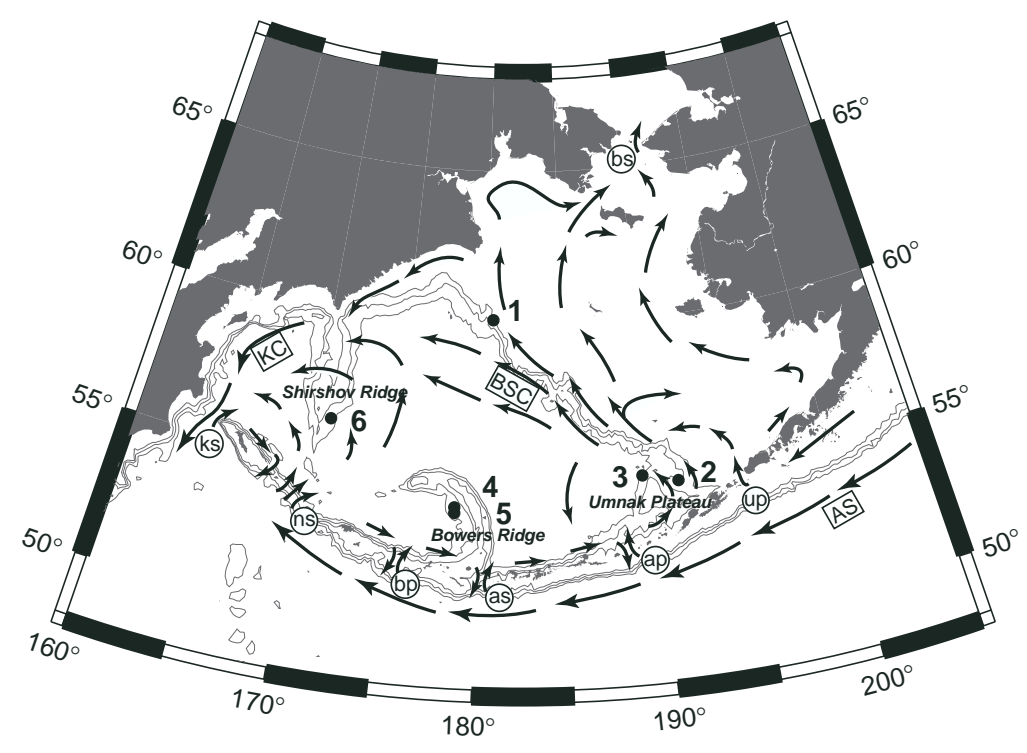

Fig. 1. Bering Sea core locations. Bathymetric contours are at 1, 2, and $3 \mathrm{~km}$. Details of the numbered core locations are in Table 1 . Mean surface circulation is indicated (modified from Stabeno et al. (1999)). Currents (rectangles) and geographic features (circles) referred to in the text are labeled: Kamchatka Current (KC), Bering Slope Current (BSC), Alaskan Stream (AS), Bering Strait (bs), Kamchatka Strait (ks), Near Strait (ns), Buldir Pass (bp), Amchitka Strait (as), Amutka Pass (ap), and Unimak Pass (up). 
Table 1

The cores used in this study

\begin{tabular}{|c|c|c|c|c|}
\hline Location & $\#$ & Core & Depth (m) & Latitude/Longitude \\
\hline Bering Slope & 1 & HLY02-02-3JPC & 1132 & $\mathrm{~N} 60.1279^{\circ} / \mathrm{E} 180.5582^{\circ}$ \\
\hline Umnak Plateau & 2 & HLY02-02-51JPC & 1467 & $\mathrm{~N} 54.5532^{\circ} / \mathrm{E} 191.3331^{\circ}$ \\
\hline Umnak Plateau & 3 & $\mathrm{RC} 14-121$ & 2532 & $\mathrm{~N} 54.8500^{\circ} / \mathrm{E} 189.3233^{\circ}$ \\
\hline Bowers Ridge & 4 & HLY02-02-17JPC & 2209 & $\mathrm{~N} 53.9330^{\circ} / \mathrm{E} 178.6988^{\circ}$ \\
\hline Bowers Ridge & 5 & VINO19-12GGC & 2745 & $\mathrm{~N} 53.7367^{\circ} / \mathrm{E} 178.7083^{\circ}$ \\
\hline Shirshov Ridge & 6 & ANTP-42PC & 2393 & $\mathrm{~N} 56.3870^{\circ} / \mathrm{E} 171.0770^{\circ}$ \\
\hline
\end{tabular}

paleoclimatological work in the Bering Sea region is based on siliceous microfossil abundances (Zhuze, 1962; Sancetta and Robinson, 1983; Sancetta et al., 1985; Morley and Robinson, 1986; Starratt, 1993). In particular, \% Nitzschia indicates greater sea-ice coverage in the last glacial period along the eastern shore of the Bering Sea, including the Pervenets Canyon region and the Umnak Plateau. Modern distribution of Nitzschia is consistent with observed sea-ice extent, where the southern slope including the Umnak Plateau is relatively ice-free.

From the abundance of low-oxygen benthic foraminifer species, near Pervenets Canyon, Starratt (1995) inferred that the oxygen minimum zone (OMZ) fluctuated in the past. Gorbarenko (1996), in the Okhotsk and Bering Seas, found two episodes of deglacial freshening of surface water associated with increases in $\% \mathrm{CaCO}_{3}, \%$ opal, and \%organic carbon $\left(\mathrm{C}_{\text {org }}\right)$. However, these data are difficult to correlate with the global observations from the last glacial maximum (LGM) and deglaciation because of poor age control.

In this paper, we will discuss our observations of the deglaciation in the Bering Sea, incorporating previously unpublished diatom and foraminifer $\delta^{18} \mathrm{O}$ from three older cores: RC14-121 (R.V. Conrad, Umnak Plateau), VINO19-12GGC (R.V. Vinogradov, Bowers Ridge), and ANTP-42PC (R.V. Melville, Shirshov Ridge). Our synthesis will show that the changes we observe were widespread, not only within the Bering Sea, but probably throughout the open North Pacific.

\section{Bering Sea hydrography}

The Bering Sea lies between the Aleutian Islands to the south, Siberia to the northwest, and Alaska to the northeast, and consists of a broad continental shelf (50-150 m deep) and a deep basin $(<4000 \mathrm{~m}$ deep) (Fig. 1). The principal surface circulation in the basin is a cyclonic gyre, whose western boundary current is the southward flowing Kamchatka Current. Alaskan Stream water flows northward through passes between the Aleutian Islands and is incorporated into this gyre circulation. The Bering Slope Current (BSC), which flows along the edge of the continental shelf, marks the eastern edge of the gyre.

On the shelf, the principal surface flow is northward, with net northward flow through the Bering Strait, which is $85 \mathrm{~km}$ wide and $50 \mathrm{~m}$ deep (Schumacher and Stabeno, 1998). Water from the Bering Sea is relatively low salinity and rich in nutrients, and is an important component of the upper halocline in the Arctic (Cooper et al., 1997). With reduced sea level $(\sim 130 \mathrm{~m}$ lower $)$ during the last glacial period, the continental shelf was subaerially exposed, isolating the North Pacific from the Arctic and North Atlantic. The Bering Strait reopened during the deglaciation, no later than $11,000{ }^{14} \mathrm{C} \mathrm{yr}$ before present (BP) (latest $\sim 13,000 \mathrm{yr}$ BP) (Elias et al., 1997).

To the south, the Bering Sea is connected to the North Pacific through various straits and passes, the largest of which are (from west to east) Kamchatka Strait (4420 m), Near Strait (2000 m), Buldir Pass $(640 \mathrm{~m})$, Amchitka Strait $(1155 \mathrm{~m})$, and Amutka Pass (430 m) (Fig. 1). Physical properties of water across the Aleutian Islands diverge deeper than $2000 \mathrm{~m}$, indicating relatively unimpeded exchange between the Bering Sea and North Pacific at and above the depth of Near Strait. Constricted exchange of deep water occurs through Kamchatka Strait. In the eastern Bering Sea, northward flow through the Unimak Pass ( $<80 \mathrm{~m}$ deep) is the major conduit between the North Pacific and the shelf (Stabeno et al., 1999). At the LGM, this pass was closed, but exchange through the remainder of the 
Aleutian Arc was probably not significantly affected.

NPIW is formed by cabbeling of the northward flowing warm and salty Kuroshio Current and the southward flowing cold and fresh Oyashio Current waters where they meet east of Hokkaido, Japan (Yasuda, 1997; You, 2003). In the North Pacific, the core of NPIW approximately follows the $26.8 \sigma_{\theta}$ potential density surface, and is associated with a salinity minimum and oxygen maximum. The density of the core of NPIW is determined by Okhotsk Sea Mode Water (OSMW), the product of brine rejection during winter sea-ice formation. OSMW flows out of the Okhotsk Sea through the Kuril Islands, and mixes with WSAG water, forming Oyashio Current water. Today, NPIW is found at $200-400 \mathrm{~m}$ in the Bering Sea (Macdonald et al., 2001). The water mass at $400-2000 \mathrm{~m}$ originates from mixing of NPIW with intermediate-depth water that originates from the south (Roden, 2000). Deeper than $2000 \mathrm{~m}$, compared to the North Pacific, Bering Sea water is slightly fresher, warmer, and enriched in nutrients, particularly silicate, which dissolves from opal-rich seafloor sediments (Roden, 2000). Consistent with the restricted exchange of the deepest Bering Sea water with the North Pacific, $\Delta{ }^{14} \mathrm{C}$ is slightly lower than North Pacific water of equivalent depth (GEOSECS Executive Committee and Östlund, 1987).

There is a band of very high productivity along the BSC. Low stratification along the slope break is caused by tidal mixing and transverse circulation, bringing nutrients from $300-800 \mathrm{~m}$ depths to the surface and supporting production to high tropic levels (Springer et al., 1996). The OMZ in the Bering Sea is the most intense at $\sim 900 \mathrm{~m}$ water depth, with concentrations of dissolved oxygen $\left(\left[\mathrm{O}_{2}\right]\right)$ as low as $15 \mu \mathrm{mol} / \mathrm{kg}$ (Roden, 2000).

\section{Methods}

For stable isotope analysis, 0.5 -cm-thick (in laminated intervals) or 1-cm-thick (in massive intervals) samples with dry mass of $1-5 \mathrm{~g}$ were taken every $12 \mathrm{~cm}$ in the HLY cores. Two-centimeter-thick samples were taken every $4 \mathrm{~cm}$ in VINO19-12GGC and every $5 \mathrm{~cm}$ in ANTP-42PC. Sediment samples were oven dried at $50{ }^{\circ} \mathrm{C}$, then washed with tap water through a $63-\mu \mathrm{m}$ sieve. Benthic foraminifera were picked from the $>250$ $\mu \mathrm{m}$ fraction, planktonic from the $150-250-\mu \mathrm{m}$ fraction. Single tests of a hispid species of the
Table 2

Uncorrected AMS ${ }^{14} \mathrm{C}$ ages measured on $N$. pachyderma (s.) and corrected, calibrated ages

\begin{tabular}{|c|c|c|c|}
\hline Core & Depth $(\mathrm{cm})$ & ${ }^{14} \mathrm{C}$ yr BP $\pm \sigma$ & $\operatorname{yr} \mathrm{BP} \pm$ \\
\hline HLY02-02-3JPC & $140.5-142.5$ & $10,050 \pm 60$ & $10,340_{10,300}^{10,620}$ \\
\hline HLY02-02-3JPC & $352.5-353.5$ & $10,850 \pm 65$ & $11,650_{10,900}^{11,920}$ \\
\hline HLY02-02-3JPC & $600.5-601.5$ & $12,400 \pm 65$ & $13,500_{13.470}^{13,810}$ \\
\hline HLY02-02-3JPC & $906.5-909.5$ & $13,350 \pm 80$ & $14,400_{14,330}^{15,360}$ \\
\hline HLY02-02-51JPC & $134.5-135.5$ & $10,600 \pm 60$ & $11,250_{10,850}^{11,600}$ \\
\hline HLY02-02-51JPC & $177.5-178.5$ & $12,500 \pm 60$ & $13,540_{13,490}^{13,830}$ \\
\hline HLY02-02-51JPC & $241.5-242.5$ & $14,050 \pm 85$ & $15,920_{15,680}^{16,170}$ \\
\hline HLY02-02-17JPC & $155.5-156.5$ & $10,000 \pm 60$ & $10,320_{10,290}^{10,600}$ \\
\hline HLY02-02-17JPC & $185.5-186.5$ & $12,550 \pm 65$ & $13,590_{13,490}^{14,000}$ \\
\hline HLY02-02-17JPC & $215.5-216.5$ & $13,400 \pm 60$ & $14,450_{14,350}^{15,420}$ \\
\hline
\end{tabular}

Calibrations performed with Calib4.4html (Stuiver et al., 1998) using $\Delta R=300 \mathrm{yr}$, corresponding to a $\sim 700$-yr reservoir correction. We report the maximum probability calendar ages with the upper and lower limits of the $1 \sigma$ range.

benthic genus Uvigerina, and eight tests of the planktonic species Neogloboquadrina pachyderma (sinistral) were analyzed from each sample on a VG PRISM-III mass spectrometer with an Isocarb system $\left(90^{\circ} \mathrm{C}\right.$ common acid bath) for $\delta^{18} \mathrm{O}$ with a precision of $\pm 0.07 \%$. Exceptions are HLY02-0251JPC, where a costate Uvigerina species was used, and in VINO19-12GGC and ANTP-42PC where $15 N$. pachyderma (s.) comprised each analysis. Uvigerina is not present in all samples. Percent $\mathrm{CaCO}_{3}$ was measured as in Keigwin et al. (1992). Methods for counting diatom species relative abundance are described in Sancetta et al. (1985). Diatom $\delta^{18} \mathrm{O}$ data and a lower resolution version of the diatom relative abundance data from RC14-121 were previously published in Sancetta et al. (1985).

Radiocarbon dating was performed at the National Ocean Sciences Accelerator Mass Spectrometry (NOSAMS) facility at WHOI on $N$. pachyderma (s.) $>150 \mu \mathrm{m}$ (Table 2 ). In calibrating our dates, we assumed the local anomaly from the mean global reservoir correction $(\Delta R)$ was constant at $300 \mathrm{yr}$. The modern $\Delta R$ in the North Pacific is not well known; estimates include $80-360 \mathrm{yr}$ in the northern and eastern Bering Sea (Dumond and Griffn, 2002), $320 \pm 40 \mathrm{yr}$ at the Kuril Islands and $40 \pm 40 \mathrm{yr}$ in the Sea of Japan (Kuzmin et al., 2002), and $240 \pm 50$ yr near Kamchatka Strait (Robinson and Thompson, 1981). It is very likely that $\Delta R$ is spatially and temporally variable as a function of local upwelling strength and circulation, so our 


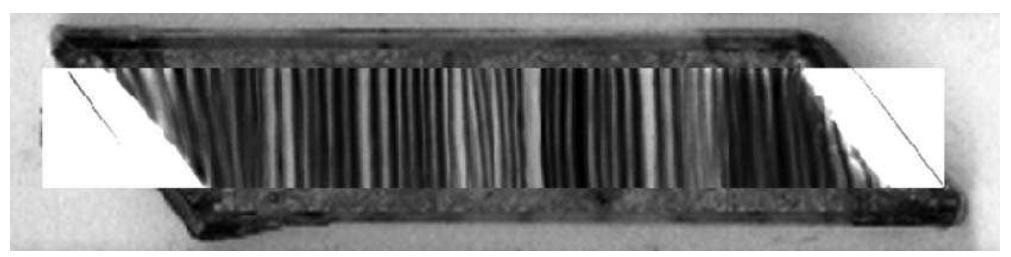

Fig. 2. Positive X-radiograph of a u-channel sample taken from HLY02-02-1GGC (255-267 cm), a companion core to HLY02-02-3JPC. This $12 \times 2.5 \mathrm{~cm}$ sample is from a depth interval that is the equivalent of the uppermost laminated interval HLY02-02-3JPC. From our estimates of sediment accumulation rate, each light-dark pair probably represents one year of accumulation. Note the cyclic variability in lamina thickness indicating sub-decadal variability in the seasonal deposition of sediment.

assumed value of $300 \mathrm{yr}$ should only be regarded as a reasonable guess. $\Delta R$ may have varied by up to a few hundred years through time and between these sites, but this would not affect the conclusions of this paper.

\section{Results ${ }^{1}$}

\subsection{Lithology}

All of our cores contain one or two deglacial intervals which are visually identified as high $\% \mathrm{CaCO}_{3}$, high $\%$ opal, and high $\% \mathrm{C}_{\text {org }}$ intervals with a distinctly greenish hue. HLY02-02-3JPC contains the most expanded deglacial sequence of the cores in this study, at $\sim 8 \mathrm{~m}$ long, with an average sediment accumulation rate of $190 \mathrm{~cm} / \mathrm{kyr}$ from the beginning to the end of the laminated sequences. There are four visibly laminated intervals, which are composed of pairs of dark and light olive laminae ranging in thickness from $<1$ to $2 \mathrm{~mm}$ (Fig. 2). Intervening massive intervals and the deepest $6 \mathrm{~m}$ of sediment are composed of very fine grained sticky homogeneous dark olive-gray mud. The topmost $1.4 \mathrm{~m}$ of sediment is firm dark-olivegray mud. Holocene sediments from the Bowers and Shirshov Ridges are diatomaceous and contain moderately high $\mathrm{CaCO}_{3}$. The sediment accumulation rates in HLY02-02-51JPC and HLY02-02$17 \mathrm{JPC}$ are $15-20 \mathrm{~cm} / \mathrm{kyr}$ during the deglaciation. We currently have no age control for the Holocene portions of the HLY cores because of the rarity of planktonic foraminifera and the unknown amount of sediment lost from the top of piston cores during the coring process.

\footnotetext{
${ }^{1}$ All data reported in this paper are posted on the NOAA Paleoclimatology Program website (www.ncdc.noaa.gov/paleo/ paleo.html).
}

For the time interval corresponding to the deglaciation, stratigraphic correlation between the HLY cores is based on ten ${ }^{14} \mathrm{C}$ dates, and in the other cores it is based on lithology. The upper and lower laminated intervals in HLY02-02-51JPC correspond to the upper one and lower three laminated intervals in HLY02-02-3JPC. In the other four cores, the analogs to the laminated sequence are the one or two "green layers," which are indicated with shaded bars in Figs. 3 and 4. For the cores with no age control, this correlation is approximate, assuming that green and laminated intervals represent contemporaneous dysaerobic conditions at the sediment-water interface. In RC14-121, three uncorrected, uncalibrated ${ }^{14} \mathrm{C}$ dates were measured on 20 -cm-thick sections of sediment and were interpreted by Sancetta et al. (1985) as maximum, not exact ages, establishing the uppermost lithological unit of this core $(0-175 \mathrm{~cm})$ as Holocene (Table 2).

\subsection{Oxygen isotope data}

There are two rapid decreases of planktonic $\delta^{18} \mathrm{O}$ in HLY02-02-3JPC, at 888-924 cm and 348-372 cm (Fig. 3), which occur at 14,400 and 11,650 yr BP, respectively. Linearly interpolating between the four ${ }^{14} \mathrm{C}$ dates, the transitions occur in $\leqslant 190 \mathrm{yr}$ and $\leqslant 130 \mathrm{yr}$ (Fig. 3). The magnitude of the $\delta^{18} \mathrm{O}$ events is 0.7-0.8\%. In RC14-121 and ANTP-42PC, the $\delta^{18} \mathrm{O}$ measurements begin probably after the start of the deglaciation since the highest benthic $\delta^{18} \mathrm{O}$ measurements in those cores are lower than the LGM values in similar-depth cores HLY02-0217JPC and VINO19-12GGC, which are at $\sim 5 \%$. In $\mathrm{RC} 14-121$, there is a $\sim 1 \%$ decrease in benthic $\delta^{18} \mathrm{O}$ in adjacent samples at $170-190 \mathrm{~cm}$ (Fig. 4). In the rest of the Bering Sea cores, there are no robust features in foraminifer $\delta^{18} \mathrm{O}$ in the data currently available. 

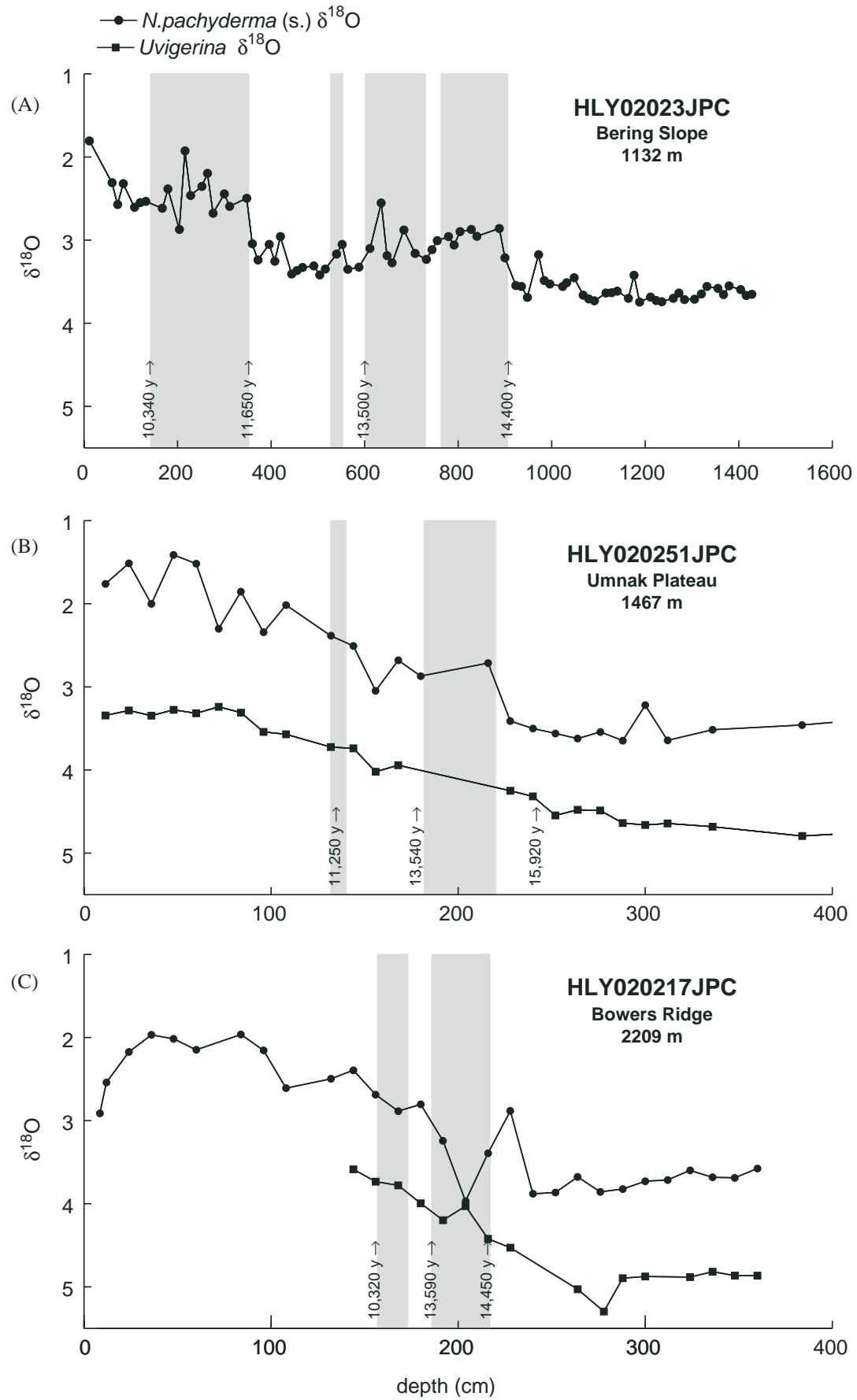

Fig. 3. Shaded bars represent "green" layers, which are characterized by high $\% \mathrm{CaCO}_{3}, \% \mathrm{C}_{\text {org}}$, and \%opal. In (A) and (B), these layers are laminated, where the laminae are probably annual pairs (see text). $\delta^{18} \mathrm{O}$ data is of Uvigerina with costate test in (B), hispid test in $(\mathrm{C})$. The ${ }^{14} \mathrm{C}$ dates in (A) are calibrated to calendar years (Table 2). The two abrupt $\sim 0.7-0.8 \%$ decreases in $\delta^{18} \mathrm{O}$ in panel (A) occur at 14,400 and $11,650 \mathrm{yr} B P$, each event lasting at most $\sim 200 \mathrm{yr}$. Assuming direct correlation of the green layers between cores, the sediment accumulation rates range from $\geqslant 12 \mathrm{~cm} / \mathrm{kyr}$ in $(B)$ and $(\mathrm{C})$ to $190 \mathrm{~cm} / \mathrm{kyr}$ during the deglaciation in (A). Note that the $x$-axis scales are not the same between the panels. 

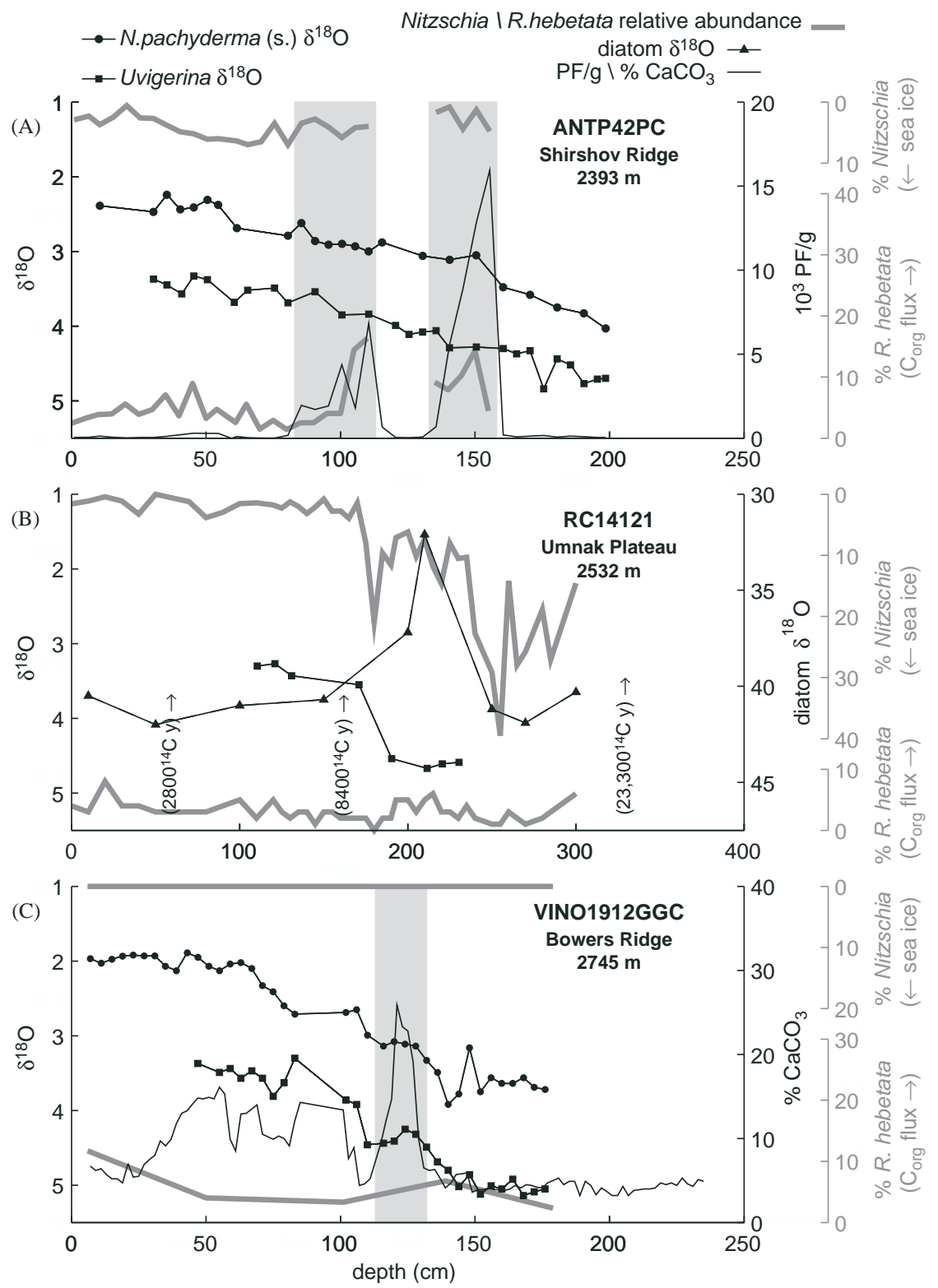

Fig. 4. Shaded bars represent "green" layers, which are characterized by high $\% \mathrm{CaCO}_{3},{ }^{\circ} \mathrm{C}_{\mathrm{org}}$, and $\%$ opal. $\delta^{18} \mathrm{O}$ data is of Uvigerina with hispid test in (A), (B), and (C). The thin line in (C) is $\% \mathrm{CaCO}_{3}$, in (A) it is \# planktonic foraminifera (PF) per gram dry sediment, a proxy for $\% \mathrm{CaCO}_{3}$. Presence of Nitzschia is associated with sea ice, $R$. hebetata is associated with high nutrient availability and $\mathrm{C}_{\mathrm{org}}$ flux. Nitzschia abundance patterns show that maximum extent of sea ice may not have reached the Bowers or Shirshov Ridge core sites during the LGM or YD. Note that the $x$-axis scales are not the same between the panels. The $y$-axis scales for a property on each panel are identical. Previously reported in Sancetta et al. (1985) were the diatom $\delta^{18} \mathrm{O}$ data and the three uncorrected, uncalibrated ${ }^{14} \mathrm{C}$ dates in (B), which were measured on the organic fraction of $20 \mathrm{~cm}$-thick sections of sediment and interpreted as maximum, not exact ages, establishing the uppermost lithologic unit of this core $(0-175 \mathrm{~cm})$ as Holocene.

\subsection{Diatom relative abundance data}

In Umnak Plateau core RC14-121 (Fig. 4), the new data at closer sample spacing support the earlier observations of Sancetta et al. (1985). The sum of the abundances of the diatoms Nitzschia grunowii and Nitzschia cylindra (both sometimes assigned to Fragilariopsis) indicate the presence of 
sea ice. During the late glacial or early deglacial transition, these sea-ice species occur at a relative abundance of $>20 \%$. There is a subsequent decrease in Nitzschia that is contemporaneous with a $\sim 9 \%$ decrease in bulk opal $\delta^{18} \mathrm{O}$. This is followed by a newly resolved increase in Nitzschia, which occurs as the Uvigerina $\delta^{18} \mathrm{O}$ decreases. Nitzschia abundance from ANTP-42PC of Shirshov Ridge is low throughout the deglaciation, and is zero in each of the samples at VINO19-12GGC. The species Rhizosolenia hebetata, which indicates high nutrient availability and $\mathrm{C}_{\text {org }}$ flux, shows highest relative abundance during the green layers in ANTP-42PC. In RC14-121, $R$. hebetata shows no significant changes, with an average relative abundance of $\sim 3 \%$ through the deglaciation and Holocene.

\section{Discussion}

\subsection{Chronology and correlations}

The sequence of Bering Sea laminated sediment is similar to the California Borderland Basins and Gulf of California, where laminations occur during the Holocene and the Bølling-Allerød (Keigwin and Jones, 1990; Behl and Kennett, 1996; Zheng et al., 2000; van Geen et al., 2003). Based on a simple age model where we linearly interpolate between the four ${ }^{14} \mathrm{C}$ dates, the four laminated intervals in HLY02-02-3JPC may correspond to (1) the Bølling, (2) the early Allerød, (3) the Allerød following the Inter-Allerød Cold Period, and (4) the early Holocene. This correlation will need confirmation from more detailed ${ }^{14} \mathrm{C}$ dating and a more robust estimate of the reservoir correction. From our estimate of sediment accumulation rate and the lamina thickness, each light-dark pair probably represents one year of accumulation.

The lithology of the deglacial sequence in the Bering Sea is similar to that observed in cores from the Okhotsk Sea and Bering Sea (Gorbarenko, 1996) and the open North Pacific (Keigwin et al., 1992; Gorbarenko, 1996; Keigwin, 1998) where during the deglaciation, rapid decreases in planktonic foraminifer $\delta^{18} \mathrm{O}$ precede intervals of high $\% \mathrm{CaCO}_{3}$. Percent $\mathrm{C}_{\text {org }}$ and \%opal are generally high during these intervals as well. From dry bulk density measurements and an estimate of sediment accumulation rate, Keigwin et al. (1992) determined that not only the percentage, but the fluxes of the biogenic components increased. This conclusion has received further support from accumulation rates calculated using the excess Th method (Crusius et al., 2004).

In cores from the far Northwest Pacific, Okhotsk Sea, and Bering Sea Gorbarenko (1996) determined that the negative planktonic $\delta^{18} \mathrm{O}$ events occurred at 12,500 and $9300{ }^{14} \mathrm{C}$ yr BP using a 1100 -yr reservoir correction. Calibrated to calendar years using $\Delta R=300 \mathrm{yr}$, these become 15,400 and $11,100 \mathrm{yr} \mathrm{BP}$, respectively. Considering the difficulty in identifying the location of the $\delta^{18} \mathrm{O}$ events in cores with low sediment accumulation rates, these ages are reasonably close to our dating of the events in HLY02-02$3 \mathrm{JPC}$ as 14,400 and $11,650 \mathrm{yr} \mathrm{BP}$.

The deglacial $\delta^{18} \mathrm{O}$ decrease of $\sim 9 \%$ measured in diatom silica in RC14-121 is much larger than the foraminifer $\delta^{18} \mathrm{O}$ decreases measured in any of the other Bering Sea cores. As discussed in Sancetta et al. (1985), diatom $\delta^{18} \mathrm{O}$ is more sensitive to changes in surface hydrography than foraminifer $\delta^{18} \mathrm{O}$, and because of the magnitude of the event, it probably represents a freshening of surface water. If it were entirely due to warming, the diatom $\delta^{18} \mathrm{O}$ signal would represent a temperature increase of $\sim 18^{\circ} \mathrm{C}$ (calibration of Shemesh et al. (1992)), which is not probable. Sancetta et al. (1985) hypothesized that the source of the freshening was a large flux of meltwater from retreating alpine glaciers in Alaska.

Of the three study regions with diatom data, only the Umnak Plateau (RC14-121) has indications of significant change in sea ice in the past, with two maxima in Nitzschia at what appear to be the LGM and the YD. The Nitzschia maximum at $2.5 \mathrm{~m}$ is interpreted to represent extreme glacial conditions with sea-ice cover throughout the year (Sancetta et al., 1985). Today, the maximum winter ice edge in the Bering Sea does not reach the Bowers Ridge, and just reaches the Umnak Plateau (Niebauer et al., 1999). No sea-ice diatoms are present in any of the samples analyzed from the VINO19-12GGC (Bowers Ridge). Katsuki et al. (2003) report that abundance of Thalassiosira gravida suggests sea ice was proximate at the crest but not the western side of the Bowers Ridge at the LGM. Nitzschia is present at Shirshov Ridge core ANTP-42PC but in low abundance throughout the record. Percent $R$. hebetata is relatively high in the older green layer and at the base of the younger green layer, suggesting high $\mathrm{C}_{\text {org }}$ flux to the sediments when these layers were deposited. Numbers of planktonic foraminifera per gram dry sediment (a proxy for $\% \mathrm{CaCO}_{3}$ ) reach a peak in both the green layers at 1-2 orders of magnitude higher than in intervening 
sediments, so probably represent high $\mathrm{CaCO}_{3}$ flux at those times as well.

\subsection{What produces the laminated sediment?}

Laminated sediments occur when the dissolved oxygen at the sediment-water interface is too low for burrowing macrofauna $\left(\left[\mathrm{O}_{2}\right]<5 \mu \mathrm{M}\right)$. This can be caused by the intersection of an intense OMZ with the seafloor. It also can occur when the flux of $\mathrm{C}_{\text {org }}$ is so high that the oxygen at the bottom of the water column is consumed by respiration. A third mechanism is seasonal fall-out of mat-forming diatoms or bacteria which can form a thick enough layer to suffocate benthic macrofauna (see Kemp, 1996).

In cores from the low-latitude eastern North Pacific during the deglaciation, there is an increase in the extent of laminations from north to south (Zheng et al., 2000), toward the low-oxygen intermediate water end member from the equatorial upwelling region. Stott et al. (2000) and van Geen et al. (2003) document asynchrony of laminations in cores from the Pacific coast of California and Baja, highlighting the influence of local export production in the occurrence of laminated sediment. In the Bering Sea, despite its proximity to the source of well-oxygenated NPIW, the belt of high productivity in the $\mathrm{BSC}$ appears to have drawn $\left[\mathrm{O}_{2}\right]$ low enough to bring it near the $5 \mu \mathrm{M}$ threshold for laminae preservation.

A simple explanation for the contemporaneous sequences of laminated and dysaerobic sediments in widely separated regions of the North Pacific is that the primary control is the $\left[\mathrm{O}_{2}\right]$ of the large-scale intermediate water mass and that flux of NPIW was reduced in the YD and other cold deglacial climate events. But anoxia caused by an increase in export production leaves a similar geochemical imprint in the sedimentary record, and there is evidence of higher fluxes of biogenic sedimentary components during the deglacial events. Based on data available at present, we cannot distinguish between the two hypotheses. It is likely that both processes are involved.

\section{Conclusions}

(1) The deglacial lithology in the Bering Sea can be correlated to other parts of the North Pacific. The deglaciation is characterized by one to two "green layers," which are occasionally laminated.
(2) There is a widespread occurrence of laminated sediments in the North Pacific, from the welldocumented California margin and Gulf of California anoxic basins to the continental slope of the Bering Sea. In one of our cores from the continental slope near the Pervenets Canyon, the laminations occur during the Bølling-Allerød and the early Holocene, which is similar to Behl and Kennett's (1996) findings in Santa Barbara Basin.

(3) The primary control on the presence of laminated sediments in the North Pacific could be the oxygen content of NPIW. But both ventilation and export production probably contribute to the dysaerobic conditions.

(4) Two abrupt freshening and/or warming events are recorded in planktonic foraminifer $\delta^{18} \mathrm{O}$ at 14,400 and 11,650 yr BP, which directly precede the "green layers."

(5) There is a YD-like cold event in the Bering Sea region, which is expressed as a maximum of seaice diatoms Nitzschia in a core from the Umnak Plateau.

\section{Acknowledgments}

We thank Mary R. Carman and Alan R. Gagnon for assistance preparing and analyzing stable isotope samples, the crew of the USCGC Healy for their contribution to the success of the Bering Sea cruise, the NOSAMS facility for expediting our radiocarbon samples, and Cox Analytical of Götheburg, Sweden, for providing the X-ray image. The Oak Foundation of Boston, Massachusetts, and the WHOI Academic Programs Office provided support for Mea Cook. This project was funded by NSF Grant OPP-9912122. We thank Sergei Gorbarenko, Yusuke Okazaki, Kozo Takahashi, an anonymous reviewer, and Jerry McManus for helpful comments. Fig. 1 was made with GMT (Wessel and Smith, 1998). This is WHOI contribution no. 11155.

\section{References}

Ahagon, N., Ohkushi, K., Uchida, M., Mishima, T., 2003. Middepth circulation in the northwest Pacific during the last deglaciation: evidence from foraminiferal radiocarbon ages. Geophysical Research Letters 30 (21), 2097.

Andreev, A., Watanabe, S., 2002. Temporal changes in dissolved oxygen of the intermediate water in the Subarctic North Pacific. Geophysical Research Letters 29 (14). 
Behl, R.J., Kennett, J.P., 1996. Brief interstadial events in the Santa Barbara Basin, NE Pacific, during the past $60 \mathrm{kyr}$. Nature 379, 243-246.

Boyle, E.A., Keigwin, L.D., 1987. North Atlantic thermohaline circulation during the past 20,000 years linked to high-latitude surface temperature. Nature 330, 35-40.

Carlson, P.R., Karl, H.A., 1988. Development of large submarine canyons in the Bering Sea, indicated by morphologic, seismic, and sedimentologic characteristics. Geological Society of America Bulletin 100, 1594-1615.

Cooper, L.W., Witledge, T.E., Grebmeier, J.M., Weingartner, T., 1997. The nutrient, salinity, and stable oxygen isotope composition of Bering and Chukchi Seas waters in and near the Bering Strait. Journal of Geophysical Research 102 (C6), 12,563-12,573.

Crusius, J., Pedersen, T.F., Kienast, S., Keigwin, L., Labeyrie, L., 2004. Influence of northwest Pacific productivity on north Pacific intermediate water oxygen concentrations during the bølling-allerød interval (14.7-12.9 ka). Geology 32 (7), 633-636.

Dumond, D.E., Griffin, D.G., 2002. Measurements of the marine reservoir effect on radiocarbon ages in the eastern Bering Sea. Arctic 55 (1), 77-86.

Elias, S.A., Short, S.K., Birks, H.H., 1997. Late Wisconsin environments of the Bering Land Bridge. Paleogeography, Paleoclimatology, Paleoecology 136, 293-308.

Emile-Geay, J., Cane, M.A., Naik, N., Seager, R., Clement, A.C., van Geen, A., 2003. Warren revisited: atmospheric freshwater uxes and "Why is no deep water formed in the North Pacific". Journal of Geophysical Research 108 (C6), 3178.

GEOSECS Executive Committee, Östlund, H.G., 1987. Shorebased Data and Graphics. GEOSECS Atlantic, Pacific, and Indian Ocean Expeditions, vol. 7, National Science Foundation.

Gorbarenko, S.A., 1996. Stable isotope and lithologic evidence of late-glacial and Holocene oceanography of the northwestern Pacific and its marginal seas. Quaternary Research 46, 230-250.

Herguera, J.C., Jansen, E., Berger, W.H., 1992. Evidence for a bathyal front at $2000 \mathrm{~m}$ depth in the glacial Pacific, based on a depth transect on Ontong Java Plateau. Paleoceanography 7 (3), 273-288.

Hill, K.L., Weaver, A.J., Freeland, H.J., Bychkov, A., 2003. Evidence of change in the Sea of Okhotsk: implications for the North Pacific. Atmosphere-Ocean 41 (1), 49-63.

Joyce, T.M., Dunworth-Baker, J., 2003. Long-term hydrographic variability in the Northwest Pacific Ocean. Geophysical Research Letters 30 (2), 1043.

Katsuki, K., Takahashi, K., Jordan, R.W., Matsushita, K., Sengoku, T., 2003. Surface circulation changes based on fossil diatoms in the Bering Sea and the western subarctic Pacific. Kaiyo Monthly 35, 394-400.

Keigwin, L.D., 1998. Glacial-age hydrography of the far Northwest Pacific Ocean. Paleoceanography 13 (4), 323-339.

Keigwin, L.D., Jones, G.A., 1990. Deglacial climatic oscillations in the Gulf of California. Paleoceanography 5 (6), 1009-1023.

Keigwin, L.D., Jones, G.A., Froelich, P.N., 1992. A 15,000 year paleoenvironmental record from Meji Seamount far northwestern Pacific. Earth and Planetary Science Letters 111, 425-440.

Kemp, A.E.S., 1996. Laminated sediments as paleo-indicators. In: Kemp, A.E.S. (Ed.), Paleoclimatology and Paleoceano- graphy from Laminated Sediments. The Geological Society, pp. vii-xii.

Kuzmin, Y.V., Burr, G.S., Jull, A.J.T., 2002. Radiocarbon reservoir correction ages in the Peter the Great Gulf, Sea of Japan, and eastern coast of the Kunashir, Southern Kuriles (Northwestern Pacific). Radiocarbon 43, 477-481.

Lund, D.C., Mix, A.C., 1998. Millennial-scale deep water oscillations: re-actions of the North Atlantic in the deep Pacific from 10 to $60 \mathrm{ka}$. Paleoceanography 13, 10-19.

Macdonald, A.M., Suga, T., Curry, R.G., 2001. An isopycnally averaged North Pacific climatology. Journal of Atmospheric and Oceanic Technology 18, 394-420.

Matsumoto, K., Oba, T., Lynch-Stieglitz, J., Yamamoto, H., 2002. Interior hydrography and circulation of the glacial Pacific Ocean. Quaternary Science Reviews 21, 1693-1704.

McManus, J.F., Francois, R., Gherardi, J.-M., Keigwin, L.D., Brown-Leger, S., 2004. Collapse and rapid resumption of Atlantic meridional circulation linked to deglacial climate changes. Nature 428, 834-837.

Morley, J.J., Robinson, S.W., 1986. Improved method for correlating late Pleistocene/Holocene records from the Bering Sea: application of a biosiliceous geochemical stratigraphy. Deep-Sea Research I 33 (9), 1203-1211.

Niebauer, H.J., Bond, N.A., Yakunin, L.P., Plotnikov, V.V., 1999. An update on the climatology and sea ice of the Bering Sea. In: Loughlin, T.R., Ohtani, K. (Eds.), Dynamics of the Bering Sea. University of Alaska Sea Grant, AK-SG-99-03, pp. 29-59.

Ortiz, J.D., O'Connell, S.E., DelViscio, J., Dean, W., Carriquiry, J.D., Marchitto, T., Zheng, Y., van Geen, A., 2004. Enhanced marine productivity off western North America during warm climate intervals of the past 52 kyr. Geology 32 (6), 521-524.

Robinson, S.W., Thompson, G., 1981. Radiocarbon corrections for marine shell dates with application to southern Pacific Northwest Coast prehistory. Syesis 14, 45-57.

Roden, G.I., 1995. Aleutian Basin of the Bering Sea: thermohaline, oxygen, nutrient, and current structure in July 1993. Journal of Geophysical Research 100 (C7), 13,539-13,554.

Roden, G.I., 2000. Flow and water property structures between the Bering Sea and Fiji in the summer of 1993. Journal of Geophysical Research 105 (C12), 28,595-28,612.

Sancetta, C., Robinson, S.W., 1983. Diatom evidence on Wisconsin and Holocene events in the Bering Sea. Quaternary Research 20, 232-245.

Sancetta, C., Heusser, L., Labeyrie, L., Naidu, A.S., Robinson, S.W., 1985. Wisconsin-Holocene paleoenvironment of the Bering Sea: evidence from diatoms, pollen, oxygen isotopes and clay minerals. Marine Geology 62, 55-68.

Schumacher, J.D., Stabeno, P.J., 1998. The continental shelf of the Bering Sea. In: Robinson, A.R., Brink, K.H. (Eds.), The Global Coastal Ocean: Regional Studies and Synthesis. The Sea, vol. XI. Wiley, New York, pp. 789-823.

Shemesh, A., Charles, C.D., Fairbanks, R.G., 1992. Oxygen isotopes in biogenic silica: global changes in ocean temperature and isotopic composition. Science 256, 1434-1436.

Springer, A.M., McRoy, C.P., Flint, M.V., 1996. The Bering Sea Green Belt: shelf-edge processes and ecosystem production. Fisheries Oceanography 5 (3/4), 205-223.

Stabeno, P.J., Schumacher, J.D., Ohtani, K., 1999. The physical oceanography of the Bering Sea. In: Loughlin, T.R., Ohtani, K. (Eds.), Dynamics of the Bering Sea. University of Alaska Sea Grant, AK-SG-99-03, pp. 1-29. 
Starratt, S.W., 1993. Late Quaternary paleoceanography of the Pervenets Canyon area of the Bering Sea: evidence from the diatom ora. Diatom Research 8 (1), 159-170.

Starratt, S.W., 1995. Latest Quaternary foraminifers and sediment transport in Pervenets Canyon, Bering Sea. Marine Micropaleontology 26, 233-243.

Stott, L.D., Berelson, W., Douglas, R., Gorsline, D., 2000. Increased dissolved oxygen in Pacific intermediate waters due to lower rates of carbon oxidation in sediments. Nature 407, 367-370.

Stuiver, M., Reimer, P., Bard, E., Beck, J., Burr, G., Hughen, K., Kromer, B., McCormac, G., van der Plicht, J., Spurk, M., 1998. INTCAL98 Radiocarbon Age Calibration, 24000-0 cal BP. Radiocarbon 40 (3), 1041-1083.

Talley, L.D., 2003. Shallow, intermediate, and deep overturning components of the global heat budget. Journal of Physical Oceanography 33, 530-560.

van Geen, A., Zheng, Y., Bernhard, J.M., Cannariato, K.G., Carriquiry, J., Dean, W.E., Eakins, B.W., Pike, J., 2003. On the preservation of laminated sediments along the western margin of North America. Paleoceanography 18 (4), 1098.

Vidal, L., Labeyrie, L., Cortijo, E., Arnold, M., Duplessy, J.-C., Michel, E., Becqué, S., van Weering, T., 1997. Evidence for changes in the North Atlantic Deep Water linked to meltwater surges during the Heinrich events. Earth and Planetary Science Letters 146, 13-27.
Warner, M.J., Roden, G.I., 1995. Chlorofluorocarbon evidence for recent ventilation of the deep Bering Sea. Nature 373, 409-412.

Warren, B.A., 1983. Why is no deep water formed in the North Pacific. Journal of Marine Research 41, 327-347.

Wessel, P., Smith, W.H.F., 1998. New, improved version of Generic Mapping Tools released. EOS Transactions of the American Geophysical Union 79 (47), 579.

Yasuda, I., 1997. The origin of the North Pacific Intermediate Water. Journal of Geophysical Research 102 (C1), 893-909.

You, Y., 2003. Implications of cabbeling on the formation and transformation mechanism of North Pacific Intermediate Water. Journal of Geophysical Research C5, 3134.

Zahn, R., Schönfeld, J., Kudrass, H.-R., Park, M.-H., Erlenkeuser, H., Grootes, P., 1997. Thermohaline instability in the North Atlantic during meltwater events; stable isotope and ice-rafted detritus records from core SO75-26KL, Portuguese margin. Paleoceanography 12, 696-710.

Zheng, Y., van Geen, A., Anderson, R.F., Gardner, J.V., Dean, W.E., 2000. Intensification of the Northeast Pacific oxygen minimum zone during the Bølling-Allerød warm period. Paleoceanography 15 (5), 528-536.

Zhuze, A.P., 1962. Stratigraficheskie i paleogeograficheskie issledovaniya $\mathrm{v}$ severo-zapadnoi chasti Tikhogo okeana. Izdatel'stvo Akademii Nauk SSSR. 


\title{
Chapter 3
}

\section{The deglaciation in the Bering Sea}

\begin{abstract}
Cores from within the oxygen minimum zone in the Bering Sea were laminated during the Bølling-Ållerød (BA, 14.7-12.9 ky BP), a phenomenon which has been observed in cores from around much of the rim of the North Pacific, from the Japanese margin to the California Margin and Gulf of California. A compilation of published and unpublished ${ }^{14} \mathrm{C}$ measured in pairs of benthic and planktonic foraminifera from the North Pacific shows no consistent change in the ${ }^{14} \mathrm{C}$ of subsurface water between the $\mathrm{BA}$ and the Younger Dryas (YD, 12.9-11.7 ky BP) or Last Glacial Maximum (LGM, 23-21 ky BP). The relative timing of the lithological transitions in a partially-laminated, high sediment-accumulationrate $(200 \mathrm{~cm} / \mathrm{ky})$ core from $1132 \mathrm{~m}$ in the Northern Bering Sea is very close to the timing of the centennial- and millennial-scale climate events in Greenland ice core (GISP2) $\delta^{18} \mathrm{O}_{\text {ice }}$ to well within the uncertainty of the age model. I do not know the absolute timing of these events between the Bering Sea and GISP2 because the surface reservoir correction $(\Delta R)$ is not well constrained. However, the match of the relative timing suggests that $\Delta R$ was fairly constant through the deglaciation. The two rapid decreases in $N$. pachyderma (s.) $\delta^{18} \mathrm{O}$ at the beginning of the Bølling and the end of the YD in this core (Cook et al., 2005) are accompanied by large, but brief decreases in the relative abundance of $N$. pachyderma (s.). This suggests that the $\delta^{18} \mathrm{O}$ reflects transient warmings, but sustained freshening of surface water.
\end{abstract}

\subsection{Introduction}

The heat transport associated with the Atlantic meridional overturning circulation (AMOC) is considered one of the most important components of the climate system. Because of the sheer breadth of the Pacific, the poleward heat transport associated with the wind-driven shallow gyre circulation at $24^{\circ} \mathrm{N}$ is two-thirds the magnitude of the heat transport associated with the AMOC at the same latitude (Talley, 2003). The Pacific contains the ocean's largest 


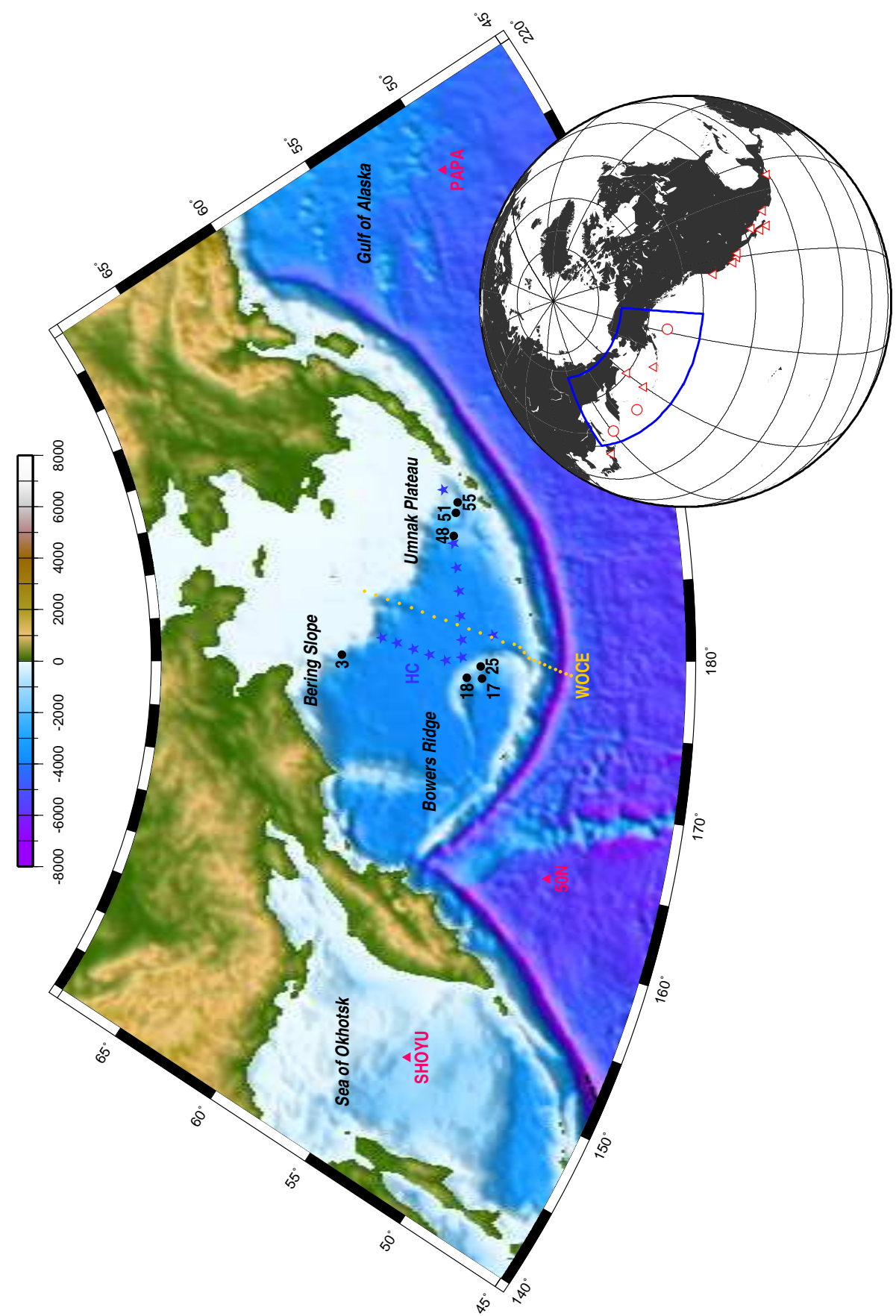

Figure 3-1: The scale for color bathymetry and topography is in meters. Coring sites from HLY02-02 are labeled with black dots and the site number. See Table 3.1 for details. WOCE stations are in yellow. Hydrocasts from the HLY02-02 cruise are in blue stars. Sediment traps discussed in text are purple triangles. On the inset map, red circles/triangles denote North Pacific coring sites where dysoxic/laminated sediments are found during the deglaciation (Keigwin and Jones (1990); Behl and Kennett (1996); Zheng et al. (2000); Marret et al. (2001); van Geen et al. (2003); Ortiz et al. (2004); Crusius et al. (2004); Narita et al. (2004); and this study). 
reservoir of deep water and dissolved inorganic carbon, so a significant change in circulation in the Pacific could potentially have a large impact on global climate. Since relatively few high-quality Pleistocene paleoceanographic records exist from the open Pacific, it is not well understood what changes occurred in the Pacific during the deglaciation, when large reorganizations occurred in the North Atlantic. In the western North Atlantic, sedimentary $\left[{ }^{231} \mathrm{~Pa}\right] /\left[{ }^{230} \mathrm{Th}\right]$ approaches the production ratio of 0.093 during Heinrich Event 1 (H1, 17.5 ky BP) and the Younger Dryas (YD, 12.9-11.6 ky BP), suggesting that the AMOC was very weak or shut down during these cold climate events (McManus et al., 2004). For these two periods, passive water mass tracers $\left(\delta^{13} \mathrm{C}\right.$ and $\left.\mathrm{Cd} / \mathrm{Ca}\right)$ suggest that there was a greater contribution of southern source intermediate and deep waters in the North Atlantic (Boyle and Keigwin, 1987; Zahn et al., 1997; Vidal et al., 1997). Some investigators have suggested that the circulations in the North Atlantic and North Pacific are out of phase, where the AMOC is strong when the rate of formation of North Pacific Intermediate Water (NPIW) is weak, and vice versa (Kiefer et al., 2001). The geological records from the North Pacific are suggestive, but not conclusive.

\section{Ventilation of the North Pacific during the deglaciation}

In the North Pacific, there was a widespread occurrence of dysoxic and laminated sediment during the deglaciation at oxygen-minimum-zone (OMZ) depths ( 800-1200 m), in particular, during the Bølling-Ållerød (BA, 14.89-12.89 ky BP, citetStuiM95+). Observations of dysoxic and laminated sediments have been made across most of the rim of the Pacific, including the Mexican margin (Hendy et al., 2003), the Gulf of California (van Geen et al., 2003; Keigwin and Jones, 1990), the California borderland basins (Behl and Kennett, 1996), off the Pacific northwest (McKay et al., 2004), the Gulf of Alaska (Marret et al., 2001), the Bering Sea (Cook et al., 2005), and the Japanese margin (Narita et al., 2004) (see Figure 31). There is yet no consensus on the primary mechanism for this phenomenon, although the apparent basin-wide extent of reduction of the $\left[\mathrm{O}_{2}\right]$ in the OMZ suggests a basin-wide change in chemistry.

The position of the minimum in oxygen in the water column is a function of circulation and the consumption of oxygen by remineralization of the organic matter which originates from the surface ocean (Wyrtki, 1962). There are several mechanisms which can lower $\left[\mathrm{O}_{2}\right]$ of intermediate-depth Pacific water including: (1) decrease in the formation rate of $\mathrm{O}_{2}$-rich 
North Pacific intermediate water (NPIW), (2) decrease in the $\left[\mathrm{O}_{2}\right]$ of newly-formed NPIW without a change in ventilation rate (Crusius et al., 2004), (3) intensification of the OMZ from greater $\mathrm{C}_{\text {org }}$ export from the surface ocean and subsequent remineralization at depth (McKay et al., 2004).

If the formation rate of NPIW is entirely responsible for the changes in lithology, then this would support the hypothesis that the anti-phase relationship of the North Atlantic and North Pacific circulations. One way to test this hypothesis is by reconstructing the ${ }^{14} \mathrm{C}$ of the subsurface North Pacific using pairs of benthic and planktonic foraminifer ${ }^{14} \mathrm{C}$ measurements. All else being equal, if NPIW grew weaker, then I would expect a decrease in ${ }^{14} \mathrm{C}$ content of intermediate-depth water-that is, a decrease of benthic ${ }^{14} \mathrm{C}$ relative to planktonic ${ }^{14} \mathrm{C}$. There are only a few time series of pairs of benthic-planktonic ${ }^{14} \mathrm{C}$ from the LGM through the deglaciation: from the Japan margin (Ahagon et al., 2003; Duplessy et al., 1989), the Santa Barbara Basin (Ingram and Kennett, 1995), and the northeast Pacific near the California-Oregon border (Mix et al., 1999).

The core of NPIW follows the $26.8 \sigma_{\theta}$ potential density surface (Yasuda, 1997; You, 2003), which is shallow (200-400 m) in the modern Bering Sea and the Gulf of Alaska (Macdonald et al., 2001). Macdonald et al. (2001) note that in the Gulf of Alaska, the $26.8 \sigma_{\theta}$ isopycnal surface may outcrop for short periods in the winter and ventilate the intermediate depths. This is supported by hydrographic and tritium data and potential vorticity calculations of Van Scoy et al. (1991). The $26.8 \sigma_{\theta}$ isopycnal surface is also shallow ing the Bering Sea. The presence of CFC's in the abyssal Bering Sea Basin (Warner and Roden, 1995), suggests a small amount of deep water formation within the last 40 years, probably from brine rejection during sea-ice formation. Ohkushi et al. (2003) suggest from radiolarian data that the Bering Sea was a significant locus of intermediate-depth ventilation during the glacial period, when sea surface temperatures were colder.

\section{Deglacial SST change in the North Pacific}

There is sparse marine evidence of a YD cooling in the open Pacific, an event with a small enough duration to perhaps be obscured by the relatively low sediment accumulation rates in the Pacific basin and poor preservation of calcite. Kiefer and Kienast (2005) review published Pacific SST proxy records and conclude that the spatial pattern of deglacial warming was heterogeneous, with Younger-Dryas-like deglacial cold intervals observed in 


\begin{tabular}{llrc}
\hline \multicolumn{1}{c}{ location } & \multicolumn{1}{c}{ core } & depth & latitude/longitude \\
\hline Bering Slope & HLY02-02-3JPC & $1132 \mathrm{~m}$ & $\mathrm{~N} 60.1279^{\circ} / \mathrm{E} 180.5582^{\circ}$ \\
Bowers Ridge & HLY02-02-17JPC & $2209 \mathrm{~m}$ & $\mathrm{~N} 53.9330^{\circ} / \mathrm{E} 178.6988^{\circ}$ \\
Bowers Ridge & HLY02-02-25GGC & $721 \mathrm{~m}$ & $\mathrm{~N} 53.9963^{\circ} / \mathrm{E} 179.5842^{\circ}$ \\
Bowers Ridge & HLY02-02-18GGC & $856 \mathrm{~m}$ & $\mathrm{~N} 53.6099^{\circ} / \mathrm{E} 178.7225^{\circ}$ \\
Umnak Plateau & HLY02-02-51JPC & $1467 \mathrm{~m}$ & $\mathrm{~N} 54.5532^{\circ} / \mathrm{E} 191.3331^{\circ}$ \\
Umnak Plateau & HLY02-02-55JPC & $1005 \mathrm{~m}$ & $\mathrm{~N} 54.3991^{\circ} / \mathrm{E} 192.0861^{\circ}$ \\
Umnak Plateau & HLY02-02-48JPC & $1960 \mathrm{~m}$ & $\mathrm{~N} 54.7911^{\circ} / \mathrm{E} 189.5997^{\circ}$ \\
\hline
\end{tabular}

Table 3.1: The cores used in this study. See Figure 3-1 for core locations.

marginal basins but not in the open Pacific, and commencement of deglacial surface warming beginning after H1. Lacustrine records of pollen (Peteet and Mann, 1994; Ager, 2003) and $\delta^{18} \mathrm{O}$ of biogenic silica (a temperature proxy, Hu and Shemesh (2003)) from Alaska suggest a warm and moist BA, and a relatively cool and dry YD. This inference is supported by a glacier advance in southwest Alaska dated to the YD (Briner et al., 2002).

The purpose of this study is to address some of the outstanding questions about the deglacial North Pacific using new sediment cores collected during a cruise to the Bering Sea in June, 2002, and with a compilation of published and unpublished North Pacific data. In particular, how did the ${ }^{14} \mathrm{C}$ of subsurface water change during deglacial climate events? And how did the surface water of the North Pacific change during the deglaciation?

\subsection{Methods}

The cores in this study were collected in June, 2002, from the Bering Sea on HLY02-02 (see Figure 3-1 and Table 3.1 for core locations and depths). Samples were prepared as described in Cook et al. (2005). Briefly, sediment samples were dried at $50^{\circ} \mathrm{C}$, then washed with tap water through a $63 \mu \mathrm{m}$ sieve. Neogloboquadrina pachyderma (sinistral) and Uvigerina sp. were picked from the $212-250 \mu \mathrm{m}$ and $>250 \mu \mathrm{m}$ size fractions, respectively. The planktonic fauna $>150 \mu \mathrm{m}$ were counted and identified, and I calculated the relative abundance of $N$. pachyderma (s.) as the number of that species divided by the total number of individuals counted in the sample. Confidence limits on the relative abundance of N. pachyderma (s.) were calculated at the $95 \%$ level as in Fatela and Taborda (2002).

Isotope measurements on 8-10 N. pachyderma (s.) or a single Uvigerina sp. were made on a PRISM mass spectrometer with a common acid bath at $90^{\circ} \mathrm{C}$, and are reported relative 


\begin{tabular}{|c|c|c|c|c|}
\hline depth $(\mathrm{cm})$ & species & ${ }^{14} \mathrm{C}$ y $\mathrm{BP} \pm \sigma$ & cal y $\mathrm{BP} \sigma$ & $\pm 2 \sigma$ \\
\hline \multicolumn{5}{|c|}{ HLY02-02-3JPC } \\
\hline $140.5-142.5$ & N. pachyderma (s.) & $10,050 \pm 60$ & $10,510 \pm{ }_{50}^{70}$ & $\pm_{150}^{130}$ \\
\hline $352.5-353.5$ & N. pachyderma (s.) & $10,850 \pm 65$ & $11,550 \pm{ }_{180}^{150}$ & $\pm_{270}^{320}$ \\
\hline $600.5-601.5$ & N. pachyderma (s.) & $12,400 \pm 65$ & $13,440 \pm \pm_{100}^{90}$ & $\pm_{150}^{180}$ \\
\hline $839.5-840.5$ & N. pachyderma (s.) & $13,300 \pm 70$ & $14,600 \pm{ }_{210}^{250}$ & $\pm_{390}^{370}$ \\
\hline $839.5-840.5$ & G. affinis & $14,250 \pm 65$ & & \\
\hline 906.5-909.5 & N. pachyderma (s.) & $13,350 \pm 80$ & $14,700 \pm{ }_{210}^{240}$ & $\pm_{460}^{350}$ \\
\hline $1427.5-1428.5$ & N. pachyderma (s.) & $18,100 \pm 130$ & $20,430 \pm{ }_{190}^{150}$ & $\pm_{340}^{410}$ \\
\hline \multicolumn{5}{|c|}{ HLY02-02-51JPC } \\
\hline $134.5-135.5$ & N. pachyderma (s.) & $10,600 \pm 60$ & $11,190 \pm_{40}^{40}$ & $\pm_{80}^{110}$ \\
\hline $177.5-178.5$ & N. pachyderma (s.) & $12,500 \pm 60$ & $13,550 \pm \pm_{90}^{80}$ & $\pm_{150}^{160}$ \\
\hline $241.5-242.5$ & N. pachyderma (s.) & $14,050 \pm 85$ & $15,700 \pm{ }_{220}^{190}$ & $\pm_{390}^{420}$ \\
\hline \multicolumn{5}{|c|}{ HLY02-02-17JPC } \\
\hline $155.5-156.5$ & N. pachyderma (s.) & $10,000 \pm 60$ & $10,460 \pm 60$ & $\pm_{170}^{110}$ \\
\hline $185.5-186.5$ & N. pachyderma (s.) & $12,550 \pm 65$ & $13,600 \pm{ }_{100}^{100}$ & $\pm_{170}^{150}$ \\
\hline $214.5-215.5$ & N. pachyderma (s.) & $13,600 \pm 50$ & $15,110 \pm{ }_{120}^{100}$ & $\pm_{210}^{260}$ \\
\hline $214.5-215.5$ & N. labradorica & $14,200 \pm 110$ & & \\
\hline $215.5-216.5$ & N. pachyderma (s.) & $13,400 \pm 60$ & $14,830 \pm{ }_{150}^{160}$ & $\pm_{390}^{300}$ \\
\hline $383.5-384.5$ & N. pachyderma (s.) & $25,200 \pm 130$ & $28,500 \pm$ & \pm \\
\hline
\end{tabular}

Table 3.2: Uncorrected AMS ${ }^{14} \mathrm{C}$ ages and corrected, calibrated ages. Calibrations performed with Calib5.0.1 (Reimer et al., 2004) using the Marine04 calibration (Hughen et al., 2004b). I use $\Delta \mathrm{R}=400 \mathrm{y}$, corresponding to a reservoir correction of $800 \mathrm{y}$. I report the median calendar ages with the upper and lower limits of the $\sigma$ and $2 \sigma$ ranges.

\begin{tabular}{llll}
\hline core & species & $\delta^{13} \mathrm{C}$ & $\delta^{18} \mathrm{O}$ \\
\hline HLY-02-02-MC02 & Cibicidoides tenuimoargo & -0.825 & 2.143 \\
HLY-02-02-MC02 & Uvigerina peregrina & -0.902 & 3.419 \\
HLY-02-02-MC05 & Cibicidoides spp.A & -0.390 & 2.804 \\
HLY-02-02-MC05 & Cibicidoides spp.A & -0.388 & 2.708 \\
HLY-02-02-MC05 & Uvigerina canariensis & -0.764 & 3.545 \\
HLY-02-02-MC05 & Uvigerina peregrina & -0.770 & 3.382 \\
HLY-02-02-MC16 & Cibicidoides mundulus & -0.394 & 2.991 \\
HLY-02-02-MC16 & Cibicidoides mundulus & -0.414 & 2.964 \\
HLY-02-02-MC19 & Uvigerina peregrina & -1.237 & 4.108 \\
HLY-02-02-MC24 & Uvigerina peregrina & -1.134 & 3.434 \\
HLY-02-02-MC31 & Cibicidoides kullenberg & -0.052 & 2.867 \\
HLY-02-02-MC43 & Uvigerina peregrina & -1.288 & 3.665 \\
HLY-02-02-MC50 & Uvigerina peregrina & -1.149 & 3.501 \\
HLY-02-02-MC56 & Uvigerina peregrina & -0.991 & 3.210 \\
HLY-02-02-MC56 & Uvigerina peregrina & -1.107 & 3.219 \\
\hline
\end{tabular}

Table 3.3: Stable isotope ratios from rose-Bengal stained Cibicidoides and Uvigerina from sediments from the upper-most $(0-2 \mathrm{~cm})$ sediments from multicores, which capture the sediment-water interface (unpublished data courtesy of D. McCorkle). These data are plotted in Figure 3-2. 
to PDB via NBS-19 (Coplen, 1996). Radiocarbon ages in Table 3.2 were measured at the National Ocean Sciences Accelerator Mass Spectrometer Facility at WHOI. I converted radiocarbon ages to calendar years with Calib5.0.1, using $\Delta R=400 \mathrm{y}$, so that the reservoir age of surface water is assumed to be constant at $R=800 \mathrm{y}$. I report the median of the probability density function of the calibrated calendar age (Telford et al., 2004). $\Delta R$ is the local anomaly of the apparent age of surface water from the global mean, and is poorly constrained in the Bering Sea (see discussion in Cook et al. (2005)). Reported uncertainties in Table 3.2 do not take into account uncertainty in $(R+\Delta R)$. For the radiocarbon ages older than $25 \mathrm{ky}$, the reported calendar age is the intersection of the radiocarbon age with the Globigerina bulloides radiocarbon record from the Cariaco Basin (Hughen et al., 2004a) on the ss09sea age model of the GRIP ice core (Johnsen et al., 2001). Age models for each core are simply constructed as linear interpolation of median calibrated ages.

\section{Equilibrium $\delta^{18} \mathbf{O}_{\text {calcite }}$ calculation}

In experiments performed by Kim and O'Neil (1997), where calcite precipitated from solutions of $\mathrm{NaHCO}_{3}$ and $\mathrm{CaCl}_{2}$ in deionized water, the fractionation factor, $\alpha_{\left(\text {calcite }-\mathrm{H}_{2} \mathrm{O}\right)}$, was determined as an exponential function of $T^{-1}$,

$$
\ln \alpha_{\left(\text {calcite }-\mathrm{H}_{2} \mathrm{O}\right)}=A T^{-1}+B
$$

where

$$
\alpha_{\text {calcite }-\mathrm{H}_{2} \mathrm{O}}=\frac{\left(\frac{18 \mathrm{O}}{16}\right)_{\text {calcite }}}{\left(\frac{18}{16}\right)_{\mathrm{H}_{2} \mathrm{O}}}=\frac{1000+\delta^{18} \mathrm{O}_{\mathrm{CaCO}_{3}(\mathrm{PDB})}}{1000+\delta^{18} \mathrm{O}_{\mathrm{H}_{2} \mathrm{O}(\mathrm{SMOW})}} \cdot \frac{\left(\frac{{ }^{18} \mathrm{O}}{{ }^{16} \mathrm{O}}\right)_{\mathrm{PDB}}}{\left(\frac{18 \mathrm{O}}{16}\right)_{\mathrm{SMOW}}}
$$

and

$$
\frac{\left(\frac{18 \mathrm{O}}{16 \mathrm{O}}\right)_{\mathrm{PDB}}}{\left(\frac{18 \mathrm{O}}{16 \mathrm{O}}\right)_{\mathrm{SMOW}}}=1.03092
$$

In this paper, all $\delta^{18} \mathrm{O}_{\text {calcite }}$ is reported relative to the PDB standard through NBS-19 (Coplen, 1996), and $\delta^{18} \mathrm{O}_{\mathrm{H}_{2} \mathrm{O}}$ and $\delta^{18} \mathrm{O}_{\mathrm{SW}}$ are relative to the SMOW standard. Kim and O'Neil (1997) performed experiments with a range of $T$ and $[\mathrm{Ca}]_{\mathrm{o}}$, the initial concentration of calcium in the solution, where $\alpha_{\text {calcite }-\mathrm{H}_{2} \mathrm{O}}$ increased with greater $T$ and with greater $[\mathrm{Ca}]_{\mathrm{o}}$. The ratio of the concentrations of major ions in seawater is fairly uniform in the ocean (variation is on the order of $1 \%$ ); at a salinity of $35,[\mathrm{Ca}]=10.5 \mathrm{mM}$ (Wilson, 1975). I approximated the relationship between $\alpha_{\text {calcite }-\mathrm{H}_{2} \mathrm{O}}$ and $T$ for $[\mathrm{Ca}]_{\mathrm{o}}=10 \mathrm{mM}$ by calculating 


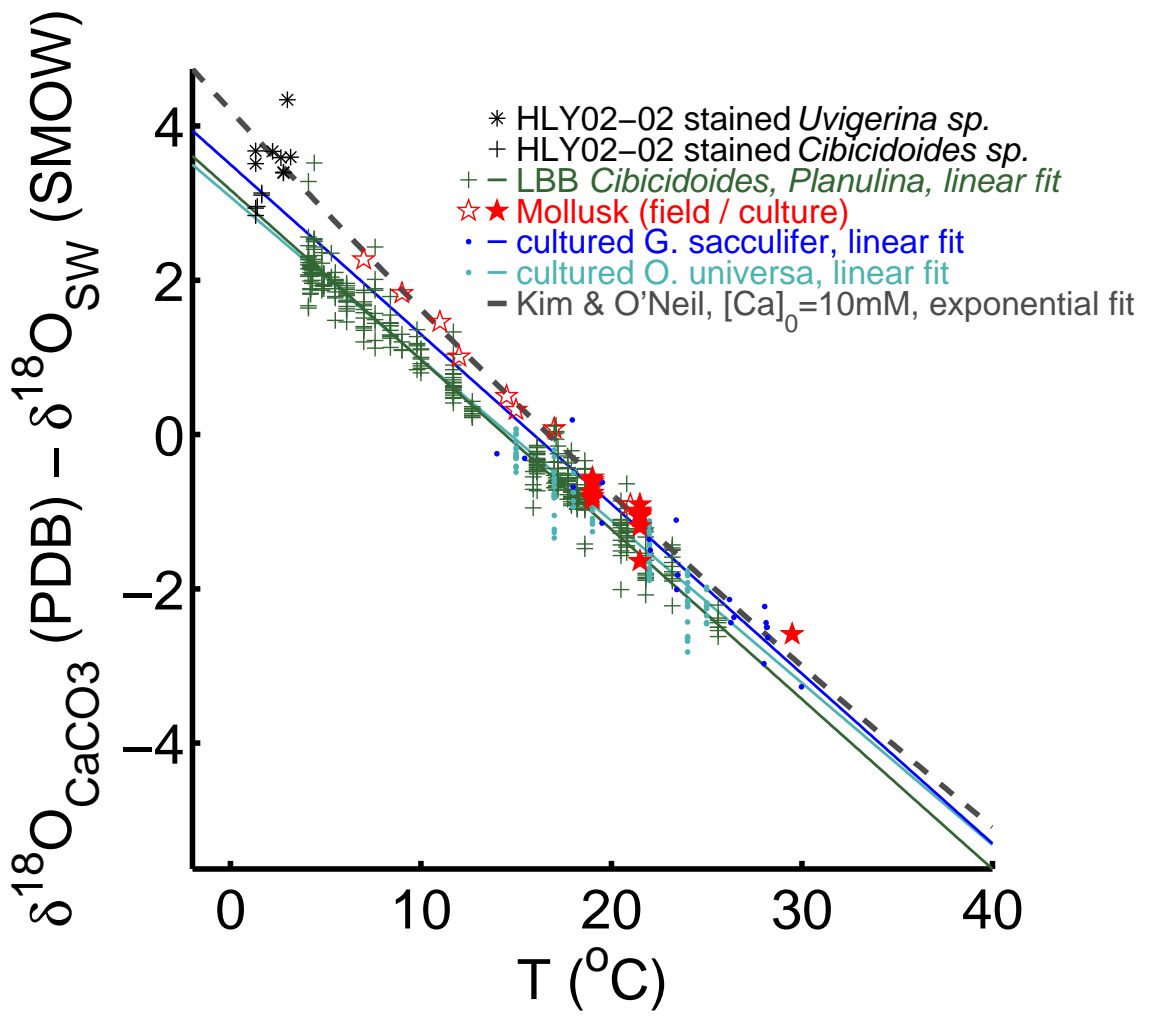

Figure 3-2: Compilation of $\left(\delta^{18} \mathrm{O}_{\text {calcite }}(\mathrm{PDB})-\delta^{18} \mathrm{O}_{\mathrm{SW}}(\mathrm{SMOW})\right)$ and temperature $(T)$ (modified from Lynch-Stieglitz et al. (1999)). Planktonic foraminifer cultures are of Globigerinoides sacculifer (Erez and Luz, 1983) and Orbulina universa (Bemis et al., 1998). Mollusk data include both cultured and field samples of a variety of genera and species (Epstein et al., 1953). Cibicidoides and Planulina species are multicore-top sediments from Little Bahama Bank (Slowey and Curry, 1995; Curry et al., 1993). HLY02-02 data are Uvigerina and Cibicidoides individuals stained with Rose Bengal from multicore-top sediments (unpublished data courtesy of D. McCorkle, see Table 3.3). All data are corrected, if necessary, so that the standards for $\delta^{18} \mathrm{O}_{\text {calcite }}$ and $\delta^{18} \mathrm{O}_{\mathrm{SW}}$ are PDB and SMOW, respectively. The thin lines are linear least-squares best fits to each set of planktonic culture data and the Little Bahama Bank data. The thick grey dashed line is the estimate of the theoretical exponential relationship between $\left(\delta^{18} \mathrm{O}_{\text {calcite }}(\mathrm{PDB})-\delta^{18} \mathrm{O}_{\mathrm{SW}}(\mathrm{SMOW})\right)$ and $T$ where $[\mathrm{Ca}]_{\mathrm{o}}=10 \mathrm{mM}$ (based on the inorganic calcite precipitation experiments of Kim and O’Neil (1997)) (Equation 3.1). 


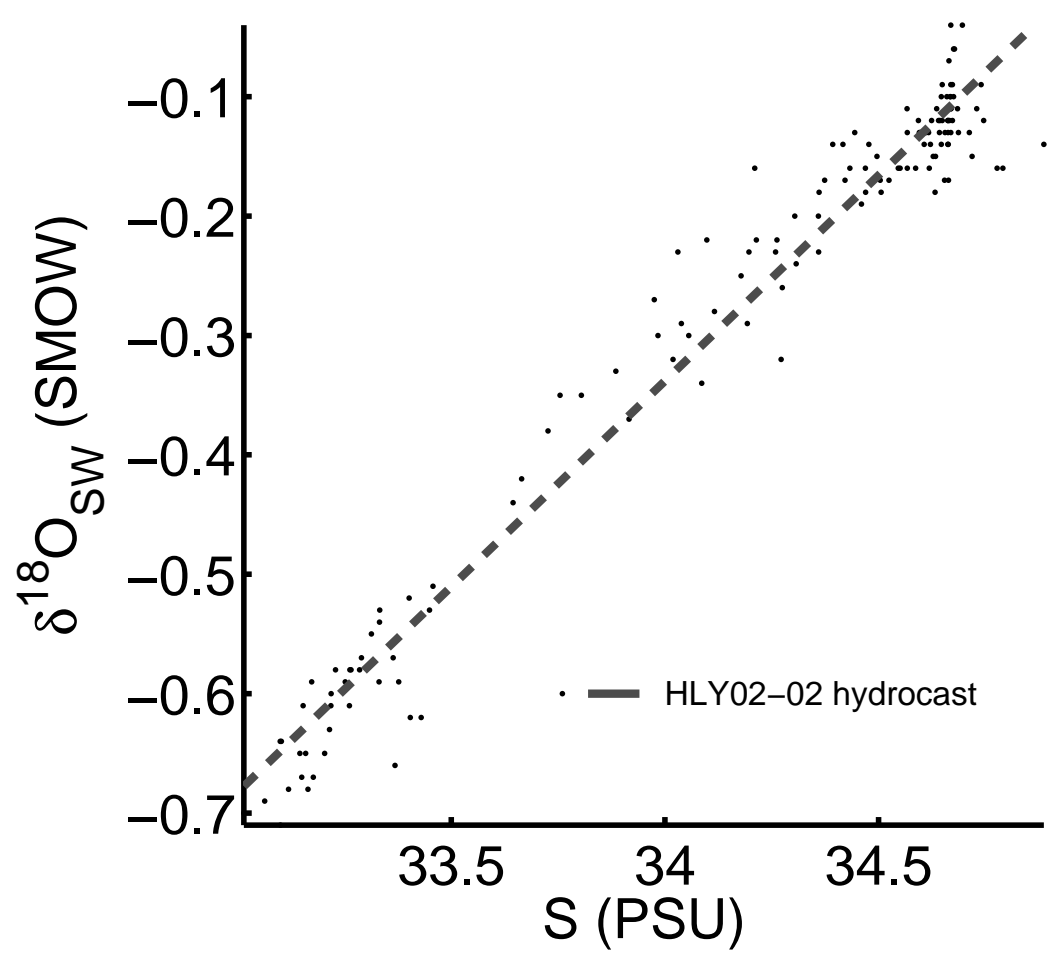

Figure 3-3: HLY02-02 hydrocast data. See Figure 3-1 for hydrocast locations. Unpublished data courtesy of D. McCorkle. The thick grey dashed line is a linear least-squares fit to the HLY02-02 data (Equation 3.3). 
the mean parameters, $A$ and $B$, for the experiments at $5 \mathrm{mM}$ and $15 \mathrm{mM}$ (Figure 3-2). The resulting expression for $\left(\delta^{18} \mathrm{O}_{\text {calcite }}-\delta^{18} \mathrm{O}_{\mathrm{H}_{2} \mathrm{O}}\right)$ as a function of $T$ (in Kelvin) is

$$
\delta^{18} \mathrm{O}_{\text {calcite }}-\delta^{18} \mathrm{O}_{\mathrm{H}_{2} \mathrm{O}}=-1000+\frac{1000+\delta^{18} \mathrm{O}_{\mathrm{H}_{2} \mathrm{O}}}{1.03092} \exp \left(\frac{19.87}{T}-38.09 \times 10^{-3}\right) .
$$

The difference is relatively insensitive to $\delta^{18} \mathrm{O}_{\mathrm{H}_{2} \mathrm{O}}$. For a $10 \%$ increase in $\delta^{18} \mathrm{O}_{\mathrm{H}_{2} \mathrm{O}}$, which is a larger range than most measured values in the modern ocean, and for $T=0-40^{\circ} \mathrm{C}$, $\left(\delta^{18} \mathrm{O}_{\text {calcite }}-\delta^{18} \mathrm{O}_{\mathrm{H}_{2} \mathrm{O}}\right)$ increases by an average of $0.006 \%$. This is less than measurement precision of $\delta^{18} \mathrm{O}$. In Figure 3-2, the $\delta^{18} \mathrm{O}_{\text {calcite }}$ curve is calculated for $\delta^{18} \mathrm{O}_{\mathrm{H}_{2} \mathrm{O}}=0 \%$.

It is generally considered sufficient to estimate the relationship between $\left(\delta^{18} \mathrm{O}_{\text {calcite }}-\delta^{18} \mathrm{O}_{\mathrm{SW}}\right)$ and $T$ with a first- or second-order polynomial because the scatter in field and laboratory data is large enough that use of an exponential relationship does not significantly improve goodness of fit. However, at temperatures lower than $10^{\circ} \mathrm{C}$, beyond the range of most inorganic and planktonic foraminifer culturing experiments, the polynomial and exponential curves diverge. Benthic foraminifera Cibicidoides and Planulina (Lynch-Stieglitz et al., 1999) from the Bahamas, and Cibicidoides from the Bering Sea fall on the extrapolation of a linear fit through the planktonic foraminifer culture data (Bemis et al., 1998; Erez and Luz, 1983) (Figure 3-2). The quantity $\left[\delta^{18} \mathrm{O}_{\text {calcite }}-\delta^{18} \mathrm{O}_{\mathrm{SW}}\right]$ of field samples of mollusks (Epstein et al., 1953) and Uvigerina (McCorkle, unpublished) are higher, and fall on the theoretical exponential curve. I chose to use the exponential relationship to calculate equilibrium $\delta^{18} \mathrm{O}_{\text {calcite }}$ in this paper because it is the relationship I would expect from an Arrhenius behavior of $\alpha_{\left(\text {calcite- }-\mathrm{H}_{2} \mathrm{O}\right)}$. Using this relationship, Uvigerina sp. calcifies in equilibrium, as postulated by Shackleton (1974).

When estimating a change in $T$ from two measurements of $\delta^{18} \mathrm{O}_{\text {calcite }}$, both values of must be corrected for the whole-ocean change in $\delta^{18} \mathrm{O}_{\mathrm{SW}}$ due to the volume of continental ice (Waelbroeck et al., 2002). After this correction, I may set $\delta^{18} \mathrm{O}_{\mathrm{H}_{2} \mathrm{O}}$ to $0 \%$ because the absolute value of $\delta^{18} \mathrm{O}_{\mathrm{H}_{2} \mathrm{O}}$ does not significantly affect $\Delta T$. The expression for $\Delta T$ becomes

$$
T_{2}-T_{1}=\frac{19.87}{38.09 \times 10^{-3}+\ln \left(\frac{\delta^{18} \mathrm{O}_{\text {calcite } 2}+1000}{1000 / 1.03092}\right)}-\frac{19.87}{38.09 \times 10^{-3}+\ln \left(\frac{\delta^{18} \mathrm{O}_{\text {calcite } 1}+1000}{1000 / 1.03092}\right)}
$$

Berner (1975) conducted inorganic calcite precipitation experiments in seawater and found that the precipitates contained 7-10 mol\% $\mathrm{Mg}$, however he did not measure the 
$\delta^{18} \mathrm{O}$ of these precipitates. Tarutani et al. (1969) determined that the amount of $\mathrm{Mg}$ in inorganically precipitated calcite is related to the $\delta^{18} \mathrm{O}$, where $\delta^{18} \mathrm{O}$ increases by $0.078 \%$ for an increase in $1 \mathrm{~mol} \% \mathrm{Mg}$ of the calcite. The $[\mathrm{Mg}] /[\mathrm{Ca}]$ of a typical Quaternary foraminifer is $1-10 \mathrm{mmol} / \mathrm{mol}$ (Rosenthal et al., 1999), so this effect is probably not significant. I will make the assumption that Equation 3.2 is also applicable to calcite precipitation in seawater, and will substitute $\delta^{18} \mathrm{O}_{\mathrm{SW}}$ for $\delta^{18} \mathrm{O}_{\mathrm{H}_{2} \mathrm{O}}$ in Equation 3.2.

I calculated a linear least-squares fit to hydrocast data collected during the HLY02-02 cruise (Figure 3-3) (McCorkle, unpublished) to find this relationship between $S$ and $\delta^{18} \mathrm{O}_{\mathrm{SW}}$

$$
\delta^{18} \mathrm{O}_{\mathrm{SW}}=-12.5+0.357 S \quad\left(n=142 ; r^{2}=0.9657 ; p<10^{-6}\right) .
$$

This relationship is almost identical to the one calculated for Okhotsk Sea hydrocasts and GEOSECS data in Keigwin (1998). Combining equations 3.1 and 3.3, we can calculate equilibrium $\delta^{18} \mathrm{O}_{\text {calcite, }}$, given $T$ and $\mathrm{S}$ :

$$
\delta^{18} \mathrm{O}_{\text {calcite }}=-12.5+0.357 S-1000+\frac{1000-12.5+0.357 S}{1.03092} \exp \left(\frac{19.87}{T}-38.09 \times 10^{-3}\right)
$$

In Figure 3-4c is equilibrium $\delta^{18} \mathrm{O}_{\text {calcite }}$ calculated with Equation 3.4 and $T$ and $S$ from the WOCE dataset (refer to Figure 3-1 for WOCE station locations). The WOCE transect was conducted in Summer, 1993. In Figures 3-4a-c, I use Levitus et al. (1998) climatology from the nearest gridbox to calculate the equilibrium $\delta^{18} \mathrm{O}_{\text {calcite }}$ in the top $400 \mathrm{~m}$ of the water column throughout the year for three Bering Sea coring sites to see how much the equilibrium $\delta^{18} \mathrm{O}$ in the surface ocean changes seasonally.

\section{Planktonic fauna and SST}

The two predominant species in the Bering Sea during the last glacial cycle are N. pachyderma (s.) and G. bulloides. N. pachyderma (s.) is the dominant species in the polar regions. Coretop planktonic-foraminifer faunal assemblages are often calibrated against SST in order to reconstruct SST in the past (Imbrie and Kipp, 1971). The key assumption of this method is that one can define assemblages of foraminifera whose relative abundances are a linear function of $T$, and that the function defined with coretop sediments and modern SST is applicable in the past. The most complete fauna-SST calibration dataset (Prell et al., 1999) 

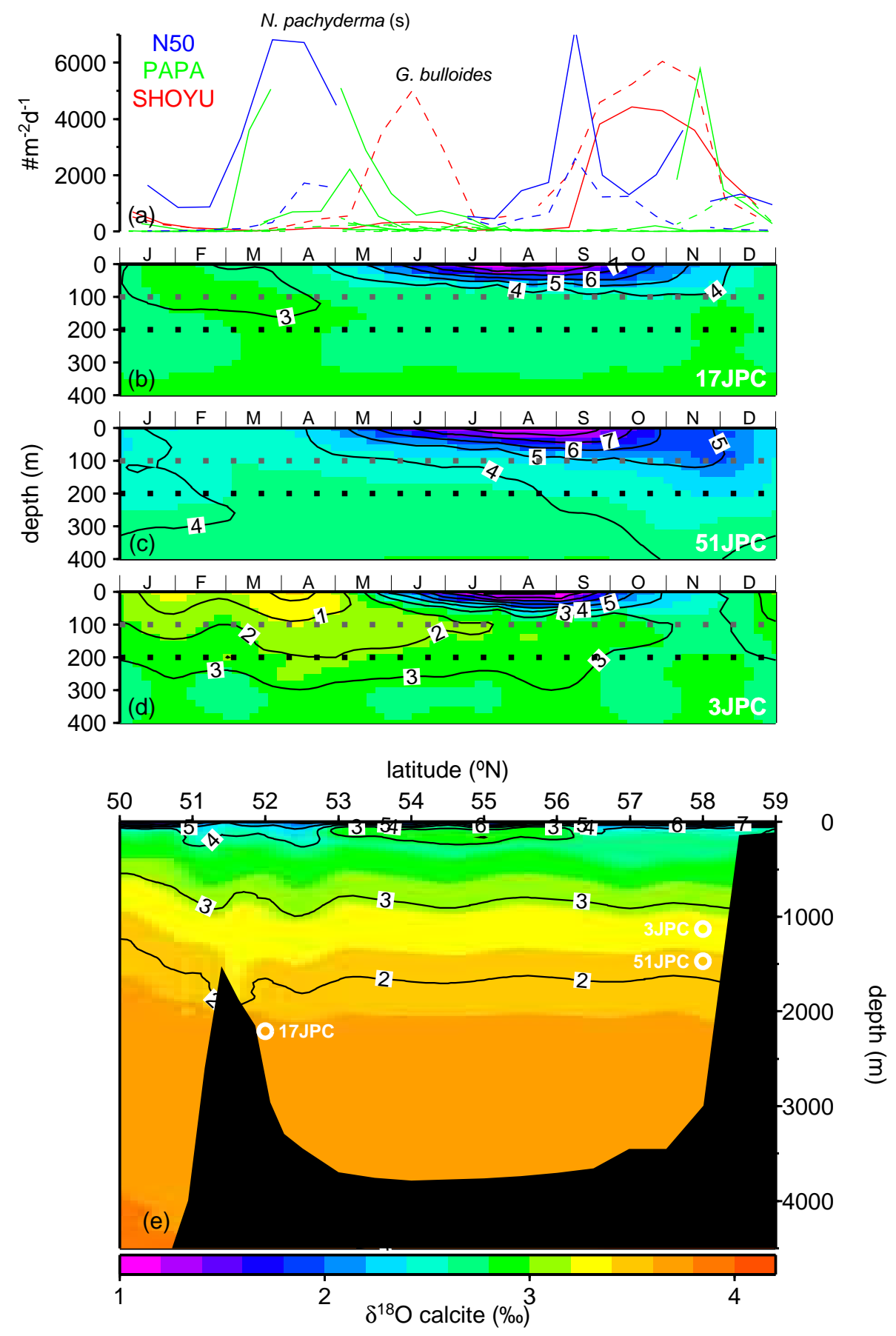

Figure 3-4: (a) Flux of N. pachyderma (s.) and G. bulloides from sediment trap deployments from the Gulf of Alaska (PAPA, September 1982 to August 1986) (Sautter and Thunell, 1989), the far northwest Pacific (50N, Dec, 1997 to Nov, 1998)(Kuroyanagi et al., 2002), and the Sea of Okhotsk (SHOYU, August 1990 to August 1991) (Alderman, 1989). (b)-(d) color contours are equilibrium $\delta^{18} \mathrm{O}_{\text {calcite }}$ calculated for three coring sites, from Levitus et al. (1998) data. (e) equilibrum $\delta^{18} \mathrm{O}_{\text {calcite }}$ calculated from WOCE data collected in summer, 1993 (see Figure 3-1 for station locations). In (b)-(e), black contour lines are $T\left({ }^{\circ} \mathrm{C}\right)$. 
includes few data from the Pacific, and no data from the high-latitude Pacific. Therefore, I do not try to convert measured changes in the relative abundance of $N$. pachyderma (s.) to SST, but use these data as a qualitative measure of temperature.

\subsection{Results}

\section{Lithology}

The lithology of the cores consist of massive, dysoxic, and laminated sediment (Figure 3-5). There are radiocarbon dates in one core from each of the three coring regions (Table 3.2). On Bowers Ridge, cores from the ridge crest typically had low sediment accumulation rates, where Termination I (TI) and the Holocene are contained in the top 10-30 cm (e.g. cores 25GGC and 18GGC). Core 17JPC was collected on the west flank of Bowers Ridge, where sediment accumulation rates are an order of magnitude higher than on the crest. I tentatively correlate $17 \mathrm{JPC}$ with the other Bowers Ridge cores at the base of the laminated/dysoxic layers in each core. This correlation is supported by $N$. pachyderma (s.) $\delta^{18} \mathrm{O}$ in 25GGC, where I can identify the deglaciation and LGM. In 18GGC, the correlation is supported by features in the magnetic suceptibility and $\gamma$-attenuation data (not shown). I use the bases of two thick black ash layers found in each Umnak Plateau core for correlation, assuming that they were deposited synchronously and instantaneously. Using these correlations, and assuming a coretop age of $0 \mathrm{y} \mathrm{BP}$, the lithology of the cores is plotted against age in Figure 3-6. Though the coretops are almost certainly older than 0 y, the lithology shown at the tops of the cores in Figure 3-6 are corroborated by the companion multicores at these sites. The ages of the lithological transitions are in Table 3.4.

\section{Apparent ventilation ages}

I estimated apparent ventilation age in two cores during the Bølling warm phase. In 17JPC, I measured ${ }^{14} \mathrm{C}$ of benthic foraminifer Nonionella labradorica at its maximum abundance and N. pachyderma (s.) in the same sample (Figure 3-7 and Table 3.2). I measured the benthic-planktonic pair at a benthic abundance peak in 17JPC in order to minimize bias in the $\Delta^{14} \mathrm{C}$ due to bioturbation of non-coeval foraminifera into the sample (Broecker et al., 1999). In 3JPC, I measured Globobuliminia affinis and N. pachyderma (s.). The Bølling is laminated in 3JPC, so I was not constrained to a benthic abundance peak (Figure 3-7 and 

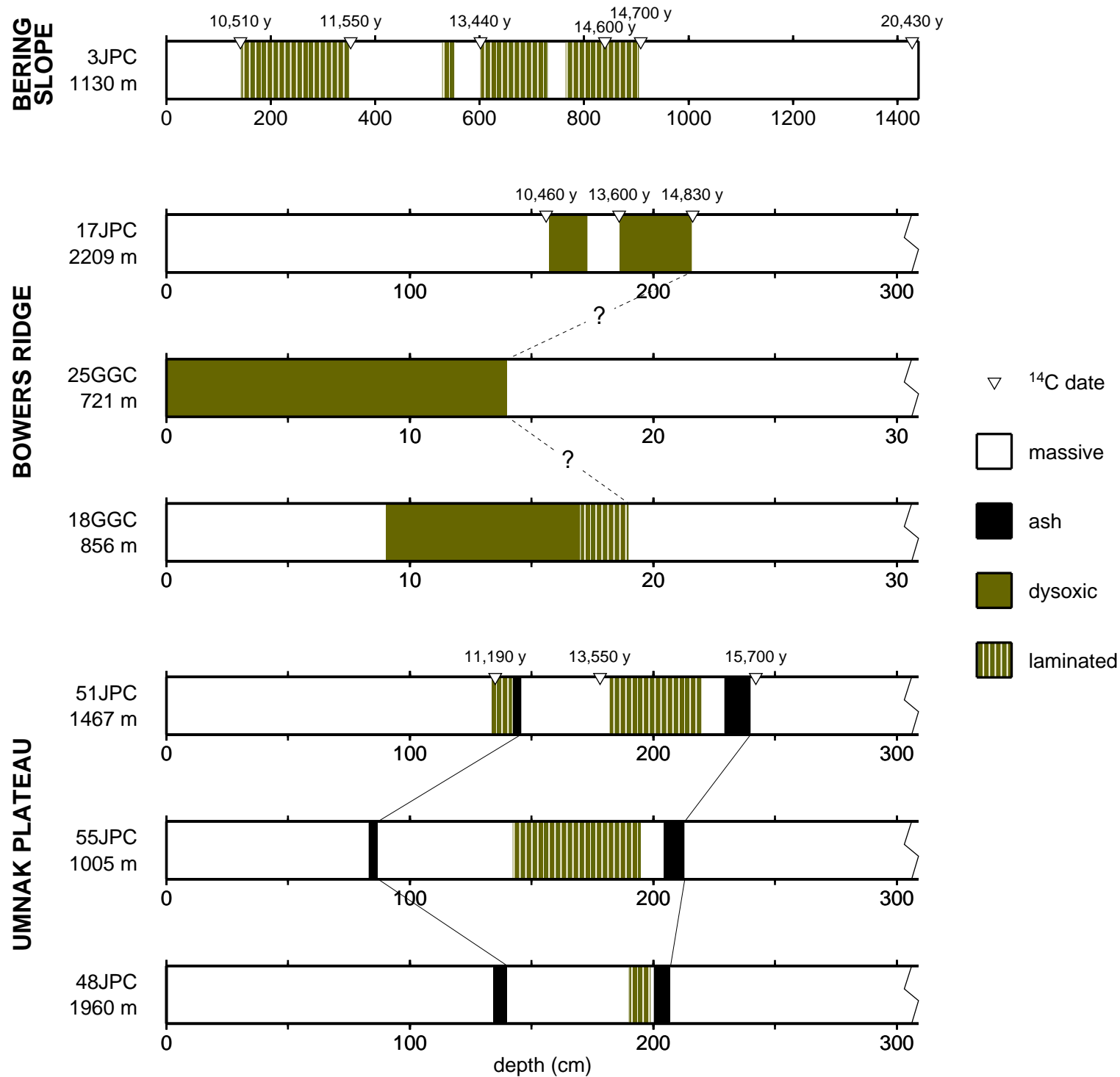

Figure 3-5: Lithology of HLY02-02 cores. Note the x-axes are different for each core. The radiocarbon dates measured on $N$. pachyderma (s.) and calibrated to calendar years with the Marine04 dataset with Calib5.0.1, using $\Delta \mathrm{R}=400 \mathrm{y}$, so that $R+\Delta R=800 \mathrm{y}$ (Table 3.2). Correlation between 51JPC and the undated Umnak Plateau cores is at the base of 2 black ash layers that are assumed to be synchronously deposited. Tentative correlation is made between 17JPC and the undated Bowers Ridge cores at the base of the laminated-dysoxic layer. In $25 \mathrm{GGC}$, this correlation is supported by $N$. pachyderma (s.) $\delta^{18} \mathrm{O}$; in $18 \mathrm{GGC}$ it is supported by magnetic suceptibility and bulk density measurements. 


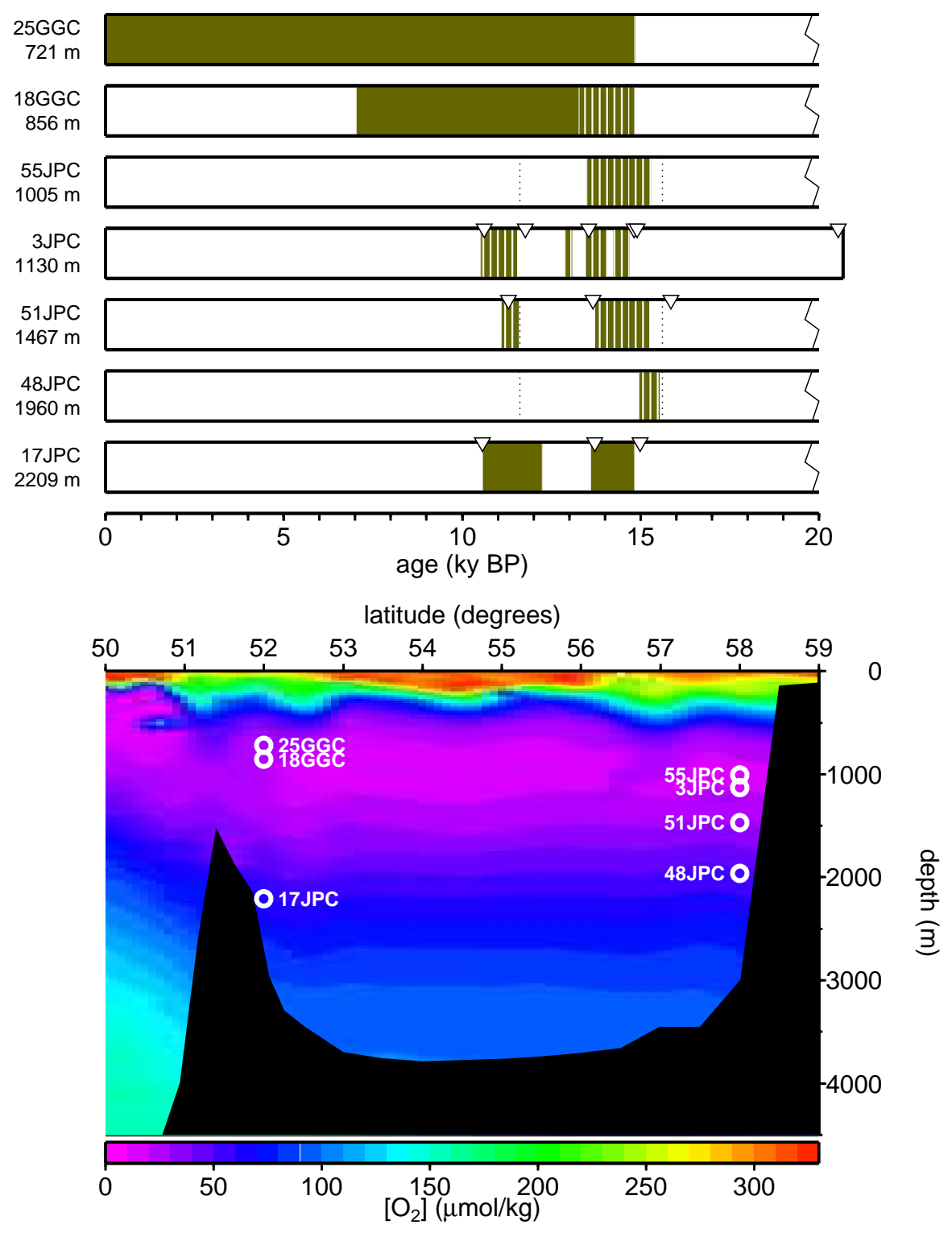

Figure 3-6: Top: Lithology of HLY02-02 cores versus calibrated calendar age. The cores are arranged according to water depth of coring site. Ash layers in 48JPC, 51JPC, and 55JPC are assumed to have been deposited instantaneously, and are indicated with black dashed lines. See Figure 3-5 for a legend describing symbols and shading. Bottom: $\left[\mathrm{O}_{2}\right]$ from the WOCE dataset is contoured, with coring site depths indicated. Cores collected from the Bowers Ridge are plotted on the left, cores collected from the continental slope are plotted on the right. The cores within the modern-day OMZ are laminated during the deglaciation. The bathymetry drawn is interpolation of the depth of the bottom for each WOCE station. 

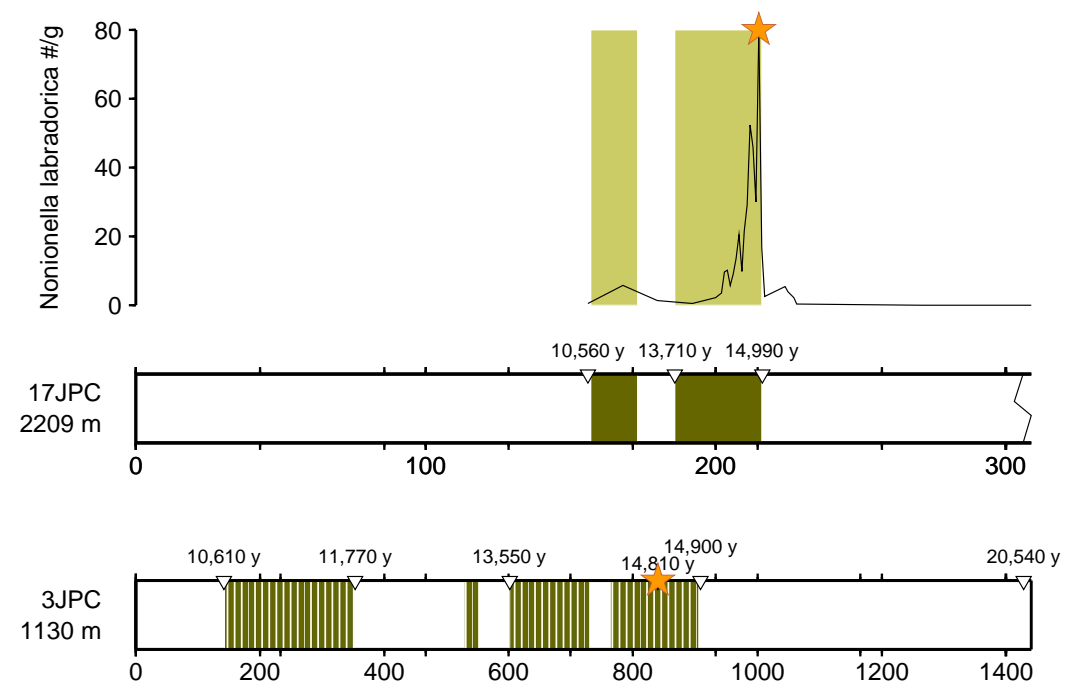

Figure 3-7: I measured paired benthic-planktonic radiocarbon dates in 2 cores. In 17JPC, I chose to date the maximum in abundance of Nonionella labradorica (orange star), which is $1 \mathrm{~cm}$ above the base of the dysoxic layer equivalent to the BA. In 3JPC, I measured Globobulimina affinis in a sample from the laminated interval equivalent to the Bølling. In both cores, I measured N. pachyderma (s.) in the same samples.

Table 3.2).

To develop a context for these two measurements, I compiled published and unpublished pairs of benthic and planktonic foraminifer ${ }^{14} \mathrm{C}$ dates from the North Pacific region from the Last Glacial Maximum (LGM, 23-19 ky BP) through the present. In Appendix A, I describe in detail three methods for quantifying the depletion of ${ }^{14} \mathrm{C}$ in subsurface water relative to surface water: (1) the simple difference between benthic ${ }^{14} \mathrm{C}$ age and planktonic ${ }^{14} \mathrm{C}$ age, $\Delta_{b-p}$, (2) estimate of the $\Delta^{14} \mathrm{C}$ of subsurface water relative to surface water, $\Delta^{14} \mathrm{C}_{0}-\Delta^{14} \mathrm{C}_{s w}$, and (3) apparent ventilation age of subsurface water, $t_{v}$, taking into account changes in atmospheric $\Delta^{14} \mathrm{C}$.

\section{The $\delta^{18} \mathrm{O}$ and faunal record}

In Figure 3-8 are the raw isotope data and $N$. pachyderma (s.) relative abundance. The highest $N$. pachyderma (s.) $\delta^{18} \mathrm{O}$ at the bottom of 3 JPC $(3.7 \%)$ does not reach the maximum value reached in $N$. pachyderma (s.) $\delta^{18} \mathrm{O}$ in $17 \mathrm{JPC}(3.9 \%$ ), but according to the age model in $17 \mathrm{JPC}$, at $20 \mathrm{ky} \mathrm{BP}$ the two cores have the same planktonic $\delta^{18} \mathrm{O}$ to within measurement uncertainties (Figure 3-9 and Figure 3-10). The N. pachyderma (s.) relative abundance in $3 \mathrm{JPC}(70 \%)$ is lower than $17 \mathrm{JPC}(90 \%)$ at this time as well, but since there 


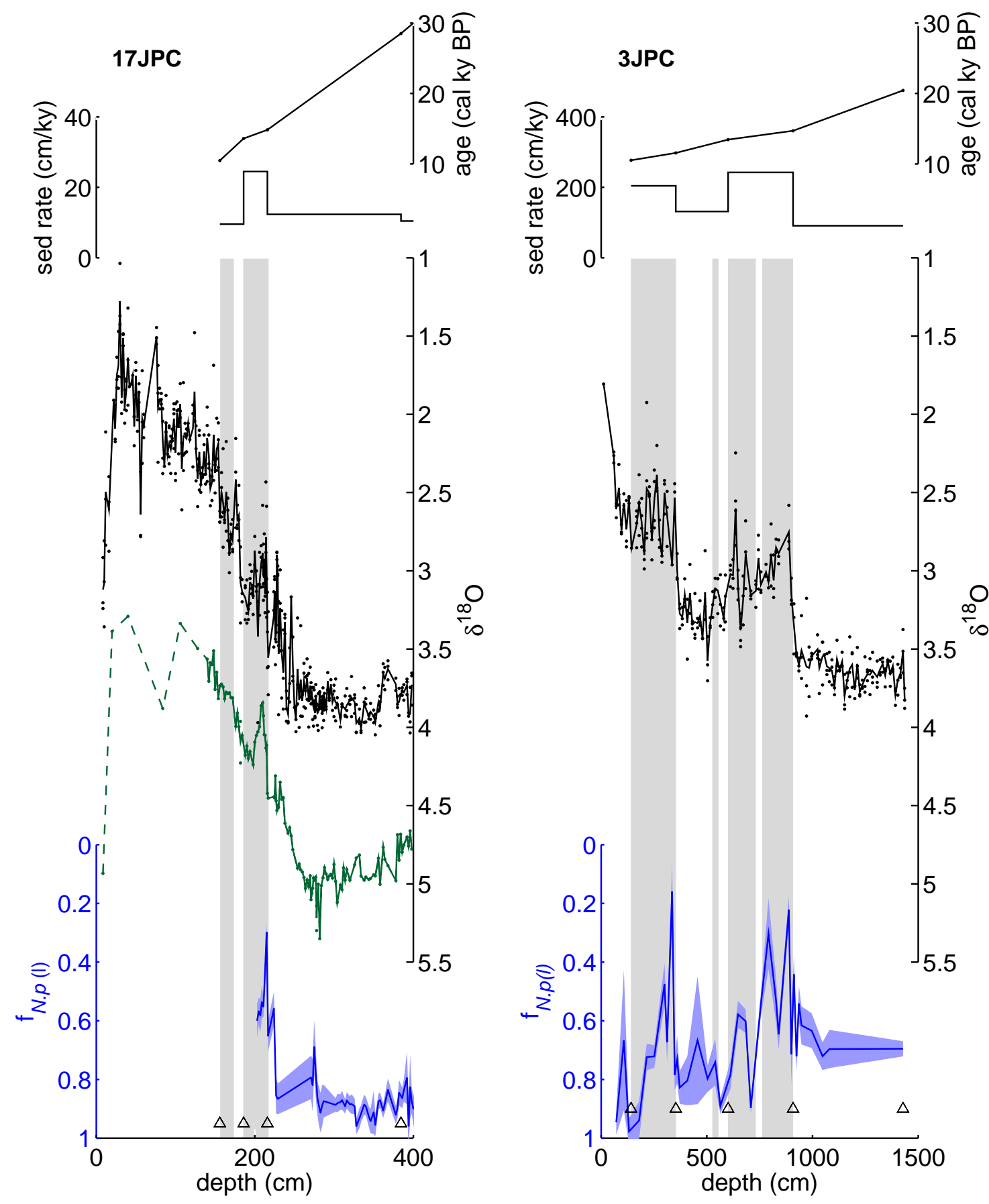

Figure 3-8: Raw $\delta^{18} \mathrm{O}$ data from $N$. pachyderma (s.) (black) and Uvigerina sp. (green) for HLY02-02-17JPC (left) and HLY02-02-3JPC (right). Each dot is an analysis, the lines go through the mean value in each sample ( $\mathrm{n}=3$ for each sample). Triangles denote location of measured radiocarbon dates. Blue lines are relative abundance of $N$. pachyderma (s.), with 95\% confidence limits calculated as in Fatela and Taborda (2002). The age model assumes constant sediment accumulation rate between radiocarbon dates. The grey vertical bars on the left panel denote dysoxic lithological units in 17JPC, on the right panel, they denote laminated layers in 3JPC. 

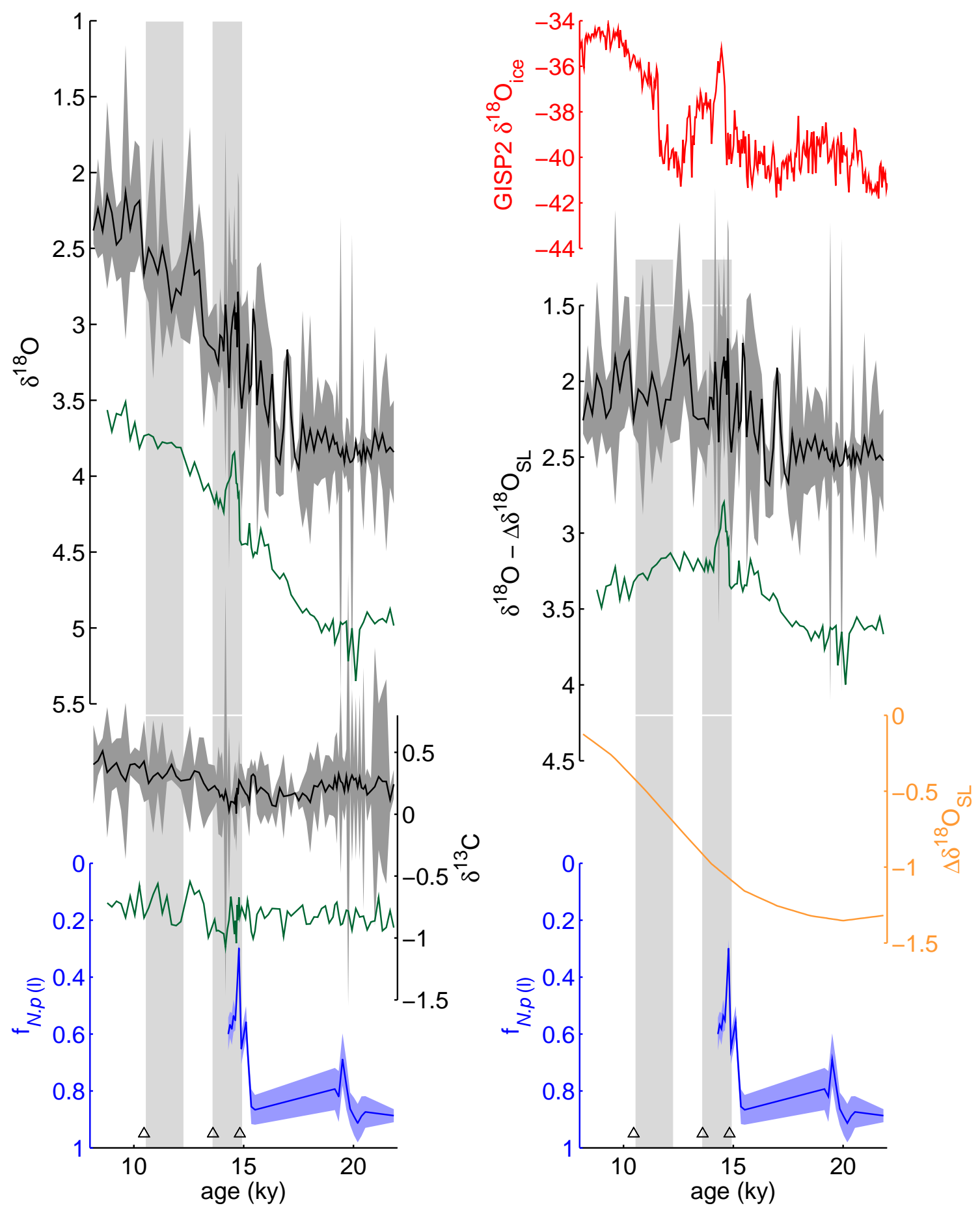

Figure 3-9: 17JPC data plotted against age. In the left-hand panel, N. pachyderma (s.) $\delta^{18} \mathrm{O}$ and $\delta^{13} \mathrm{C}$ are in black. Grey contours are the $95 \%$ confidence limits. Uvigerina sp. $\delta^{18} \mathrm{O}$ and $\delta^{13} \mathrm{C}$ are in green. Relative abundance of $N$. pachyderma (s.) is in blue, where the blue countours are the $95 \%$ confidence limit. In the right-hand panel, in red is the GISP2 $\delta^{18} \mathrm{O}$ of ice (Stuiver et al., 1995). In orange is the mean change in $\delta^{18} \mathrm{O}$ of seawater due to the melt of continental ice (Waelbroeck et al., 2002). On this panel, the mean-ocean change in $\delta^{18} \mathrm{O}$ is subtracted from the $17 \mathrm{JPC} \delta^{18} \mathrm{O}$. 

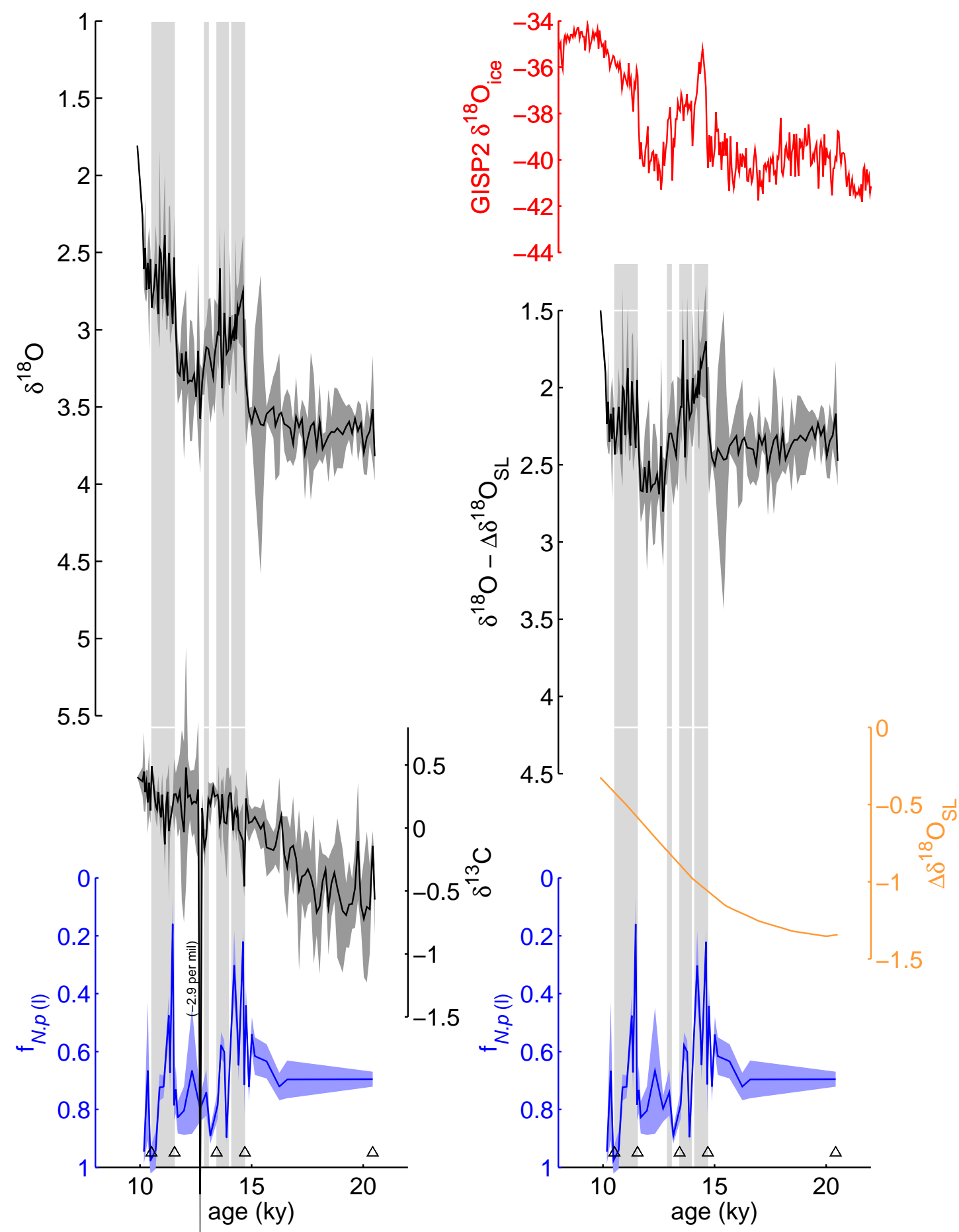

Figure 3-10: 3JPC data plotted against age. In the left-hand panel, N. pachyderma (s.) $\delta^{18} \mathrm{O}$ and $\delta^{13} \mathrm{C}$ are in black. Grey contours are the $95 \%$ confidence limits. Relative abundance of $N$. pachyderma (s.) is in blue, where the blue countours are the $95 \%$ confidence limit. In the right-hand panel, in red is the GISP2 $\delta^{18} \mathrm{O}$ of ice (Stuiver et al., 1995). In orange is the mean change in $\delta^{18} \mathrm{O}$ of seawater due to the melt of continental ice (Waelbroeck et al., 2002). On this panel, the mean-ocean change in $\delta^{18} \mathrm{O}$ is subtracted from the 3JPC $\delta^{18} \mathrm{O}$. 


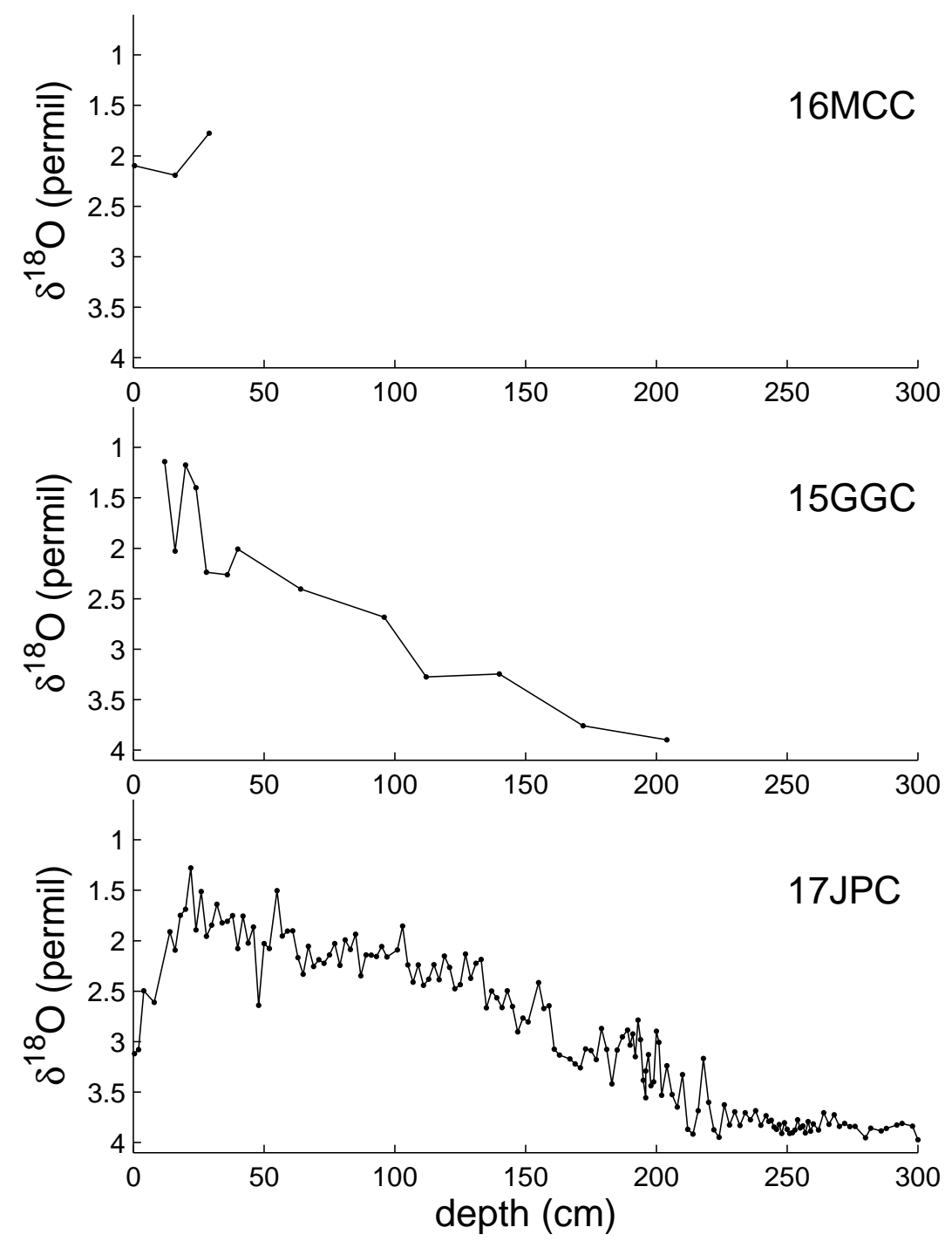

Figure 3-11: N. pachyderma (s.) $\delta^{18} \mathrm{O}$ from $17 \mathrm{JPC}$ and its two companion cores $15 \mathrm{GGC}$ and $16 \mathrm{MC}-\mathrm{C}$. The $1.5 \%$ increase in the top $30 \mathrm{~cm}$ of $17 \mathrm{JPC}$ is not seen in its two companion cores. I conclude that it is not a climatic signal. 
are few faunal data from the bottom 3 meters of 3JPC, this may not be a robust observation.

In the $N$. pachyderma (s.) $\delta^{18} \mathrm{O}$ record in $17 \mathrm{JPC}, \delta^{18} \mathrm{O}$ begins to decrease $35 \mathrm{~cm}$ below the first dysoxic layer. At the lithological transition into the dysoxic layer there is a rapid decrease in $N$. pachyderma (s.) relative abundance. In 3JPC, where the sediment accumulation rate is an order of magnitude higher, two decreases in $N$. pachyderma (s.) $\delta^{18} \mathrm{O}$ occurred very rapidly at the boundary between massive and laminated sediment, which corresponds to the beginning of the Bølling and the end of the Younger Dryas. The amplitude of these $\delta^{18} \mathrm{O}$ events is $0.7-0.8 \%$. These changes in $\delta^{18} \mathrm{O}$ are accompanied by decreases in the relative abundance of $N$. pachyderma (s.).

During the Holocene, the $N$. pachyderma (s.) $\delta^{18} \mathrm{O}$ in 3JPC decreases continuously to $1.8 \%$ at the top of the core (Figure $3-8$ ). In $17 \mathrm{JPC}, N$. pachyderma (s.) $\delta^{18} \mathrm{O}$ reaches a minimum of $1.3 \%$ at $30 \mathrm{~cm}$, then increases sharply by $1.8 \%$ to $3.1 \%$ at the top of the core. This core-top value is not seen in the companion gravity core (15GGC) and multicore (16MC-C) for this site (Figure 3-11), calling into question whether it is a real climatic signal. In 17JPC, the Uvigerina sp. $\delta^{18} \mathrm{O}$ curve is dashed above $128 \mathrm{~cm}$ because the 5 analyses above this point were conducted on the only 5 Uvigerina sp. found in the core $0-128 \mathrm{~cm}$, and I am not confident they are in place, and not bioturbated upward from deeper in the core where they are more abundant (see Discussion).

\subsection{Discussion}

\section{Chronology}

The age model in each core assumes a constant sediment accumulation rate between ${ }^{14} \mathrm{C}$ dates. Though I do not expect the sediment accumulation rate in these cores to not be smoothly varying, this age model is very simple. The greatest uncertainty in the age models is the magnitude of the reservoir correction, $R+\Delta R$. The $\Delta R$ is the local anomaly from the global mean surface water apparent age (Bard, 1988) and is very poorly constrained in the modern North Pacific. Physical processes which affect the magnitude of $\Delta R$ include circulation, upwelling, and sea-ice formation and melting, which affects air-sea gas exchange and upper-ocean stratification.

In order to convert measured radiocarbon ages to calendar ages, I must choose a reasonable value for $\Delta R$, and assume that it has remained constant through the deglaciation. 
The nearest locations where there are modern estimates of $\Delta R$ are the Kuril Islands $(320 \mathrm{y}$, Kuzmin et al. (2002)) and Kamchatka Strait (240y, Robinson and Thompson (1981)). I chose $\Delta R=400 \mathrm{y}$ because if it were any smaller, there are events in 3JPC. I believe that these layers are correlated with GISP2 would precede the events in the ice core.

The N. pachyderma (s.) ${ }^{14} \mathrm{C}$ age measured at $215 \mathrm{~cm}$ is $200 \mathrm{y}$ older than the age at $216 \mathrm{~cm}$, identifying an age reversal, though these two dates are indistinguishable within $2 \sigma$ uncertainty. I do not use the age at $215 \mathrm{~cm}$ in constructing the age model, but do use it in calculating the apparent ventilation age of this sample. I discuss the reliability of the measurements in 17JPC later in the next section.

\section{Lithology}

The oxygen minimum zone (OMZ) in the modern Bering Sea is most intense at about $1000 \mathrm{~m}$ (Figure 3-6b), where lowest $\left[\mathrm{O}_{2}\right]$ measured on the WOCE profile is $15 \mu \mathrm{mol} / \mathrm{kg}$. No laminated coretop sediments have been found in the Bering Sea. During the deglaciation, it appears that the OMZ intensified, so that cores from within the OMZ (18GGC, 55JPC, 3JPC, 51JPC, and 48JPC) have intervals of laminated sediment. Core 17JPC (from $2209 \mathrm{~m}$ water depth), is deep enough to be below the OMZ. There are contemporaneous dysoxic layers with sharp lower contacts during those two time periods in 17JPC and dysoxic sediments elsewhere in the Pacific (van Geen et al., 2003; Zheng et al., 2000) which I believe are analogous to the laminated layers in the shallower cores because they occur during BA and the early Holocene.

If the cores with lowest sediment-accumulation rate, 25GGC and 18GGC, also accumulated laminated sediments during these two time periods, the evidence of laminae would be destroyed with eventual increase in $\left[\mathrm{O}_{2}\right]$ during the Holocene, as benthic macrofauna homogenized the uppermost sediments (the activity of benthic macrofauna is typically described mathematically as Fickian diffusion (Berger and Heath, 1968), with a characteristic length scale). For the same reason, in the other cores, the top boundary of a laminated interval with the overlying massive interval probably appears stratigraphically lower than when it was originally deposited by about the thickness of the length scale of diffusive bioturbation, which is typically on the order of $10 \mathrm{~cm}$ (Boudreau, 1994). For simplicity, I do not attempt to correct the apparent age of the top of an interval of laminated sediment. So the interpolated ages of these lithological transitions in Table 3.4 may be biased toward 
slightly older ages.

Bioturbation can be heterogeneous, or "advective," where chunks of sediment are transported up or down in the sediment column relative to the layer in which it originally accumulated (François et al., 2001). This is suggested in the deglacial sediments of 17JPC, where the two dysoxic layers have such a different texture and color than the intervening sediments, that centimeter-scale mottling is visible. It is likely that such processes occur in the rest of this sediment core, even in the absence of color changes in the sediment that allow the mottling to be easily seen.

Given the sedimentation rate in this core, the thickness of sediment that would accumulate during a millennial-scale climate event is on the order of $10 \mathrm{~cm}$, which is on the same spatial scale as the mottling in 17JPC. This means that a sample analyzed for $\delta^{18} \mathrm{O}$ could contain non-coeval foraminifera, and if the individuals span a transition in $\delta^{18} \mathrm{O}$, the transition in the measured profile could be offset significantly from where it would be observed if the core were not bioturbated. A radiocarbon measurement of a sample of foraminifera composed of individuals which are not coeval could be significantly biased from the age of the depth horizon from which the sample was collected. The sedimentation rate of 3JPC is an order of magnitude higher than $17 \mathrm{JPC}$, and so the isotopic and ${ }^{14} \mathrm{C}$ record in this core is more reliable.

The planktonic and benthic $\delta^{18} \mathrm{O}$ measured in the uppermost $20 \mathrm{~cm}$ of $17 \mathrm{JPC}$ increases by $1.5 \%$. I do not see such an isotopic feature in any other Bering Sea cores. I expect the companion gravity core at this site, 15GGC, to stratigraphically overlap with the top of $17 \mathrm{JPC}$ and contain more of the sediment column closest to the sediment-water interface. Neither the gravity core nor the companion multicore show such an isotopic feature (Figure 3-11). Therefore I conclude that the planktonic record in 17JPC was somehow disturbed during the coring procedure, or from bioturbation of high- $\delta^{18} \mathrm{O}$ individuals up from deeper within the core. Both benthic and planktonic foraminifera gradually become very rare toward the top of the core, so that even a small amount of contamination of sediment containing foraminifera with different $\delta^{18} \mathrm{O}$ could have a large impact on measured $\delta^{18} \mathrm{O}$ values at the top of the core (N. pachyderma (s.) $\delta^{18} \mathrm{O}$ measurements are made on a sampe of 8 individuals). In the case of Uvigerina sp. (which are analyzed one at a time), the sole five individuals found and analyzed in top $128 \mathrm{~cm}$ of $17 \mathrm{JPC}$ could have been transported from below. 


\begin{tabular}{|c|c|c|c|c|c|}
\hline & $\begin{array}{l}\text { GISP2 } \\
(\mathrm{y} \mathrm{BP})\end{array}$ & $\begin{array}{l}3 J P C \\
(y \mathrm{BP}) \\
\end{array}$ & $\begin{array}{l}17 \mathrm{JPC} \\
(\mathrm{y} \mathrm{BP}) \\
\end{array}$ & $\begin{array}{c}\left.\Delta_{(\text {ice }-3 J P C}\right) \\
(y)\end{array}$ & $\begin{array}{c}\left.\Delta_{(\text {ice }-17 J P C}\right) \\
(y)\end{array}$ \\
\hline Pre-Boreal & $11,650 \pm 230$ & $11,540 \pm_{180}^{150}$ & $12,240 \pm_{80}^{90}$ & $110 \pm_{290}^{280}$ & $-590 \pm 250$ \\
\hline Younger Dryas & $12,890 \pm 260$ & $12,880 \pm \pm_{120}^{110}$ & $13,600 \pm 100$ & $10 \pm_{290}^{280}$ & $-710 \pm 280$ \\
\hline IÅCP & $13,070 \pm 260$ & $13,070 \pm_{120}^{100}$ & & $0 \pm_{290}^{280}$ & \\
\hline Ållerød & $13,250 \pm 260$ & $13,440 \pm_{100}^{90}$ & & $\begin{array}{r}-190 \pm 280 \\
10 \pm 320\end{array}$ & \\
\hline Older Dryas & $14,090 \pm 280$ & $14,110 \pm_{160}^{170}$ & & $-20 \pm_{320}^{330}$ & \\
\hline Oldest Dryas & $14,670 \pm 290$ & $14,690 \pm_{210}^{240}$ & $14,830 \pm_{150}^{160}$ & $-20 \pm_{360}^{380}$ & $-160 \pm 330$ \\
\hline mean offset & & & & $-10 \pm 110$ & $-530 \pm 160$ \\
\hline
\end{tabular}

Table 3.4: Age in y BP of the mid-point of transitions in GISP2 $\delta^{18} \mathrm{O}_{i c e}$ (Stuiver et al., 1995), and the age of lithological transitions between massive and laminated sediment in 3JPC, and massive and dysoxic sediment in 17JPC. In the age models, I calibrate radiocarbon dates with $\Delta R=400 y$, so that the total reservoir correction, $R=800 y$.

The ages of transitions between massive and laminated sediment in 3JPC and 17JPC are compared to the ages of transitions between climate events in the Greenland ice cores in Table 3.4 and Figure 3-12. In the ice cores, the age of a transition is considered the mid-point of the change in $\delta^{18} \mathrm{O}_{i c e}$ (Stuiver et al., 1995). The offsets between the climate events in the Greenland ice cores and 3JPC range from -190 to 110 years, which is within the uncertainty of the ${ }^{14} \mathrm{C}$ age model. The offests between GISP2 and 17JPC are significantly larger, ranging from -710 to $-160 \mathrm{y}$, where the transitions in 17JPC are older than Greenland.

At the start of the deglaciation, the decrease in planktonic $\delta^{18} \mathrm{O}$ in $17 \mathrm{JPC}$ is gradual and begins earlier than in 3JPC (Figure 3-9 and 3-10). This is similar to what is seen in a compilation of SST proxy datasets from the Pacific by Kiefer and Kienast (2005). The greater age of the transitions in the lithology of 17JPC as well as the decrease in N. pachyderma (s.) $\delta^{18} \mathrm{O}$ that occurs below the lithological transition to dysoxic sediment could both be the result of the presence of $N$. pachyderma (s.) in sediments older than when they were deposited. If this is the case, the differences between the records in the 17JPC and 3JPC cores may not be climatic, but rather, an artifact of post-depositional processes.

If we assume that the lithological changes in 3JPC and the $\delta^{18} \mathrm{O}$ changes in GISP2 are 


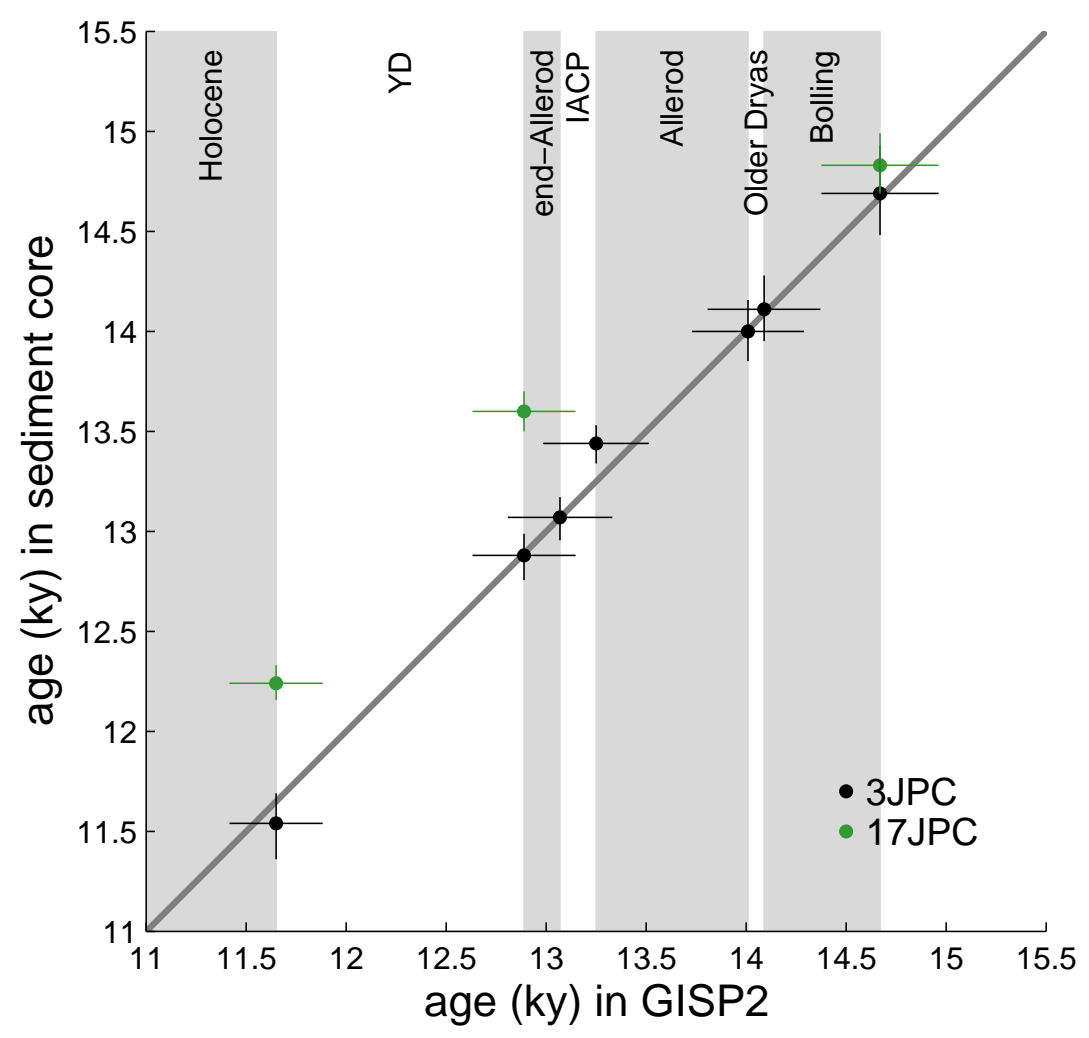

Figure 3-12: Age of events in GISP2 plotted against age of lithological transitions in 3JPC (black) and 17JPC (green). The vertical error bars are the $1 \sigma$ uncertainty in the age model. The horizontal error bars are the estimated uncertainty in the absolute age of the layercounted age model for GISP2 is $2 \%$, but the relative uncertainty is much smaller (Meese et al., 1997). 
synchronous, this implies that $\Delta R$ did not change significantly during the deglaciation. I chose $\Delta R=400 \mathrm{y}$ because if it were smaller, the lithological changes in 3JPC would preceed climate transitions in GISP2. Adjustment of $\Delta R$ would change the absolute timing of the events, but not the relative timing, and the magnitude of the mismatch between the timing of the events is well within the uncertainty of the age model. Therefore, if $\Delta R$ did not change much during the deglaciation, the correlation between GISP2 and the lithology of 3JPC is not sensitive to the absolute value of $\Delta R$.

A relatively constant $\Delta R$ is consistent with no change in sea ice extent or no change in stratification of the upper water column, processes which can affect $\Delta R$. This is a simpler, and in my opinion, more likely scenario than if $\Delta R$ was not constant during the deglaciation, because this would require a separate mechanism which would make the lithological events appear to have the same relative timing.

\section{Apparent ventilation ages}

To test whether reduced ventilation of intermediate water contributed to the low $\left[\mathrm{O}_{2}\right]$ conditions revealed by the lithology of these cores, I compiled all the published pairs of benthic and planktonic ${ }^{14} \mathrm{C}$ measurements from the North Pacific and added unpublished data of L. Keigwin, and the two new data points from this study. Analysis of the compilation shows that there was no consistent change in the ${ }^{14} \mathrm{C}$ of subsurface water shallower than $2700 \mathrm{~m}$ between the BA and the Younger Dryas (YD, 12.9-11.7 ky BP) or Last Glacial Maximum (LGM, 23-19 ky BP) (Figure 3-13). There are some limitations to the dataset used, including the small number of data points, especially during the YD. A particular challenge in measuring ${ }^{14} \mathrm{C}$ on foraminifer samples is choosing an interval of sediment in which the data will be the least biased by bioturbation. This potential bias, combined with the uncertainty in the transformation of a ${ }^{14} \mathrm{C}$ age measurement to calendar years, has the potential to prevent us from being able to know how the changes in the benthic-planktonic

${ }^{14} \mathrm{C}$ data from different cores are related to one another in time. This is particularly true for the deglaciation since the BA and YD are brief enough that they are not always possible to resolve well in sediment cores. If I had observed a significant decrease in ${ }^{14} \mathrm{C}$ of intermediate-depth water, it may not necessarily mean that there was a decrease in the rate of formation of that water mass. Reduced rate of formation of NPIW would result in lower oxygen and ${ }^{14} \mathrm{C}$ content of intermediate-depth water only if this were the only process 

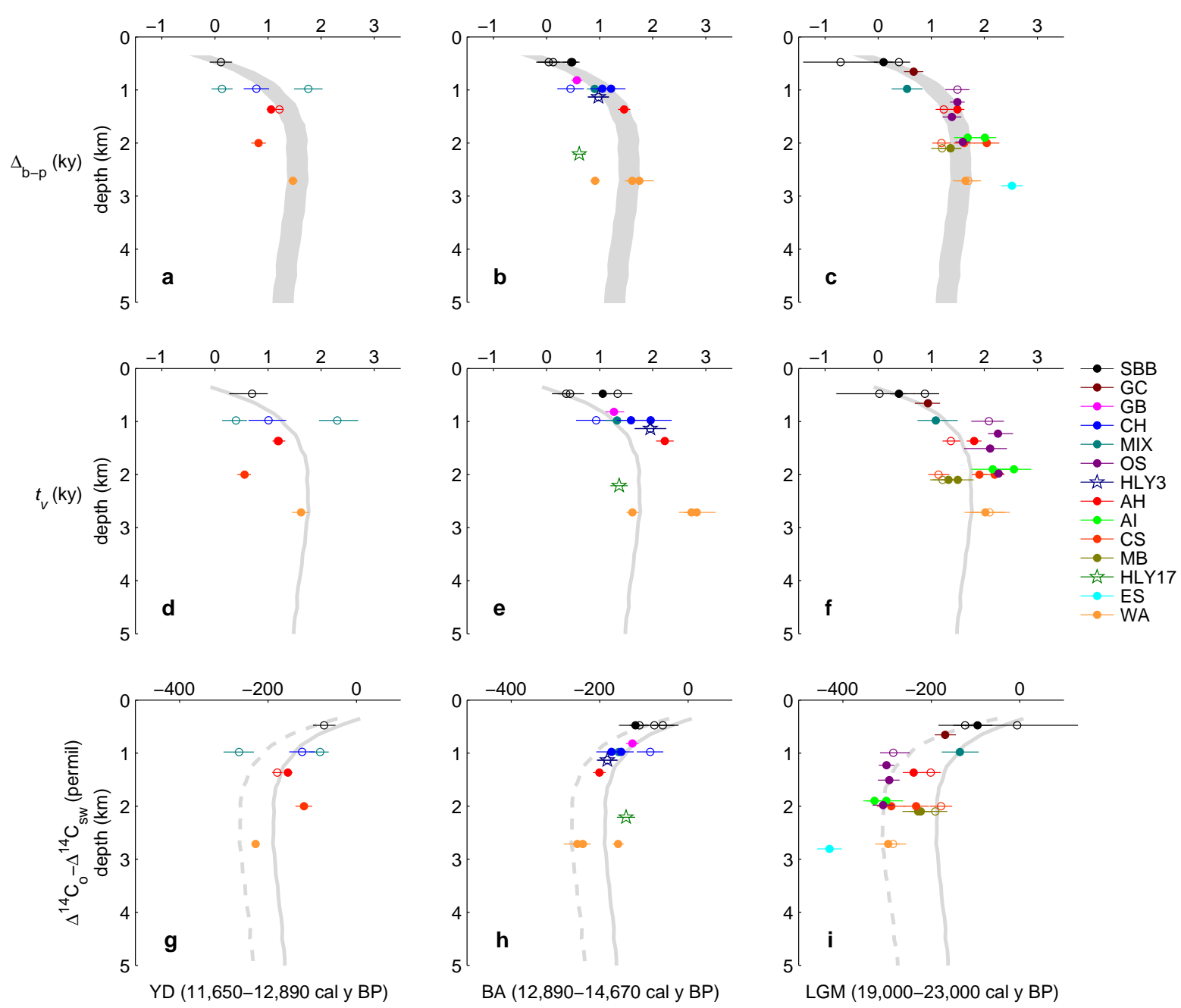

Figure 3-13: This is a summary of the analysis of a compilation of North Pacific pairs of benthic and planktonic measurements of ${ }^{14} \mathrm{C}$ conducted in Appendix 1. The three columns, from left to right, are time slices from the Younger Dryas (YD, panels a, d, and g), the Bølling-Ållerød (BA, panels b, e, and h), and the Last Glacial Maximum (LGM, panels $\mathrm{c}, \mathrm{f}$, and i). The three rows, from top to bottom, are $\Delta_{b-p}$, the difference between the ${ }^{14} \mathrm{C}$ age of benthic and planktonic foraminifera (panels $\mathrm{a}-\mathrm{c}$ ); $t_{v}$, the apparent ventilation age of subsurface water, taking into account change in atmospheric $\Delta^{14} \mathrm{C}$ (panels $\mathrm{d}-\mathrm{f}$ ); and $\Delta^{14} \mathrm{C}_{0}-\Delta^{14} \mathrm{C}_{s w}$, the difference between $\Delta^{14} \mathrm{C}$ of subsurface water and surface water (panels $\mathrm{g}-\mathrm{i}$ ). For comparison to the modern ocean, on each panel, the solid grey profile is the average North Pacific $\Delta^{14} \mathrm{C}$ from the WOCE dataset (Key et al., 2002). In panels $\mathrm{g}-\mathrm{i}$, the dashed grey profile is the modern $\Delta^{14} \mathrm{C}$ profile, corrected for the higher amount of ${ }^{14} \mathrm{C}$ in the ocean-atmosphere system for each time slice. See Figure A-4 for the calculation of mean $\Delta^{14} \mathrm{C}$ for each time slice. Each open circle is a data point which falls within the time slice. The closed circles are data points which fall within the time slice with $2 \sigma$ certainty. The error bars are $1 \sigma$. See the Appendix for details on the calculation of these three quantities, and Table A.1 for data and references. The vertical profiles of $\Delta_{b-p}, t_{v}$, and $\Delta^{14} \mathrm{C}_{0}-\Delta{ }^{14} \mathrm{C}_{s w}$ are not significantly different from the modern profile in any of the 3 time slices. 
that was changing. For example, a change in the ${ }^{14} \mathrm{C}$ of end-member components of the water mass at this depth could affect ${ }^{14} \mathrm{C}$ without a change in circulation (Wunsch, 2003); a change in the oxygen content of the Okhotsk Sea water mass which forms NPIW could affect the oxygen conent of intermediate water, without a change in formation rate (Crusius et al., 2004).

The two new data points from this study were measured in samples where known bias from bioturbation was minimized. In 17JPC, the sample was from a maximum of absolute abundance of the benthic foraminifer. In 3JPC, the sample was from a laminated interval of sediment. With eventual expansion of the North Pacific ${ }^{14} \mathrm{C}$ dataset, this question could be revisited in the future, using only data where efforts have been made to minimize bias from post-depositional processes.

\section{Deglacial SST and salinity}

When plotted against age, the shape of the $N$. pachyderma (s.) $\delta^{18} \mathrm{O}$ record in $3 \mathrm{JPC}$ is similar to the $\delta^{18} \mathrm{O}_{i c e}$ record from GISP2 (Figure 3-10), where there is a gradual increase in $N$. pachyderma (s.) $\delta^{18} \mathrm{O}$ in 3JPC (to relatively colder temperatures) in 3JPC and a gradual decrease in $\delta^{18} \mathrm{O}_{i c e}$ in GISP2 (to relatively colder temperatures).

There are large changes in the fraction $N$. pachyderma (s.) at the same time as the changes in planktonic $\delta^{18} \mathrm{O}$ (Figure 3-8). At station PAPA in the Gulf of Alaska, Sautter and Thunell (1989) estimate that only about $25 \%$ of the foraminifera from the upper water column are preserved in the sediment, the rest dissolve or are broken up in the descent to seafloor and subsequent burial and mixing. A change in the relative abundance of a particular species in the sediment record may be the consequence of a change in the amount of dissolution of the $\mathrm{CaCO}_{3}$ fraction of the sediment that has occurred, if the species is more or less resistant to dissolution (Berger and Piper, 1972). Across both these transitions, the sediment becomes less oxic, and the increase in $\mathrm{pCO}_{2}$ in porewater from organic matter oxidation would undersaturate the porewater with respect to calcite. If $N$. pachyderma (s.) is more susceptible to dissolution than the other dominant species in the planktonic foraminiferal assemblage, G. bulloides, then this could account for an exaggeration in the change in its relative abundance. However, the mean mass of a N. pachyderma (s.) test from the $212-250 \mu \mathrm{m}$ size fraction does not change systematically through the deglacial transition (data not shown), which suggests the relative abundance is probably not affected 
by a differential preservation across these events.

The rapid decreases in $N$. pachyderma (s.) $\delta^{18} \mathrm{O}$ of -0.7 and $-0.8 \%$ at the beginning of the Bølling and the end of the YD in 3JPC are probably due to a combination of warming (from the faunal data in this study) and freshening (Cook et al., 2005). In each case, the low relative abundance of $N$. pachyderma (s.) is transient, but the $\delta^{18} \mathrm{O}$ stays low, suggesting that though the warming itself is transient, there is a step decrease in salinity at this transition.

If an increase in precipitation contributed to the freshening, this would be consistent with a scenario in which there was a strong East Asian Monsoon during warm climate events. Speleothem $\delta^{18} \mathrm{O}$ records dated with uranium-series isotopes from southeast China suggest the East Asian monsoon (EAM) was strong during the BA, weak during the YD, and strong in the early Holocene (Wang et al., 2001). Flux of freshwater to the North Pacific subpolar gyre from the EAM is thought to contribute to the relatively low salinity of the subpolar North Pacific (Emile-Geay et al., 2003; Warren, 1983). In addition, the geometry of the Pacific basin results in relatively little exchange of water between the subtropical and subpolar gyres (Emile-Geay et al., 2003). A consequence of the fresh surface water of the subpolar North Pacific is that it is not able to support convective overturning such as the AMOC.

We thus speculate that the strength of the EAM may influence the amount of sea-ice formation and the density of the brine produced in the Okhotsk and Bering Seas, and ultimately, the rate of formation of intermediate water. A greater flux of freshwater to the subpolar North Pacific (as precipitation associated with the EAM) could have decreased the salinity of surface water. If fresh Okhotsk Sea surface water inhibits the formation of NPIW, this could result in decrease in ventilation and oxygen content of intermediate water, resulting in laminated and dysoxic sediments throughout the North Pacific basin. However, another effect of the freshening of surface water could be an increase in production of winter sea ice, which would have the opposite effect, an increase in production of brine, and NPIW.

Another source of freshwater to the Bering Sea could be glacial meltwater from Siberia and Alaska. Sancetta et al. (1985) suggested that the low $\delta^{18} \mathrm{O}$ event in bulk opal $(-9 \%)$ during the deglaciation from a core in the southeast Bering Sea could be due to a flux of freshwater from the Yukon. It is generally believed that Siberia and Alaska were not heavily glaciated during the LGM, based on cosmogenic dating of terrestrial glacial deposits 
(Brigham-Grette et al., 2003). However, Hill et al. (2006) have found deep incised channels on the Beringian shelf which were completely excavated then filled with sediment since the last deglaciation, implying a large flux of meltwater from Alaska. This would mean that Alaska was more heavily glaciated than previously thought.

Mikolajewicz et al. (1997) perturbed a coupled ocean-atmosphere model with a large flux of freshwater to the North Atlantic in order to study the far field effects of the consequent YD-like climate event. They find that in their model, a change in atmospheric circulation cools surface waters in the North Pacific, increasing ventilation of thermocline-depth water. We thus conclude that both cooling of North Pacific subpolar surface water from cold Siberian winds, and freshwater flux to the subpolar gyre from the EAM are atmospheric mechanisms which could explain the correlation between GISP2 and the lithology at 3JPC.

\subsection{Conclusions}

Laminated and dysoxic sediments accumulated around the rim of the North Pacific at OMZ depths during the Bølling-Ållerød and early Holocene. Analysis of a compilation of published benthic-planktonic ${ }^{14} \mathrm{C}$ measurements from the North Pacific does not clarify whether the lithological changes were due to a change in the rate of formation of intermediate water. There is a strong correlation between the timing of changes between laminated and massive sediments in the Bering Sea and the $\delta^{18} \mathrm{O}$ of ice at GISP2, which is robust, even given the uncertainty in the local reservoir correction $(\Delta R)$ at this site. The correlation suggests that there are consistent and rapid variations of both air temperature at the summit of Greenland and the oxygen content of subsurface water in the North Pacific at centennial and millenial time scales during the deglaciation, even though the climate system was undergoing a major transition. 


\title{
Chapter 4
}

\section{Marine Isotope Stage 3 in the}

\section{Bering Sea}

\begin{abstract}
In HLY02-02-17JPC, a core from the west flank of the Bowers Ridge in the south-central Bering Sea, I constructed records of benthic and planktonic $\delta^{18} \mathrm{O}$ and $\delta^{13} \mathrm{C}$ and relative abundance of $N$. pachyderma (s.), a proxy for sea surface temperature. There is statistically significant but low-amplitude variability in the faunal record. Episodes of apparent warm surface water do not correlate with any of the most prominent features of the benthic or planktonic isotopic records. Though interpretation of this dataset is limited by the preliminary age model, either there is not a coherent relationship between the isotopic and faunal records with Heinrich or Daansgard-Oeschger climate events of the last glacial period, or the effects of these events in the Bering Sea region are too subtle to be detected in these particular proxy records. These findings do not corroborate previous investigations which conclude that there was significant variability in subsurface $\delta^{13} \mathrm{C}$ and sea surface temperature in the North Pacific coinciding with Dansgaard-Oeschger and Heinrich events.
\end{abstract}

\subsection{Introduction}

During Marine Isotope Stage 3 (MIS3, ca. 50-28 ky BP), there were dramatic millennialscale climate events, which appear to have been global in impact (see Voelker and workshop participants (2002) for a review), though the most extensive geological records documenting the events are from the North Atlantic region. Warm Dansgaard-Oeschger events (or interstadials) are associated with high air temperature in Greenland and elevated atmospheric $\mathrm{CH}_{4}$ (Brook et al., 1996). Kennett et al. (2003) proposed that warmer upper-intermediate water during interstadials destabilizes methane hydrates from continental margin sediments. 
This releases $\mathrm{CH}_{4}$ gas into the water column, and if the flux is large enough, not all of the $\mathrm{CH}_{4}$ is oxidixed in the water column, and some escapes to the atmosphere. This $\mathrm{CH}_{4}$, a strong greenhouse gas, could provide a positive feedback of interstadial warming. Kennett et al. (2003) argue that wetlands could not respond rapidly enough to account for the observed fluctuations in atmospheric $\mathrm{CH}_{4}$. There is sedimentary evidence of the episodic presence of methane in marine sediments during MIS3 (see review in the Introduction of Chapter 5).

Our knowledge of the glacial history of the Pacific is sparse. Arguably the best sedimentary climate record from anywhere in the Pacific comes from Santa Barbara Basin, an anoxic basin on the California margin ( sill depth $=475 \mathrm{~m}$ ), where there is a good correlation between interstadial events and lithology; laminated sediments occur during every interstadial (Behl and Kennett, 1996). However, at this coastal site, it is uncertain whether the laminated sediment is due to reduced ventilation of upper intermediate water in the Pacific or the effects of a local change in export production. Elsewhere in the North Pacific, reconstructions of glacial oceanography have been hampered by the typically low sediment accumulation rates endemic to this ocean basin. From a site on the Emperor seamounts, Kiefer et al. (2001) concluded that North Pacific and North Atlantic sea surface temperatures (SSTs) are out of phase, and that warm Pacific SSTs are caused by reduced upwelling of cold water. However, uncertainties in the age model for this core call into question whether the planktonic SST record is in or out phase with GISP2. In a record from a 2712 m-deep core in the northeast Pacific, Lund and Mix (1998), find a correlation between high benthic $\delta^{13} \mathrm{C}$ and Heinrich events. Heinrich events were the coldest millennial-scale climate events of the last glacial period. In the North Atlantic, nutrient proxies measured from during Heinrich events are consistent with a reduction of the strength of the Atlantic meridional overturning circulation (AMOC) (Vidal et al., 1997; Keigwin and Lehman, 1994; Curry and Oppo, 1997; Keigwin and Boyle, 1999). Lund and Mix (1998) interpret their data as indicating greater ventilation of deep Pacific water when the AMOC was thought to be weak. This interpretation is similar to better ventilated intermediate depths inferred from LGM $\delta^{13} \mathrm{C}$ on the Emperor Seamounts (Keigwin, 1998).

A new sediment core, collected from $2200 \mathrm{~m}$ water depth, from Bowers Ridge, in the south-central Bering Sea, has a sediment accumulation rate during MIS3 that is comparable or higher than those of existing records of MIS3 variability, and could help resolve some of 
the ambiguity of published records from relatively low-sediment accumulation rate cores. With the Bowers Ridge core, I will test the interpretations in previous studies that there was significant millennial-scale variability in the $\delta^{13} \mathrm{C}$ of intermediate/deep water, and that sea surface temperature in the far North Pacific was high during DO events.

\subsection{Methods}

\section{Sample preparation}

HLY02-02-17JPC was collected from a site at $2209 \mathrm{~m}$ water depth on the western flank of the Bowers Ridge (Figure 3-1). Sediment samples were dried at $50^{\circ} \mathrm{C}$, then washed with tap water through a $63 \mu \mathrm{m}$ sieve. The sample was dried again at $50^{\circ} \mathrm{C}$ and the dry sample was sieved so that planktonic and benthic foraminifera could be picked from larger size fractions. N. pachyderma (s.) and Uvigerina sp. were picked from the $212-250 \mu \mathrm{m}$ and $>250 \mu \mathrm{m}$ size fractions, respectively. $\delta^{18} \mathrm{O}$ and $\delta^{13} \mathrm{C}$ measurements of 8-10 N. pachyderma (s.) or a single Uvigerina sp. were made on a PRISM mass spectrometer and are reported relative to PDB via NBS-19 (Coplen, 1996). At least 300 individual planktonic fauna $>150 \mu \mathrm{m}$ were counted, and $95 \%$ confidence limits on the relative abundance of species were calculated as in Fatela and Taborda (2002). Relative abundance of $N$. pachyderma (s.) is a proxy for sea surface temperature, where higher relative abundance corresponds to lower temperatures (see Chapter 3).

\section{Age model}

Samples of N. pachyderma (s.) were analyzed for ${ }^{14} \mathrm{C}$ at the National Ocean Sciences Accelerator Mass Spectrometer Facility at WHOI. I calibrated measured radiocarbon dates with Calib5.0.1, using a reasonable value for the reservoir correction, $\Delta \mathrm{R}=400 \mathrm{y}(R+\Delta R=$ $800 \mathrm{y})$. The surface ocean reservoir correction is poorly constrained in the modern North Pacific, see Cook et al. (2005) for discussion. The age model is simply constructed as linear interpolation of median calibrated ages. To calibrate radiocarbon dates beyond $25,000 \mathrm{y}$ to calendar years, I use a record of ${ }^{14} \mathrm{C}$ age of Globigerina bulloides from the Cariaco Basin on the GRIP ss09sea age model. The average sample spacing in 17JPC is $230 \mathrm{y}$. 


\begin{tabular}{|c|c|c|c|c|}
\hline depth $(\mathrm{cm})$ & ${ }^{14} \mathrm{C}$ y $\mathrm{BP} \pm \sigma$ & cal y BP & $\pm \sigma$ & ${ }_{-2}^{+2} 2 \sigma$ \\
\hline $155.5-156.5$ & $10,000 \pm 60$ & 10,460 & 10,400 & 10,290 \\
\hline $185.5-186.5$ & $12,550 \pm 65$ & 13,600 & $\begin{array}{l}13,500 \\
13,700\end{array}$ & $\begin{array}{l}13,430 \\
13,750\end{array}$ \\
\hline $215.5-216.5$ & $13,400 \pm 60$ & 14,830 & $\begin{array}{l}14,680 \\
14,990\end{array}$ & $\begin{array}{l}14,440 \\
15,130\end{array}$ \\
\hline $383.5-384.5$ & $25,200 \pm 130$ & 28,500 & & \\
\hline $551.5-552.5$ & $41,500 \pm 370$ & 44,530 & & \\
\hline $668.5-669.5$ & $49,100 \pm 640$ & 52,310 & & \\
\hline
\end{tabular}

Table 4.1: Uncorrected AMS ${ }^{14} \mathrm{C}$ ages and corrected, calibrated ages of $N$. pachyderma (s.) in HLY02-02-17JPC. For the three ages younger than $25{ }^{14} \mathrm{C}$ ky BP, calibrations are performed with Calib5.0html (Reimer et al., 2004) using the Marine04 calibration (Hughen et al., 2004b). I use $\Delta \mathrm{R}=400 \mathrm{y}$, corresponding to a reservoir age of surface water of $800 \mathrm{y}$. I report the median calendar ages with the upper and lower limits of the $\sigma$ and $2 \sigma$ ranges. For the measured ages older than $25,000{ }^{14} \mathrm{C}$ y, I report the intercept of this age with the G. bulloides record from the Cariaco Basin (Hughen et al., 2004a), which is tuned to the GRIP ss09sea age model. Uncertainty in these calibrations is on the order of $1-2 \mathrm{ky}$.

\subsection{Results}

The age model for 17JPC (Figure 4-1a) is preliminary, as most of this record is constrained by planktonic ${ }^{14} \mathrm{C}$ dates whose calibration to calendar years is fairly uncertain beyond 25,000 y BP (Table 4.1). As a result, I am unable to correlate events in this record with other, well-dated paleoclimate records with any confidence. The average sample spacing in 17JPC core $(230 \mathrm{y})$ is theoretically small enough to resolve millennial-scale events if present.

In the raw isotope data (Figure 4-1), there is broad variability in N. pachyderma (s.) $\delta^{18} \mathrm{O}$ with an amplitude of $\sim 0.4 \%$, and local maxima at $352 \mathrm{~cm}, 410 \mathrm{~cm}, 520 \mathrm{~cm}$, and $642 \mathrm{~cm}$. There is one notable maximum in Uvigerina sp. $\delta^{18} \mathrm{O}$, defined by 3 data points at $280 \mathrm{~cm}$, with an amplitude of $0.4 \%$. There is broad variability in the rest of the Uvigerina sp. $\delta^{18} \mathrm{O}$ record, with an amplitude of $\sim 0.4 \%$. Uvigerina $s p . \delta^{13} \mathrm{C}$ is variable with an amplitude of up to $1 \%$, with minima at $328 \mathrm{~cm}, 492 \mathrm{~cm}$, and $594 \mathrm{~cm}$. There are statistically significant but small changes in relative abundance of $N$. pachyderma (s.) in this core.

\subsection{Discussion}

We plot the HLY02-02-17JPC foraminifer data sets against age in Figure 4-2. Considering the large uncertainties in the age model, I plot the $\delta^{18} \mathrm{O}$ data without attempting to subtract whole-ocean $\delta^{18} \mathrm{O}$ change, which is on the order of $1 \%$ during MIS3 (Waelbroeck et al., 2002). I will focus on the relationships between features of the isotope records versus depth 


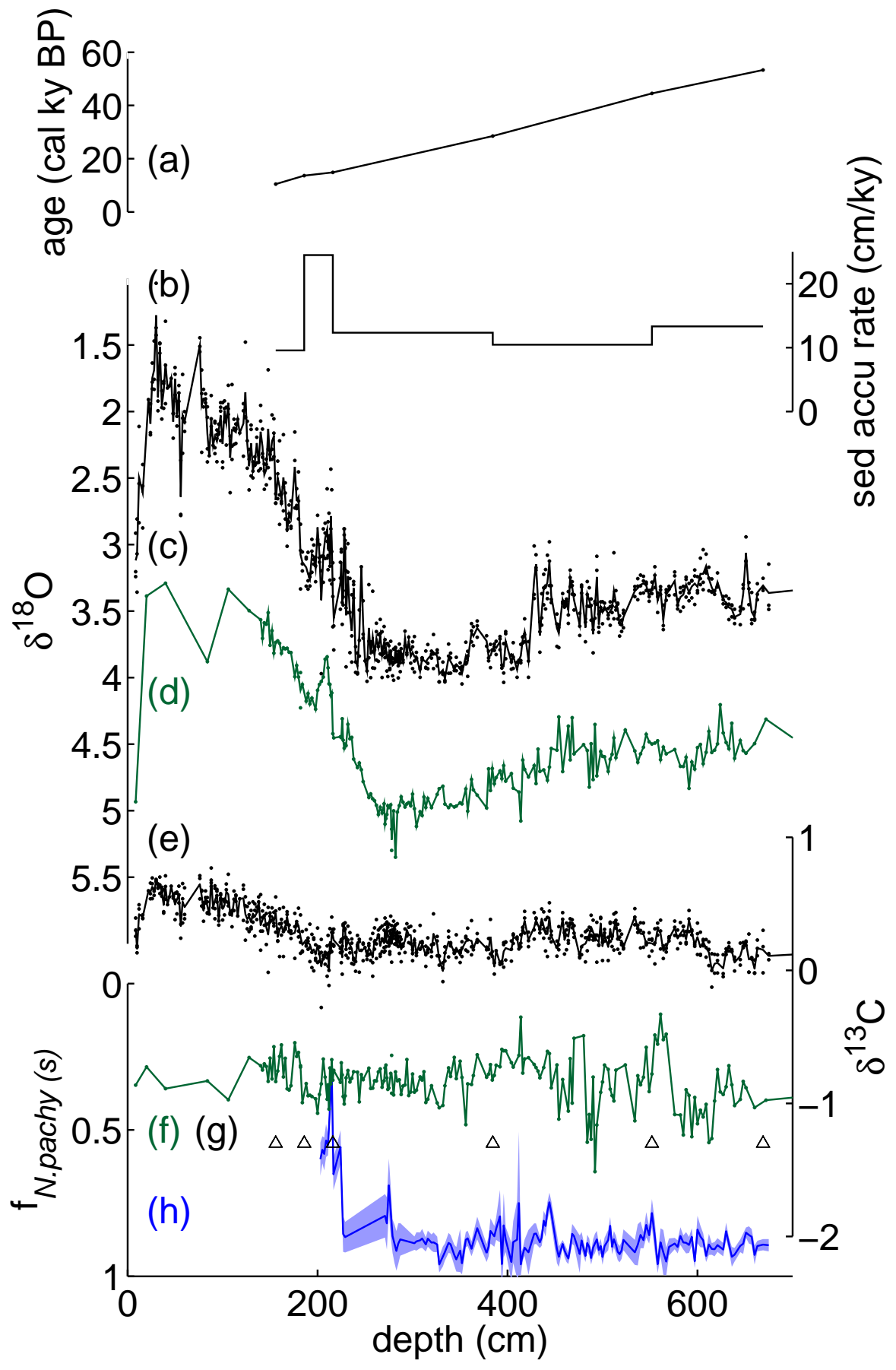

Figure 4-1: (a) Age model for HLY02-02-17JPC, constructed assuming constant sediment accumulation rate between measured $N$. pachyderma (s.) radiocarbon ages, which are calibrated to calendar years with Calib 5.0.1, using $\Delta R=400 \mathrm{y}$, or a surface reservoir age of $R+\Delta R=800 \mathrm{y}$. (b) Sediment accumulation rate $(\mathrm{cm} / \mathrm{ky})$ inferred from the age model. (c)-(d) HLY02-02-17JPC N. pachyderma (s.) (black) and Uvigerina sp. (green) $\delta^{18}$ O. Dots are individual measurements, the solid line connects the mean of the measurements in each sample $(\mathrm{n}=3)$. (e)-(f) N. pachyderma (s.) (black) and Uvigerina sp. (green) $\delta^{13} \mathrm{C} .(\mathrm{g})$ Marked with triangles, sample depths in which $N$. pachyderma (s.) radiocarbon was measured. (h) Fraction relative abundance of $N$. pachyderma (s.), with $95 \%$ confidence limits. 


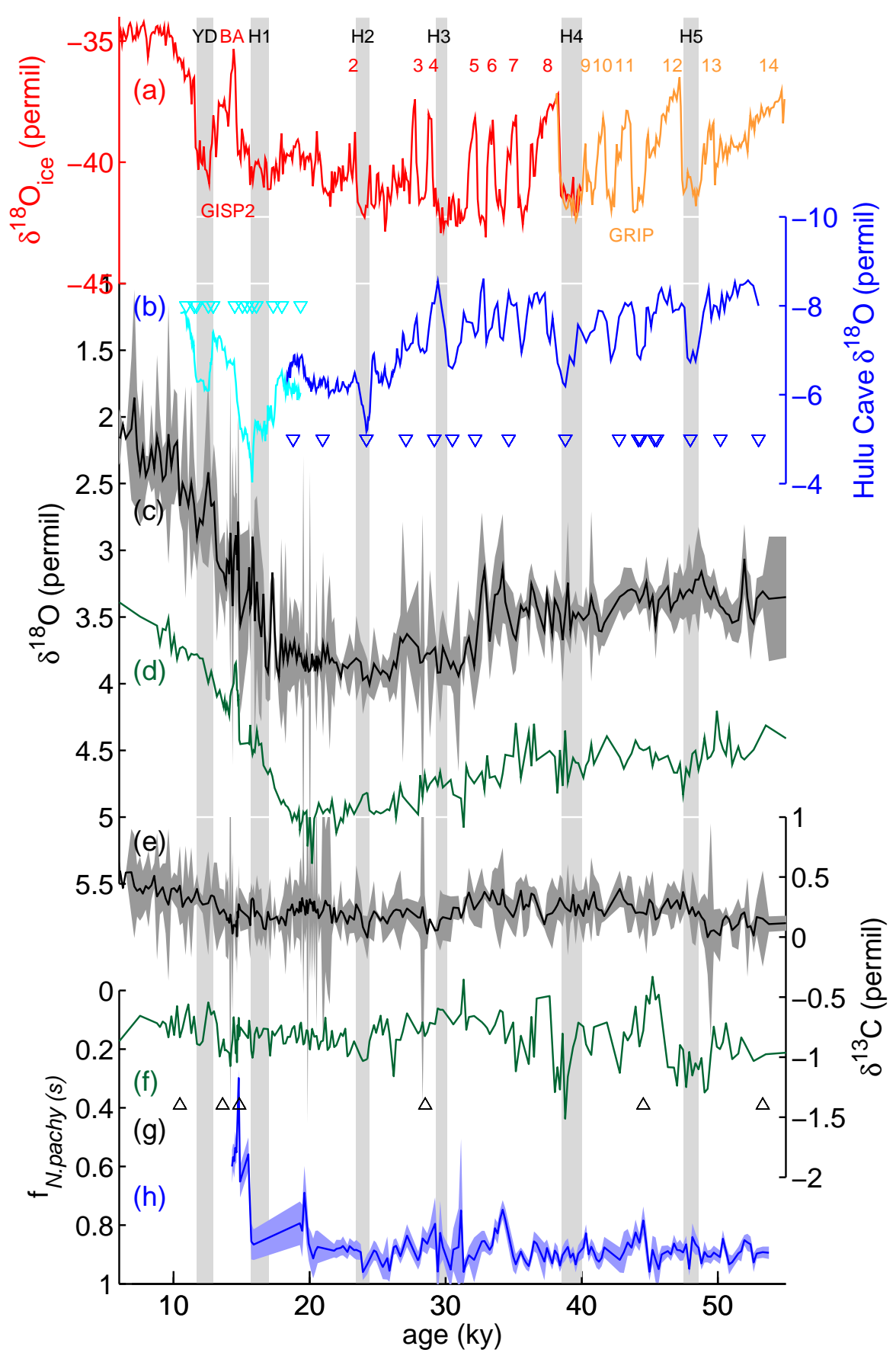

Figure 4-2: (a) $\delta^{18} \mathrm{O}_{i c e}$, of GISP2 (red, Stuiver et al. (1995)) and GRIP on the ss09sea age model (orange, Johnsen et al. (2001)). Interstadials (Dansgaard-Oeschger events) are numbered in red and orange. Grey bars mark Heinrich events, which are numbered in black. (b) Hulu stalagmite $\delta^{18} \mathrm{O}$, a proxy for East Asian monsoon strength, where lower $\delta^{18} \mathrm{O}$ indicates a stronger monsoon (Wang et al., 2001). Triangles are ${ }^{230} \mathrm{Th}$ dates, cyan data are from speleothem PD, blue from MSD (Wang et al., 2001). (c)-(d) HLY02-0217JPCN. pachyderma (s.) (black) and Uvigerina sp. (green) $\delta^{18} \mathrm{O}$. The grey shading is the $95 \%$ confidence limits on the value of the mean in each sample. (e)-(f) $N$. pachyderma (s.) (black) and Uvigerina sp. (green) $\delta^{13} \mathrm{C}$. (g) Triangles mark the location of radiocarbon measurements on N. pachyderma (s.). (i) Fraction relative abundance of N. pachyderma (s.), with $95 \%$ confidence limits. 
(Figure 4-1) within the sediment core. In Figure 4-2, I plot the GRIP $\delta^{18} \mathrm{O}_{i c e}$ on the ss09sea age model (Johnsen et al., 2001). The authors consider ss09sea more accurate than GISP2 ice core age model older than $40 \mathrm{ky} \mathrm{BP}$, but less accurate younger than $40 \mathrm{ky} \mathrm{BP}$.

In the Bering Sea during the Bølling-Ållerød, there is evidence for relatively fresh and warm surface water from low $N$. pachyderma (s.) $\delta^{18} \mathrm{O}$ and low relative abundance of N. pachyderma (s.) (see Chapter 3). Sediments from within the oxygen minimum zone are laminated. In contrast, during the Younger Dryas, sediments are oxic, there is indication that surface water was relatively salty and cold. The Younger Dryas and Bølling-Ållerød are unique events because they occur during the deglaciation, when the global climate system was undergoing a large transition. But it is not unreasonable to hypothesize that the previous stadials and interstadials may be analogous to these two events, because the sense of change in the North Atlantic is the same. If this is the case for the North Pacific, then I would predict that warm interstadial events are associated with low planktonic $\delta^{18} \mathrm{O}$ and low relative abundance of $N$. pachyderma (s.). Conversely, I would predict cold stadials and Heinrich events to be associated with high planktonic $\delta^{18} \mathrm{O}$ and high relative abundance N. pachyderma (s.). I expect that the Heinrich events and interstadials 8 and 12 are the most likely of these events to be observed in this core because of their severity and longer duration, respectively. Uvigerina is not the ideal benthic species to use in gauging the $\delta^{13} \mathrm{C}$ of bottom water, since it lives within the surface sediments, so its $\delta^{13} \mathrm{C}$ reflects pore-water $\delta^{13} \mathrm{C}$. However, it was the only benthic foraminifer species that is present throughout the core. Low Uvigerina $\delta^{13} \mathrm{C}$ would indicate low $\delta^{13} \mathrm{C}$ of porewater which could be a function of low bottom-water $\delta^{13} \mathrm{C}$, high organic carbon flux to the seafloor, or low oxygen levels in bottom water.

In Figure 4-1, though each record is variable through MIS2 and 3, there does not seem to be a consistent relationship between changes in any of the records. For example, the low benthic $\delta^{13} \mathrm{C}$ at around $594 \mathrm{~cm}$ coincides with relatively high benthic $\delta^{18} \mathrm{O}$ and relatively low planktonic $\delta^{18} \mathrm{O}$. But the planktonic and benthic $\delta^{18} \mathrm{O}$ records are neither at maxima or minima while benthic $\delta^{13} \mathrm{C}$ is low at $492 \mathrm{~cm}$. It is possible that the isotopic records represent changes in the surface and deep ocean which are independent of each other and not coherent.

The sediment accumulation rate is 1.7 times greater in 17JPC during MIS3 than the Kiefer et al. (2001) record from the Emperor Seamounts (the sampling interval of the cores 
is the same). If the temperature of surface water at the two sites changed in the same way in the past, I would expect that the signal observed by Kiefer et al. (2001) would be more well resolved in $17 \mathrm{JPC}$. The average relative abundance of $N$. pachyderma (s.) is similar at the two sites $(\sim 90 \%)$, indicating that the coldest sea surface temperatures during MIS3 were similar at the two sites. However, the 17JPC data do not show millennial-scale warmings of surface water during MIS3.

Analysis of upper-ocean temperature measurements from recent decades reveals a pattern of sea-surface and upper-ocean temperature changes during interdecadal climate events in the North Pacific (Deser et al., 1996). In this analysis, the temperature changes are spatially heterogeneous, where SST in the central North Pacific is out of phase with SST in the Gulf of Alaska, Bering Sea, and eastern North Pacific. If a similar spatial pattern of SST anomalies occurred during climate events of MIS3, there could be a significant temperature gradient between the Emperor Seamounts (in the central North Pacific) and the Bowers Ridge so that the SST proxy records at the two sites would be dissimilar.

\subsection{Conclusions}

The preliminary age model from this core does not allow us to correlate features in the isotopic and faunal records to other well-dated climate records. There is variability in N. pachyderma (s.) and Uvigerina sp. $\delta^{18} \mathrm{O}$ of an amplitude of $\sim 0.4 \%$, and variability of Uvigerina $s p . \delta^{13} \mathrm{C}$ of up to $1 \%$. There are statistically significiant changes in fraction relative abundance of $N$. pachyderma (s.) of up to $15 \%$. However, there does not appear to be any coherence between the features in the oxygen and carbon isotopic and faunal data. These data suggest, contrary to a study from the Emperor Seamounts, that there was not any millennial scale change in SST that coincide with Dasgaard-Oeschger or Heinrich events

during MIS3. However, spatial heterogeneity in North Pacific SST could account for the dissimilarity of the Bowers Ridge and Emperor Seamount records. 


\title{
Chapter 5
}

\section{Evidence of Methane in Bering Sea Sediments during Marine Isotope}

\section{Stage 3}

\begin{abstract}
During Marine Isotope Stage 3 (MIS3, 28-62 ky BP), there are very large negative excursions in planktonic and benthic $\delta^{13} \mathrm{C}$ in a $1467 \mathrm{~m}$ core from the Southeast Bering Sea near the Umnak Plateau, a region where methane hydrates are present today. Measured benthic and planktonic foraminifer $\delta^{13} \mathrm{C}$ during the excursions are as low as -6 and $-14 \%$, respectively, and are the probably the result of overgrowths of diagenetic carbonate minerals. These minerals may be formed in association with sulfate reduction of organic matter or anaerobic oxidation of methane at the base of the sulfate reduction zone. Both processes increase the alkalinity and supersaturate the porewater with respect to carbonate minerals. From a linear end-member mixing model, I estimate that the overgrowth stable isotopic composition is $\delta^{13} \mathrm{C}=-23.4 \%$ o, $\delta^{18} \mathrm{O}=6.5 \%$, and $[\mathrm{Mg}] /[\mathrm{Ca}]=72-837 \mathrm{mmol} / \mathrm{mol}$. This site is deep and cold enough to be well within the zone of methane-hydrate stability. Thus, it is unlikely that the source of methane was from local destabilization of methane hydrates due to changes in pressure or temperature at the sediment-water interface.
\end{abstract}

\section{$5.1 \quad$ Introduction}

Episodes of low $\delta^{13} \mathrm{C}$ measured in benthic foraminifera (as low as -5\% ) from ODP Site 893 in the Santa Barbara Basin coincide with warm Dansgaard-Oeschger (DO) climate events of the last glacial period (Kennett et al., 2000). Kennett proposed a "Clathrate Gun Hypothesis" (Kennett et al., 2003) in which a warming of intermediate water destabilizes methane 
$\left(\mathrm{CH}_{4}\right)$ hydrates (the term hydrates is synonymous with clathrates) during interstadials (IS). According to this controvertial hypothesis, methane (a strong greenhouse gas), is released into the water column, and a significant fraction of the gas reaches the atmosphere, enhancing global warming. There is sedimentary evidence of episodic flux of methane to surface sediments at continental margin sites, not only in the Santa Barbara Basin (low benthic $\delta^{13} \mathrm{C}$ (Kennett et al., 2000); biomarkers of aerobic and anaerobic methanotrophy, (Hinrichs et al., 2003)), but also in the Gulf of California (low benthic and planktonic $\delta^{13} \mathrm{C}$; (Keigwin, 2002), the Japan Margin (methane biomarkers; Uchida et al. (2004)), the Papua Gulf (low planktonic $\delta^{13} \mathrm{C}$; de Garidel-Thoron et al. (2004)), and the southwest Greenland Sea (low benthic and planktonic $\delta^{13} \mathrm{C}$; Millo et al. (2005)).

In this paper, from a core in the southeast Bering Sea, I identify three episodes during MIS3 where there is evidence of authigenic carbonate minerals. The minerals could be associated with high pore-water alkalinity from the anaerobic oxidation of methane. If this was the case, however, this site $(1467 \mathrm{~m})$ is well within the zone of methane hydrate stability, and does not fit into the mechanism proposed by Kennett et al. (2003), where warming of intermediate water causes destabilization of methane hydrates. If the events in this core coincide with DO events, these findings support the proposition of Kennett et al. (2003) that methane stored in continental shelf sediments can be mobilized and interact with the climate system at millennial time scales.

\section{Methane hydrates}

In organic-carbon- $\left(\mathrm{C}_{\text {org }}\right)$ rich marine sediments, when more energetically favorable oxidants are depleted, $\mathrm{C}_{\text {org }}$ is reduced to $\mathrm{CH}_{4}$ by anaerobic methanogenic archaea (Berner, 1980).

$$
2 \mathrm{CH}_{2} \mathrm{O} \rightarrow \mathrm{CH}_{4}+\mathrm{CO}_{2}
$$

The $\delta^{13} \mathrm{C}$ of this biogenic $\mathrm{CH}_{4}$ is typically -110 to $-50 \%$ because of strong kinetic fractionation during $\mathrm{CO}_{2}$ reduction (Whiticar, 1999). In some settings, an additional source of $\mathrm{CH}_{4}$ in marine sediments is thermogenic, where $\mathrm{CH}_{4}$ is one product of thermal degradation of $\mathrm{C}_{\text {org }}$ at depth in the sediment column where the temperature reaches $80-90^{\circ} \mathrm{C}$ (Whiticar, 1999). The $\delta^{13} \mathrm{C}$ of thermogenic $\mathrm{CH}_{4}$ is typically -50 to $-20 \%$, and the molecular ratio of 


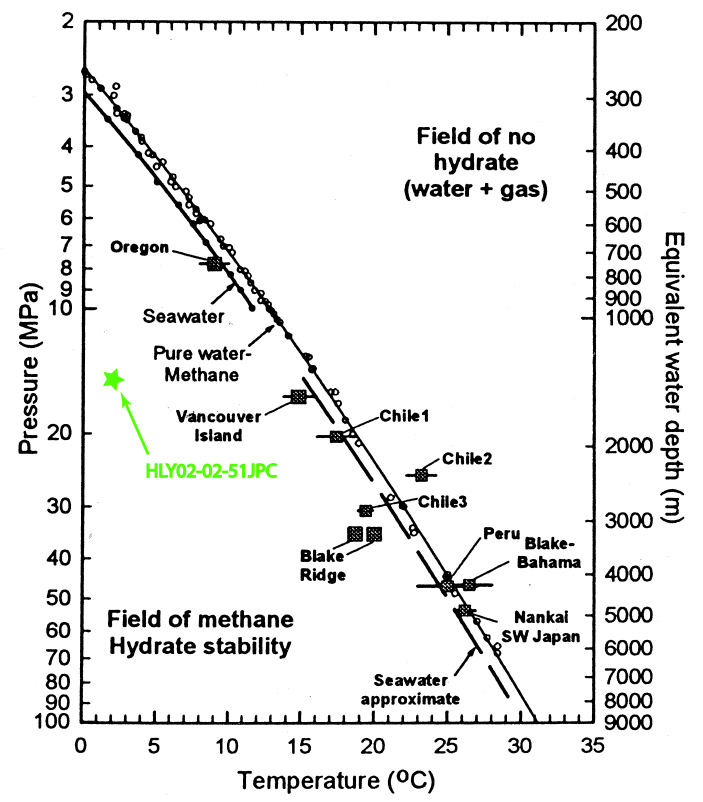

Figure 5-1: Phase diagram for $\mathrm{CH}_{4}$ hydrate stability. The solid line is for pure water, the dashed line is for seawater. Above and to the right of these lines (lower pressure and higher temperature), methane hydrate is not stable. Below and to the left of the lines, methane hydrate is stable, and with sufficient quantities of dissolved methane, hydrates will form. The HLY02-02-51JPC is at $1467 \mathrm{~m}$ water depth, and today, the bottom water temperature is $2.2^{\circ} \mathrm{C}$, well within the zone of hydrate stability. This figure is from Kastner (2001).

$\mathrm{CH}_{4}$ to larger hydrocarbon molecules, ethane $\left(\mathrm{C}_{2} \mathrm{H}_{6}\right)$ and propane $\left(\mathrm{C}_{3} \mathrm{H}_{8}\right)$,

$$
\frac{\left[\mathrm{CH}_{4}\right]}{\left[\mathrm{C}_{2} \mathrm{H}_{6}\right]+\left[\mathrm{C}_{3} \mathrm{H}_{8}\right]}=\frac{\mathrm{C} 1}{\mathrm{C} 2+\mathrm{C} 3}
$$

is less than 50. In contrast, $\frac{\mathrm{C} 1}{\mathrm{C} 2+\mathrm{C} 3}$ of biogenic $\mathrm{CH}_{4}$ is typically greater than 300 (Kastner, 2001). In regions of the seafloor where thermogenic hydrocarbons can migrate up along faults, $\mathrm{CH}_{4}$ within the sediment can be a mixture from the two sources, in which case its composition falls on a mixing line in $\frac{\mathrm{C} 1}{\mathrm{C} 2+\mathrm{C} 3}-\delta^{13} \mathrm{C}$ space.

Methane hydrates form on Earth today primarily in high-latitude permafrost regions, and in the ocean along continental margins, where there is sufficient $\mathrm{CH}_{4}$, and the proper pressure and temperature conditions (Figure 5-1) (Kvenvolden and Lorenson, 2001). Gas hydrates are isometric crystalline solids which consist of a lattice of water molecules with cages that can accommodate gas molecules that are $3.5-7.5 \times 10^{-10} \mathrm{~m}$ in diameter (Pellenbarg and Max, 2000). Methane hydrate formation is associated with a fractionation of oxygen isotopes, on the same order as fractionation associated with the formation of sea ice, with a fractionation factor, $\alpha_{(\text {hydrate-sw })}$, in the range $1.0027-1.0031$, so that hydrate 
is enriched in $\mathrm{H}_{2}{ }^{18} \mathrm{O}$ by $3 \%$ (Matsumoto and Borowski, 2000).

Gas hydrates are stable at higher temperatures than ice, and with increasing pressure, the maximum temperature required for stability increases. The lower boundary of methane hydrate stability in marine sediments is a function of geothermal heating from below. Dissociated gas at this boundary creates a seismic discontintuity called a "Bottom Simulating Reflector," (BSR, Figure 5-2), a term coined during the Deep Sea Drilling Project (DSDP) Leg XIX in the Bering Sea where it was observed on the Umnak Plateau at sites 184 and 185 (Scholl et al., 1973). At site 185, in a sample from within the BSR (665 mbsf),

$\frac{\mathrm{C} 1}{\mathrm{C} 2+\mathrm{C} 3}=2850$, and $\delta^{13} \mathrm{C}$ of $\mathrm{CH}_{4}$ gas was $-72.1 \%$, both measurements indicating a purely biogenic source for this gas (Claypool et al., 1973).

Pore water containing methane can be advected upward at convergent margins, where sediment is squeezed, like in an accretionary wedge, around salt diapirs, and up along fault planes. At passive margins as well, there can be upward flux of pore fluids from sediment compaction.

\section{Authigenic carbonates associated with anaerobic methanotrophy}

Biogenic methane will diffuse upward in the sediment column into the overlying sulfate reduction zone. In the presence of sulfate, $\mathrm{CH}_{4}$ is oxidized by syntropic anaerobic sulfatereducing bacteria and archaea (Alperin and Reeburgh, 1984).

$$
\mathrm{CH}_{4}+\mathrm{SO}_{4}^{2-} \rightarrow 2 \mathrm{HCO}_{3}^{-}+\mathrm{HS}^{-}+\mathrm{H}_{2} \mathrm{O}
$$

This reaction produces $\mathrm{HCO}_{3}^{-}$, which increases alkalinity of porewater, and increases the saturation of carbonate minerals. Sulfate reduction of organic matter also produces $\mathrm{HCO}_{3}^{-}$ (Figure 5-2).

$$
2 \mathrm{CH}_{2} \mathrm{O}+\mathrm{SO}_{4}^{2-} \rightarrow \mathrm{HCO}_{3}^{-}+\mathrm{H}_{2} \mathrm{~S}
$$

A large enough flux of $\mathrm{HCO}_{3}^{-}$into the pore water will cause it to become supersaturated with respect to carbonate minerals. The $\delta^{13} \mathrm{C}$ of authigenic carbonates associated with anaerobic oxidation of methane will be low, because the dissolved inorganic carbon (DIC) in porewater from which the carbonate precipitates is a mixture of bottom water carbon (typically, $\delta^{13} \mathrm{C}=-1$ to $1 \%$ ), carbon from the sulfate reduction of organic matter $\left(\delta^{13} \mathrm{C}=-22 \%\right.$, 


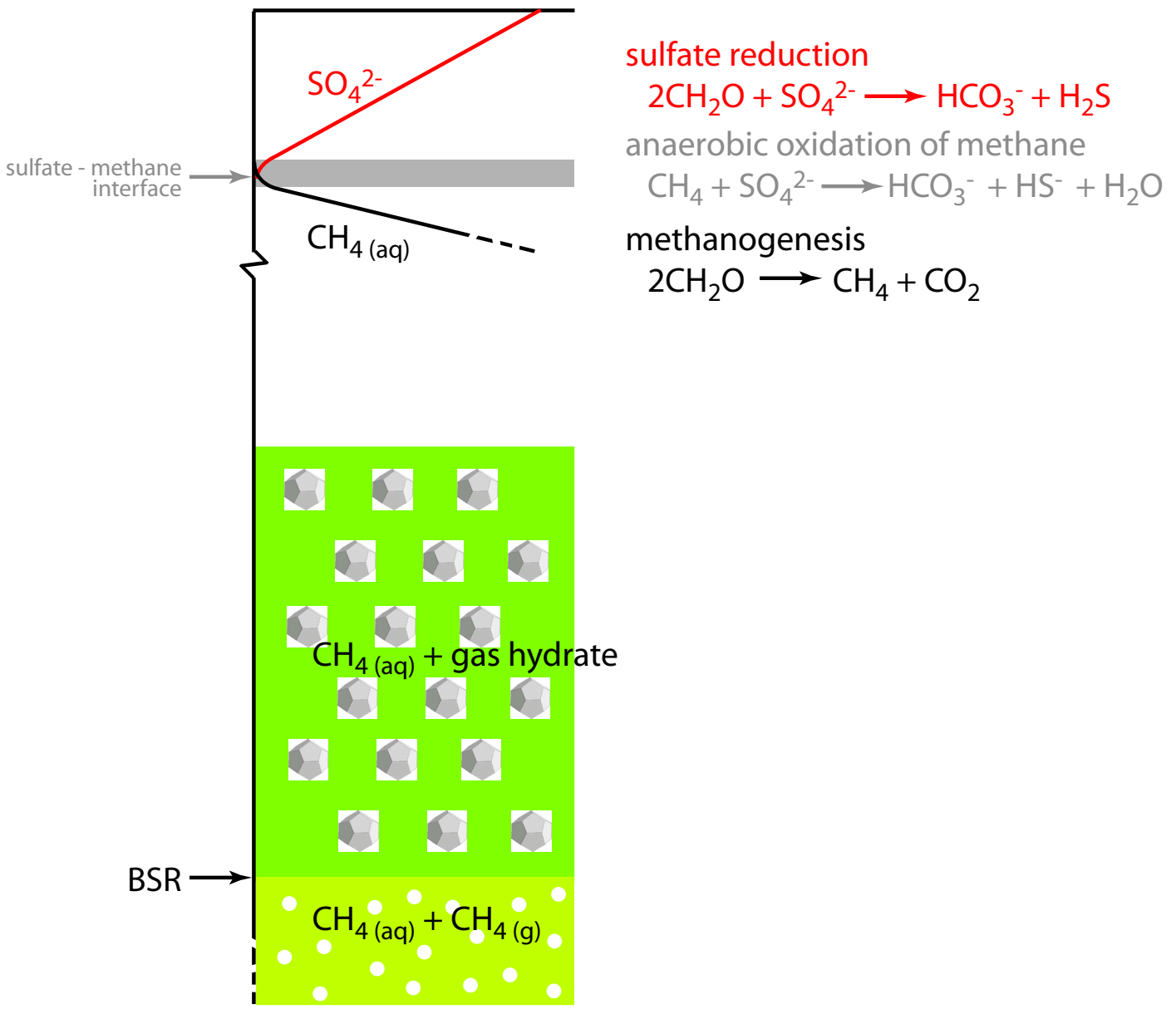

Figure 5-2: Schematic of the sulfate-methane interface, with simplified reactions which occur in the upper sediments. Both sulfate reduction of organic matter and anaerobic oxidation of methane produce $\mathrm{HCO}_{3}^{-}$, which increases the alkalinity of porewater. At the Umnak Plateau, the BSR is at 670 mbsf (meters below seafloor). At the Blake Ridge, another passive margin site with sedimentary methane hydrates off southeastern North America, the sulfate-methane interface is 20-30 mbsf (Hoehler et al., 2000), and the upper limit of hydrates is at $\sim 250 \mathrm{mbsf}$ (Lee, 2000). 
Rau et al. (1982)), and methane-derived carbon $\left(\delta^{13} \mathrm{C}=-110\right.$ to $-50 \%$ ). Depending on the seep rate of $\mathrm{CH}_{4}$, intensity of bioturbation, sediment accumulation rate, and vertical fluid velocity within sediment, the zone of carbonate precipitation can be very near the sedimentwater interface (Luff et al., 2004). At Eel River Basin (off Northern California), Orphan et al. (2004) observed that small dispersed crystals of high-Mg calcite form in sediments with high $\mathrm{CH}_{4}$ flux, and massive crusts composed of high-Mg calcite, aragonite (the highpressure polymorph of $\left.\mathrm{CaCO}_{3}\right)$, and dolomite $\left(\left[\mathrm{Ca}_{0.6}, \mathrm{Mg}_{0.4}\right] \mathrm{CO}_{3}\right)$ form with low $\mathrm{CH}_{4}$ flux. Aragonite, which has a more compact crystal structure, does not easily incorporate Mg. High-Mg calcite has variable $[\mathrm{Mg}] /[\mathrm{Ca}]$ (4-30 mol\% Mg) (Berner, 1975).

Methane seepage from the seafloor is observed to be spatially and temporally heterogeneous (Orphan et al., 2004; Schmidt et al., 2002). Torres et al. (2003) measured $\delta^{13} \mathrm{C}$ in rose-Bengal-stained $U$. peregrina at an active seep site at Hydrate Ridge, off Oregon. They also measured the $\delta^{13} \mathrm{C}$ of the pore water of the sediment in which they were found. Rose Bengal stains proteins in cytoplasm, and is used to identify living or recently-living foraminifera. They discovered that though the $\delta^{13} \mathrm{C}$ of pore water DIC was -48 to $-6 \%$, the foraminifer $\delta^{13} \mathrm{C}$ calcite was -4 to $0 \%$. They hypothesize that the foraminifera prefer to grow during episodes of low $\mathrm{CH}_{4}$ discharge, and the $\delta^{13} \mathrm{C}$ of their tests represents near-surface pore water which is more like the composition of bottom-water. Samples with low $\delta^{13} \mathrm{C}$ also had high $\mathrm{Mg} / \mathrm{Ca}$, which is characteristic of authigenic $\mathrm{CaCO}_{3}$. Torres et al. (2003) thus interpreted the lowest $\delta^{13} \mathrm{C}$ measured in these foraminifera as the result of an overprint of diagenetic carbonates associated with anaerobic oxidation of methane.

In the study by Torres et al. (2003), authigenic overgrowths were not visible with electron microscopy, even though their chemical signature was present. A small amount of diagenetic carbonate could have a measurable effect on $\delta^{13} \mathrm{C}$ and $[\mathrm{Mg}] /[\mathrm{Ca}]$ of a foraminifer sample. This because authigenic minerals have a very different composition than foraminifer calcite; $\delta^{13} \mathrm{C}$ would be the same as pore-water $\delta^{13} \mathrm{C}$ (at this site, -6 to $-48 \%$ ) and $[\mathrm{Mg}] /[\mathrm{Ca}]$ would be 1-3 orders of magnitude higher (further discussion of $\mathrm{Mg}$ in authigenic minerals in Discussion). This explanation could account for the contradictory conclusions of another study conducted on Hydrate Ridge (Hill et al., 2004), where the absence of visible overgrowths lead the authors to conclude that the very low $\delta^{13} \mathrm{C}$ measured in benthic foraminifera reflected the porewater $\delta^{13} \mathrm{C}$.

One disadvantage of using rose Bengal is that cytoplasm can persist in foraminifer tests 
for weeks to months; in low-oxygen environments, it can persist for even longer (Bernhard, 1988). So it is not capable of differentiating living from dead foraminifera. In a study of surface sediments from cold seeps in Monterey Bay, Bernhard et al. (2001) used a technique which marks adenosine triphosphate, which is only present in living cells. They found an assemblage of benthic foraminifera living in the active cold seep which included $U$. peregrina, implying that $U$. peregrina is capable of living in porewater with high methane concentrations. Whether the calcite of the $U$. peregrina test records bottom water $\delta^{13} \mathrm{C}$ or depleted pore-water $\delta^{13} \mathrm{C}$ in areas with active methane seepage remains an open question.

\subsection{Methods}

Core HLY02-02-51JPC was collected in June, 2002, from the eastern Umnak Plateau from a water depth of $1467 \mathrm{~m}$ (See Figure 3-1). The entire core was sampled every $48 \mathrm{~cm}$, and at every $8 \mathrm{~cm}$ from $450-750 \mathrm{~cm}$. Raw sediment samples were dried at $50^{\circ} \mathrm{C}$, then washed with tap water through a $63 \mu \mathrm{m}$ sieve. Planktonic foraminifer Neogloboquadrina pachyderma (sinistral) and benthic foraminifer Uvigerina peregrina were picked from the 150-250 $\mu \mathrm{m}$ and $>250 \mu \mathrm{m}$ size fractions, respectively. Without further cleaning, 8-10 N. pachyderma (s.) and a single $U$. peregrina were analyzed on a Finnigan MAT253 mass spectrometer with a Kiel device (Figure $5-3 \mathrm{~d}-\mathrm{g}$ ). $\quad \delta^{18} \mathrm{O}$ and $\delta^{13} \mathrm{C}$ are reported relative to the PDB standard via NBS-19 following the procedures of Ostermann and Curry (2000).

N. pachyderma (s.) were submitted to the National Ocean Sciences Accelerator Mass Spectrometer Facility at WHOI for AMS ${ }^{14} \mathrm{C}$ analysis. They came from samples where measured planktonic and benthic $\delta^{13} \mathrm{C}$ were not anomalously low (less than -2 permil). The ${ }^{14} \mathrm{C}$ dates (Table 5.1) were calibrated to calendar years using Calib5.0html and the Intcal2004 dataset (Reimer et al., 2004). I assume that $\Delta R$, the local anomaly of the age of surface water from the global mean, is constant at $400 \mathrm{y}$. This corresponds to a total reservoir correction, $R$, of $800 \mathrm{y}$ (see Chapter 2 for a discussion of $\Delta R$ ). I converted the oldest measured ${ }^{14} \mathrm{C}$ date to calendar years by finding the intercept of the measured age with a curve of ${ }^{14} \mathrm{C}$ age versus calendar age $\mathrm{BP}$ of Globigerina bulloides in Cariaco Basin (Hughen et al., 2004a). This record is tuned to GRIP $\delta^{18} \mathrm{O}_{i c e}$ on the ss09sea age model (Johnsen et al., 2001). I construct a simple age model for 51JPC by assuming constant sediment accumulation rates between calibrated ${ }^{14} \mathrm{C}$ ages (Figure 5-3a-b). 


\begin{tabular}{|c|c|c|c|c|}
\hline depth (cm) & ${ }^{14} \mathrm{C}$ y $\mathrm{BP} \pm \sigma$ & cal y BP & ${ }_{-}^{+} \sigma$ & ${ }_{-}^{+2} 2 \sigma$ \\
\hline $134.5-135.5$ & $10,600 \pm 60$ & 11,190 & 11,150 & 11,110 \\
\hline $177.5-178.5$ & $12,500 \pm 60$ & 13,550 & $\begin{array}{l}13,460 \\
13,630\end{array}$ & $\begin{array}{l}13,400 \\
13,710\end{array}$ \\
\hline $241.5-242.5$ & $14,050 \pm 85$ & 15,700 & $\begin{array}{l}15,480 \\
15,890\end{array}$ & $\begin{array}{l}15,310 \\
16,120\end{array}$ \\
\hline $479.5-480.5$ & $18,200 \pm 110$ & 20,537 & $\begin{array}{l}20,360 \\
20,690\end{array}$ & $\begin{array}{l}20,230 \\
20,950\end{array}$ \\
\hline $1102.5-1105.5$ & $33,400 \pm 780$ & 37,980 & & \\
\hline
\end{tabular}

Table 5.1: Uncorrected AMS ${ }^{14} \mathrm{C}$ ages and corrected, calibrated ages if $N$. pachyderma (s.) in HLY02-02-51JPC. Calibrations performed with Calib5.0html (Stuiver et al., 1998) using the Marine04 calibration (Hughen et al., 2004b). I use $\Delta \mathrm{R}=400 \mathrm{y}$, corresponding to a reservoir correction of $800 \mathrm{y}$. I report the median calendar ages with the upper and lower limits of the $\sigma$ and $2 \sigma$ ranges. For the oldest measured ${ }^{14} \mathrm{C}$ ages, I report the intercept of this age with the G. bulloides record from the Cariaco Basin (Hughen et al., 2004a), which is tuned to the GRIP ss09sea age model.

$[\mathrm{Mg}] /[\mathrm{Ca}]$ was measured by ICP-MS in two samples of $N$. pachyderma (s.) consisting of 40 individuals each. The samples underwent a full oxidative and reductive cleaning procedure in order to remove clay, metal oxides, and organic matter following the procedure of Boyle and Keigwin (1985) (with revisions by Rosenthal et al. (1995) and Boyle and Rosenthal (1996)). The only deviation from this protocol is that sonication during the final, weak-acid leach was skipped because of the fragility of the samples. Since [Ca] measured in the samples was different than that of the standard, these two data points were corrected for the matrix effect of [Ca] (K. Dahl, R. Came, unpublished data).

\subsection{Results}

We find large negative excursions in $\delta^{13} \mathrm{C}$ of both $N$. pachyderma (s.) (as low as $-13 \%$ ) and $U$. peregrina (as low as $-6.8 \%$ ). The $\delta^{13} \mathrm{C}$ of $N$. pachyderma (s.) exhibit very large negative excursions ( $\ll-2 \%$, the thin, grey, dashed line in Figure $5-3)$ at $520-552 \mathrm{~cm}, 600-624 \mathrm{~cm}$ and $672-704 \mathrm{~cm}$. These intervals are denoted by vertical grey bars in the Figure. The mean $\delta^{18} \mathrm{O}$ and $\delta^{13} \mathrm{C}$ of $U$. peregrina in the interval $450-750 \mathrm{~cm}$ is calculated, excluding samples which lie within the vertical grey bars. These values are shown in orange in Figure 5-3, and will be regarded as "typical" MIS3 values to compare the isotopic excursions to $(-1.39 \%$ for $\delta^{13} \mathrm{C}$ and $4.86 \%$ for $\left.\delta^{18} \mathrm{O}\right)$. 


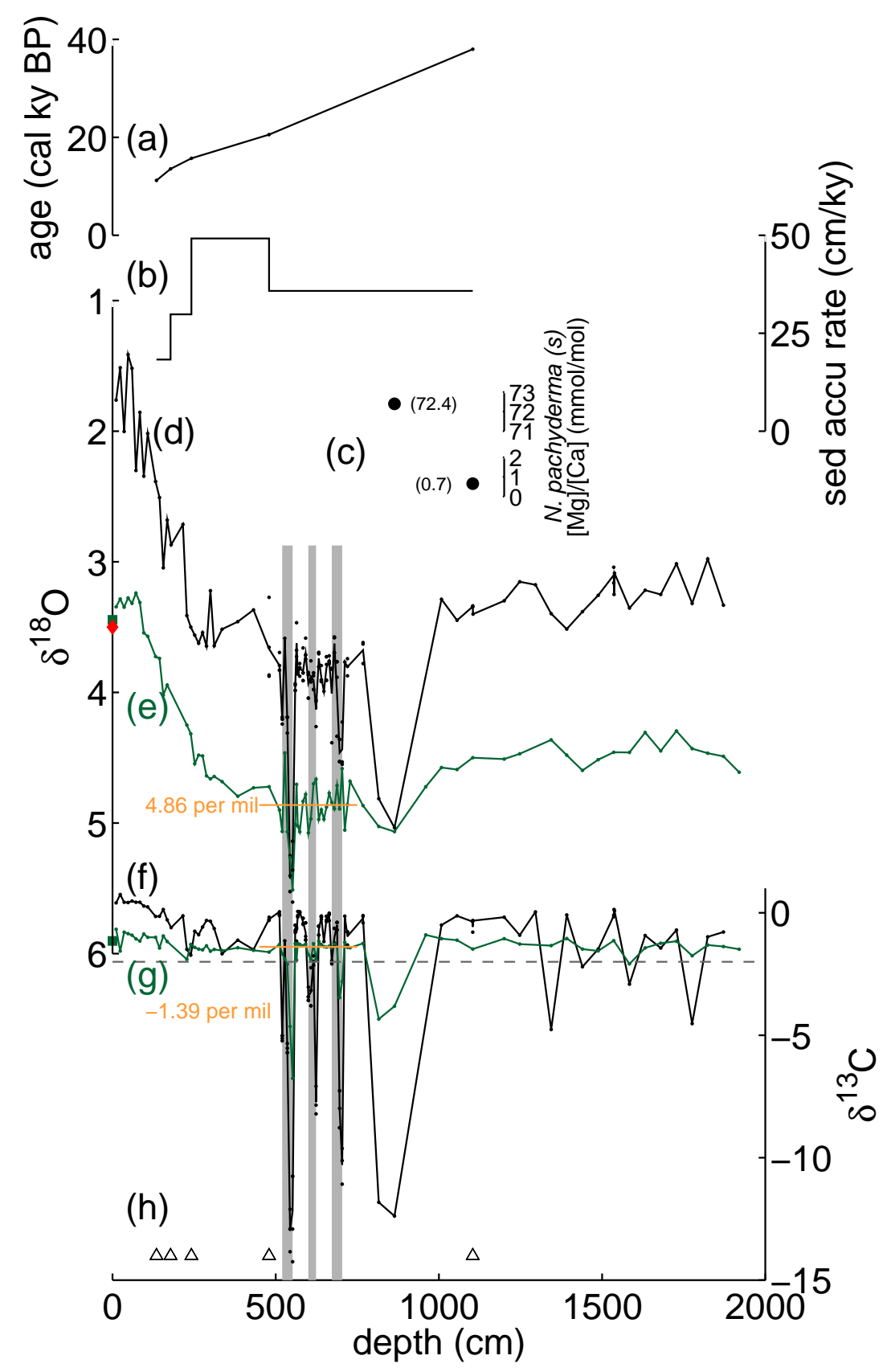

Figure 5-3: (a) The age model assumes linear sediment accumulation rate between radiocarbon dates measured on $N$. pachyderma (s.), which were calibrated to calendar years using $\Delta R=400$, corresponding to a reservoir age of surface water, $R=800$. (b) Sediment accumulation rate in $\mathrm{cm} / \mathrm{ky}$. (c) $[\mathrm{Mg}] /[\mathrm{Ca}]$ ratio measured in $N$. pachyderma (s.) in two samples. (d)-(e) N. pachyderma (s.) (black) and U. peregrina (green) points are individual $\delta^{18} \mathrm{O}$ measurements. Lines connect the mean of the points measured in each sample. The green squares on the y-axis are from a rose-Bengalstained $U$. peregrina from the top of the companion multicore at this coring site. The red diamond is the equilibrium $\delta^{18} \mathrm{O}$ calculated from the $T=2.20^{\circ} \mathrm{C}$ and $S=34.50 \%$ using Equation 3.4. These are the values interpolated for the water column at the depth of this core, $1467 \mathrm{~m}$, from hydrocasts conducted during the same cruise. (unpublished data courtesy of D. McCorkle). Thus, U. peregrina appears to calcify at approximately the equilibrium calcite value. (f) $-(\mathrm{g}) \delta^{13} \mathrm{C}$ measurements. Colors are the same as for $\delta^{18} \mathrm{O}$. The grey dashed line is $\delta^{13} \mathrm{C}=-2$. The grey vertical bars denote the three depth intervals where I have high-resolution samples in which $\delta^{13} \mathrm{C}$ of $N$. pachyderma (s.) falls below this line. In (e) and (g), respectively, the orange lines are the mean $U$. peregrina $\delta^{18} \mathrm{O}$ and $\delta^{13} \mathrm{C}$ outside these events. (h) Location of ${ }^{14} \mathrm{C}$ dates. ${ }^{77}$ 


\begin{tabular}{ccccccc}
\hline $\begin{array}{c}\text { depth } \\
(\mathrm{cm})\end{array}$ & $\#$ & $\begin{array}{c}\text { mass } \\
(\mu \mathrm{g})\end{array}$ & $\begin{array}{c}\text { mean mass } \\
(\mu \mathrm{g})\end{array}$ & $\begin{array}{c}{[\mathrm{Mg}] /[\mathrm{Ca}]} \\
(\mathrm{mmol} / \mathrm{mol})\end{array}$ & $\begin{array}{c}\delta^{13} \mathrm{C} \\
(\% 0)\end{array}$ & $\begin{array}{c}\delta^{18} \mathrm{O} \\
(\% 0)\end{array}$ \\
\hline 864 & 40 & 212 & 5.3 & 71.7 & -12.39 & 5.04 \\
1104 & 40 & 97 & 2.4 & 0.65 & -0.56 & 3.34 \\
\hline
\end{tabular}

Table 5.2: Two samples in which $N$. pachyderma (s.) was analyzed for $[\mathrm{Mg}] /[\mathrm{Ca}]$ with ICPMS. These values are corrected for the matrix effect of $[\mathrm{Ca}] . \delta^{18} \mathrm{O}$ and $\delta^{13} \mathrm{C}$ are the mean values measured in N. pachyderma (s.) in that sample.

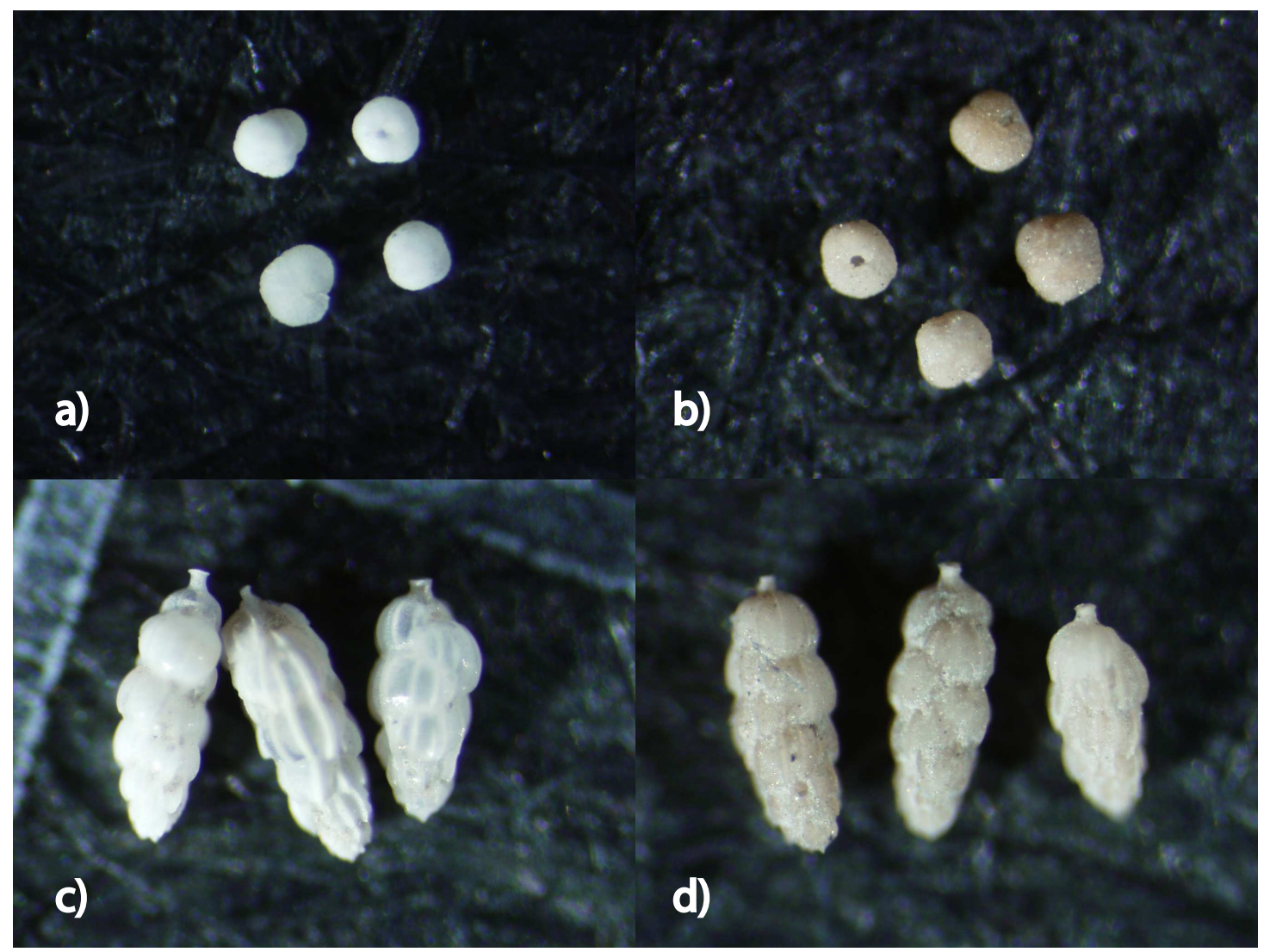

Figure 5-4: a) and c) N. pachyderma (s.) and U. peregrina from the sample at $720 \mathrm{~cm}$ (without overgrowth); b) and d) N. pachyderma (s.) and U. peregrina from the sample at $816 \mathrm{~cm}$ (with overgrowth). The width of the field of view in each panel is $500 \mu \mathrm{m}$. Note that the tests with overgrowths are yellowish. The $N$. pachyderma (s.) from the sample with overgrowth are noticably larger, and authigenic material fills the space between the costae of the $U$. peregrina tests. 


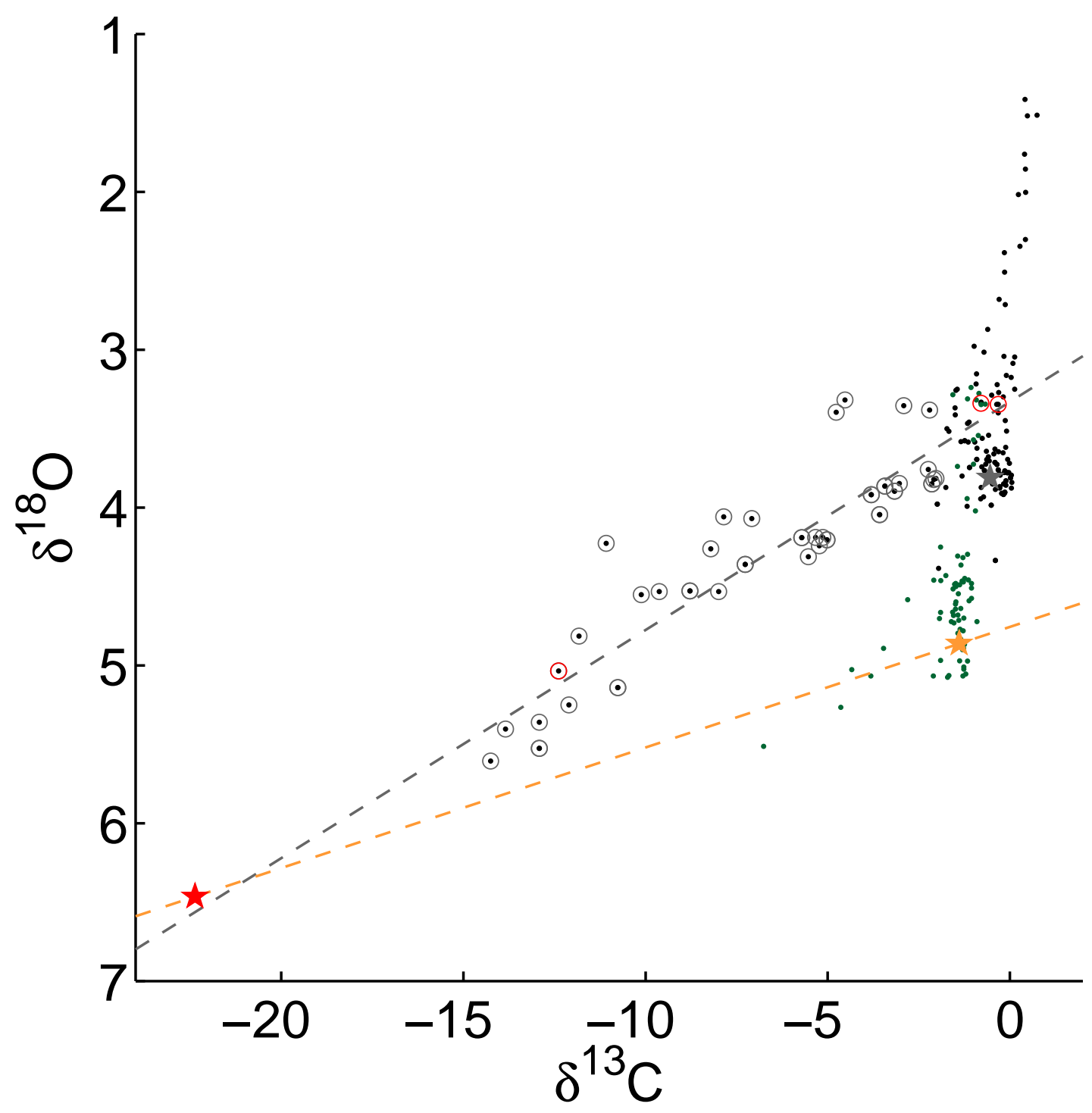

Figure 5-5: HLY02-02-51JPC N. pachyderma (s.) (black) and U. peregrina (green) stable isotope data. Circled N. pachyderma (s.) data have measured $\delta^{13} \mathrm{C}$ less than -2 . I interpret these low $\delta^{13} \mathrm{C}$ values as the signature of authigenic carbonate overgrowths. The dashed grey line is a least-squares fit to the circled points. I hypothesize that this is a mixing line between $100 \%$ glacial foraminifer calcite and $100 \%$ carbonate overgrowth $\mathrm{CaCO}_{3}$. The red star is an estimate of the composition of authigenic carbonate based on linear end-member mixing using the samples circled in red (see text for details). The mean $\delta^{13} \mathrm{C}$ and $\delta^{18} \mathrm{O}$ of samples without low $\delta^{13} \mathrm{C}$ from within the high-resolution sampling interval are marked by stars, grey for $N$. pachyderma (s.) and orange for $U$. peregrina. The orange line is the linear mixing line between the red and orange stars. 


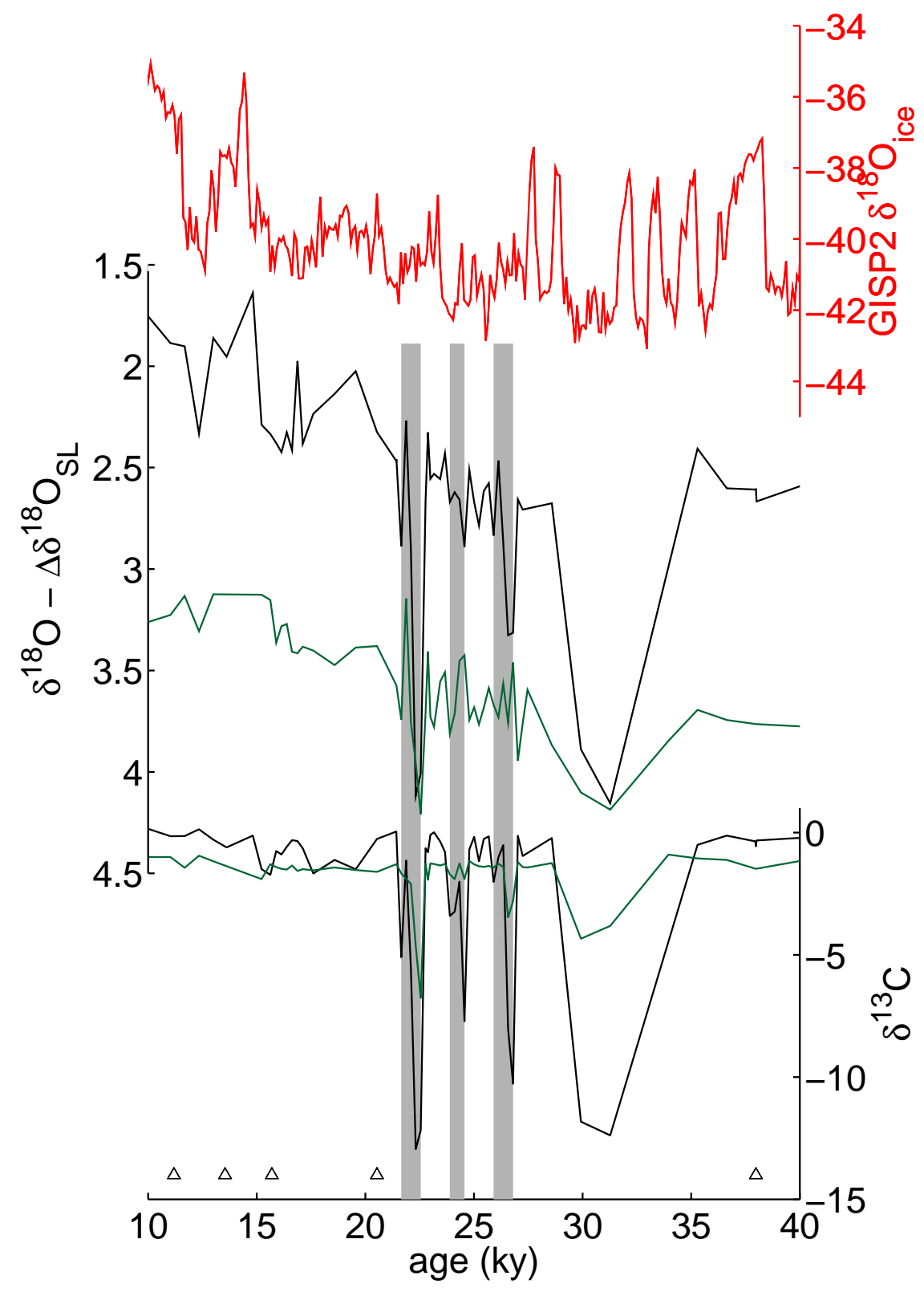

Figure 5-6: HLY02-02-51JPC data plotted against age. Black trianges indicate samples where I measured radiocarbon dates on $N$. pachyderma (s.). Data in black are of N. pachyderma (s.), data in green are $U$. peregrina. The lines are the mean value for each sample. The mean-ocean $\delta^{18} \mathrm{O}$ change due to changing global ice volume is subtracted from the measured $\delta^{18} \mathrm{O}$ record (Waelbroeck et al., 2002). $\delta^{18} \mathrm{O}_{i c e}$ in the GRIP ice core (ss09sea age model) is in red. 


\subsection{Discussion}

\section{The composition of authigenic carbonate overgrowths}

Upon visual inspection, the planktonic foraminifera in the samples with low planktonic $\delta^{13} \mathrm{C}$ appear yellowish (Figure 5-4). In the interval where I sampled closely ( $8 \mathrm{~cm}$ resolution), I defined three episodes with anomalously low $\delta^{13} \mathrm{C}$, each of which is less than $1000 \mathrm{y}$ in duration, according to the preliminary age model. In Figure 5-5, N. pachyderma (s.) $\delta^{13} \mathrm{C}$ less than $-2 \%$ are circled, and a linear least-squares fit is applied through the circled points.

$$
\delta^{18} \mathrm{O}=-0.145 \delta^{13} \mathrm{C}+3.33 \quad\left(n=47 ; r^{2}=0.826 ; p<10^{-4}\right)
$$

This line has a negative slope, indicating that low $\delta^{13} \mathrm{C}$ is correlated with high $\delta^{18} \mathrm{O}$.

We measured $[\mathrm{Mg}] /[\mathrm{Ca}]$ in $N$. pachyderma (s.) in a sample with low $\delta^{13} \mathrm{C}(864 \mathrm{~cm})$, and a sample with $\delta^{13} \mathrm{C}$ with the range expected for Quaternary benthic foraminifera $(1104 \mathrm{~cm})$ (see Figure 5-3c and Table 5.2). In typical Quaternary sediments, foraminifer $[\mathrm{Mg}] /[\mathrm{Ca}]$ is 1-10 mmol/mol (Rosenthal et al., 1999), and the data from a sample at $1104 \mathrm{~cm}$ falls close to this range $(0.7 \mathrm{mmol} / \mathrm{mol})$. At $864 \mathrm{~cm}$, a sample in which mean $\delta^{13} \mathrm{C}$ of $N$. pachyderma (s.) is $-12.4 \%$, measured $[\mathrm{Mg}] /[\mathrm{Ca}]$ is 2 orders of magnitude greater $(71.7 \mathrm{mmol} / \mathrm{mol})$. The mass of an average $N$. pachyderma (s.) in this sample is $5.3 \mu \mathrm{g}$, whereas in the sample at $1104 \mathrm{~cm}$, the average mass is $2.4 \mu \mathrm{g}$.

Not all benthic foraminifera in samples with evidence of authigenic carbonates have visual overgrowth like $N$. pachyderma (s.). It may be that the high surface area of a planktonic foraminifer test is more likely to accomodate contamination by small crystals of authigenic carbonate than the imperforate test of $U$. peregrina. For the moment, I assume that $U$. peregrina did not grow during times of active $\mathrm{CH}_{4}$ seeping and authigenic carbonate formation (as in the situation described by Torres et al. (2003)), and that the low $\delta^{13} \mathrm{C}$ measured in $U$. peregrina is also the result of contamination by authigenic carbonates which occurred after the foraminifer calcified its test.

We consider a simple model to explain the observed isotopic and chemical composition of the foraminfer tests. In this model, the isotopic or minor element composition of foraminifer tests contaminated with authigenic carbonates falls on a linear mixing curve between the compositions of primary test calcite and authigenic carbonate (Schmidt et al., 2002; Orphan 
et al., 2004)

$$
\begin{aligned}
& \delta^{18} \mathrm{O}_{\text {meas }}=\delta^{18} \mathrm{O}_{\text {foram }} \phi+\delta^{18} \mathrm{O}_{\text {auth }}(1-\phi) \\
& \delta^{13} \mathrm{C}_{\text {meas }}=\delta^{13} \mathrm{C}_{\text {foram }} \phi+\delta^{13} \mathrm{C}_{\text {auth }}(1-\phi)
\end{aligned}
$$

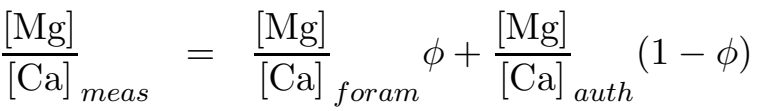

where $\phi$ is the fraction of the mass of a sample that is foraminifera $\mathrm{CaCO}_{3}$.

We can estimate the composition of the authigenic carbonate crust using the $\delta^{18} \mathrm{O}$, $\delta^{13} \mathrm{C}$, and $[\mathrm{Mg}] /[\mathrm{Ca}]$ measurements on the two samples of $N$. pachyderma (s.) in Table 5.2. I assume that the two samples, which are each composed of 40 individual $N$. pachyderma (s.) have the same mass of primary foraminifer calcite with the same $\delta^{13} \mathrm{C}, \delta^{18} \mathrm{O}$, and $[\mathrm{Mg}] /[\mathrm{Ca}]$, i.e., that the only difference between the two samples is that the sample from $864 \mathrm{~cm}$ has authigenic calcite added to it. Then the sample at $1104 \mathrm{~cm}$ is $100 \%$ foram calcite and the fraction foraminifer calcite in the sample from $864 \mathrm{~cm}$ is $\phi=\frac{97 \mu \mathrm{g}}{212 \mu \mathrm{g}}=46 \%$. Data from the two samples are circled in red in Figure 5-5. With $[\mathrm{Mg}] /[\mathrm{Ca}]_{\text {meas }}=71.7 \mathrm{mmol} / \mathrm{mol}$, and $[\mathrm{Mg}] /[\mathrm{Ca}]_{\text {foram }}=0.65 \mathrm{mmol} / \mathrm{mol}$ (Table 5.2 ), I can then apply Equation 5.6 to find $[\mathrm{Mg}] /[\mathrm{Ca}]_{\text {auth }}$ :

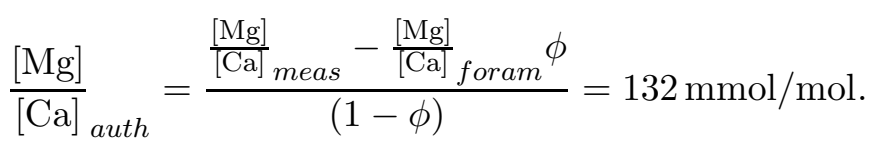

Similarly, with $\delta^{13} \mathrm{C}_{\text {meas }}=-12.39 \%$, and $\delta^{13} \mathrm{C}_{\text {foram }}=-0.56 \%$ (the mean of two measurements) (Table 5.2), I can apply Equation 5.5 to find $\delta^{13} \mathrm{C}_{\text {auth }}$ :

$$
\delta^{13} \mathrm{C}_{\text {auth }}=\frac{\delta^{13} \mathrm{C}_{\text {meas }}-\delta^{13} \mathrm{C}_{\text {foram }} \phi}{(1-\phi)}=-22.37 \%
$$

With $\delta^{18} \mathrm{O}_{\text {meas }}=5.04 \%$, and $\delta^{13} \mathrm{C}_{\text {foram }}=3.34 \%$ (the mean of two measurements) (Table 5.2), I can apply Equation 5.4 to find $\delta^{18} \mathrm{O}_{a u t h}$ :

$$
\delta^{18} \mathrm{O}_{\text {auth }}=\frac{\delta^{18} \mathrm{O}_{\text {meas }}-\delta^{18} \mathrm{O}_{\text {foram }} \phi}{(1-\phi)}=6.46 \%
$$

These values of $\delta^{13} \mathrm{C}_{\text {auth }}$ and $\delta^{18} \mathrm{O}_{\text {auth }}$ are plotted as a red star in Figure 5-5. The theoretical mixing line for benthic foraminifer connects the authigenic carbonate end member to the mean benthic $\delta^{13} \mathrm{C}$ and $\delta^{18} \mathrm{O}$ in samples from $450-740 \mathrm{~cm}$ excluding those pertaining to low $\delta^{13} \mathrm{C}$ events (illustrated in orange in Figure 5-3e-g). The few benthic data scatter near this 
theoretical mixing line, which is an encouraging sign that this model is reasonable.

In calculating these mixing lines, I assume that the composition of the authigeniccarbonate and foraminifer-calcite end members during each separate episode were identical, which may not have been the case. Variability in these end members from event to event could account for some of the scatter in the data.

The estimate of $[\mathrm{Mg}] /[\mathrm{Ca}]$ of overgrowth could be affected by the cleaning procedure for ICP-MS analysis (the same chemical cleaning procedure is not applied to samples before analyzing for $\delta^{13} \mathrm{C}$ and $\delta^{18} \mathrm{O}$ ). Fifty percent and $95 \%$ of the initial mass of the samples at $864 \mathrm{~cm}$ and $1104 \mathrm{~cm}$ were lost, respectively, during cleaning. For this procedure, loss of 50\% of the mass of a sample is considered typical. If the authigenic carbonate is more susceptible to loss, then authigenic $[\mathrm{Mg}] /[\mathrm{Ca}]$ is underestimated (it could be as low as $72 \mathrm{mmol} / \mathrm{mol}$ ). If the foraminifer calcite is more suceptible to loss, then authigenic $[\mathrm{Mg}] /[\mathrm{Ca}]$ is overestimated (it could be as high as $837 \mathrm{mmol} / \mathrm{mol}$ ). High-Mg calcite and aragonite are more soluble than pure calcite. However, in porewater that is undersaturated with respect to each of these minerals, the phase most suceptible to dissolution may be a function of the kinetics of dissolution rather than thermodynamic stability; if crystals of the less soluble mineral have a higher ratio of surface area to volume, they may actually dissolve sooner.

With the data available, I can not determine the relative contribution of sulfate reduction of organic matter and anaerobic methane oxidation to the formation of the authigenic minerals. The estimate of the $\delta^{13} \mathrm{C}$ of carbonate overgrowths, $-22.4 \%$, can be solely a product of $\mathrm{C}_{\text {org }}$ degradation by sulfate reduction (Equation 5.2), which also raises alkalinity of porewater, without the need to invoke methanotrophy. In this case, nearly all the DIC in the porewater could be from reduction of marine organic matter. The porewater DIC of $-22.4 \%$ could also be a combination of seawater DIC $\left(\delta^{13} \mathrm{C}=-1\right.$ to $\left.1 \%\right)$, sulfate reduction of organic matter $\left(\delta^{13} \mathrm{C}=-22 \%\right.$, Rau et al. (1982)), and methane-derived carbon $\left(\delta^{13} \mathrm{C}=\right.$ -110 to $-50 \%$ ). One test of the relative contribution of these two processes would be to measure the $\Delta^{14} \mathrm{C}$ of the overgrowth. Carbon from sedimentary methane would be ${ }^{14} \mathrm{C}$-free, but fresh organic matter contains the same ${ }^{14} \mathrm{C}$ as surface water.

The mixing line between benthic foraminifer data points and the estimated concentration of authigenic carbonate (the orange dashed line in Figure 5-5) was calculated assuming that the benthic foraminifera did not grow during active $\mathrm{CH}_{4}$ seeping and carbonate formation, and that the $\delta^{13} \mathrm{C}$ of its shell is that of a typical benthic foraminifer. At modern $\mathrm{CH}_{4}$ seep 
sites, the upward flux of $\mathrm{CH}_{4}$-rich porewater and associated authigenic carbonate formation is observed to be very localized and spatially and temporally heterogeneous (Orphan et al., 2004; Schmidt et al., 2002), so that the sedimentary record of a $\sim 1000$ y episode of $\mathrm{CH}_{4}$ degassing at one site may record multiple episodes of active $\mathrm{CH}_{4}$ venting and quiesence. So if this were the case at the $51 \mathrm{JPC}$ core site, the primary calcite $\delta^{13} \mathrm{C}$ may record a $\delta^{13} \mathrm{C}$ of pore water during an episode without active methane seeping, when the foraminifera are more likely to grow. And during an episode of $\mathrm{CH}_{4}$ venting, the authigenic carbonate would form with a lower pore water $\delta^{13} \mathrm{C}$.

The theoretical $\delta^{18} \mathrm{O}$ of authigenic carbonate is $1.6 \%$ higher than mean $\delta^{18} \mathrm{O}$ of $U$. peregrina measured outside low $\delta^{13} \mathrm{C}$ events in samples 450-750 cm. According to Equation 3.1 (Chapter 3), U. peregrina calcifies near equilibrium today. The higher $\delta^{18} \mathrm{O}$ of the authigenic carbonate could be from 1) a change in porewater $\left.\delta^{18} \mathrm{O}, 2\right)$ a thermodynamic effect, such as change in temperature, or a difference in the mineralogy between the overgrowth and the foraminifer calcite, and/or 3) a kinetic effect, where the $[\mathrm{Mg}]$ of the porewater and/or authigenic calcite affects growth rate and incorporation of oxygen isotopes (Berner, 1975; Tarutani et al., 1969).

The porewater $\delta^{18} \mathrm{O}$ is conceivably influenced by oceanic basalt at the bedrock-sediment interface and the numerous ash layers in this sediment core from nearby Aleutian back-arc volcanics. However, fluids which have circulated through these volcanic rocks have low $\delta^{18} \mathrm{O}$, and could not account for the anomalously high $\delta^{18} \mathrm{O}$ of authigenic minerals. The $\delta^{18} \mathrm{O}$ of water in $\mathrm{CH}_{4}$ hydrates is enriched by $\sim 3 \%$ (Matsumoto and Borowski, 2000). The presence of water from the decomposition of hydrates could account for some part of the enrichment of pore water $\delta^{18} \mathrm{O}$ and authigenic minerals. But it probably does not account for all of it; a $1.6 \%$ enrichment requires the pore water to be $50 \%$ hydrate water.

The mineralogy of the overgrowths in this core is unknown, but in modern cold seeps, the authigenic minerals can be composed of high-Mg calcite, aragonite and/or dolomite (Luff et al., 2004). The fractionation of oxygen isotopes as a function of temperature has been determined experimentally by Kim and O'Neil (1997) for calcite (at 10-40²), by Kim et al. (2004) for aragonite (at 5-40 C), and by Fritz and Smith (1970) for dolomite 


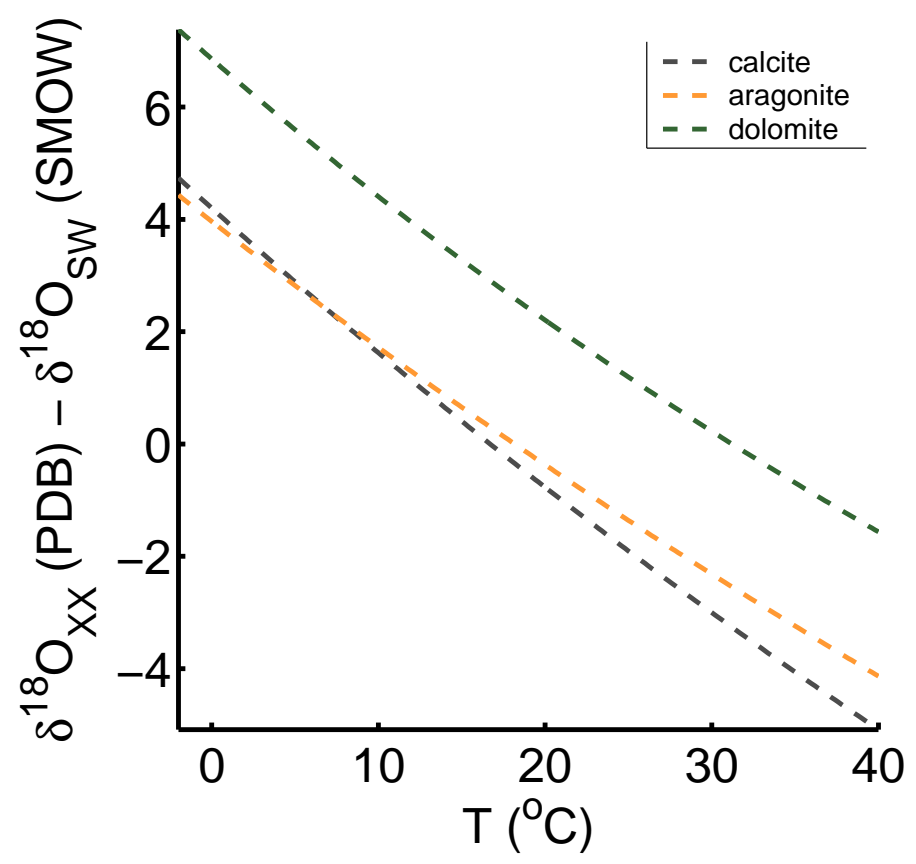

Figure 5-7: In grey is the equilibrium $\delta^{18} \mathrm{O}$ of calcite as a function of temperature (if $[\mathrm{Ca}]_{0}=10 \mathrm{mM}$, see Chapter 2 for discussion) (Kim and O'Neil, 1997). In orange is the equilibrium $\delta^{18} \mathrm{O}$ of aragonite (Kim et al., 2004). At low temperatures, these two curves are very similar. In green is equilibrium $\delta^{18} \mathrm{O}$ of dolomite $\left(\left[\mathrm{Ca}_{60}, \mathrm{Mg}_{40}\right] \mathrm{CO}_{3}\right)$ (Fritz and Smith, 1970). 
$\left(\left[\mathrm{Ca}_{60} \mathrm{Mg}_{.40}\right] \mathrm{CO}_{3}\right.$, at $\left.25-79^{\circ} \mathrm{C}\right)$. The fractionation factors, $\alpha_{\left(\mathrm{XX}-\mathrm{H}_{2} \mathrm{O}\right)}$

$$
\alpha_{\left(\mathrm{XX}-\mathrm{H}_{2} \mathrm{O}\right)}=\frac{\left(\frac{18 \mathrm{O}}{16}\right)_{\mathrm{XX}}}{\left(\frac{18 \mathrm{O}}{16 \mathrm{O}}\right)_{\mathrm{H}_{2} \mathrm{O}}}
$$

are

$$
\begin{gathered}
\left.1000 \ln \alpha_{\left(\text {calcite }-\mathrm{H}_{2} \mathrm{O}\right.}\right)=17.32 \times 10^{3} T^{-1}-29.00 \\
\left.1000 \ln \alpha_{\left(\text {aragonite }-\mathrm{H}_{2} \mathrm{O}\right.}\right)=19.87 \times 10^{3} T^{-1}-39.09 . \\
\left.1000 \ln \alpha_{\left(\text {dolomite }-\mathrm{H}_{2} \mathrm{O}\right.}\right)=2.62 \times 10^{6} T^{-2}+2.17
\end{gathered}
$$

and are plotted in Figure 5-7, where all three curves are extrapolated to temperatures down to $-2^{\circ} \mathrm{C}$. At low temperatures, the $\delta^{18} \mathrm{O}$ of aragonite and calcite are very similar, but dolomite $\delta^{18} \mathrm{O}$ is on average $2.6 \%$ higher. The presence of authigenic dolomite in the overgrowths could account for its enriched $\delta^{18} \mathrm{O}$. The $[\mathrm{Mg}] /[\mathrm{Ca}]$ of dolomite is $667 \mathrm{mmol} / \mathrm{mol}$, which falls in the upper range of $[\mathrm{Mg}] /[\mathrm{Ca}]$ I estimated possible for the overgrowths $(72-$ $837 \mathrm{mmol} / \mathrm{mol})$.

In 51JPC $(1467 \mathrm{~m})$, benthic $\delta^{18} \mathrm{O}$ changes from $4.9 \%$ (mean glacial value for individuals not affected by authigenic overgrowths) to $3.5 \%$ (modern, from a rose-Bengal stained individual from the coretop) (see Figure 5-3). If the glacial-interglacial change in deep-water $\delta^{18} \mathrm{O}_{\mathrm{H}_{2} \mathrm{O}}$ is $-1.1 \%$ (Schrag et al., 2002), the additional $0.3 \%$ decrease, if entirely due to temperature, means that the deep water at this site was $1.1^{\circ} \mathrm{C}$ cooler (with Equation 3.2). Today, the bottom water at this coring site is $2.2^{\circ} \mathrm{C}$ (D. McCorkle, unpublished data). From the equation of state of seawater (Fofonoff, 1985) and estimates of temperature, salinity and pressure at the coring site, the freezing point at the sediment-water interface at this site was $-2.9^{\circ} \mathrm{C}$ at MIS3 (taking into account lower sea level). So the maximum cooling physically possible during MIS3 is $[(2.2-1.1)-(-2.9)]=4^{\circ} \mathrm{C}$. If the $1.6 \%$ enrichment of $\delta^{18} \mathrm{O}$ was entirely due to temperature, it would be a $5.7^{\circ} \mathrm{C}$ cooling (Equation 3.2 ). Therefore, theoretically, an inexplicable cooling of bottom water during these isotopic events could account for some, but not all of the enriched $\delta^{18} \mathrm{O}$. Adkins et al. (2002) estimate the glacial deep Pacific ocean (at ODP1123, at $3290 \mathrm{~m}$ water depth) temperature to be $2.5 \pm 0.5^{\circ} \mathrm{C}$ colder than today.

Finally, kinetic factors affect the $\delta^{18} \mathrm{O}$ of carbonate minerals. Berner (1975) found that calcite which precipitates inorganically from seawater contains $2-7 \mathrm{~mol} \% \mathrm{Mg}(20-$ 


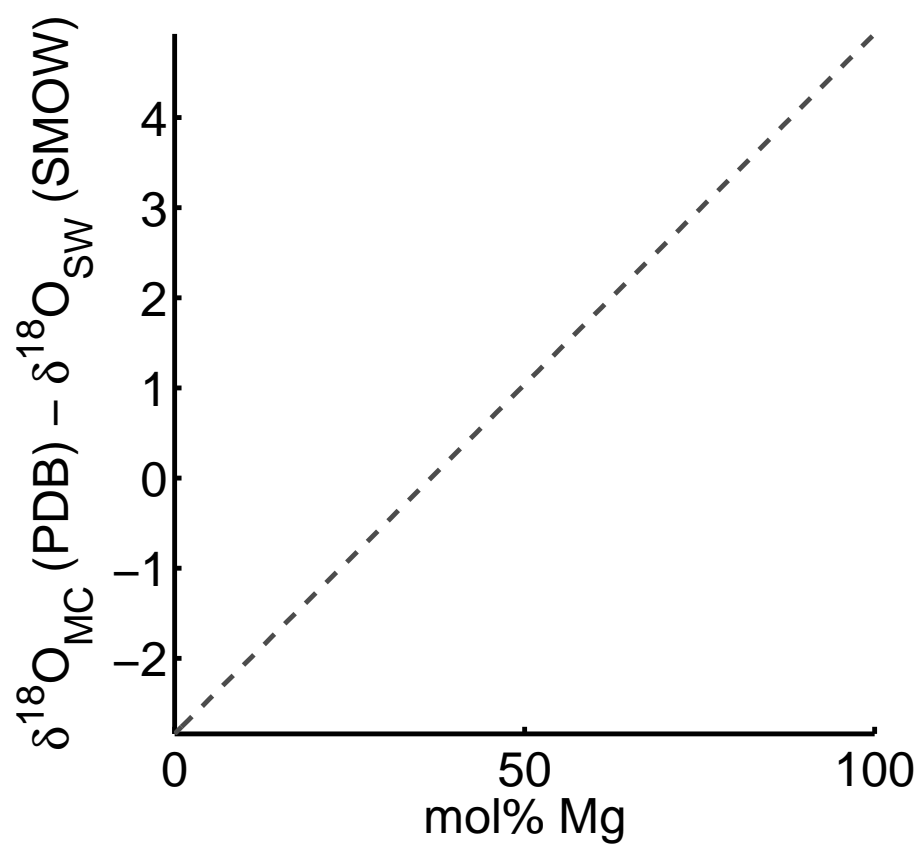

Figure 5-8: The expected change in $\delta^{18} \mathrm{O}$ of magnesian calcite as a function of $\mathrm{mol} \% \mathrm{Mg}$ (empirical relationship from Tarutani et al. (1969)).

$75 \mathrm{mmol} / \mathrm{mol}$ ). As $\mathrm{Mg}$ is incorporated into the calcite crystal lattice, it causes the growth surface to have higher solubility than pure calcite, and this retards the growth rate. The $\delta^{18} \mathrm{O}$ of the Mg-containing (magnesian) calcite is also affected, where

$$
1000 \ln \alpha_{\left(\mathrm{MC}-\mathrm{H}_{2} \mathrm{O}\right)}=0.0776 m+27.61
$$

where MC is magnesian calcite, and $m$ is the mol\% $\mathrm{Mg}$ of the MC (Tarutani et al. (1969), experiment conducted at $25^{\circ} \mathrm{C}$ ). This relationship is nearly linear, where $\delta^{18} \mathrm{O}$ increases $0.078 \%$ for every $1 \mathrm{~mol} \% \mathrm{Mg}$ increases (Figure 5-8). If I assume the overgrowth is all magnesian calcite, and I use the estimate of the $[\mathrm{Mg}] /[\mathrm{Ca}]$ of the overgrowth, the expected enrichment of $\delta^{18} \mathrm{O}$ (using Equation 5.7) is $0.9 \%$ (0.5-3.5\%o). Enrichment of $\delta^{18} \mathrm{O}$ associated with magnesian calcite could also account for some, but not all of the high $\delta^{18} \mathrm{O}$ of the overgrowths.

In summary, the high $\delta^{18} \mathrm{O}$ of the authigenic minerals could be accounted for if the minerals are composed of high-Mg calcite and/or dolomite. The presence of hydrate-derived water would also increase the $\delta^{18} \mathrm{O}$. 


\section{The souce of methane}

If the authigenic minerals are associated with a greater flux of methane to the surface sediments, this raises a quandary. The coring site of 51JPC is so cold and deep, that destabilization of methane hydrates at this site would require an unrealistic warming $\left(15^{\circ} \mathrm{C}\right)$ or sea-level drop $(-1100 \mathrm{~m})$. However, methane can be transported within the hydrate stability zone if (1) the concentration is not high enough to form hydrate or (2) there is a kinetic barrier to the formation of hydrate. Brewer et al. (1998) showed that methane gas released into seawater (at pressure and temperature conditions within the hydrate stability zone) formed a crust of hydrate around the periphery of the bubble, isolating the gas in the interior of the bubble from the seawater, and slowing the hydrate formation. The positive buoyancy of the bubble then would move it upward. In the Black Sea, there are active methane seeps observed within the hydrate stability zone (Klaucke et al., 2005). There may be processes active at the Umnak Plateau in the past which, like in the Black Sea, mobilize methane and transported to the sediment-water interface, but at this time, this is highly speculative, and if the minerals are indeed associated with methane, it is a mystery what the processes was.

\section{Climate implications}

According to the preliminary age model, the duration of each of the three episodes of low $\delta^{13} \mathrm{C}$ was less than $1000 \mathrm{y}$, and the events appeared to be spaced greater than $1000 \mathrm{y}$ apart. Though the age model is too preliminary to show if the events in the core coincide chronologically with Dansgaard-Oeschger (DO) events, they appear to have similar duration and timing. If these episodes coincide with DO events, then it supports the part of the hypothesis of Kennett et al. (2003), that sedimentary methane hydrates interact with the climate system on short timescales. However, the mechanism proposed by those investigators can not explain the presence of methane in a coring site that is as deep and cold as 51JPC.

\subsection{Conclusions and Future Work}

We find evidence of authigenic carbonates with low $\delta^{13} \mathrm{C}$, high $\delta^{18} \mathrm{O}$, and high $[\mathrm{Mg}] /[\mathrm{Ca}]$ which occur during MIS3 in a core from $1500 \mathrm{~m}$ from the Umnak Plateau region. These overgrowths may be associated with anaerobic oxidation of methane. Future work includes 
sampling the rest of this core at high resolution and improving the age model. I will also measure bulk $\mathrm{C}_{\text {org }} \delta^{13} \mathrm{C}$ and the concentration and $\delta^{13} \mathrm{C}$ of biomarkers of anaerobic and aeorobic methanotrophy, if present during these events. These measurements will help to elucidate whether methane was involved in the formation of the minerals, and if so, what the origin of the methane might have been. I will also make the same measurements in a shallower core, from within the water depths where fluctuations of water temperature have the potential to affect the stability of sedimentary gas hydrates. 


\section{Chapter 6}

\section{Summary}

The main contribution of this thesis is that it expands the geographic range of highresolution paleoceanographic observations to the far-North Pacific. In Cook et al. (2005) (Chapter 2 of the thesis), I reported the preliminary stratigraphic data from new sediment cores collected during HLY02-02 in the Bering Sea. The most important findings reported in this paper are (1) that there are sites in the Bering Sea with high sediment accumulation rate and good calcium carbonate preservation, (2) that laminated and dysoxic sediments accumulated at intermediate depths, and (3) that there are rapid (occurring in less than 220 y) $0.7-0.8 \%$ decreases in $N$. pachyderma (s.) $\delta^{18} \mathrm{O}$ during the deglaciation.

In Chapter 3, I present high-resolution stratigraphic and faunal data of the deglaciation from two Bering Sea cores, one from the Bering Slope and one from Bowers Ridge (Figure 61). I also present a compilation of published and unpublished ${ }^{14} \mathrm{C}$ data from planktonic (surface-ocean dwelling) and benthic (surface-sediment dwelling) foraminifera. I found that the vertical profile of ${ }^{14} \mathrm{C}$ does not appear to have been significantly different than today at the Last Glacial Maximum ( $\sim 21 \mathrm{k} \mathrm{BP})$, the Bølling-Ållerød (BA, a brief, warm climate event during the deglaciation, 14.7-12.9 k BP) and Younger Dryas (YD, a cold climate event which followed the BA, 12.9-11.7 k BP) (See Figure A-1 for core locations, and Figure 313 for data). The ${ }^{14} \mathrm{C}$ calculations are described in detail in Appendix 1. Interpretation of this dataset is limited by (1) the small number of North Pacific data points and (2) the fact that many of the benthic and planktonic foraminifer ${ }^{14} \mathrm{C}$ measurements from this

dataset are probably affected by post-depositional processes which are known to bias ${ }^{14} \mathrm{C}$ measurements. In addition the simplified version of the behavior of oxygen and ${ }^{14} \mathrm{C}$ in the 


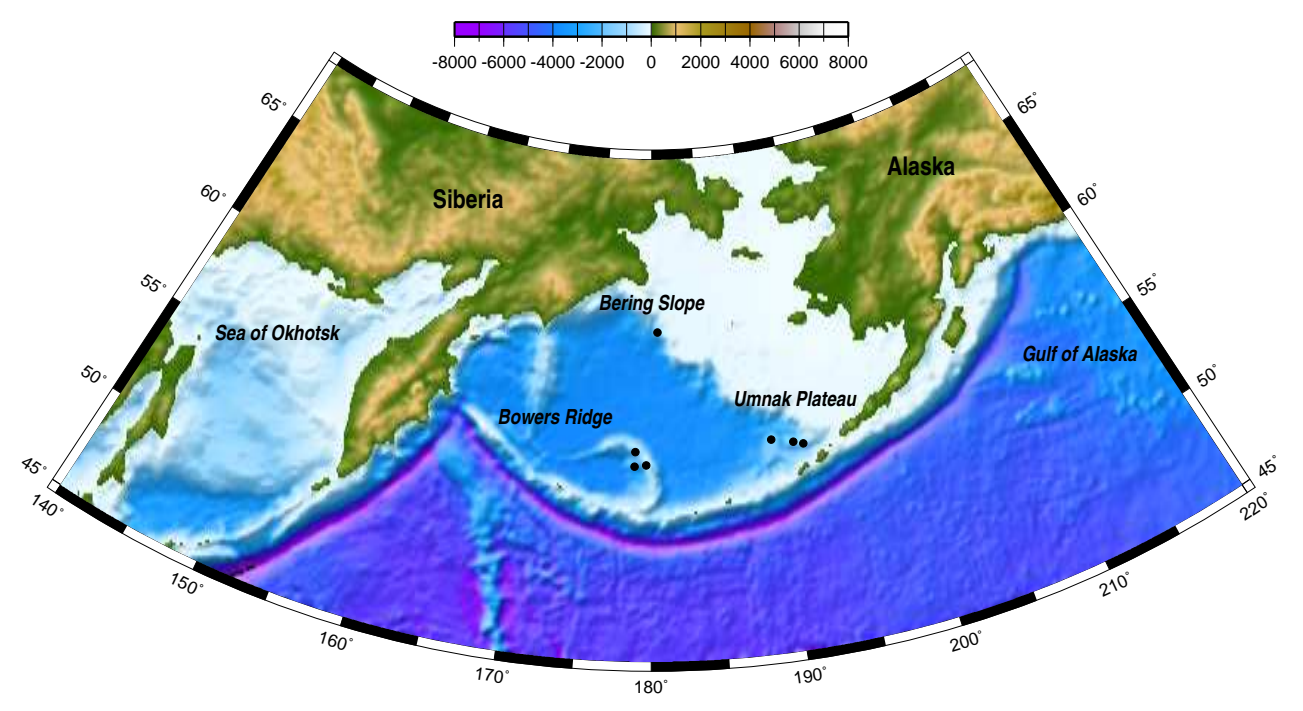

Figure 6-1: The Bering Sea. The scale for color bathymetry and topography is in meters. Coring sites from HLY02-02 are labeled with black dots.

ocean as reviewed here is only accurate to the first order, as long as the two mechanisms I described are the only processes that are changing. If I had observed a significant change in the ${ }^{14} \mathrm{C}$ profile of the North Pacific, it would be consistent with a change in circulation, but it would not require it.

In the core from the Bering Slope, I find that there are very rapid (occurring in less than 220 years) decreases in planktonic $\delta^{18} \mathrm{O}$ at two times during the deglaciation corresponding to the beginning of the BA warm period, and the end of the YD cold period. These isotopic shifts are each accompanied by a transient decline in the relative abundance of the cold-water planktonic foraminifer species, $N$. pachyderma (s.). Since the two $\delta^{18} \mathrm{O}$ changes are steps, and the warmings implied by the decreases in abundance of N. pachyderma (s.) are transient, I conclude that these isotopic events each represent a combination of two processes: a sudden and transient warming, and a sudden and sustained freshening of surface water in the Bering Sea. I made one simple test of whether the faunal record was affected by differential dissolution among the planktonic species. The test result was negative, but the inferred warming would be more robust with another proxy for sea surface temperature. The Bering Slope core is intermittently laminated, and the sediment accumulation rate is very high $(200 \mathrm{~cm} / \mathrm{ky})$. These two physical characteristics make the records from this core minimally affected by post-depositional processes which jumble the records from cores with lower sediment accumulation rates (like the one from Bowers Ridge), and therefore it is 
much more reliable.

The final important observation made in Chapter 3 is that the ages of the transitions between laminated and not-laminated sediment in the Bering Slope core correspond to the ages of the transitions between warm and cold events with duration of centuries to a millennium as they are defined in an ice core from the summit of Greenland (GISP2) to well within the uncertainties of the independent age models of these two records (see Figure 312). This correlation is robust, even considering the uncertainty in the apparent age of surface water in the Bering Sea during the deglaciation. At this time, I can not do more than speculate about a mechanism that connects the surface water temperature and salinity in the Bering Sea, the oxygen content of $1130 \mathrm{~m}$ depth water in the Bering Sea, and air temperature over Greenland. However, these observations will provide a strong constraint to any proposed mechanism that connects the North Pacific and the North Atlantic on centennial to millennial time scales.

In Chapter 4, I present high-resolution records of planktonic and benthic $\delta^{18} \mathrm{O}$ and $\delta^{13} \mathrm{C}$, as well as relative abundance of $N$. pachyderma (s.) from the core from the Bowers Ridge (2200 m water depth) which spans the period from about 50,000 years ago to the present. I find no evidence of coherent millennial-scale events in benthic $\delta^{13} \mathrm{C}$ or $N$. pachyderma (s.) relative abundance and $\delta^{18} \mathrm{O}$ (Figure 4-2). These data suggest that there was not significant variability in the surface water or $2200 \mathrm{~m}$ water temperature, salinity or nutrient content from 50,000 to 20,000 years ago. Several investigators have suggested previously that there were statistically significant changes in the $\delta^{13} \mathrm{C}$ of intermediate and deep water coinciding with the millennial-scale climate events which are observed to occur in the North Atlantic region (i.e. Lund and Mix (1998); Mix et al. (1999)), which they interpret as a change in the rate of formation of these water masses. In a record of far-North Pacific surface water variability at the Emperor Seamounts, Kiefer et al. (2001) conclude that there were large and rapid changes in sea surface temperatures which coincide with the Atlantic millennial climate events. The Bowers Ridge record has comparable or higher temporal resolution than these published records. Though the age model for the core is very preliminary, if the sediment accumulated continuously (and there is no seismic or lithological evidence that this was not the case), events with duration and spacing on the order of a thousand or more years ought to be detectable. None are seen, which suggests that either surface water at the Emperor Seamounts and Bowers Ridge are not changing the same way in the past. 
In Chapter 5, I present another set of planktonic and benthic $\delta^{18} \mathrm{O}$ and $\delta^{13} \mathrm{C}$ records from the last glacial period, this one from the Umnak Plateau region, in the southeast Bering Sea (1570 m water depth). These records differ from the ones presented in Chapter 4 in that there are extremely large, episodic, negative excursions in benthic and planktonic $\delta^{13} \mathrm{C}$. These $\delta^{13} \mathrm{C}$ excursions are not related to the use of $\delta^{13} \mathrm{C}$ as a nutrient proxy. The $\delta^{13} \mathrm{C}$ values measured (as low as $-14 \% \mathrm{PDB}$ ) are far outside the range of $\delta^{13} \mathrm{C}$ normally found in Pleistocene foraminifera (-1 to $1 \%$ PDB), and are associated with anomalously high $\delta^{18} \mathrm{O}$ (Figure 5-5). I hypothesize that these isotopic features are the result of episodic occurrence of overgrowths of carbonate minerals on the foraminifer shells. This is supported by the physical appearance of foraminifera from samples with anomalous isotopes (Figure 5-4), which often have visible yellowish crusts on them, and are significantly greater in mass (Table 5.2). I constructed a simple end-member mixing model to estimate the isotopic composition and $[\mathrm{Mg}] /[\mathrm{Ca}]$ of the overgrowths, and find that they are consistent with the chemical signature of carbonate minerals that form inorganically in seawater.

Why these overgrowths occur is not clear. The overgrowths could conceivably be the result of saturation of porewater with respect to carbonate minerals due to decomposition of organic matter via sulfate reduction. However, I speculate that the overgrowths are associated with episodic flux of methane-rich porewater to the surface sediments. Inorganic carbonate minerals frequently form at active methane seeps in the modern ocean. Also, there is seismic evidence of methane deep in sediments (hundreds of meters below the seafloor) at this site. Based on the preliminary age model for this core, I can not tell yet whether these episodes coincide with the millennial-scale climate events of the last glacial period, but they do have similar duration and timing as those events. If they are indeed synchronous with events, this may imply that sedimentary methane interacts with the climate system on short time scales.

Methane is a very powerful greenhouse gas (more potent than carbon dioxide), and records of atmospheric methane concentration reconstructed from ice cores show that during the warm millennial-scale climate events, there is more methane in the atmosphere (Chappellaz et al., ????). Kennett et al. (2003) proposed a fascinating but very controversial hypothesis dubbed the "The Clathrate Gun Hypothesis," in which warming of intermediatedepth water during millennial-scale warm climate events caused world-wide destabilization of sedimentary deposits of methane (in the form of methane clathrates). In this model, some 
of the methane escapes oxidation in the water column and enters the atmosphere, where it enhances global warming. However, the Umnak Plateau coring site is cold and deep enough that thermodynamic destabilization of methane clathrates is unlikely to occur. If the authigenic minerals are related to methane in the sediments, it is an open question how the methane was transported to the surface sediments.

\section{Future directions}

The work on these Bering Sea cores is still in the early stages. I have established stratigraphies for the best cores at each coring site, and tested some of the interpretations of previous investigators who have worked in the North Pacific. But there are still many open questions that can be addressed in the future: (1) What mechanism is responsible for the lithological changes during the deglaciation? There are several other geochemical proxies (for surface ocean primary productivity, porewater oxygen content, and the redox state of surface sediments) which could shed light on this question. As a postdoctoral investigator, I will work more on this problem using ${ }^{14} \mathrm{C}$ and $\delta^{13} \mathrm{C}$ of a variety of benthic foraminifer species. (2) On a related note, what ties subsurface oxygen in the Bering Sea to Greenland surface air temperature? Whatever mechanism ties the two together must be unaffected by the large changes that occur during the deglaciation, including the melting of the Laurentide ice sheet on North America, the shift of the shoreline from the edge of the continental slope to its present position hundreds of kilometers away with rising sea level, and opening of the Bering Strait. This question could be further explored in a coupled ocean-atmosphere model. (3) Where does the freshwater come from that we see evidence of during the deglaciation? Conventional wisdom says that Alaska was not highly glaciated at the Last Glacial Maximum. (4) If there was indeed methane in surface sediments of the Umnak Plateau during warm millennial-scale climate events, how did it get there? Could methane-rich fluids migrate up a fault from the relict subduction zone during an earthquake? To further investigate this question I will look in this core and at least one other shallower core from the Umnak Plateau and try to establish whether these episodes were indeed related to methane by looking for organic biomarkers which are diagnostic of methanotrophic organisms, and whether they seem to occur synchronously in multiple cores. 


\title{
Appendix A
}

\section{Apparent ventilation age of the North Pacific during the last deglacial transition}

\begin{abstract}
I present three ways to quantify the depletion of ${ }^{14} \mathrm{C}$ in subsurface water relative to surface water in the past from measurements of $\Delta^{14} \mathrm{C}$ in benthic and planktonic foraminifera. Each method produces a subtly different quantity. I compile published and unpublished pairs of benthic and planktonic foraminifer ${ }^{14} \mathrm{C}$ measurements from the North Pacific from during the last glacial Termination. The data do not show a significant, coherent change in subsurface ${ }^{14} \mathrm{C}$ during the Bølling-Ållerød (14.7-12.9 ky BP) and the Younger Dryas (12.9$11.7 \mathrm{ky} \mathrm{BP}$ ) and the Last Glacial Maximum (23-21 ky BP) compared to today. However, because of the stratigraphy and faunal abundances in North Pacific cores, finding benthic and planktonic foraminifera from the same sample with reliable ${ }^{14} \mathrm{C}$ is very difficult. This null result could be a consequence of the limitations of this dataset.
\end{abstract}

\section{A.1 Benthic-planktonic ${ }^{14} \mathrm{C}$ age difference}

A conventional ${ }^{14} \mathrm{C}$ age is calculated from $\Delta^{14} \mathrm{C}$ measured on a sample and the Libby ${ }^{14} \mathrm{C}$ decay constant, $\lambda_{L}=\frac{1}{8033 y}$,

$$
\left({ }^{14} \mathrm{C} \text { age }\right)_{L}=-\lambda_{L}^{-1} \ln \left(\frac{\Delta^{14} \mathrm{C}}{1000}+1\right)
$$


where $\Delta^{14} \mathrm{C}$ is calculated relative to a "pre-industrial, pre-nuclear" atmosphere (PIPN):

$$
\Delta^{14} \mathrm{C}=1000\left(\frac{{ }^{14} \mathrm{C} /{ }^{12} \mathrm{C}}{{ }^{14} \mathrm{C} /{ }^{12} \mathrm{C}_{P I P N}}-1\right)
$$

Measured ${ }^{14} \mathrm{C} /{ }^{12} \mathrm{C}$ is corrected for (1) the effects of isotopic fractionation and (2) so that the conventional ${ }^{14} \mathrm{C}$ age is in years before "present" $(\mathrm{BP})$, where the present is defined as the year $1950 \mathrm{AD}$. A ${ }^{14} \mathrm{C}$ age calculated with the true decay constant, $\lambda=\frac{1}{8266 y}$, is 1.029 times the magnitude of $\left({ }^{14} \mathrm{C} \text { age }\right)_{L}$, the ratio of $\lambda$ to $\lambda_{L}$

$$
\begin{aligned}
\left({ }^{14} \text { Cage }\right) & =-\lambda^{-1} \ln \left(\frac{\Delta^{14} \mathrm{C}}{1000}+1\right) \\
& =\frac{\lambda_{L}}{\lambda}\left({ }^{14} \mathrm{C} \text { age }\right)_{L}
\end{aligned}
$$

The difference between a benthic and planktonic ${ }^{14} \mathrm{C}$ age using the true half life, $\Delta_{b-p}$, is larger than the difference using the Libby half life, $\Delta_{b-p L}$, by the same ratio. Though a conventional ${ }^{14} \mathrm{C}$ age is calculated with $\lambda_{L}$, I use $\Delta_{b-p}$ because this quantity can be directly compared to other estimates of the apparent ventilation age of subsurface water in units of true calendar years.

In a compilation of pairs of benthic and planktonic ${ }^{14} \mathrm{C}$ ages from North Pacific cores (Figure A-1), I plot $\Delta_{b-p}$ from three time slices in Figure A-2, the Younger Dryas (YD, 11,650-12,890 y BP), the Bølling-Ållerød (BA, 12,890-14,670 y BP), and the Last Glacial Maximum (LGM, 19,000-23,000 y BP) (see Table A.1). The time periods for BA and YD are defined as the midpoint of the rapid transitions in $\delta^{18} \mathrm{O}_{i c e}$ from GISP2 (Stuiver et al., 1998). This record has an independent, layer-counted age model during the deglaciation. Closed symbols are data points where the median of the calibrated planktonic calendar age falls within the given time slices with $95 \%(2 \sigma)$ certainty. The median age of data plotted with open symbols fall within the time slice, but the entire $2 \sigma$ range do not. The standard deviation of $\Delta_{b-p}$ is the square root of the sum of squares of standard deviations of the benthic and planktonic ages $\left(\sigma=\left(\sigma_{b}^{2}+\sigma_{p}^{2}\right)^{1 / 2}\right)$, assuming that the errors in these two ages are uncorrelated.

For reference, I plot $\Delta_{b-p}$ with a profile of mean North Pacific $\Delta^{14} \mathrm{C}$ from the WOCE dataset (Key et al., 2002). This profile includes stations from $0^{\circ} \mathrm{N}$ to $55^{\circ} \mathrm{N}$. The modern $\Delta^{14} \mathrm{C}$ profile is converted to apparent age using Equation A.1. This profile is not corrected for the 
effects of fossil fuel burning or nuclear tests on ${ }^{14} \mathrm{C}$. In the North Pacific, the penetration of $\mathrm{CO}_{2}$ from these two phenomena is largely confined to the uppermost $1 \mathrm{~km}$ and has the net effect of elevating $\Delta^{14} \mathrm{C}$ (Key, 2001; Sarmiento and Gruber, 2002).

The quantity that is directly comparable to $\Delta_{b-p}$ is the difference between the profile of $\Delta^{14} \mathrm{C}$ converted to apparent age and the apparent age of the surface water. The global mean apparent age of ocean surface water $(R)$ is $400 \mathrm{y}$, but it is greater in areas with greater upwelling and sea ice cover (Bard, 1988). In Figure A-2, I subtract $R$ from the profile of apparent age as the upper bound of the shaded area. I subtract $800 \mathrm{y}$, a typical surface water age in an upwelling area, from the profile as the lower bound of the shaded area. This is to illustrate the expected variability in $\Delta_{b-p}$ since the planktonic ${ }^{14} \mathrm{C}$ ages are not corrected for the deviation of local surface water apparent age from the global mean value, $\Delta R$.

The calendar ages of two new data points from this study, from HLY02-02-3JPC and HLY02-02-17JPC, do not fall within the BA, but just before. I plot these data points on the BA time slices in Figures A-2, A-4, and A-6 because within the sediment cores, the samples are within the dysoxic/laminated stratigraphic unit which I believe was deposited during the BA. To distinguish them from the other data, I plot these points with star-shaped symbols.

\section{A.2 $\quad \Delta^{14} \mathrm{C}$ of subsurface water}

Using the well-known rate of decay of ${ }^{14} \mathrm{C}$, the trajectory of $\Delta^{14} \mathrm{C}$ of a sample of benthic foraminifera can be "undecayed" backward in time

$$
\Delta^{14} \mathrm{C}(y)=1000\left[\left(\frac{\Delta^{14} \mathrm{C}_{m}}{1000}+1\right) \mathrm{e}^{\lambda y}-1\right]
$$

where $\Delta^{14} \mathrm{C}_{m}$ is the value measured in a benthic foraminifer sample today, and $y$ is age of the sample in calendar years BP. This decay trajectory is plotted as the exponential black line in Figure A-3, where the $1 \sigma$ and $2 \sigma$ measurement uncertainty is propagated through time and contoured in dark and light grey, respectively.

The $\Delta^{14} \mathrm{C}$ of the sample at the time the benthic foraminifera calcified their shells, $\Delta{ }^{14} \mathrm{C}_{0}$, is estimated by finding the intersection of the decay trajectory with the estimated calendar age of the sediment sample. In Figure A-3, the $1 \sigma$ and $2 \sigma$ contours of the resulting joint 


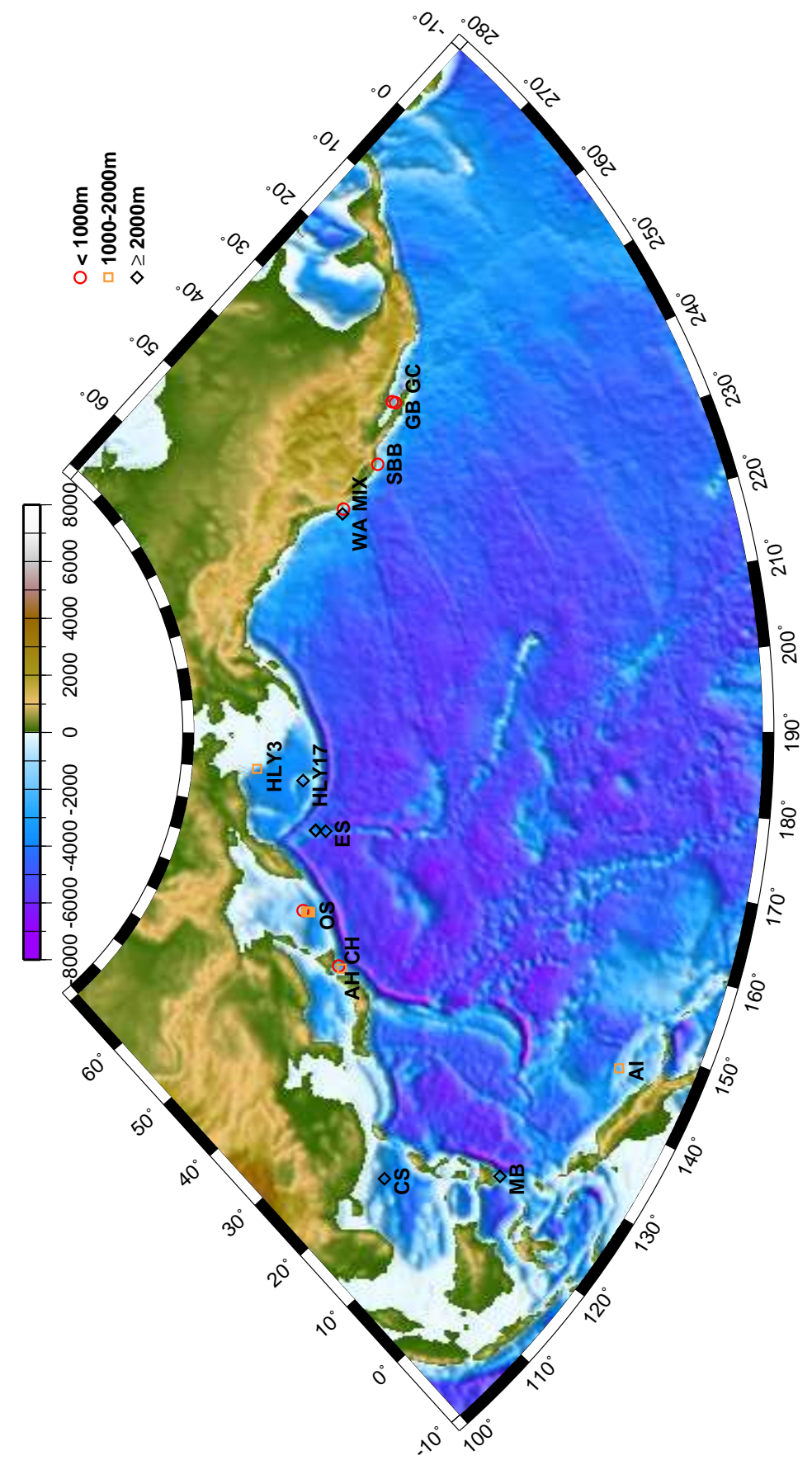

Figure A-1: Locations of sediment cores in a compilation of published and unpublished pairs of benthic and planktonic ${ }^{14} \mathrm{C}$ ages. Red circles are coring sites shallower than $1 \mathrm{~km}$ water depth, orange squares are coring sites 1-2 km, and black diamonds are coring sites deeper than $2 \mathrm{~km}$. Coring site depths are not corrected for deglacial sea level change. Each site is annotated with the acronyms used in this chapter. See Table A.1 for references and details of the cores. 

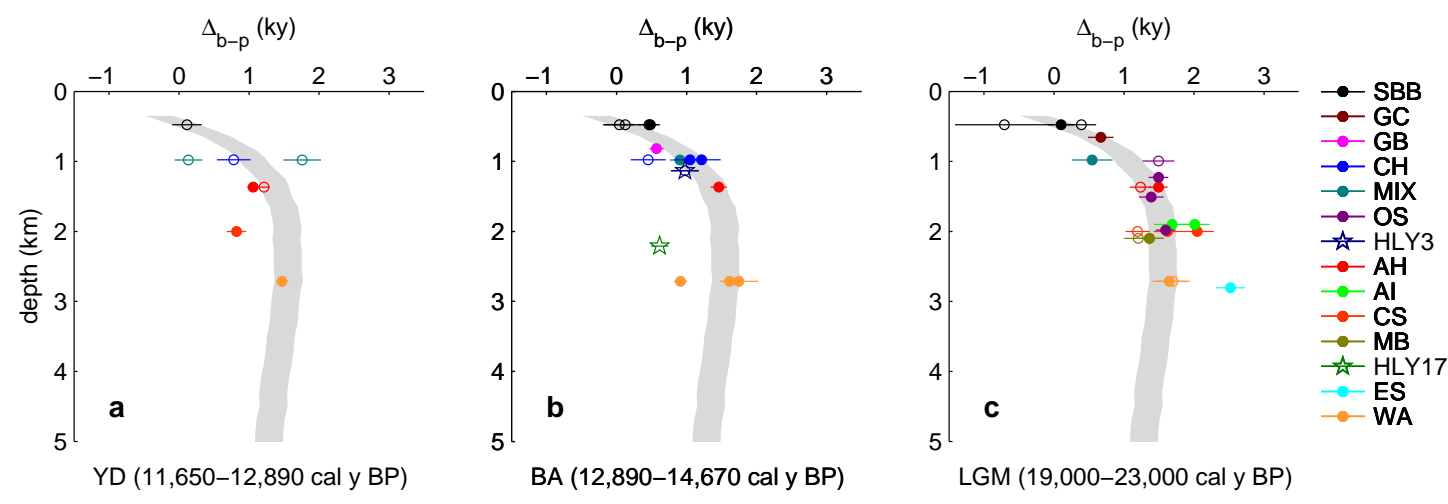

Figure A-2: Compilation of pairs of benthic and planktonic foraminifer ${ }^{14} \mathrm{C}$ ages from the North Pacific. Plotted here is $\Delta_{b-p}$, the difference between the ${ }^{14} \mathrm{C}$ age in ky (using the true half life) of benthics and planktonics. The average North Pacific $\Delta^{14} \mathrm{C}$ profile from the WOCE dataset (Key et al., 2002) is converted to apparent age with Equation A.1. The right-hand edge of the shaded region is the apparent age profile minus $400 \mathrm{y}$ (the mean apparent age of surface water), and the left-hand edge of the shaded region is the apparent age profile minus $800 \mathrm{y}$ (a hypothetical apparent age of surface water in an upwelling region). The time periods of the YD and BA are as defined in Stuiver et al. (1998). For each time slice, I plot data for which the median calibrated planktonic calendar age falls within the defined time periods. The filled symbols are data points where the calibrated planktonic calendar age falls within the time interval with $95 \%(2 \sigma)$ certainty. Table A.1 contains the data, references, and explanation of the acronyms used here.

probability distribution (PDF) are drawn in black. The joint PDF is integrated along $\Delta^{14} \mathrm{C}$ to find the $\mathrm{PDF}$ of $\Delta^{14} \mathrm{C}_{0}$. If $\Delta^{14} \mathrm{C}$ of benthic foraminifera is the same as that of the bottom water at the core site, then $\Delta{ }^{14} \mathrm{C}_{0}$ is an estimate of the ${ }^{14} \mathrm{C}$ activity of this water in the past. The $\mathrm{PDF}$ of $\Delta{ }^{14} \mathrm{C}_{0}$ is drawn in black on the left-hand y-axis with the $1 \sigma$ and $2 \sigma$ ranges.

In order to compare the reconstructed $\Delta^{14} \mathrm{C}$ activity of subsurface water to a modern profile of mean North Pacific $\Delta^{14} \mathrm{C}$, I subtract the estimate of the mean surface ocean $\left(\Delta^{14} \mathrm{C}_{s w}\right)$ (Hughen et al., 2004b) from $\Delta^{14} \mathrm{C}_{0}$. In Figure A-4, I plot $\Delta^{14} \mathrm{C}_{0}-\Delta^{14} \mathrm{C}_{s w}$ for the three time slices. For reference, I plot in the solid grey curve the Key et al. (2002) profile of $\Delta^{14} \mathrm{C}$, where the $R(400 \mathrm{y})$ is subtracted so that the curve is relative to the mean pre-industrial, pre-nuclear surface ocean.

The other reference, the dashed grey line is what the modern profile would look like with higher $\Delta^{14} \mathrm{C}$ everywhere. During a time when the atmospheric and surface ocean $\Delta^{14} \mathrm{C}$ were higher than today, if the ocean circulation was precisely the same as it is today, the $\Delta^{14} \mathrm{C}_{0}-\Delta^{14} \mathrm{C}_{s w}$ would be larger in magnitude. This is because of the exponential decay 


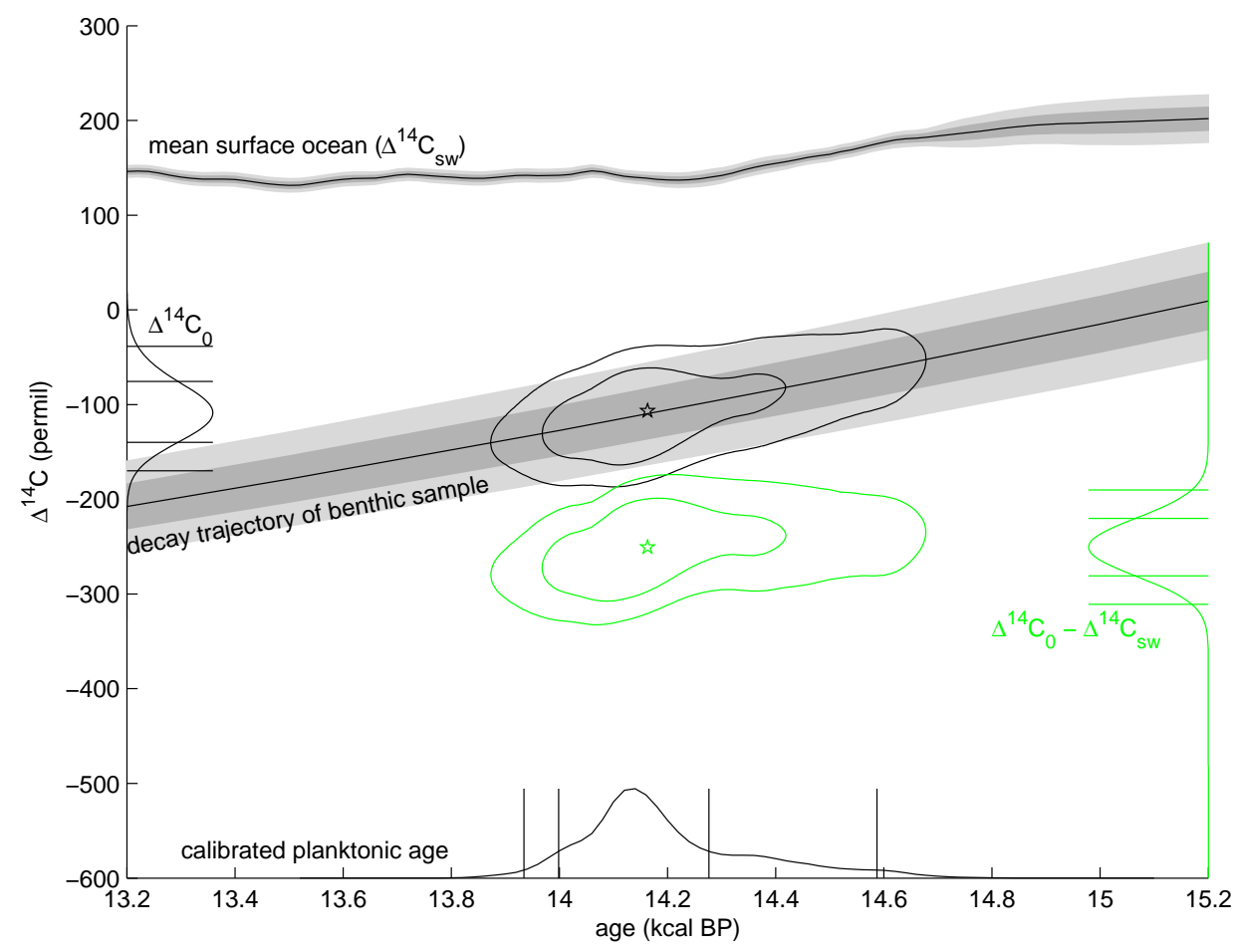

Figure A-3: Schematic of calculation of $\Delta^{14} \mathrm{C}_{0}$ and $\Delta{ }^{14} \mathrm{C}_{0}-\Delta^{14} \mathrm{C}_{s w}$. The intersection of the decay trajectory of the benthic foraminifer sample with the calendar age of the sample is drawn with black contours at the $1 \sigma$ and $2 \sigma$ levels. The integral of this joint probability distribution (PDF) along the y-axis is the PDF of $\Delta{ }^{14} \mathrm{C}_{0}$, which is drawn with the $1 \sigma$ and $2 \sigma$ ranges on the left-hand axis. For comparison to a modern mean North Pacific $\Delta^{14} \mathrm{C}$ profile, the mean surface ocean $\Delta^{14} \mathrm{C}$ (Hughen et al., 2004b) is subtracted from this estimate of $\Delta^{14} \mathrm{C}_{0}$ to find $\Delta^{14} \mathrm{C}_{0}-\Delta{ }^{14} \mathrm{C}_{s w}$, the depletion of ${ }^{14} \mathrm{C}$ in the benthic sample relative to the global mean surface ocean value. This joint PDF is plotted in green, and the integrated PDF is on the right-hand axis. The medians of the joint PDFs are marked with stars. 

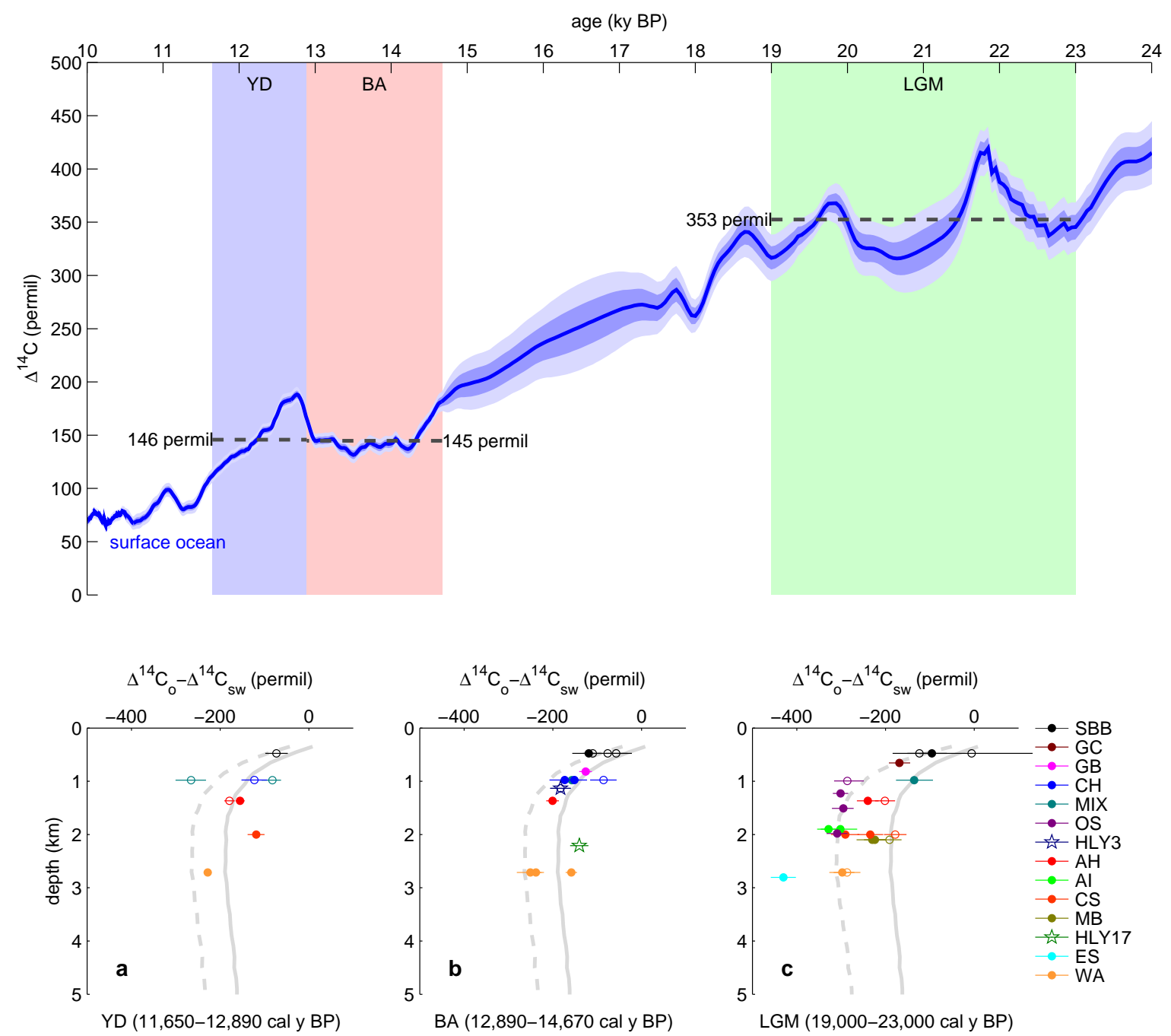

Figure A-4: Top panel: Mean surface ocean $\Delta^{14} \mathrm{C}$ (Hughen et al., 2004a). The mean $\Delta^{14} \mathrm{C}$ during the YD, BA, and LGM are drawn with dashed lines, and annotated. Bottom panels: Compilation of pairs of benthic and planktonic foraminifer ${ }^{14} \mathrm{C}$ ages from the North Pacific. Plotted here is $\Delta^{14} \mathrm{C}_{0}-\Delta^{14} \mathrm{C}_{s w}$, the difference between the estimated $\Delta^{14} \mathrm{C}$ of water in which the benthic foraminifera grew and the mean surface ocean $\Delta^{14} \mathrm{C}$ at that time. The solid grey line is the mean North Pacific $\Delta^{14} \mathrm{C}$ profile from the WOCE dataset minus the $\Delta^{14} \mathrm{C}$ of a mean PIPN surface ocean where $R=400 \mathrm{y}\left(\Delta^{14} \mathrm{C}_{s w}=-49.6 \%\right.$ ) (Key et al., 2002). The dashed grey line is the same profile, but where the ${ }^{14} \mathrm{C}$ age everywhere in the ocean was decreased by exactly the apparent age of the mean surface water for that time period. If the ocean circulation was exactly the same, but the atmospheric and surface ocean ${ }^{14} \mathrm{C}$ was higher, the subsurface $\Delta^{14} \mathrm{C}$ would be the dashed grey profile. 
of ${ }^{14} \mathrm{C}$. Given two samples that are $1000 \mathrm{y}$ apart in age, the $\Delta^{14} \mathrm{C}$ difference between the two is greater the younger the samples are, and the $\Delta^{14} \mathrm{C}$ difference is smaller the older the samples are. The dashed grey curve is the modern $\Delta^{14} \mathrm{C}$ profile, but where for each time period, the apparent age of the mean surface water $\Delta^{14} \mathrm{C}$ is subtracted.

\section{A.3 Apparent ventilation age}

There is a long-term decrease in ${ }^{14} \mathrm{C}$ production in the atmosphere through the late Pleistocene, which is thought to be the consequence of a strengthening geomagnetic field and increase in shielding of Earth from cosmic rays (Bard, 1998) (see Figure A-5). This has the effect that a sample generally appears relatively younger than its calendar age, since atmospheric ${ }^{14} \mathrm{C}$ was higher in the past than today. The decrease in atmospheric ${ }^{14} \mathrm{C}$ was not monotonic, there are superimposed shorter-scale fluctuations in ${ }^{14} \mathrm{C}$ production owing to variations in solar activity and the geomagnetic field. In addition, changes in the global carbon cycle and ocean circulation, both important reservoirs of ${ }^{14} \mathrm{C}$, affect the ${ }^{14} \mathrm{C} /{ }^{12} \mathrm{C}$ ratio in the atmosphere.

Since a benthic foraminifer grows in water composed of constituents which were last in contact with the atmosphere at some point in the past, the difference between a benthic and planktonic ${ }^{14} \mathrm{C}$ age is likely to be somewhat smaller than it would have been if atmospheric ${ }^{14} \mathrm{C}$ was constant. Adkins and Boyle (1997) proposed a method of interpreting the ${ }^{14} \mathrm{C}$ ages of benthic and planktonic foraminifera that takes into account changes in atmospheric $\Delta^{14} \mathrm{C}$.

The Adkins and Boyle (1997) method uses the simplifying assumption that the parcel of water in which the benthic foraminifer grew descended from the sea surface as a closed system. The authors acknowlege that this assumption is never true for a parcel of water in the real ocean, but that calculating the ${ }^{14} \mathrm{C}$ content of this theoretical water mass allows them to take into account changing atmospheric $\Delta^{14} \mathrm{C}$. The trajectory of the $\Delta^{14} \mathrm{C}$ of the water parcel, once it is removed from contact with the atmosphere, is

$$
\Delta^{14} \mathrm{C}(t)=1000\left[\left(\frac{\Delta^{14} \mathrm{C}\left(t_{0}\right)}{1000}+1\right) \mathrm{e}^{-\lambda t}-1\right]
$$

where $\Delta^{14} \mathrm{C}\left(t_{0}\right)$ is the $\Delta^{14} \mathrm{C}$ of the parcel at the moment it leaves the surface ocean, and $t$ is time. 


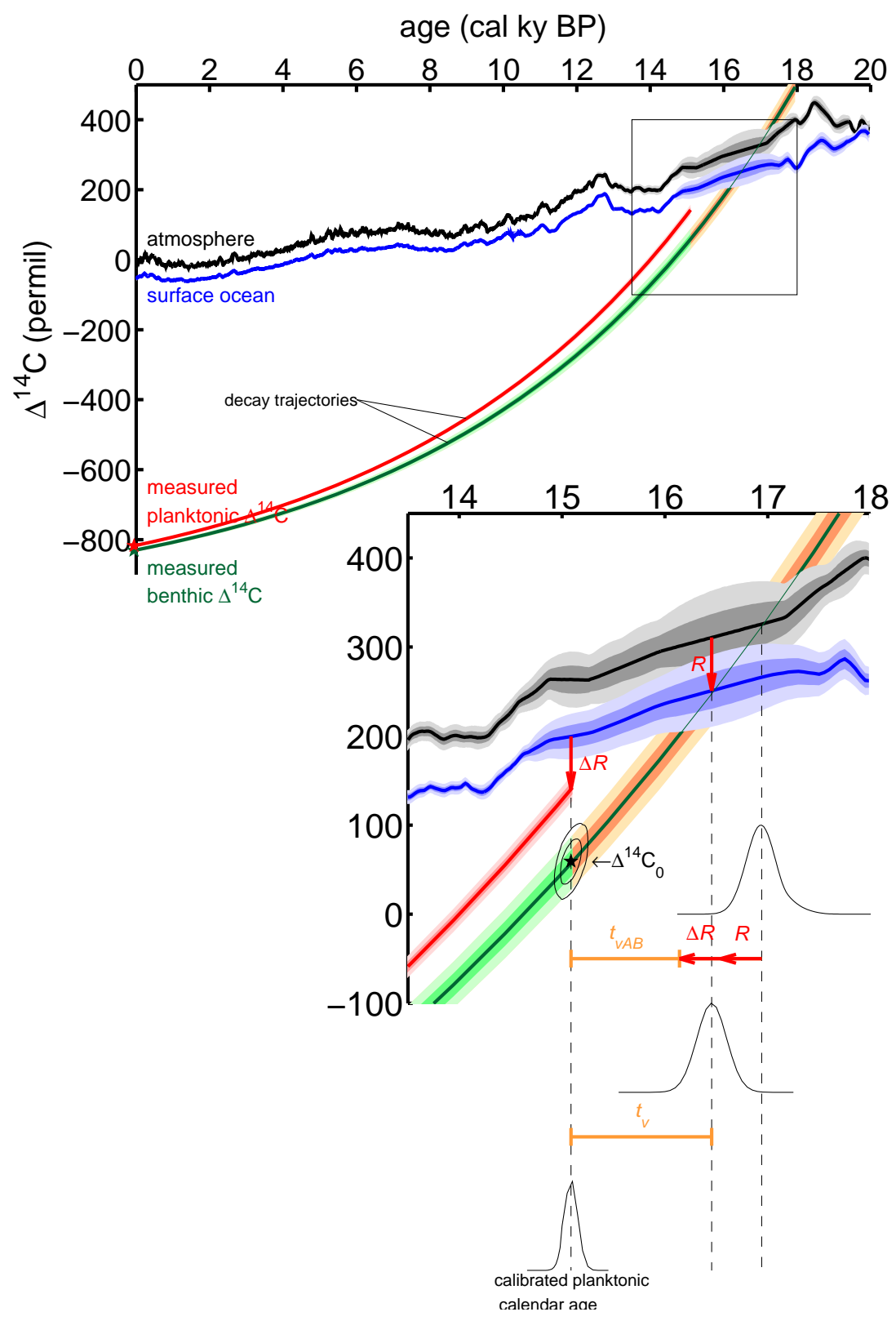

Figure A-5: Schematic of calculation of $t_{v}$ and $t_{v A B}$. In the upper panel in grey is atmospheric $\Delta^{14} \mathrm{C}$ (Reimer et al., 2004), in blue is the mean surface ocean $\Delta^{14} \mathrm{C}$ (Hughen et al., 2004b). In red is the trajectory of ${ }^{14} \mathrm{C}$ decay backward in time of a planktonic sample, in green is the decay trajectory for a benthic sample. For each of these 4 curves, the $1 \sigma$ and $2 \sigma$ uncertainties are contoured. In the inset panel, the orange curve is the trajectory of a hypothetical water parcel in which the benthic foraminifera grew. The probability distributions (PDFs) of the intersection of the decay trajectories with the $\Delta^{14} \mathrm{C}$ time series are drawn, where the median of the PDFs are indicated with dashed lines. From left to right, the PDFs are the intersection of the planktonic decay trajectory with the surface ocean curve (taking into account $\Delta R$, the local anomaly from the global mean age of surface water), the intersection of the water parcel decay trajectory with the mean surface ocean, and the intersection of the water parcel decay trajectory with the atmosphere. The apparent ventilation age calculated as in Adkins and Boyle (1997) is $t_{v A B}$. In this study, I use the quantity $t_{v}$. 

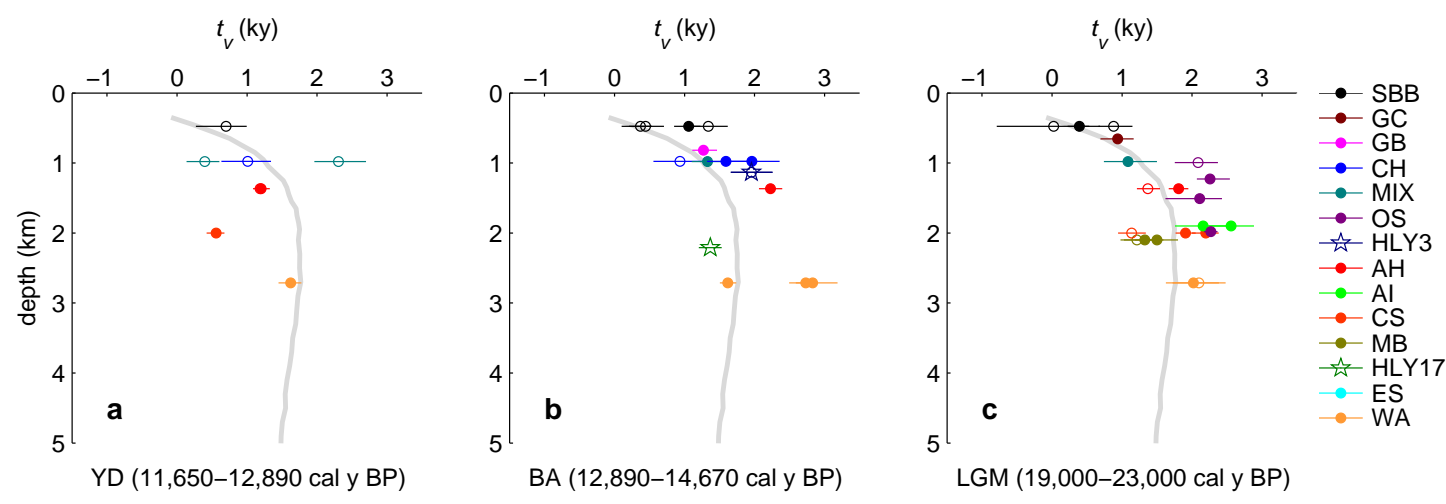

Figure A-6: Compilation of pairs of benthic and planktonic foraminifer ${ }^{14} \mathrm{C}$ age from the North Pacific. Plotted here is $t_{v}$, the difference between the ${ }^{14} \mathrm{C}$ age in ky (using the true half life) of benthics and planktonics taking into account change in atmospheric ${ }^{14} \mathrm{C}$, assuming that the water in which the benthic foraminifera grew descended from the surface ocean as a closed system. The grey shaded region, the colors, symbols, and acronyms are the same as in Figure A-2.

Assuming that the $\Delta^{14} \mathrm{C}$ of benthic foraminifera is the same as $\Delta^{14} \mathrm{C}$ of the water in which they live, and that the parcel is a closed system, the trajectory of the parcel of water is the same as the "undecay" trajectory of the benthic sample (Equation A.3). This is illustrated as the green trajectory in Figure A-5, where the orange portion beyond the calendar age of the sample is the trajectory of the hypothetical water parcel. The $1 \sigma$ and $2 \sigma$ uncertainty from measurement error are shown as shaded contours.

The apparent ventilation age of the parcel of water with respect to the atmosphere is the difference between the calendar age of the sample and the intersection of this trajectory with the Intcal2004 record of atmospheric $\Delta^{14} \mathrm{C}$ (Reimer et al., 2004). Then, the estimate of the local apparent age of surface water $(R+\Delta R)$ is subtracted to find the apparent age with respect to the local surface ocean, $t_{v A B}$. This calculation is functionally the same as finding the difference between the calibrated age of the uncorrected benthic sample with respect to the atmosphere and the calibrated age of the planktonic sample (corrected for $R+\Delta R)$ with respect to the surface ocean, then subtracting $R+\Delta R$. Since $t_{v}$ takes into account $\Delta R$, like $\Delta_{b-p}$, it is the apparent age of subsurface water relative to local surface water, rather than from a mean surface ocean.

This hypothetical parcel of water is not one that I expect to have ever existed in the real ocean, where it is highly unlikely that a water parcel would descend from the sea surface without being transformed by mixing with surrounding water masses. If we consider the 
slightly more realistic scenario in which the parcel is a mixture of several end members.

$$
\begin{aligned}
\Delta^{14} \mathrm{C} & =a \Delta{ }^{14} \mathrm{C}_{1}+b \Delta{ }^{14} \mathrm{C}_{2}+c \Delta \Delta^{14} \mathrm{C}_{3} \\
1 & =a+b+c
\end{aligned}
$$

The $\Delta^{14} \mathrm{C}$ of the water parcel is the sum of the $\Delta^{14} \mathrm{C}$ of each constituent water mass, each weighted by the fraction of the parcel it composes. In this case, change in the $\Delta^{14} \mathrm{C}$ of the parcel could be the result of a change in the fraction of a constituent, or a change in the $\Delta^{14} \mathrm{C}$ of a constituent. So though the water parcel itself is fictional, it is useful in that it includes a correction which takes into account a known phenomenon, the variable atmospheric $\Delta^{14} \mathrm{C}$.

I modified the Adkins and Boyle (1997) method slightly by finding the intersection of the parcel of water with a mean surface ocean curve (Hughen et al., 2004b), so that $t_{v}$ is relative to the mean surface ocean at the time the hypothetical water parcel would have been at the sea surface, rather than relative to local surface water. This is functionally the same as finding the difference between the calendar age of the uncorrected benthic sample with respect to the mean surface ocean, and the calendar age of the planktonic sample with respect to the surface ocean taking into account $\Delta R$. I report the uncertainty of this difference as the $1 \sigma$ and $2 \sigma$ ranges of the PDF of the difference between the PDFs of the calibrated calendar ages. These PDFs are typically non-Gaussian and can be obtained from the downloadable versions of Calib (http://www.calib.org). I plot time slices of $t_{v}$ in Figure A-6 with the modern profile of apparent age, where $R$ is subtracted. I do not take into account the local $\Delta R$ when finding the intersection of the benthic trajectory with the surface ocean because this would imply that the local $\Delta R$ is that same as that in the region where subsurface water is formed. By making each $t_{v}$ relative to a mean surface ocean, I make no assumptions about the source region of the subsurface water.

\section{A.4 Discussion}

The greatest advantage of $\Delta_{b-p}$ is its simplicity - it is the difference between two ${ }^{14} \mathrm{C}$ measurements. However, it does not take into account either variability in the apparent age of the surface-ocean, or the known decrease of atmospheric $\Delta^{14} \mathrm{C}$ through the Pleistocene. In 


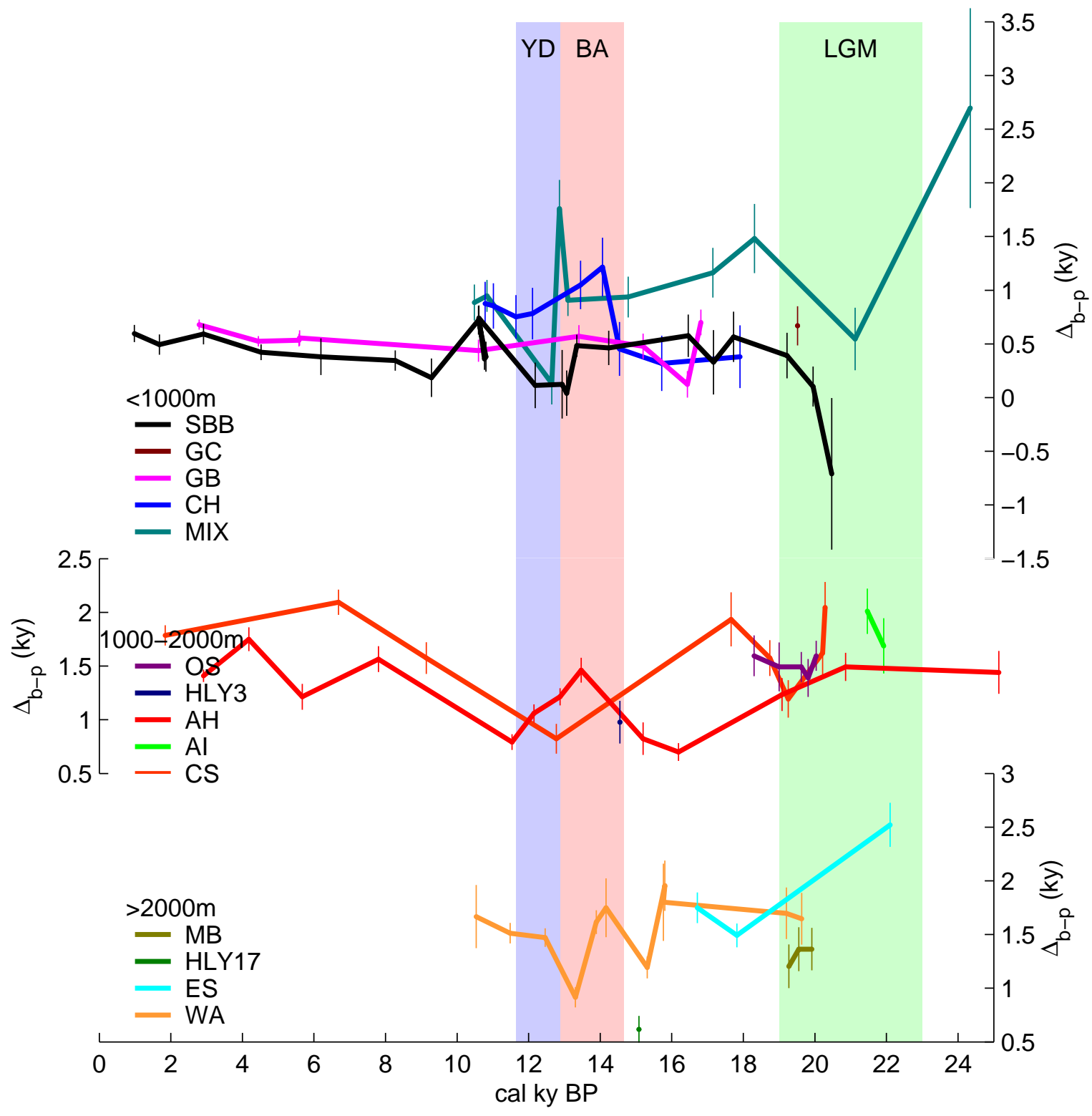

Figure A-7: $\Delta_{b-p}$ from a compilation of pairs of benthic and planktonic foraminifer ${ }^{14} \mathrm{C}$ age from the North Pacific. $1 \sigma$ uncertainties are plotted at each data point. The three time slices in Figure A-2 are shaded in blue, pink, and green, and are the YD, BA, and LGM, respectively. The colors for each time series is the same as in Figure A-2. 
a region with positive $\Delta R, \Delta_{b-p}$ appears smaller than in a region where $\Delta R=0$, even if the ${ }^{14} \mathrm{C}$ content of the subsurface water is the same at both sites. In Figure A-2, I expect that there is some spread of data points to the left (to smaller values of $\Delta_{b-p}$ ) from the effect of a positive $\Delta R$ in some regions. Since $\Delta R$ is very poorly constrained in the past, it is conservative to compare $\Delta_{b-p}$ to a modern profile which shows a likely range as a function of $\Delta R$. However, since this range is on the same order as the magnitude of change in $\Delta_{b-p}$ during the time periods of interest, the three time slices do not look significantly different from one another (see the individual time series in Figure A-7). Just regarding the data points that fall within the time slices with $95 \%$ certainty, during the YD two out of three points fall below the modern range, during the BA one out of nine points falls below the modern range. It would be difficult to argue that the data for these time intervals are significantly different than the modern profile. During the LGM, one point falls below and three fall above the modern range out of 14 points, where there appears to be the same or slightly greater $\Delta_{b-p}$ at $2-3 \mathrm{~km}$ depth.

For most sites, the time series of $\Delta_{b-p}$ is variable within the time period of interest. Though some of the individual records may contain statistically significant changes during the deglaciation, when amassed (Figure A-7), it is evident that all of the records together do not show the same story. And in fact, some of the relative maxima and minima fall within the same time period. The uncertainty in the calibration of planktonic ${ }^{14} \mathrm{C}$ ages is great enough that it would not be possible to tell whether changes occurring in each core are synchronous. It is also possible that there were indeed significant changes in $\Delta^{14} \mathrm{C}$ that were too brief to resolve in sediment cores.

Calculation of $\Delta^{14} \mathrm{C}_{0}$ depends on one additional piece of information, $\Delta R . \Delta R$ is used to estimate the calendar age of the sample from the planktonic $\Delta^{14} \mathrm{C}$ measurement. Knowing the calendar age of the sample allows one to transform the difference in ${ }^{14} \mathrm{C}$ content of the benthic and planktonic samples (or the mean surface ocean) from ${ }^{14} \mathrm{C}$ years to $\Delta^{14} \mathrm{C}$, and estimate the profile of ${ }^{14} \mathrm{C}$ activity in the subsurface water. The profiles of $\Delta{ }^{14} \mathrm{C}_{0}-\Delta{ }^{14} \mathrm{C}_{s w}$ are different from the profiles of $\Delta_{b-p}$ because $\Delta^{14} \mathrm{C}$ changes exponentially with time.

During the YD, $\Delta^{14} \mathrm{C}_{0}-\Delta^{14} \mathrm{C}_{s w}$ appears significantly higer than the expected profile if the circulation was the same as today (dashed grey line in Figure A-4a). During the BA and LGM, the data points fall near the expected profile and at values slightly higher. During the LGM, the exception is from the deepest core in the profile (ES), which is significantly 


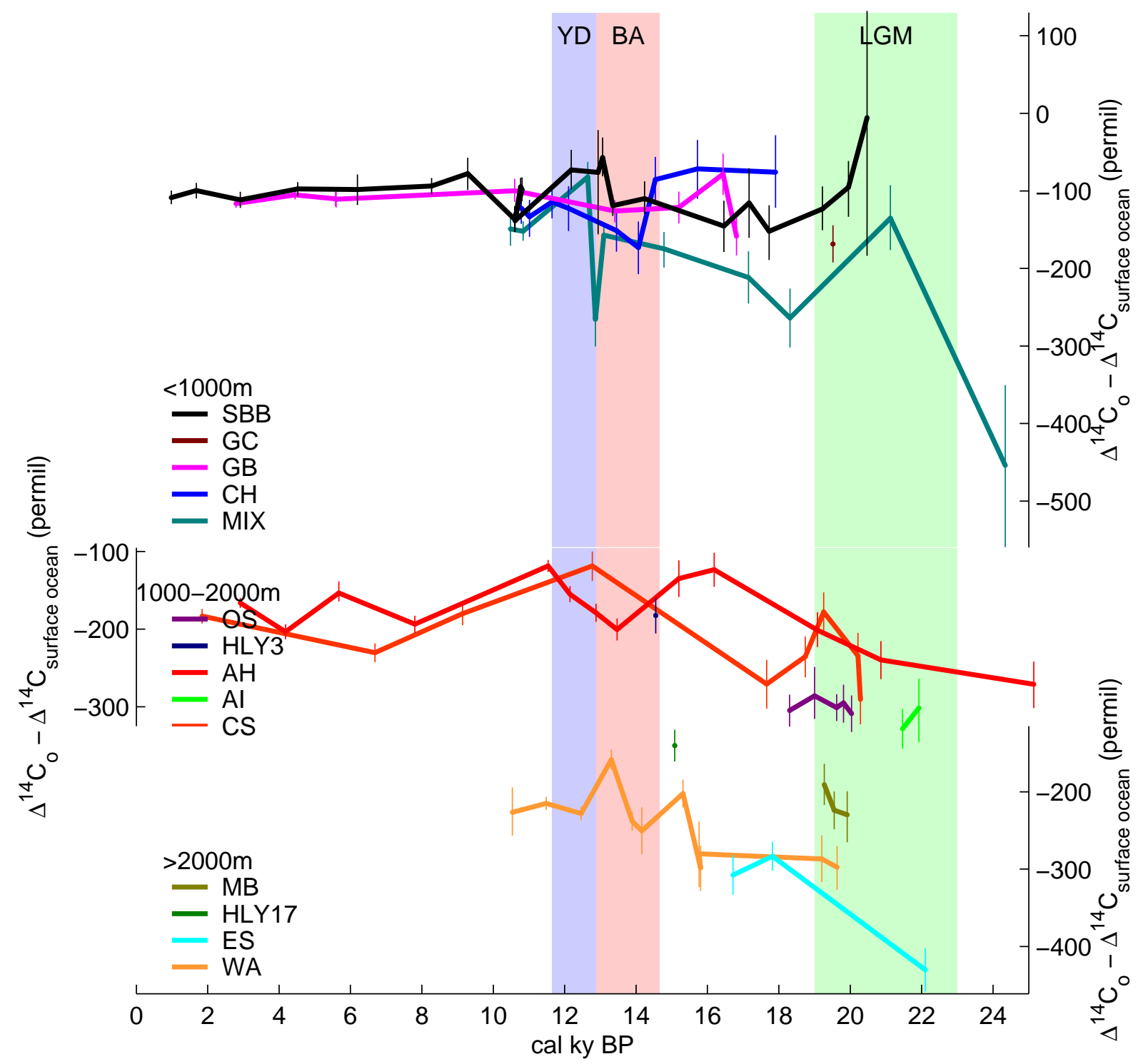

Figure A-8: $\Delta^{14} \mathrm{C}_{0}-\Delta^{14} \mathrm{C}_{s w}$ from a compilation of pairs of benthic and planktonic foraminifer ${ }^{14} \mathrm{C}$ age from the North Pacific. $1 \sigma$ uncertainties are plotted at each data point. The three time slices in Figure A-4 are shaded in blue, pink, and green, and are the YD, BA, and LGM, respectively. The colors for each time series is the same as in Figure A-4. 
lower by $150 \%$. From these data, it appears that during the YD and BA, subsurface Pacific water above $2700 \mathrm{~m}$ water depth may have been slightly enriched in ${ }^{14} \mathrm{C}$ relative to today, and during the LGM, they were the same or slightly enriched relative to today. Deep Pacific water deeper than $2700 \mathrm{~m}$, from one data point from the Emperor Seamounts, may have been significantly depleted in ${ }^{14} \mathrm{C}$.

Compared to $\Delta_{b-p}$, the amplitude of changes of $t_{v}$ through time are larger (compare Figure A-9 and Figure A-7). Relative to the modern profile, $t_{v}$ may be lower during the YD, though again, this is hard to tell, given the small number and large scatter of data points. The majority of data points from the BA and LGM time slices are higher than the modern profile, which suggests that, subsurface North Pacific water was out of contact with the atmosphere for longer during these time periods, compared to today. This interpretation of the $t_{v}$ data is contrary to that of $\Delta^{14} \mathrm{C}_{0}-\Delta^{14} \mathrm{C}_{s w}$ data. 


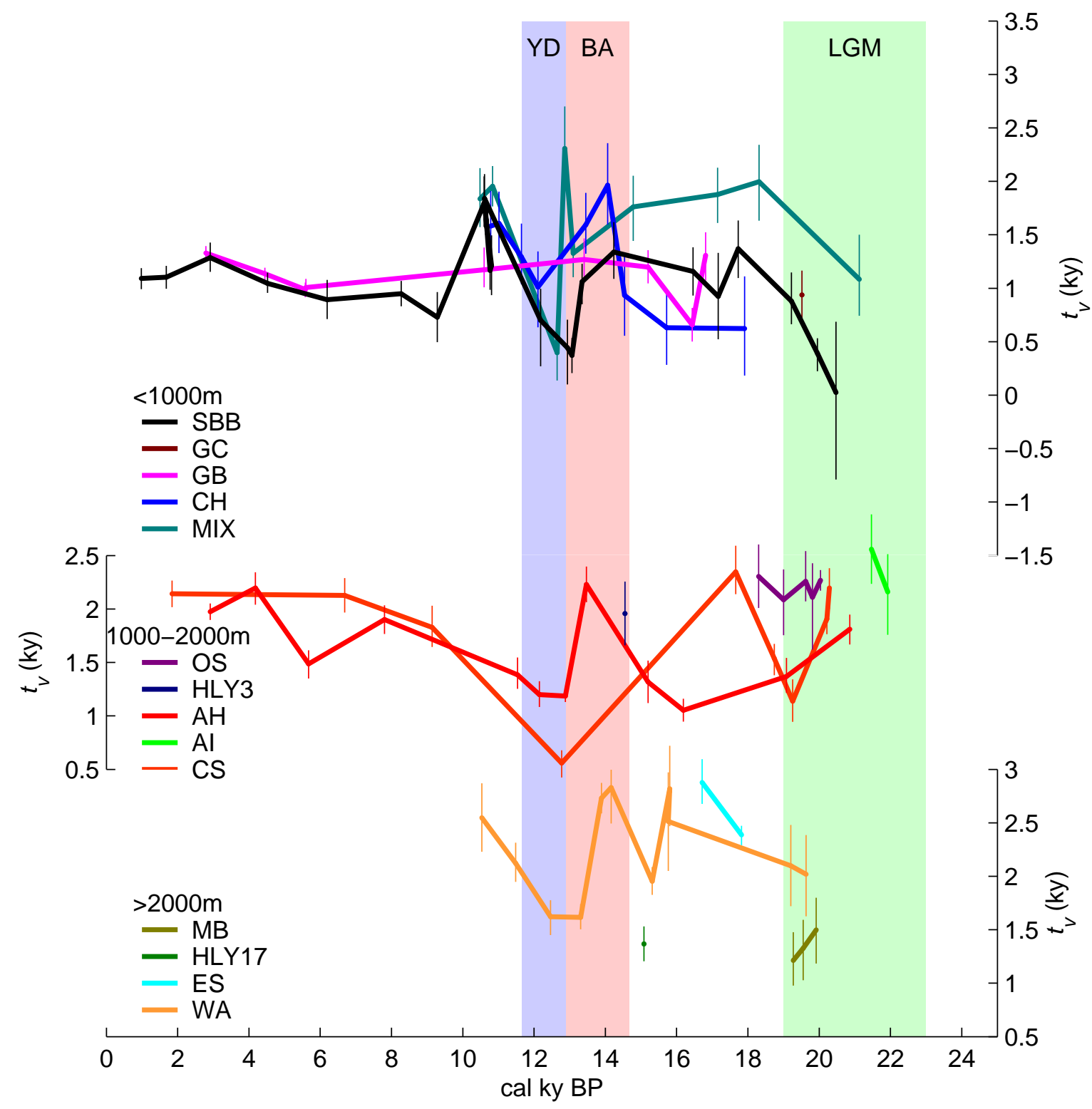

Figure A-9: $t_{v}$ from a compilation of pairs of benthic and planktonic foraminifer ${ }^{14} \mathrm{C}$ age from the North Pacific. $1 \sigma$ uncertainties are plotted at each data point. The three time slices in Figure A-4 are shaded in blue, pink, and green, and are the YD, BA, and LGM, respectively. The colors for each time series is the same as in Figure A-6. 
planktonic ${ }^{14} \mathrm{C}$ age benthic ${ }^{14} \mathrm{C}$ age

calendar age

$\Delta_{b-p}$

$\Delta^{14} \mathrm{C}_{0}-\Delta{ }^{14} \mathrm{C}_{s w}$

$t_{v}$
$\pm 1 \sigma / 2 \sigma$

time

$\mathrm{SBB}$ $\pm 1 \sigma / 2 \sigma$ $\pm 1 \sigma / 2 \sigma$ period

$1,850 \pm 60 / 120$ $2,430 \pm 50 / 100$
$3,000 \pm 60 / 120$ $980 \pm 60 / 150$ $475 \mathrm{~m}, \Delta R=$

y (Ingram and
$-109 \pm \quad 9 / 17$
$-100 \pm 10 / 20$

Kennett, 1995$)$
$1,090 \pm 100 / 210$ $2,520 \pm 70 / 140$ $3,000 \pm 60 / 120$ $3,555 \pm 50 / 100$ $4,130 \pm 80 / 160$ $4,800 \pm 50 / 100$ $6,200 \pm 70 / 140$ $8,235 \pm 60 / 120$ $9,050 \pm 90 / 180$ $10,160 \pm 70 / 140$ $10,300 \pm 80 / 160$ $10,280 \pm 70 / 140$ $10,170 \pm 70 / 140$ $11,180 \pm 180 / 360$ $11,830 \pm 290 / 580$ $11,980 \pm 180 / 360$

$12,350 \pm 60 / 120$

$13,130 \pm 120 / 240$

$14,630 \pm 120 / 240$

$15,210 \pm 150 / 300$

$15,720 \pm 140 / 280$

$16,820 \pm 180 / 360$

$17,410 \pm 150 / 300$

$18,380 \pm 680 / 1360$

$25,470 \pm 240 / 480$

$5,210 \pm 50 / 100$

$6,570 \pm 150 / 300$

$8,570 \pm 70 / 140$

$9,230 \pm 150 / 300$

$10,860 \pm 110 / 220$

$10,670 \pm 110 / 220$

$10,630 \pm 70 / 140$

$10,890 \pm 90 / 180$

$11,290 \pm 100 / 200$

$11,950 \pm 110 / 220$

$12,020 \pm 100 / 200$

$12,820 \pm 80 / 160$

$13,580 \pm 100 / 200$

$680+90 / 130$

$600 \pm 80 / 160$

$2,920 \pm 70 / 150$

$4,520 \pm 90 / 170$

$6,200 \pm 70 / 200$

$8,270 \pm 70 / 110$

$9,290 \pm_{100}^{130} /{ }_{240}^{180}$

$10,600 \pm 70 / 270$

$10,810 \pm \frac{120}{170} / 220$

$10,770 \pm 150 / 190$

$10,610 \pm 70 / 270$

$12,190 \pm \pm_{280}^{430} / 610$

$12,940 \pm_{220}^{330} / 810$

$13,070 \pm 140 / 220$

$13,350 \pm 50 / 100$

$14,240 \pm 220 / 490$

$490 \pm 90 / 190$

$590 \pm 100 / 190$

$420 \pm 70 / 150$

$380 \pm 170 / 340$

$-100 \pm 10 / 20$

$-112 \pm 10 / 21$

$-97 \pm \quad 9 / 18$

$-98 \pm 19 / 40$

$-94 \pm 10 / 22$

$340 \pm 90 / 190$

$190 \pm 180 / 360$

$720 \pm 130 / 270$

$380 \pm 140 / 280$

$-78 \pm{ }_{21}^{21} / 42$

$-137 \pm 17 / 33$

$-98 \pm 16 / 31$

$360 \pm 100 / 200$

$740 \pm 120 / 230$

$110 \pm 210 / 420$

$120 \pm 320 / 640$

$40 \pm 210 / 420$

$480 \pm 100 / 210$

$460 \pm 160 / 320$

$15,190 \pm 150 / 300$

$15,530 \pm 250 / 500$

$16,460 \pm_{160}^{160} / 320$

$580 \pm 200 / 400$

$330 \pm 300 / 600$

$16,270 \pm 180 / 360$

$17,200 \pm 100 / 200$

$\pm_{170 / 380}$

$570 \pm 230 / 470$

$390+210 / 420$

$17,510 \pm 100 / 200$

$100 \pm 190 / 370$

$-95 \pm$

$1,100 \pm \pm_{110}^{110} / 210$

$1,040+100 / 180$

$890 \pm 190 / 350$

$950 \pm 120 / 220$

$730 \pm 230 / 450$

$1,800 \pm 220 / 430$

$1,210 \pm 280 / 590$

$1,170 \pm_{180}^{200} / 430$

$1,840 \pm_{190}^{230} / 360$

$700 \pm_{430}^{290} / 610$

$17,690 \pm 90 / 180 \quad 20,470 \pm 820 / 1480$ $26,080 \pm 320 / 640$

$710 \pm 710 / 1410$

GC: DSDP480, Guaymas Basin, $655 \mathrm{~m}, \Delta R=550 \mathrm{y}$ (Keigwin, unpublished)

$17,000 \pm 130 / 260$

$17,650 \pm 120 / 240 \quad 19,520 \pm 240 / 360$

$3,420 \pm 35 / 70$

$4,710 \pm 40 / 80$

$5,610 \pm 45 / 90$

$5,630 \pm 60 / 120$

$10,125 \pm 80 / 160$

$12,395 \pm 80 / 160$

$13,685 \pm 100 / 200$

$14,580 \pm 100 / 200$

$14,870 \pm 100 / 200$

GB: AII125-8-55GGC

,56JPC, Guaymas

Basin, $819 \mathrm{~m}, \Delta R=395$ y (Keigwin, 2002)

$4,080 \pm 30 / 60$

$5,220 \pm 25 / 50$

$6,130 \pm 35 / 70$

$6,170 \pm 35 / 70$

$2,790 \pm 30 / 70$

$4,450 \pm 50 / 110$

$680 \pm 50 / 90$

$5,580 \pm{ }_{40}^{60} / 90$

$5,600 \pm 70 / 120$

$10,550 \pm 60 / 120$

$10,600 \pm 80 / 290$

$12,950 \pm 60 / 120$

$13,410 \pm 60 / 180$

$14,150 \pm 55 / 110$

$15,200 \pm \pm_{140}^{130} / 260$

$14,700 \pm 65 / 130$

$16,440 \pm 130 / 270$

$520 \pm 50 / 100$

$540 \pm 60 / 120$

$560 \pm 70 / 140$

$440 \pm 100 / 210$

$570 \pm 100 / 210$

$480 \pm 120 / 230$

$120 \pm 120 / 250$

$440 \pm_{340}^{260} / 820$

$370 \pm_{160}^{160} / 330$

$1,060 \pm_{210}^{170} / 360$

$1,340 \pm_{250}^{280} / 580$

$1,160 \pm_{230}^{230} / 450$

$920 \pm 410 / 770$

$-145 \pm 33 / 66$

$-116 \pm 45 / 90$

$-152 \pm 34 / 76$

$-123 \pm 29 / 56$

$-95 \pm 34 / 71$

$1,370 \pm 270 / 650$

$880 \pm_{220}^{270} / 540 \quad$ LGM

$390 \pm 140 / 390 \quad$ LGM

$20 \pm_{810}^{660} / 1490$

LGM $940 \pm 250 / 460$

LGM

$-116 \pm \quad 6 / 11$

$1,330 \pm 60 / 60 / 130$

$-105 \pm \quad 6 / 12$

$1,140 \pm 60 / 130$

$-110 \pm{ }_{10}^{9} / 17$

$-111 \pm 11 / 27$

$990 \pm 70 / 140$

$-100 \pm$

$1,010 \pm 80 / 170$

$-126 \pm$

$1,170 \pm_{160}^{210} / 430$

$1,270 \pm_{160}^{200} / 410$

$1,200 \pm_{150}^{160} / 310$

$-78 \pm 22 / 52$

$660 \pm_{160}^{160} / 320$

BA

$1,310 \pm_{230}^{220} / 400$

BA

BA

BA

$-158 \pm 25 / 49$
Ð

응

只皮当?

б

ㄷㅇ 0

- 凤寻

हु 20 .

$\rightarrow$ व

है है

य है?

క

$\triangle \vec{B}$ औ

त)

थक

․

- 8 \&

क \& 8

을 놀

承. 苟

节苞

- 0 प्र

$\Xi \smile \sum 0$

․․ㄹ․

苛吉思

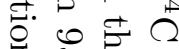

हु०

วิ

9 .

2 눙

(⿻)

ใ.

䗆

- 己

穴节.

声央先.

它客 


\begin{tabular}{|c|c|c|c|c|c|c|c|}
\hline & $\begin{array}{c}\text { planktonic }{ }^{14} \mathrm{C} \text { age } \\
\pm 1 \sigma / 2 \sigma\end{array}$ & $\begin{array}{c}\text { benthic }{ }^{14} \mathrm{C} \text { age } \\
\pm 1 \sigma / 2 \sigma\end{array}$ & $\begin{array}{l}\text { calendar age } \\
\quad \pm 1 \sigma / 2 \sigma\end{array}$ & $\begin{array}{l}\Delta_{b-p} \\
\pm 1 \sigma / 2 \sigma\end{array}$ & $\begin{array}{l}\Delta^{14} \mathrm{C}_{0}-\Delta^{14} \mathrm{C}_{s w} \\
\quad \pm 1 \sigma / 2 \sigma\end{array}$ & $\begin{array}{l}t_{v} \\
\pm 1 \sigma / 2 \sigma\end{array}$ & $\begin{array}{l}\text { time } \\
\text { period }\end{array}$ \\
\hline & & CH: CH84-14, far $\mathrm{N}$ & ortheast Pacific, & $78 \mathrm{~m}, \Delta R=160 \mathrm{y}$ & (Duplessy et al., 19 & $89)$ & \\
\hline & $10,000 \pm 140 / 280$ & $10,850 \pm 140 / 280$ & $10,780 \pm 210 / 300$ & $870 \pm 200 / 410$ & $-122 \pm 22 / 41$ & $1,580 \pm_{300}^{330} / 520$ & \\
\hline & $10,230 \pm 140 / 280$ & $11,060 \pm 150 / 300$ & $11,020 \pm_{200}^{180} / 300$ & $850 \pm 210 / 420$ & $-134 \pm 22 / 56$ & $1,610 \pm_{280}^{300} / 530$ & \\
\hline & $10,640 \pm 150 / 300$ & $11,370 \pm 130 / 260$ & $11,650 \pm_{300}^{240} / 5300$ & $750 \pm 200 / 410$ & $-114 \pm 20 / 45$ & $1,290 \pm_{260}^{310} / 500$ & \\
\hline & $10,870 \pm 150 / 300$ & $11,630 \pm 180 / 360$ & $12,110 \pm \pm_{320}^{460} / 600$ & $780 \pm 240 / 480$ & $-123 \pm 29 / 57$ & $1,010 \pm_{380}^{330} / 670$ & YD \\
\hline & $12,180 \pm 160 / 320$ & $13,200 \pm 150 / 300$ & $13,450 \pm_{160}^{160} / 340$ & $1,050 \pm 230 / 450$ & $-151 \pm 29 / 54$ & $1,590 \pm_{270}^{300} / 570$ & BA \\
\hline & $12,750 \pm 150 / 300$ & $13,930 \pm 220 / 440$ & $14,070 \pm_{240}^{150} / 390$ & $1,210 \pm 270 / 550$ & $-173 \pm{ }_{34}^{33} / 68$ & $1,960 \pm_{370}^{390} / 830$ & BA \\
\hline & $13,060 \pm 140 / 280$ & $13,500 \pm 200 / 400$ & $14,540 \pm_{300}^{230} / 4300$ & $450 \pm 250 / 500$ & $-85 \pm 29 / 63$ & $930 \pm_{380}^{380} / 740$ & $\mathrm{BA}$ \\
\hline & $13,830 \pm 150 / 300$ & $14,140 \pm 200 / 400$ & $15,720 \pm \pm_{220}^{220} / 420$ & $320 \pm 260 / 510$ & $-72 \pm 37 / 77$ & $630 \pm 350 / 690$ & \\
\hline & $15,570 \pm 210 / 420$ & $15,940 \pm 190 / 380$ & $17,910 \pm_{360}^{370} / 520$ & $380 \pm 290 / 580$ & $-76 \pm \begin{array}{l}48 \\
46\end{array} / 92$ & $620 \pm_{440}^{490} / 920$ & \\
\hline & & MIX: ODP1019 & Northeast Pacific & $980 \mathrm{~m}, \Delta R=320$ & y (Mix et al., 1999) & & \\
\hline & $9,950 \pm 110 / 220$ & $10,810 \pm 120 / 240$ & $10,480 \pm{ }_{140}^{110} / 260$ & $880 \pm 170 / 340$ & $-149 \pm \frac{19}{21} / \frac{44}{37}$ & $1,840 \pm 270 / 530$ & \\
\hline & $10,210 \pm 120 / 240$ & $11,130 \pm 80 / 160$ & $10,840 \pm 170 / 280$ & $950 \pm 150 / 300$ & $-152 \pm 13 / 27$ & $1,950 \pm_{190}^{190} / 340$ & \\
\hline & $11,410 \pm 170 / 340$ & $11,540 \pm 90 / 180$ & $12,650 \pm_{250}^{240} / 530$ & $130 \pm 200 / 400$ & $-82 \pm{ }_{24}^{20} / 59$ & $400 \pm_{260}^{210} / 340$ & YD \\
\hline & $11,580 \pm 140 / 280$ & $13,290 \pm 220 / 440$ & $12,860 \pm \frac{90}{70} / 230$ & $1,760 \pm 270 / 540$ & $-265 \pm 34 / 68$ & $2,310 \pm_{340}^{390} / 810$ & YD \\
\hline & $11,950 \pm 110 / 220$ & $12,830 \pm 90 / 180$ & $13,100 \pm_{100}^{80} / 160$ & $910 \pm 150 / 290$ & $-157 \pm 16 / 34$ & $1,330 \pm 200 / 310$ & BA \\
\hline & $13,350 \pm 120 / 240$ & $14,260 \pm 140 / 280$ & $14,780 \pm_{240}^{270} / 360$ & $940 \pm 190 / 380$ & $-175 \pm 22 / 50$ & $1,760 \pm \pm_{320}^{290} / 560$ & \\
\hline & $15,080 \pm 120 / 240$ & $16,210 \pm 190 / 380$ & $17,150 \pm 140 / 270$ & $1,160 \pm 230 / 460$ & $-212 \pm 34 / 67$ & $1,880 \pm \pm_{270}^{250} / 530$ & \\
\hline & $16,040 \pm 140 / 280$ & $17,480 \pm 280 / 560$ & $18,320 \pm 350 / 410$ & $1,480 \pm 320 / 640$ & $-264 \pm 38 / 77$ & $2,000 \pm_{370}^{350} / 680$ & \\
\hline & $18,550 \pm 210 / 420$ & $19,080 \pm 190 / 380$ & $21,120 \pm_{400}^{300} / 7200$ & $550 \pm 290 / 580$ & $-135 \pm{ }_{41}^{42} / 81$ & $1,080 \pm \pm_{340}^{420} / 610$ & LGM \\
\hline & $21,240 \pm 280 / 560$ & $23,860 \pm 860 / 1720$ & $24,340 \pm \begin{array}{r}370 \\
430\end{array} / 980$ & $2,700 \pm 930 / 1860$ & $-454 \pm_{106}^{103} / 207$ & & \\
\hline & & & Okhotsk Sea, $\Delta I$ & $=550 \mathrm{y}$ (Keigwin & 2002) & & \\
\hline & NES25-1-27GGC, 99 & $5 \mathrm{~m}$ & & & & & \\
\hline & $16,750 \pm 200 / 400$ & $18,200 \pm 95 / 190$ & $19,000 \pm_{220}^{230} /{ }_{530}^{660}$ & $1,490 \pm 230 / 460$ & $-286 \pm \begin{array}{l}37 \\
30\end{array} / 55$ & $2,090 \pm_{330}^{280} / 660$ & LGM \\
\hline & B34-91, $1227 \mathrm{~m}$ & & & & & & \\
\hline & $17,200 \pm 80 / 160$ & $18,650 \pm 110 / 220$ & $19,620 \pm{ }_{130}^{150} / 240$ & $1,490 \pm 140 / 280$ & $-301 \pm{ }_{18}^{17} / 35$ & $2,260 \pm \pm_{190}^{280} / 380$ & LGM \\
\hline & NES25-1-20GGC, 14 & $97 \mathrm{~m}$ & & & & & \\
\hline & $16,750 \pm 200 / 400$ & $18,200 \pm 95 / 190$ & $19,000 \pm \pm_{220}^{230} / 660$ & $1,490 \pm 230 / 460$ & $-286 \pm{ }_{30}^{37} /{ }_{76}^{55}$ & $2,090 \pm_{330}^{280} / 660$ & LGM \\
\hline & $17,200 \pm 80 / 160$ & $18,650 \pm 110 / 220$ & $19,620 \pm 150 / 240$ & $1,490 \pm 140 / 280$ & $-301 \pm 17 / 36$ & $2,260 \pm \pm_{190}^{280} / 620$ & LGM \\
\hline & $17,350 \pm 100 / 200$ & $18,700 \pm 140 / 280$ & $19,810 \pm 140 / 180 / 310$ & $1,390 \pm 180 / 350$ & $-295 \pm 23 / 52$ & $2,110 \pm_{490}^{320} / 670$ & LGM \\
\hline & NES25-1-18GGC, 17 & $61 \mathrm{~m}$ & & & & & \\
\hline & $16,250 \pm 120 / 240$ & $17,800 \pm 140 / 280$ & $18,300 \pm_{330}^{290} / \frac{420}{390}$ & $1,590 \pm 190 / 380$ & $-305 \pm{ }_{21}^{21} / 42$ & $2,300 \pm_{290}^{300} / 510$ & \\
\hline & NES25-1-15GGC, 19 & $90 \mathrm{~m}$ & & & & & \\
\hline & $17,650 \pm 80 / 160$ & $19,200 \pm 110 / 220$ & $20,040 \pm \begin{array}{r}50 \\
50\end{array} / 100$ & $1,590 \pm 140 / 280$ & $-309 \pm{ }_{24}^{23} / 47$ & $2,270 \pm_{100}^{100} / 190$ & LGM \\
\hline & & HLY3: HLY02- & 2-03JPC, Bering & Sea, $1132 \mathrm{~m}, \Delta R=$ & $400 \mathrm{y}$ (this study) & & \\
\hline & $13,300 \pm 70 / 140$ & $14,250 \pm 180 / 360$ & $14,550 \pm_{230}^{210} / 310$ & $980 \pm 200 / 400$ & $-182 \pm{ }_{23}^{23} / 46$ & $1,960 \pm_{300}^{300} / 590$ & $\mathrm{BA}$ \\
\hline
\end{tabular}


$\begin{array}{crr}\text { planktonic }{ }^{14} \mathrm{C} \text { age } & \text { benthic }{ }^{14} \mathrm{C} \text { age } & \text { calendar age } \\ \pm 1 \sigma / 2 \sigma & \pm 1 \sigma / 2 \sigma & \pm 1 \sigma / 2 \sigma\end{array}$ AH: MR01-K03-PC

$$
\pm 1 \sigma / 2 \sigma
$$

$\Delta_{b-p}$
$+1 \sigma / 2 \sigma$

$\Delta^{14} \mathrm{C}_{0}-\Delta{ }^{14} \mathrm{C}_{s w}$

$t_{v}$ $\pm 1 \sigma / 2 \sigma$

$\pm 1 \sigma / 2 \sigma \quad$ time

$3,290 \pm 40 / 80$

$4,270 \pm 100 / 200$

$5,450 \pm 110 / 220$

$7,500 \pm 110 / 220$

$10,600 \pm 50 / 100$

$10,900 \pm 55 / 110$

$11,420 \pm 60 / 120$

$12,230 \pm 50 / 100$

$13,450 \pm 85 / 170$

$14,150 \pm 55 / 110$

$16,450 \pm 110 / 220$

$18,200 \pm 65 / 130$

$21,500 \pm 110 / 220$

$23,560 \pm 110 / 220$

$25,700 \pm 150 / 300$

$4,660 \pm 40 / 80$

$2,910 \pm 50 / 130$

$5,970 \pm 40 / 80$

$6,630 \pm 40 / 80$

$9,020 \pm 40 / 80$

$11,370 \pm 50 / 100$

$11,930 \pm 60 / 120$

$12,600 \pm 50 / 100$

$13,650 \pm 100 / 200$

$14,250 \pm 120 / 240$

$14,830 \pm 60 / 120$

$17,650 \pm 100 / 200$

$19,650 \pm 110 / 220$

$22,900 \pm 160 / 320$

$24,880 \pm 110 / 220$

$27,540 \pm 150 / 300$

$4,180 \pm_{130}^{160} / 290$

$5,670 \pm_{110}^{160} / 240$

$7,800 \pm_{100}^{110} / 200$

$11,540 \pm_{170}^{130} / 260$

$12,150 \pm 110 / 230$

$12,880 \pm 30 / 50$

$13,470 \pm 50 / 140$

$15,200 \pm 110 / 240$

$16,190 \pm 80 / 160$

$19,080 \pm 110 /{ }_{220}^{300}$

$20,860 \pm 90 / 180$

$25,140 \pm{ }_{210}^{240} / 380$

$1366 \mathrm{~m}, \Delta R=160 \mathrm{y}$ (Ahagon et al., 2003

$1,410 \pm 60 / 120 \quad-166 \pm 6 / 13 \quad 1,970 \pm 80 / 160$

$1,750 \pm 110 / 220-203 \pm 10 / 19$

$1,210 \pm 120 / 240-154 \pm 15 / 22$

$1,560 \pm 120 / 240-194 \pm 11 / 26$

$790 \pm 70 / 150-119 \pm 8 / 16$

$1,060 \pm 80 / 170-155 \pm{ }_{10}^{10} / 20$

$1,210 \pm 80 / 160-179 \pm \frac{12}{12} / 24$

$1,460 \pm 120 / 230-201 \pm{ }_{14}^{14} / 28$

$820 \pm 150 / 300-135 \pm 23 / 47$

$700 \pm 80 / 170 \quad-123 \pm{ }_{22}^{22} / 45$

$1,230 \pm 150 / 310-201 \pm 22 / 45$

$1,490 \pm 130 / 260 \quad-240 \pm{ }_{25}^{24} / 49$

$1,440 \pm 200 / 400 \quad-271 \pm{ }_{31}^{29} / 59$

$2,200 \pm 150 / 30$

$2,200 \pm_{160}^{150} / 280$

$1,490 \pm 140 / 260$

$1,900 \pm 130 / 260$

$1,380 \pm_{130}^{160} / 240$

$1,200 \pm{ }_{120}^{130} / 260$

$1,190 \pm 60 / 110$

$2,230 \pm{ }_{160}^{170} / 320$

$1,320 \pm_{200}^{200} / 400$

$1,050 \pm_{110}^{110} / 210$

$1,370 \pm_{150}^{170} / 310 \quad$ LGM

$1,810 \pm 140 / 270$

LGM

$1,360 \pm 160 / 320$

$1,890 \pm 220 / 440$

$590 \pm 250 / 500$

AI: MD97-2138, Admiralty Island, $1900 \mathrm{~m}, \Delta R=80 \mathrm{y}$ (Broecker et al., 2004

\begin{tabular}{|c|c|c|c|c|c|c|}
\hline \multicolumn{7}{|c|}{ AI: MD97-2138, Admiralty Island, $1900 \mathrm{~m}, \Delta R=80$ y (Broecker et al., 2004) } \\
\hline $18,636 \pm 150 / 300$ & $20,590 \pm 140 / 280$ & $21,460 \pm 290 / 500$ & $2,010 \pm 210 / 420$ & $-328 \pm 26 / 51$ & $2,560 \pm_{320}^{330} / 630$ & LGM \\
\hline $18,950 \pm 200 / 400$ & $20,590 \pm 150 / 300$ & $21,930 \pm_{540}^{270} / 740$ & $1,690 \pm 260 / 510$ & $-302 \pm{ }_{44}^{38} / 86$ & $2,160 \pm_{400}^{350} / 600$ & LGM \\
\hline \multicolumn{7}{|c|}{ CS: Sonne50-37KL, South China Sea, sill depth $2000 \mathrm{~m}, \Delta R=0$ y (Broecker et al., 1990) } \\
\hline $2,235 \pm 46 / 92$ & $3,970 \pm 80 / 160$ & $1,840 \pm \begin{array}{l}60 \\
50\end{array} / 110$ & $1,790 \pm 100 / 190$ & $-183 \pm \quad \begin{array}{l}9 \\
9\end{array} / 19$ & $2,140 \pm_{130}^{120} / 250$ & \multirow{6}{*}{ YD } \\
\hline $6,235 \pm 57 / 113$ & $8,270 \pm 100 / 200$ & $6,690 \pm 70 / 150$ & $2,090 \pm 120 / 240$ & $-230 \pm \frac{12}{12} / 24$ & $2,130 \pm \pm_{160}^{160} / 310$ & \\
\hline $8,500 \pm 78 / 156$ & $10,030 \pm 120 / 240$ & $9,140 \pm_{110}^{90} /{ }_{170}^{220}$ & $1,570 \pm 150 / 290$ & $-180 \pm 15 / 30$ & $1,830 \pm \pm_{180}^{200} / 390$ & \\
\hline $11,090 \pm 78 / 156$ & $11,890 \pm 110 / 220$ & $12,770 \pm 80 / 370$ & $820 \pm 140 / 280$ & $-118 \pm{ }_{20}^{18} / 39$ & $560 \pm_{140}^{120} / 260$ & \\
\hline $15,220 \pm 106 / 212$ & $17,100 \pm 220 / 440$ & $17,660 \pm{ }_{110}^{130} / 240$ & $1,930 \pm 250 / 500$ & $-271 \pm{ }_{32}^{31} / 63$ & $2,350 \pm_{210}^{250} / 560$ & \\
\hline $15,900 \pm 81 / 163$ & $17,430 \pm 140 / 280$ & $18,740 \pm 90 / 150$ & $1,570 \pm 170 / 330$ & $-236 \pm 26 / 53$ & $1,540 \pm_{160}^{140} / 280$ & \\
\hline $16,430 \pm 96 / 192$ & $17,590 \pm 140 / 280$ & $19,260 \pm{ }_{160}^{140} / 320$ & $1,190 \pm 170 / 350$ & $-178 \pm 25 / 51$ & $1,140 \pm_{190}^{200} / 490$ & LGM \\
\hline $17,365 \pm 110 / 219$ & $18,940 \pm 160 / 320$ & $20,220 \pm_{100}^{90} / 160$ & $1,620 \pm 200 / 400$ & $-234 \pm{ }_{29}^{29} / 58$ & $1,910 \pm_{140}^{150} / 300$ & LGM \\
\hline $17,457 \pm 131 / 262$ & $19,445 \pm 190 / 380$ & $20,290 \pm_{120}^{110} / 220$ & $2,050 \pm 240 / 470$ & $-291 \pm{ }_{32}^{32} / 65$ & $2,200 \pm_{200}^{190} / 380$ & LGM \\
\hline \multicolumn{7}{|c|}{ MB: MD98-2181, Morotai Basin, $2100 \mathrm{~m}, \Delta R=80 \mathrm{y}$ (Broecker et al., 2004) } \\
\hline $16,725 \pm 150 / 300$ & $18,050 \pm 130 / 260$ & $19,550 \pm_{190}^{260} / 370$ & $1,360 \pm 200 / 410$ & $-224 \pm{ }_{25}^{24} / 51$ & $1,330 \pm_{300}^{270} / 580$ & LGM \\
\hline $16,520 \pm 150 / 300$ & $17,690 \pm 130 / 260$ & $19,280 \pm \pm_{250}^{190} / 350$ & $1,200 \pm 200 / 410$ & $-191 \pm 26 / 54$ & $1,210 \pm 270 / 450$ & LGM \\
\hline $17,025 \pm 150 / 300$ & $18,350 \pm 120 / 240$ & $19,910 \pm \pm_{110}^{140} /{ }_{400}^{230}$ & $1,360 \pm 200 / 400$ & $-230 \pm \begin{array}{l}30 \\
36\end{array} / 69$ & $1,500 \pm_{310}^{300} / 590$ & LGM \\
\hline \multicolumn{7}{|c|}{ HLY17: HLY02-02-17JPC, Bering Sea, $2209 \mathrm{~m}, \Delta R=400 \mathrm{y}$ (this study) } \\
\hline $13,600 \pm 50 / 100$ & $14,200 \pm 110 / 220$ & $15,090 \pm \frac{60}{70} / 140$ & $620 \pm 120 / 250$ & $-140 \pm{ }_{21}^{20} / 41$ & $1,370 \pm 160 / 330$ & \\
\hline
\end{tabular}




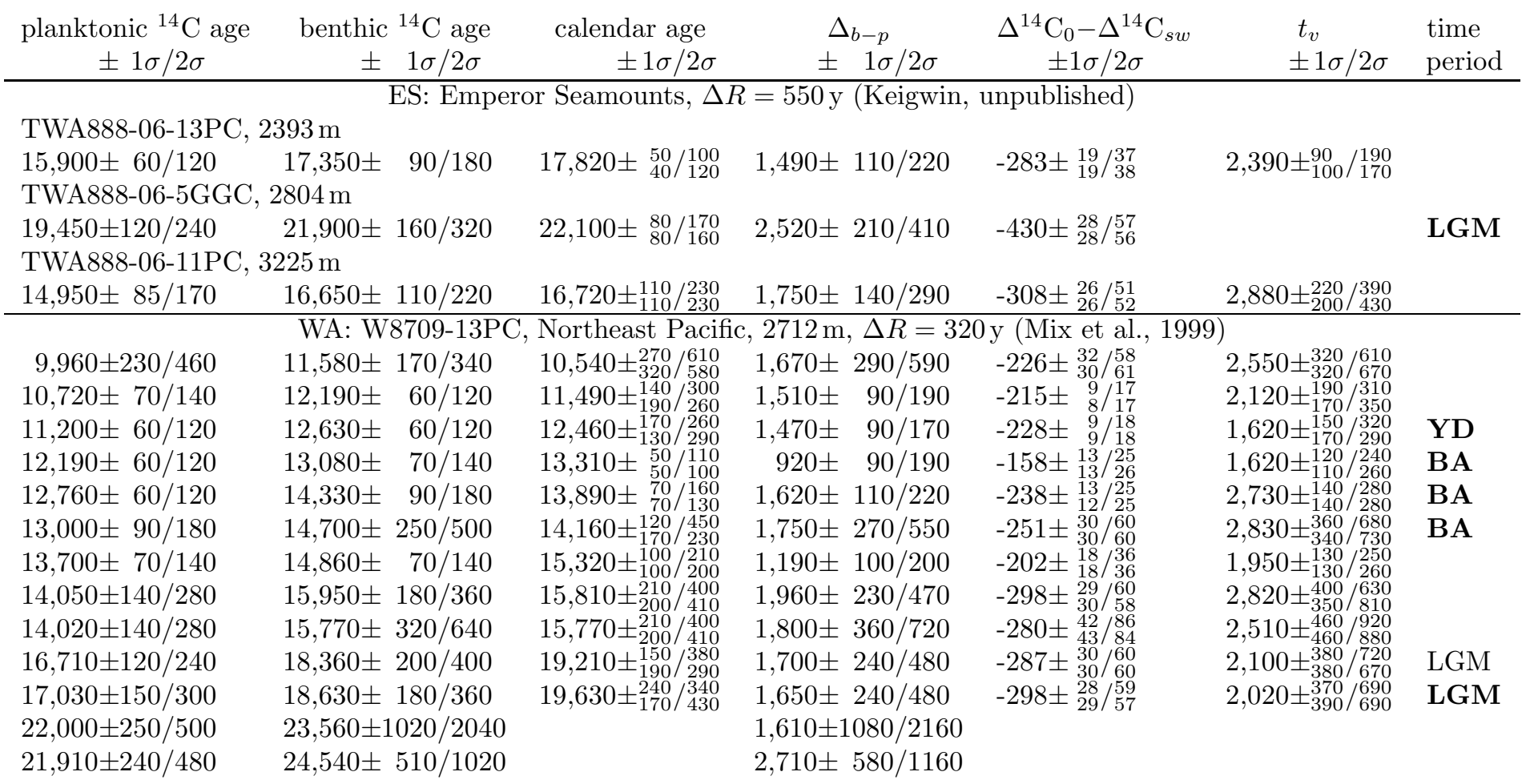




\section{Bibliography}

Adkins, J. F., Boyle, E. A., 1997. Changing atmospheric $\Delta^{14} \mathrm{C}$ and the record of deep water paleo-ventilation ages. Paleoceanography 12, 337-344.

Adkins, J. F., McIntyre, K., Schrag, D. P., 2002. The salinity, temperature, and $\delta^{18} \mathrm{O}$ of the glacial deep ocean. Science 298, 1769-1773.

Ager, T. A., 2003. Late quaternary vegetation and climate history of the central Bering land bridge from St. Michael Island, western Alaska. Quaternary Research 60, 19-32.

Ahagon, N., Ohkushi, K., Uchida, M., Mishima, T., 2003. Mid-depth circulation in the northwest Pacific during the last deglaciation: evidence from foraminiferal radiocarbon ages. Geophysical Research Letters 30 (21), 2097, doi:10.1029/2003GL018287.

Alderman, S. E., 1989. Planktonic foraminifer in the Sea of Okhotsk: population an stable isotopic analysis from a sediment trap. Ph.D. thesis, MIT/WHOI Joint Program.

Alperin, M. J., Reeburgh, W. S., 1984. Geochemical observations supporting anaerobic methane oxidation. In: Crawford, R. L., Hanson, R. S. (Eds.), Microbial growth on C-1 compounds. American Society for Microbiology, pp. 282-289.

Bard, E., 1988. Correction of accelerator mass spectrometry ${ }^{14} \mathrm{c}$ ages measured in planktonic foraminifera: paleoceanographic implications. Paleoceanography 3 (6), 635-645.

Bard, E., 1998. Geochemical and geophysical implications of the radiocarbon calibration. Geochimica et Cosmochimica Acta 62 (12), 2025-2038.

Behl, R. J., Kennett, J. P., 1996. Brief interstadial events in the Santa Barbara Basin, NE Pacific, during the past 60 kyr. Nature 379, 243-246.

Bemis, B. E., Spero, H. J., Bijma, J., Lea, D. W., 1998. Reevaluation of the oxygen isotopic composition of planktonic foraminifera: experimental results and revised paleotemperature equations. Paleoceanography 13 (2), 150-160.

Berger, W. H., Heath, G. R., 1968. Vertical mixing in pelagic sediments. Journal of Marine Research 16 (2), 134-143.

Berger, W. H., Piper, D. J. W., 1972. Planktonic foraminifera: differential settling, dissolution, and redeposition. Journal of Limnology and Oceanography 17 (2), 275-287.

Berner, R. A., 1975. The role of magnesium in the crystal growth of calcite and aragonite from sea water. Geochimica et Cosmochimica Acta 39. 
Berner, R. A., 1980. Early Diagenesis: a Theoretical Approach. Princeton University Press, Princeton, N.J., pp. 174-177.

Bernhard, J. M., 1988. Postmortem vital staining in benthic foraminifera: duration and importance in population and distributional studies. Journal of Foraminiferal Research 18 (2), 143-146.

Bernhard, J. M., Buck, K. R., Barry, J. P., 2001. Monterey Bay cold-seep biota: assemblages, abundance, and ultrastructure of living foraminifera. Deep-Sea Research I 48, $2233-2249$.

Boudreau, B. P., 1994. Is burial velocity a master parameter for bioturbation. Geochimica et Cosmochimica Acta 58 (4), 1243-1249.

Boyle, E. A., Keigwin, L. D., 1985. Comparison of Atlantic and Pacific paleochemical records for the last 250,000 years: changes in deep ocean circulation and chemical inventories. Earth and Planetary Science Letters 76, 135-150.

Boyle, E. A., Keigwin, L. D., 1987. North Atlantic thermohaline circulation during the past 20,000 years linked to high-latitude surface temperture. Nature 330, 35-40.

Boyle, E. A., Rosenthal, Y., 1996. Chemical hydrography of the South Atlantic during the last glacial maximum: $\delta^{13}$ c versus cd. In: Wefer, G. (Ed.), The South Atlantic: Present and Past Circulation. Sprinter-Verlag, New York, pp. 423-443.

Brewer, P. G., Orr, Jr., F. M., Friederich, G., Kvenvolden, K. A., Orange, D. L., 1998. Gas hydrate formation in the deep sea: In situ experiments with controlled release of methane, natural gas and carbon dioxide. Energy and Fuels 12, 183-188.

Brigham-Grette, J., Gualtieri, L. M., Glushkova, O., Hamilton, T. D., Mostoller, D., Kotov, A., 2003. Chlorine-36 and ${ }^{14} \mathrm{c}$ chronology support a limited last glacial maximum across central Chukotka, Northeastern Siberia, and no Beringian ice sheet. Quaternary Research $59,386-398$.

Briner, J. P., Kaufman, D. S., Werner, A., Caffee, M., Levy, L., Manley, W. F., Kaplan, M. R., Finkel, R. C., 2002. Glacier readvance during the late glacial (Younger Dryas?) in the Ahklun Mountains, southwestern Alaska. Geology 30, 679-682.

Broecker, W., Barker, S., Clark, E., Hajdas, I., Bonani, G., Stott, L., 2004. Ventilation of the glacial deep Pacific Ocean. Science 306, 1169-1172.

Broecker, W. S., Matsumoto, K., Clark, E., Hajdas, I., Bonani, G., 1999. Radiocarbon age differences between coexisting species. Paleoceanography 14, 431-436.

Broecker, W. S., Peng, T. H., Trumbore, S., Bonani, G., Wolfli, W., 1990. The distribution of radiocarbon in the glacial ocean. Radiocarbon 4 (1), 103-117.

Brook, E. J., Sowers, T., Orchardo, J., 1996. Rapid variations in atmospheric methane concentration during the past 110,000 years. Science 273, 1087-1091.

Chappellaz, J., Blunier, T., Kints, S., Dallenbach, A., Bamola, J.-M., Schwander, J., Raynaud, D., , Stauffer, B., ???? Changes in the atmospheric $\mathrm{CH}_{4}$ gradient between Greenland and Antarctica during the Holocene. Journal of Geophysical Research 102. 
Claypool, G. E., Presley, B. J., Kaplan, I. R., 1973. Gas analyses in sediment samples from legs 10, 11, 13, 14, 15, 18, and 19. In: Creager, J. S., Scholl, D. W. (Eds.), Initial Reports of the Deep Sea Drilling Project. Vol. 19. Wasington (U.S. Government Princeton Office), pp. 879-884.

Cook, M. S., Keigwin, L. D., Sancetta, C. A., 2005. The deglacial history of surface and intermediate water of the Bering Sea. Deep-Sea Research II 52, 2163-2173.

Coplen, T. B., 1996. Editorial: more uncertainty than necessary. Paleoceanography 11 (4), 369-370.

Crusius, J., Pedersen, T. F., Kienast, S., Keigwin, L., Labeyrie, L., 2004. Influence of northwest pacific productivity on north pacific intermediate water oxygen concentrations during the bølling-ållerød interval (14.7-12.9 ka). Geology 32 (7), 633-636.

Curry, W. B., Oppo, D. W., 1997. Synchronous high-frequency oscillations in tropical sea surface temperatures and North Atlantic Deep Water production during the last glacial cycle. Paleoceanography 21 (1), 1-14.

Curry, W. B., Slowey, N., Lohmann, G. P., 1993. Oxygen and carbon isotopic fractionation of aragonitic and calcitic benthic foraminifera on Little Bahama Bank, Bahamas. EOS, Transactions of the American Geophysical Union 73 (43), 368.

de Garidel-Thoron, T., Beaufort, L., Bassinot, F., Henry, P., 2004. Evidence for large methane releases to the atmosphere from deep-sea gas-hydrate dissociation during the last glacial episode. Proceedings of the National Academy of Sciences 101 (25), 91879192.

Deser, C., Alexander, M. A., Timlin, M. S., 1996. Upper-ocean thermal variations in the North Pacific during 1970-1991. Journal of Climate 9, 1840-1855.

Duplessy, J. C., Arnold, M., Bard, E., Juillet-Leclerc, A., Kallel, N., Labeyrie, L., 1989. AMS ${ }^{14} \mathrm{C}$ study of transient events and of the ventilation rate of the Pacific intermediate water during the last deglaciation. Radiocarbon 31, 493-502.

Emile-Geay, J., Cane, M. A., Naik, N., Seager, R., Clement, A. C., van Geen, A., 2003. Warren revisited: atmospheric freshwater fluxes and "Why is no deep water formed in the North Pacific". Journal of Geophysical Research 108 (C6), 3178, doi:10.1029/2001JC001058.

Epstein, S., Buchsbaum, R., Lowenstam, H. A., Urey, H. C., 1953. Revised carbonate-water isotopic temperature scales. Bulletin of the Geological Society of America 64, 1315-1325.

Erez, J., Luz, B., 1983. Experimental paleotemperature equation for planktonic foraminifera. Geochimica et Cosmochimica Acta 47, 1025-1031.

Fatela, F., Taborda, R., 2002. Confidence limits of species proportions in microfossil assemblages. Marine Micropaleontology 45, 169-174.

Fofonoff, N. P., 1985. Physical properties of seawater: A new salinity scale and equation of state for seawater. Journal of Geophysical Research 90 (C2), 3332-3342. 
François, F., Poggiale, J.-C., Durbec, J.-P., Stora, G., 2001. A new model of bioturbation for a functional approach to sediment reworking resulting from macrobenthic communities. In: Aller, J. (Ed.), Organism-Sediment Interaction. University of South Carolina Press, pp. $73-86$.

Fritz, P., Smith, D. G. W., 1970. The isotopic composition of secondary dolomites. Geochimica et Cosmochimica Acta 34, 1161-1173.

Hendy, I. L., Thunell, R. C., Pedersen, T. F., 2003. Stagnation of the eastern tropical Pacific during deglaciation: Porewater oxygen concentration shifts in the Gulf of Tehuantepec. EOS Transactions, AGU 84 (46), OS22C-07.

Hill, J. C., Driscoll, N. W., Donnelly, J. P., 2006. New evidence of high discharge to the Chukchi shelf during the Last Glacial Maximum. Geology, submitted.

Hill, T. M., Kennett, J. P., Valentine, D. L., 2004. Isotopic evidence for the incorporation of methane-derived carbon into foraminifera from modern methane seeps, Hydrate Ridge, Northeast Pacific. Geochimica et Cosmochimica Acta 22, 4619-4627.

Hinrichs, K.-U., Hmelo, L. R., Sylva, S. P., 2003. Molecular fossil record of elevated methane levels in late Pleistocene coastal waters. Science 299, 1214-1217.

Hoehler, T. M., Borowski, W. S., Alperin, M. J., Rodriguez, N. M., Paull, C. K., 2000. Model, stable isotope and radiotracer characterization of anaerobic methane oxidation in gas hydrate-bearing sediments of the Blake Ridge. In: Paull, C. K., Matsumoto, R., Wallace, P. J., Dillon, W. P. (Eds.), Proceedings of the Ocean Drilling Program: Scientific Results, 164. College Station, TX (Ocean Drilling Program), pp. 79-85.

Hu, F. S., Shemesh, A., 2003. A biogenic-silica record of climatic change during the last glacial-interglacial transition in southwestern Alaska. Quaternary Research 59, 379-385.

Hughen, K., Lehman, S., Southon, J., Overpeck, J., Marchal, O., Herring, C., Turnbull, J., 2004a. ${ }^{14} \mathrm{C}$ activity and global carbon cycle changes over the past 50,000 years. Science 303, 202-207.

Hughen, K. A., Baillie, M. G. L., Bard, E., Beck, J. W., Bertrand, C. J. H., Blackwell, P. G., Buck, C. E., Burr, G. S., Cutler, K. B., Damon, P. E., Edwards, R. L., Fairbanks, R. G., Friedrich, M., Guilderson, T. P., Kromer, B., McCormac, G., Manning, S., Ramsey, C. B., Reimer, P. J., Reimer, R. W., Remmele, S., Southon, J. R., Stuiver, M., Talamo, S., Taylor, F. W., van der Plicht, J., Weyhenmeyer, C. E., 2004b. Marine04 marine radiocarbon age calibration, 0-26 cal kyr BP. Radiocarbon 46 (3), 1059-1086.

Imbrie, J., Kipp, N. G., 1971. A new micropaleontological method for quantitative paleoclimatology: Application to a late Pleistocene Caribbean core. In: Turekian, K. K. (Ed.), The Late Cenozoic Glacial Ages. Yale University Press, New Haven, CT, pp. 71-181.

Ingram, B. L., Kennett, J. P., 1995. Radiocarbon chronology and planktonic-benthic foraminiferal ${ }^{14} \mathrm{C}$ age differences in Santa Barbara Basin sediments, Hole 893A. In: Proceedings of the Ocean Drilling Program, Scientific Results. Vol. 146. National Science Foundation, pp. 19-27. 
Johnsen, S. J., Dahl-Jensen, D., Gundestrup, N., Steffensen, J. P., Clausen, H. B., Miller, H., Masson-Delmotte, V., Sveinbjörnsdottir, A. E., White, J., 2001. Oxygen isotope and palaeotemperature records from six Greenland ice-core stations: Camp Century, Dye-3, GRIP, GISP2, Renland and NorthGRIP. Journal of Quaternary Science 16 (4), 299-307.

Kastner, M., 2001. Gas hydrates in convergent margins: formation, occurrence, geochemistry, and global significance. In: Paull, C. K., Dillion, III, W. P. (Eds.), Natural Gas Hydrates: Occurrence, Distribution, and Detection. American Geophysical Union, Washington, D.C., pp. 67-86.

Keigwin, L. D., 1998. Glacial-age hydrography of the far Northwest Pacific Ocean. Paleoceanography 13 (4), 323-339.

Keigwin, L. D., 2002. Late Pleistocene-Holocene paleoceangraphy and ventilation of the Gulf of California. Journal of Oceanography 58, 421-432.

Keigwin, L. D., Boyle, E. A., 1999. Surface and deep ocean variability in the northern Sargasso Sea during Marine Isotope Stage 3. Paleoceanography 14 (2), 164-170.

Keigwin, L. D., Jones, G. A., 1990. Deglacial climatic oscillations in the Gulf of California. Paleoceanography 5 (6), 1009-1023.

Keigwin, L. D., Lehman, S. J., 1994. Deep circulation change linked to Heinrich Event 1 and Younger Dryas in a mid-depth North Atlantic core. Paleoceanography 9 (2), 185-194.

Kennett, J. P., Cannariato, K. G., Hendy, I. L., Behl, R. J., 2000. Carbon isotopic evidence for methane hydrate instability during Quaternary interstadials. Science 288, 128-133.

Kennett, J. P., Cannariato, K. G., Hendy, I. L., Behl, R. J., 2003. Methane Hydrates in Quaternary Climate Change: the Clathrate Gun Hypothesis. American Geophysical Union, Washington, D.C.

Key, R. M., 2001. Radiocarbon. In: Steele, J. H., Thorpe, S. A., Turekian, K. K. (Eds.), Encyclopedia of Ocean Sciences. Academic Press, pp. 2338-2353.

Key, R. M., Quay, P. D., Schlosser, P., McNichol, A. P., von Reden, K. F., Schneider, R. J., Elder, K. L., Stuiver, M., Östlund, H. G., 2002. WOCE radiocarbon IV: Pacific Ocean results; P10, P13N, P14C, P18, P19, S4P. Radiocarbon 44 (1), 239-392.

Kiefer, T., Kienast, M., 2005. Patterns of deglacial warming in the Pacific Ocean: a review with emphasis on the time interval of Heinrich Event 1. Quaternary Science Reviews 24, $1063-1081$.

Kiefer, T., Sarnthein, M., Erlenkeuser, H., Grootes, P. M., Roberts, A. P., 2001. North Pacific response to millennial-scale change in ocean circulation over the last 60 kyr. Paleoceanography 16 (2), 179-189.

Kim, S.-T., O'Neil, J. R., 1997. Equilibrium and nonequilibrium oxygen isotope effects in synthetic carbonates. Geochimica et Cosmochimica Acta 61 (16), 3461-3475.

Kim, S.-T., O'Neil, J. R., Mucci, A., Hillaire-Marcel, C., 2004. Oxygen isotope fractionation between synthetic aragonite and water: influence of solution chemistry. EOS, Transactions, American Geophysical Union 85 (47), Fall Meeting Supplement, Abstract V51C0589 . 
Klaucke, I., Sahling, H., Burk, D., Weinrebe, W., Bohrmann, G., 2005. Mapping deepwater gas emissions with sidescan sonar. EOS, Transactions, American Geophysical Union $86(38), 341$.

Kuroyanagi, A., Kawahata, H., Nishi, H., Honda, M. C., 2002. Seasonal changes in plankotnic foraminifera in the North Pacific Ocean: sediment trap experiments from subarctic and subtropical gyres. Deep-Sea Research II 49, 5627-5645.

Kuzmin, Y. V., Burr, G. S., Jull, A. J. T., 2002. Radiocarbon reservoir correction ages in the Peter the Great Gulf, Sea of Japan, and eastern coast of the Kunashir, Southern Kuriles (Northwestern Pacific). Radiocarbon 43, 477-481.

Kvenvolden, K. A., Lorenson, T. D., 2001. The global occurrence of natural gas hydrates. In: Paull, C. K., Dillion, III, W. P. (Eds.), Natural Gas Hydrates: Occurrence, Distribution, and Detection. American Geophysical Union, Washington, D.C., pp. 3-18.

Lee, M. W., 2000. Gas hydrates amount estimated from acoustic logs at the Blake Ridge, sites 994, 995, and 997. In: Paull, C. K., Matsumoto, R., Wallace, P. J., Dillon, W. P. (Eds.), Proceedings of the Ocean Drilling Program: Scientific Results, 164. College Station, TX (Ocean Drilling Program), pp. 193-198.

Levitus, S., Boyer, T., Conkright, M., O’Brien, T., Antonov, J., Stephens, C., Stathoplos, L., Johnson, D., Gelfeld, R., 1998. World Ocean Database 1998 Volume 1: Introduction. NOAA Atlas NESDIS 18. U.S. Government Printing Office, Washington, D.C.

Luff, R., Wallmann, K., Aloisi, G., 2004. Numerical modeling of carbonate crust formation at cold vent sites: significance for fluid and methane budgets and chemosynthetic biological communities. Earth and Planetary Science Letters 221, 337-353.

Lund, D. C., Mix, A. C., 1998. Millennial-scale deep water oscillations: reflections of the North Atlantic in the deep Pacific from 10 to 60 ka. Paleoceanography 13, 10-19.

Lynch-Stieglitz, J., Curry, W. B., Slowey, N., 1999. A geostropic transport estimate for the Florida Current from the oxygen isotope composition of benthic foraminifera. Paleoceanography 14 (3), 360-373.

Macdonald, A. M., Suga, T., Curry, R. G., 2001. An isopycnally averaged North Pacific climatology. Journal of Atmospheric and Oceanic Technology 18, 394-420.

Marret, F., de Vernal, A., Bendera, F., Harland, R., 2001. Late Quaternary sea-surface conditions at DSDP Hole 594 in the southwest Pacific Ocean based on dinoflagellate cyst assemblages. Journal of Quaternary Science 16 (7), 739-751.

Matsumoto, R., Borowski, W. S., 2000. Gas hydrate estimates from newly determined oxygen isotopic fractionation $\left(\alpha_{\text {gh-iw }}\right)$ and $\delta_{18} \mathrm{O}$ anomalies of the interstitial waters: Leg 164, Blake Ridge. In: Paull, C. K., Matsumoto, R., Wallace, P. J., Dillon, W. P. (Eds.), Proceedings of the Ocean Drilling Program: Scientific Results, 164. College Station, TX (Ocean Drilling Program), pp. 59-66.

McKay, J., Pedersen, T., Kienast, S., 2004. Organic carbon accumulation over the last 16 kyr off Vancouver Island, Canada: evidence for increased marine productivity during the deglacial. Quaternary Science Reviews 23, 261-281. 
McManus, J. F., Francois, R., Gherardi, J.-M., Keigwin, L. D., Brown-Leger, S., 2004. Collapse and rapid resumption of Atlantic meridional circulation linked to deglacial climate changes. Nature 428, 834-837.

Meese, D. A., Gow, A. J., Alley, R. B., Zielinski, G. A., Grootes, P. M., Ram, M., Taylor, K. C., Mayewski, P. A., Bolzan, J. F., 1997. The Greenland Ice Sheet Project 2 depth-age scale: methods and results. Journal of Geophysical Research C11, 26,411-26,423.

Mikolajewicz, U., Crowley, T. J., Schiller, A., Voss, R., 1997. Modelling teleconnections between the North Atlantic and North Pacific during the Younger Dryas. Nature 387, $384-387$.

Millo, C., Sarnthein, M., Erlenkeuser, H., 2005. Methane-driven late Pleistocene $\delta^{13} \mathrm{C}$ minima and overflow reversals in the southwestern Greenland Sea. Geology 33 (11), 873-876.

Mix, A. C., Lund, D. C., Pisias, N. G., Bodén, P., Bornmalm, L., Lyle, M., Pike, J., 1999. Rapid climate oscillations in the Northeast Pacific during the last deglaciation reflect Northern and Southern Hemisphere sources. In: Mechanisms of Global Climate Change at Millennial Time Scales. Geophysical Monographs - 112. American Geophysical Union, pp. $127-148$.

Narita, H. N., Minami, H. M., Kuramoto, T. K., Minagawa, M. M., Oba, T. O., Ikehara, K. I., Aramaki, T. A., Ohkushi, K. O., 2004. Paleoenvironmental and paleoproductivity records off Shimokita during the last $27 \mathrm{ka}$. In: 8th International Conference on Paleoceanography, Biarritz, France. pp. 97-98.

Ohkushi, K., Itaki, T., Nemoto, N., 2003. Last glacial-Holocene change in intermediatewater ventilation in the Northwestern Pacific. Quaternary Science Reviews 22, 1477-1484.

Orphan, V. J., Ussler, III, W., Naehr, T. H., House, C. H., Hinrichs, K.-U., Paul, C. K., 2004. Geological, geochemicl, and microbiological heterogeneity of the seafloor around methane vents in the Eel River Basin, offshore California. Chemical Geology 205, 265289 .

Ortiz, J. D., O’Connell, S. E., DelViscio, J., Dean, W., Carriquiry, J. D., Marchitto, T., Zheng, Y., van Geen, A., 2004. Enhanced marine productivity off western North America during warm climate intervals of the past 52 kyr. Geology, in press.

Ostermann, D. R., Curry, W. B., 2000. Calibration of stable isotopic data: an enriched $\delta^{18} \mathrm{O}$ standard used for source gas mixing detection and correction. Paleoceanography 15 (3), $353-360$.

Pellenbarg, R. E., Max, M. D., 2000. Introduction, physical properties, and natural occurrence of hydrate. In: Max, M. D. (Ed.), Natural Gas Hydrate in Oceanic and Permafrost Environments. Kluwer Academic Press, pp. 1-8.

Peteet, D., Mann, D., 1994. Late-glacial vegetational, tephra, and climatic history of southwestern Kodiak Island, Alaska. Ecoscience 1, 255-267.

Prell, W., Martin, A., Cullen, J., Trend, M., 1999. The Brown University foraminiferal data base. IGBP PAGES/World Data Center-A for Paleoclimatology Data Contribution Series \#1999-027. NOAA/NGDC Paleoclimatology Program, Boulder CO, USA. 
Rau, G. H., Sweeny, R. E., Kaplan, I. R., 1982. Plankton ${ }^{13} \mathrm{C}:{ }^{12} \mathrm{C}$ ratio changes with latitude: differences between northern and southern oceans. Deep-Sea Research 29 (8A), $1035-1039$.

Reimer, P. J., Baillie, M. G. L., Bard, E., Bayliss, A., Beck, J. W., Bertrand, C., Blackwell, P. G., Buck, C. E., Burr, G., Cutler, K. B., Damon, P. E., Edwards, R. L., Fairbanks, R. G., Friedrich, M., Guilderson, T. P., Hughen, K. A., Kromer, B., McCormac, F. G., Manning, S., Ramsey, C. B., Reimer, R. W., Remmele, S., Southon, J. R., Stuiver, M., Talamo, S., Taylor, F. W., van der Plicht, J., Weyhenmeyer, C. E., 2004. Radiocarbon calibration from 0-26 cal kyr BP. Radiocarbon 46, 1029-1058.

Robinson, S. W., Thompson, G., 1981. Radiocarbon corrections for marine shell dates with application to southern Pacific Northwest Coast prehistory. Syesis 14, 45-57.

Rosenthal, Y., Boyle, E. A., Labeyrie, L., Oppo, D., 1995. Glacial enrichment of authigenic $\mathrm{Cd}$ and $\mathrm{U}$ in subantarctic sediments: a climatic control on the element's oceanic budget? Paleoceanography 10, 395-413.

Rosenthal, Y., Field, M. P., Sherrell, R. M., 1999. Precise determination of element/calcium ratios in calcareous samples using sector field inductively coupled plasma mass spectrometry. Analytical Chemistry 71, 3248-3252.

Sancetta, C., Heusser, L., Labeyrie, L., Naidu, A. S., Robinson, S. W., 1985. WisconsinHolocene paleoenvironment of the Bering Sea: evidence from diatoms, pollen, oxygen isotopes and clay minerals. Marine Geology 62, 55-68.

Sarmiento, J. L., Gruber, N., 2002. Sinks for anthropogenic carbon. Physics Today 55 (8), $30-36$.

Sautter, L. R., Thunell, R. C., 1989. Seasonal sucession of planktonic foraminifer: results from a four-year time-series sediment trap experiment in the northeast Pacific. Journal of Foraminiferal Research 19 (4), 253-267.

Schmidt, M., Botz, R., Winn, K., Stoffers, P., Theissen, O., Herzig, P., 2002. Seeping hydrocarbons and related carbonate mineralisations in sediments south of Lihir Island (Nwe Ireland forearc basin, Paupua New Guinea). Chemical Geology 186, 249-264.

Scholl, D. W., Creager, J. S., Boyce, R. E., Echols, R. J., Fullam, T. J., Grow, J. A., Koizumi, I., Lee, H. J., Ling, H. Y., Stewart, R. J., Supko, P. R., Worsley, T. R., 1973. Site 185. In: Initial Reports of the Deep Sea Drilling Project. Vol. 19. Washington, D. C. (U. S. Government Printing Office), pp. 169-216.

Schrag, D. P., Adkins, J. F., McIntyre, K., Alexander, J., Hodell, D. A., Charles, C. D., McManus, J. F., 2002. The oxygen isotopic composition of seawater during the Last Glacial Maximum. Quaternary Science Reviews 21, 331-342.

Shackleton, N., 1974. Attainment of isotope equilibrium between ocean water and the benthonic foraminifera genus Uvigerina: isotopic changes in the ocean during the last glacial. In: Les Méthodes quantitatives d'étude des variations du climate au cours du Pleistocene: Colloque international: Gif-sur-Yvette, 5-9 Juin 1973. Editions du Centre national de la recherche scientifique, Paris. 
Slowey, N. C., Curry, W. B., 1995. Glacial-interglacial differences in circulation and carbon cycling within the upper western North Atlantic. Paleoceanography 10 (4), 715-732.

Stuiver, M., Grootes, P. M., Braziunas, T. F., 1995. The GISP2 $\delta^{18} \mathrm{O}$ record of the past 16500 years and the role of the sun, ocean and volcanoes. Quaternary Research 44, 341354.

Stuiver, M., Reimer, P., Bard, E., Beck, J., Burr, G., Hughen, K., Kromer, B., McCormac, G., van der Plicht, J., Spurk, M., 1998. INTCAL98 Radiocarbon Age Calibration, 24000-0 cal BP. Radiocarbon 40 (3), 1041-1083.

Talley, L. D., 2003. Shallow, intermediate, and deep overturning components of the global heat budget. Journal of Physical Oceanography 33, 530-560.

Tarutani, T., Clayton, R. N., Mayeda, T. K., 1969. The effect of polymorphism and magnesium substitution on oxygen isotope fractionation between calcium carbonate and water. Geochimica et Cosmochimica Acta 33, 987-996.

Telford, R. J., Heegaard, E., Birks, H. J. B., 2004. The intercept is a poor estimate of a calibrated radiocarbon age. The Holocene 14 (2), 296-298.

Torres, M. E., Mix, A. C., Kinports, K., Haley, B., Klinkhammer, G. P., McManus, J., de Angelis, M. A., 2003. Is methane venting at the seafloor recorded by $\delta^{13} \mathrm{C}$ of benthic foraminifera shells? Paleoceanography 18 (3), 1062, doi:10.1029/2002PA000824.

Uchida, M., Shibata, Y., Ohkushi, K., Ahagon, N., Hoshiba, M., 2004. Episodic methane release events from last glacial marginal sediments in the western North Pacific. Geochemistry Geophysics Geosystems 5 (8), Q08005, doi:10.1029/2004GC000699.

van Geen, A., Zheng, Y., Bernhard, J. M., Cannariato, K. G., Carriquiry, J., Dean, W. E., Eakins, B. W., Pike, J., 2003. On the preservation of laminated sediments along the western margin of North America. Paleoceanography 18 (4), 1098, doi:10.1029/2003PA000911.

Van Scoy, K. A., Olson, D. B., Fine, R. A., 1991. Ventilation of North Pacific Intermediate Waters: the role of the Alaskan Gyre. Journal of Geophysical Research 96 (C9), 16,80116,810 .

Vidal, L., Labeyrie, L., Cortijo, E., Arnold, M., Duplessy, J.-C., Michel, E., Becqué, S., van Weering, T., 1997. Evidence for changes in the North Atlantic Deep Water linked to meltwater surges during the Heinrich events. Earth and Planetary Science Letters 146, $13-27$.

Voelker, A. H. L., workshop participants, 2002. Global distribution of centennial-scale records for Marine Isotope Stage (MIS) 3: a database. Quaternary Science Reviews 21, $1185-1212$.

Waelbroeck, C., Labeyrie, L., Michel, E., Duplessy, J. C., McManus, J. F., Lambeck, K., Balbon, E., Labracherie, M., 2002. Sea-level and deep water temperature changes derived from benthic foraminifera isotopic records. Quaternary Science Reviews 21 (1-3), 295305 . 
Wang, Y. J., Cheng, H., Edwards, R. L., An, Z. S., Wu, J. Y., Shen, C.-C., Dorale, J. A., 2001. A high-resolution absolute-dated late Pleistocene monsoon record from Hulu Cave, China. Science 294, 2345-2348.

Warner, M. J., Roden, G. I., 1995. Chlorofluorocarbon evidence for recent ventilation of the deep Bering Sea. Nature 373, 409-412.

Warren, B. A., 1983. Why is no deep water formed in the North Pacific? Journal of Marine Research 41, 327-347.

Whiticar, M. J., 1999. Carbon and hydrogen isotope systematics of bacterial formation and oxidation of methane. Chemical Geology 161, 291-314.

Wilson, T. R. S., 1975. Chemical Oceanography, 2nd Edition. Vol. 2. Academic Press, London, pp. 365-413.

Wunsch, C., 2003. Determining paleoceanographic circulations, with emphasis on the Last Glacial Maximum. Quaternary Science Reviews 22, 371-385.

Wyrtki, K., 1962. The oxygen minima in relation to ocean circulation. Deep-Sea Research $9,11-23$.

Yasuda, I., 1997. The origin of the North Pacific Intermediate Water. Journal of Geophysical Research 102 (C1), 893-909.

You, Y., 2003. Implications of cabbeling on the formation and transformation mechanism of North Pacific Intermediate Water. Journal of Geophysical Research C5, 3134, doi:10.1029/2001JC001285.

Zahn, R., Schönfeld, J., Kudrass, H.-R., Park, M.-H., Erlenkeuser, H., Grootes, P., 1997. Thermohaline instability in the North Atlantic during meltwater events; stable isotope and ice-rafted detritus records from core SO75-26KL, Portuguese margin. Paleoceanography $12,696-710$.

Zheng, Y., van Geen, A., Anderson, R. F., Gardner, J. V., Dean, W. E., 2000. Intensification of the Northeast Pacific oxygen minimum zone during the Bølling-Allerød warm period. Paleoceanography 15 (5), 528-536. 